University of Louisville

ThinkIR: The University of Louisville's Institutional Repository

Electronic Theses and Dissertations

8-2018

\title{
Coal ash exposure and behavioral impairments among children in Louisville, Kentucky.
}

Chisom Nmesoma Odoh

University of Louisville

Follow this and additional works at: https://ir.library.louisville.edu/etd

Part of the Epidemiology Commons

\section{Recommended Citation}

Odoh, Chisom Nmesoma, "Coal ash exposure and behavioral impairments among children in Louisville, Kentucky." (2018). Electronic Theses and Dissertations. Paper 3046.

https://doi.org/10.18297/etd/3046

This Doctoral Dissertation is brought to you for free and open access by ThinkIR: The University of Louisville's Institutional Repository. It has been accepted for inclusion in Electronic Theses and Dissertations by an authorized administrator of ThinkIR: The University of Louisville's Institutional Repository. This title appears here courtesy of the author, who has retained all other copyrights. For more information, please contact thinkir@louisville.edu. 


\title{
COAL ASH EXPOSURE AND BEHAVIORAL IMPAIRMENTS AMONG CHILDREN IN LOUISVILLE, KENTUCKY
}

\author{
By \\ Chisom Nmesoma Odoh \\ MPH, Tennessee State University, 2015 \\ BA, Fisk University, 2012

\begin{abstract}
A Dissertation
Submitted to the Faculty of the

School of Public Health and Information Sciences of the University of Louisville in Partial Fulfillment of the Requirements for the Degree of

Doctor of Philosophy in Public Health Sciences

University of Louisville

Louisville, Kentucky
\end{abstract} \\ Department of Epidemiology and Population Health
}

August 2018 



\title{
COAL ASH EXPOSURE AND BEHAVIORAL IMPAIRMENTS AMONG CHILDREN IN LOUISVILLE, KENTUCKY
}

\author{
By \\ Chisom Nmesoma Odoh \\ MPH, Tennessee State University, 2015 \\ BA, Fisk University, 2012 \\ Dissertation Approved on
}

July 2, 2018

by the following Dissertation Committee

Dr. Kristina Zierold, PhD, MS

Dr. Richard Baumgartner, $\mathrm{PhD}$

Dr. Kathy Baumgartner, PhD

Dr. Lonnie Sears, PhD

Dr. Guy Brock, PhD 


\section{ACKNOWLEDGMENTS}

I have been opportune to have received support, guidance, and assistance from numerous people during my doctoral journey. I am grateful for the impact my supervisor, faculty, friends, and family have made on my professional and personal life. I would like to first express my appreciation to my supervisor, Dr. Kristina Zierold- for believing in me when I did not believe in myself, constantly encouraging me with her supportive words, advocating for me, and being the best mentor I could ever ask for. Dr. Zierold embodies compassion, integrity, thoroughness, gratitude, authenticity, humility, and humor. The standard of leadership you have set will continue to guide me through the rest of my career and I appreciate you for that.

I would also like to thank my committee members- Dr. Lonnie Sears, Dr. Guy

Brock, Dr. Richard Baumgartner, and Dr. Kathy Baumgartner for their input towards making my dissertation a success. Heartfelt thanks to Lindsay Tompkins and Jack Pfeiffer for their dedication, input, and support on the coal ash project. Thank you, Lindsay, for making field work interesting and fun and thank you for the wisdom and poise you have showed me.

I would like to thank my mentors outside the University of Louisville- Drs. Pamela Hull and Muktar Aliyu for their continuous support, mentorship and career guidance. I thank Islamiat Oladipupo, Diana Stojda, Colette Davis, and Elmang Nchako, good friends and colleagues who contributed a great deal to the completion of this dissertation. From taking time to brainstorm ideas to helping me to calm down when 
stressing out, I will forever remain grateful to you all. True friends are worth more than gold - I am privileged to have gained great friends that embody the true meaning of friendship.

Finally, I would like to thank my family- my mom, Francisca Odoh; my second mom, Unyime Eyoh; my sisters Ebere Okafor, Nkiruka Aganbi, Cherechi Igbokwe; and my brothers Somayina and Chiazam Odoh. They have always supported me in all my endeavors with their prayers, unwavering love, kind words, and generosity. Special thanks to my sister Cherechi Igbokwe for sponsoring my education in the United States. She saw something that I could not see, believed in me, and sacrificed her own needs to enable me succeed in a new environment. I will not be where I am today if not for her. Thank you to all those I missed out. I look forward to celebrating many more milestones with you all. 


\title{
ABSTRACT \\ COAL ASH EXPOSURE AND BEHAVIORAL IMPAIRMENTS AMONG CHILDREN IN LOUISVILLE, KENTUCKY
}

\author{
Chisom Nmesoma Odoh
}

July 2, 2018

Introduction: Coal ash, generated from the combustion of coal is principally made up of fly ash, which consists of small particles and metals that can affect the development of children. Coal ash is predominately stored in landfills and surface impoundments, of which many are in proximity to residential areas. According to the Environmental Protection Agency, 25\% of residents in proximity to electric power plants are children. Few studies have reported a positive association between coal ash and its by-products and neurobehavioral disorders. The purpose of this study is to explore the relationship between coal ash and its components and behaviors underlying autism that includes social, thought, and obsessive-compulsive problems.

Methods: Analysis addressed filter fly ash, lift tape fly ash, and combined filter and lift tape fly ash. Body and home metal concentrations were derived from metals found in nails and filters, respectively. Fly ash from lift tape and filter were measured using Scanning Electron Microscopy (SEM) and Energy-Dispersive X-ray Spectrometry (EDX), while the metals found in nails and filters were measured using Proton Induced Emission X-ray (PIXE). Scores from the Child Behavior Checklist were analyzed to assess social, thought, and obsessive-compulsive problems. Logistic regression models, rank sum tests, and correlation tests were used to assess the relationship between fly ash and metals, and social, thought, and obsessive-compulsive problems. 
Results: There was no statistically significant association between the outcomes and fly ash measures. Results from this research suggest that increased copper levels may be associated with the development of social problems in children (Odds Ratio $(\mathrm{OR})=5.44$, $95 \%$ Confidence Interval $(\mathrm{CI})=1.07-27.6)$. We also found that exposure to an aggregate of all metals was most strongly associated with thought problems with a linear doseresponse relationship $(\mathrm{OR}=8.80$ for tertile 2 ; $\mathrm{OR}=30.2$ for tertile 3; Ptrend $<0.001)$.

Conclusion: Pollutants such as fly ash and metals found in coal ash may affect the behavior of children and need to be further studied. Future research is needed to further understand the etiology between behaviors underlying ASD and environmental factors. 


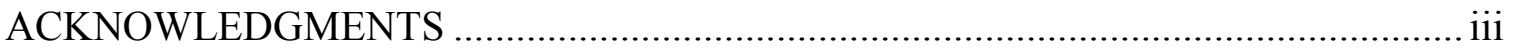

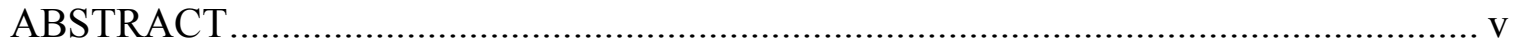

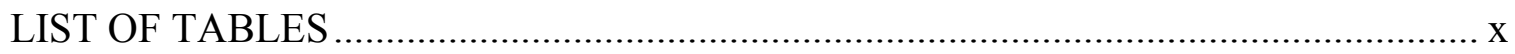

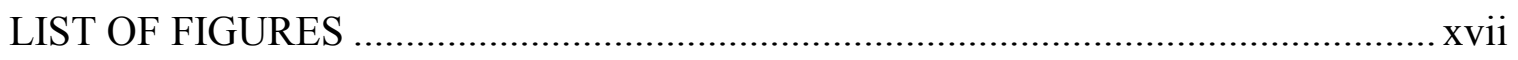

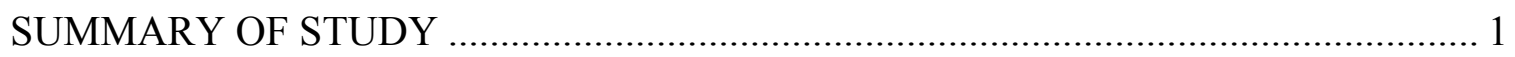

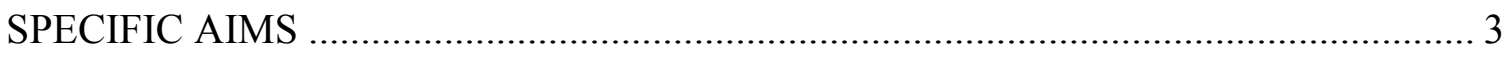

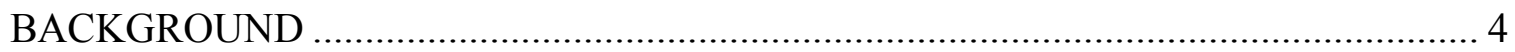

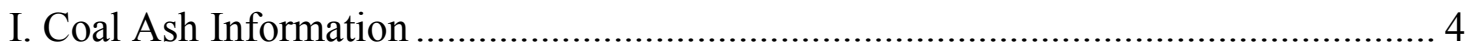

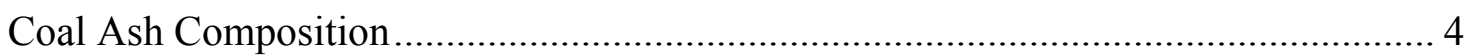

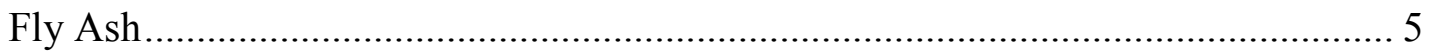

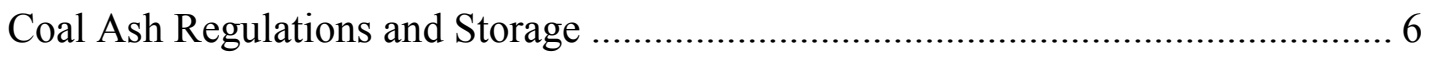

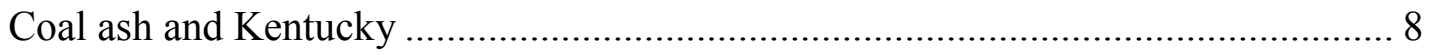

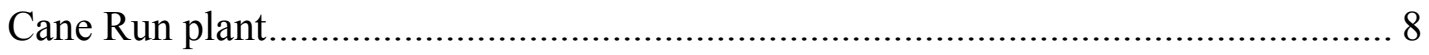

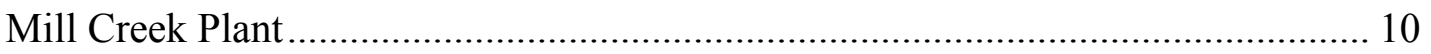

Content of coal ash/fly ash and relationship with health in general ......................... 11

Heavy Metals Often Found in Fly Ash ................................................................ 12

Additional Trace Metals/Elements found in Fly Ash ............................................... 14

Other Hazardous Contents of Fly Ash .............................................................. 17

Coal Ash Effects on Worker's Health ................................................................. 18

Coal ash and fly ash effect on children's health .................................................... 19

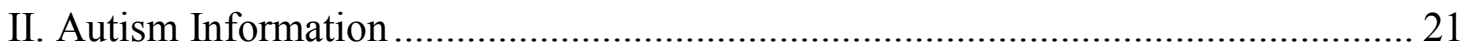

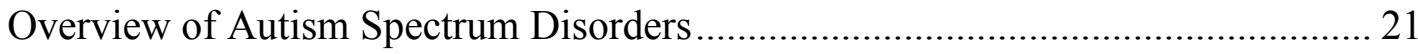

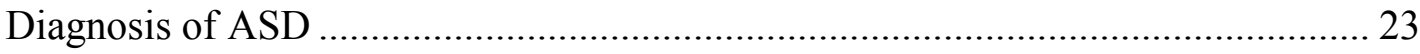

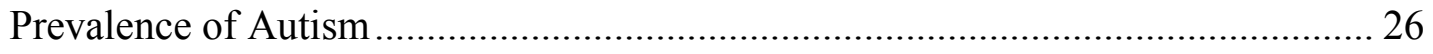

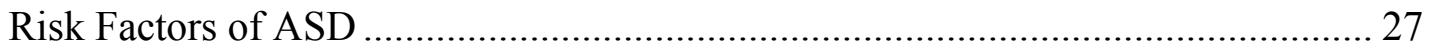

III. Environmental Factors for Autism and Neurobehavioral Disorders ...................... 31

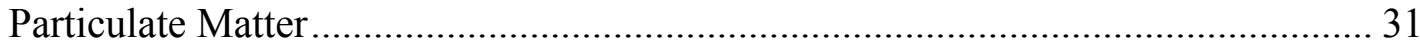

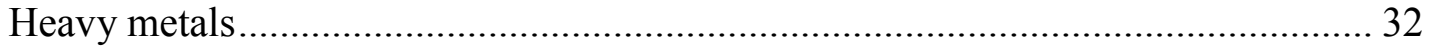

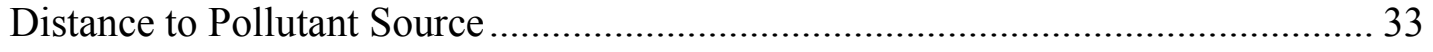

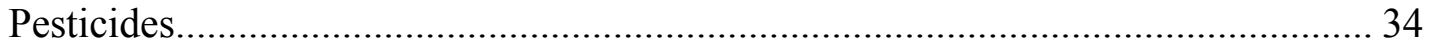

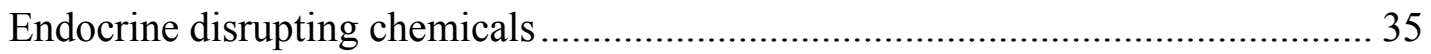




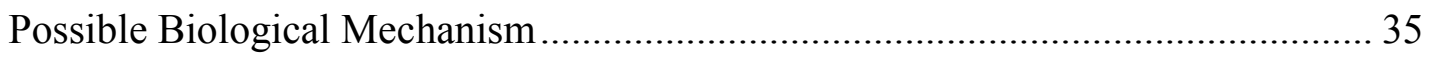

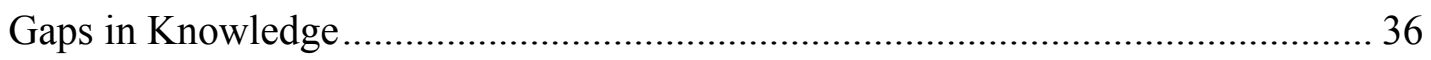

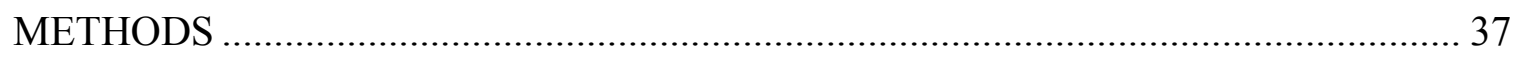

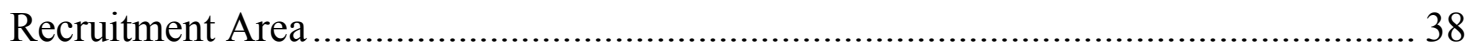

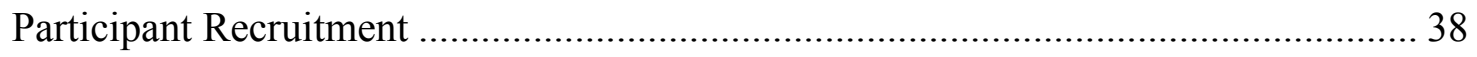

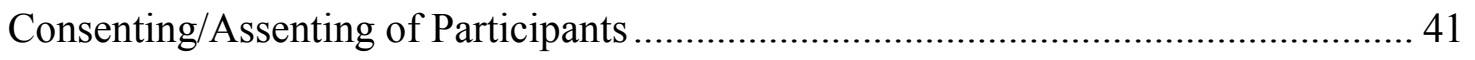

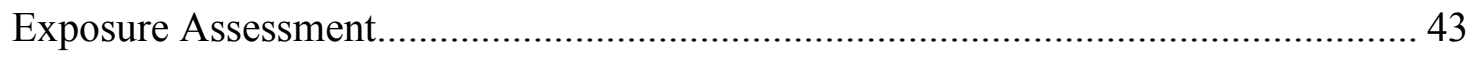

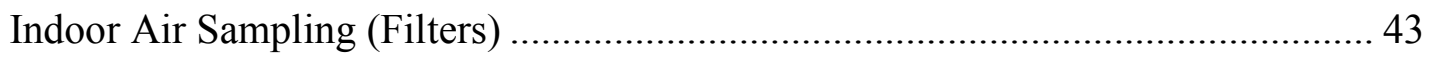

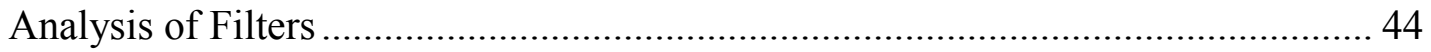

Toenail and Finger Nail Samples (Metal Body Burden) ......................................... 46

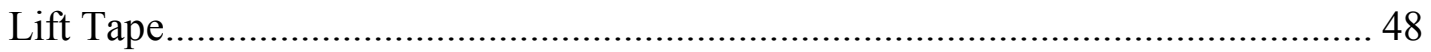

Assessment of ASD measures (Outcome Assessment) .................................................. 49

Child Behavioral Checklist................................................................................ 49

Assessment of Covariates (via Questionnaires) ........................................................... 52

Environmental Health History Questionnaire .......................................................... 52

The Pediatric Health History Form and Environmental Home Assessment.............. 53

Variable Definition and Statistical Analysis............................................................... 54

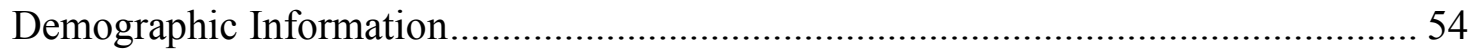

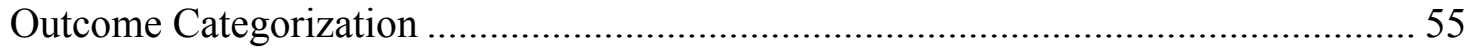

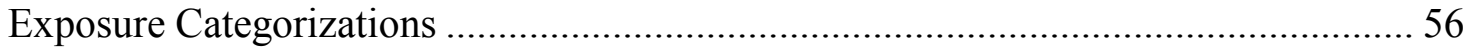

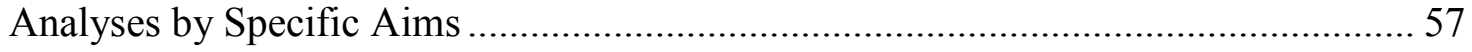

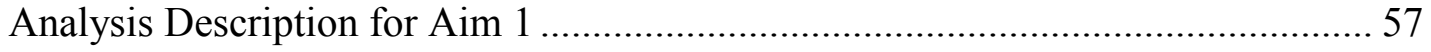

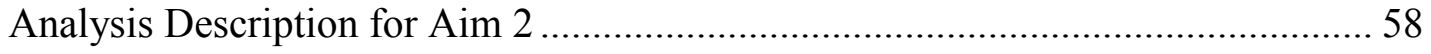

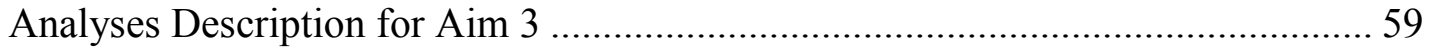

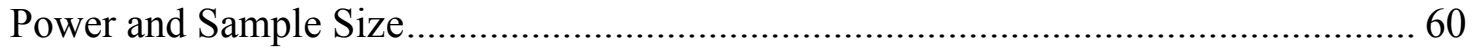

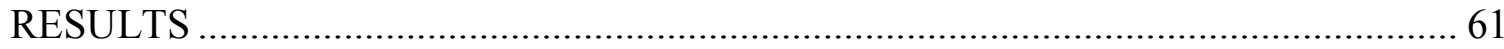

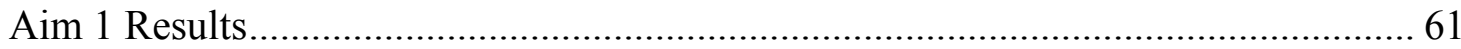

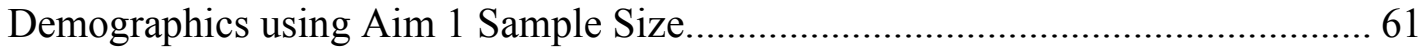

Regression Results ........................................................................................ 72

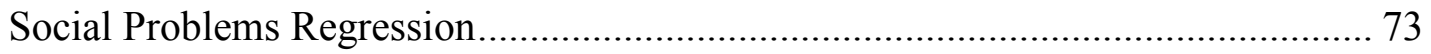

Thought Problems Regression ...................................................................... 78

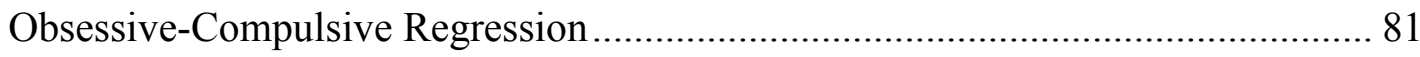

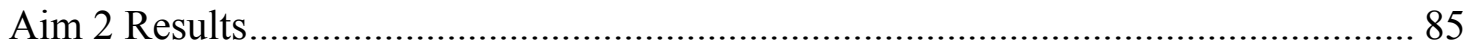

Individual Metal Quartile Derivation................................................................. 85 
Quartile Sum of All Metals.............................................................................. 93

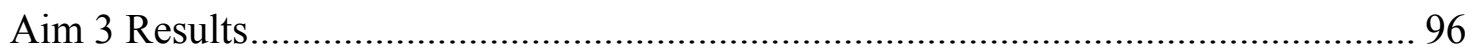

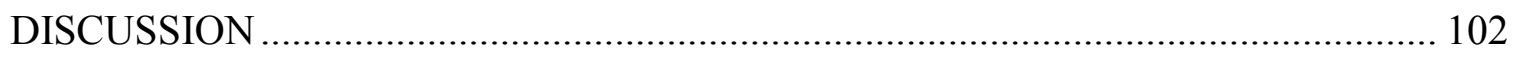

Relationship between Fly Ash Measures and Outcomes ..................................... 102

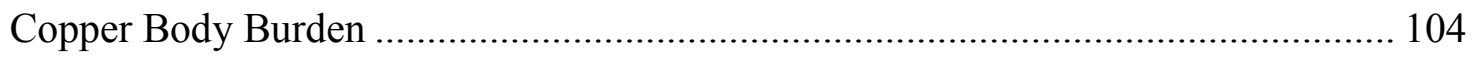

Relationship of Aggregate of All Metals and Outcomes ....................................... 105

Body and Home Metal Correlation ................................................................. 106

Relationship between Significant Covariates and Outcomes ................................ 107

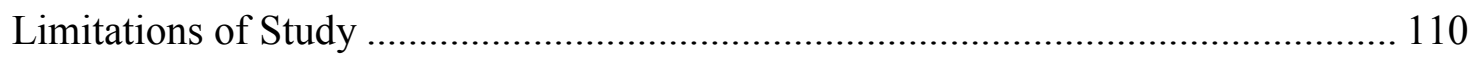

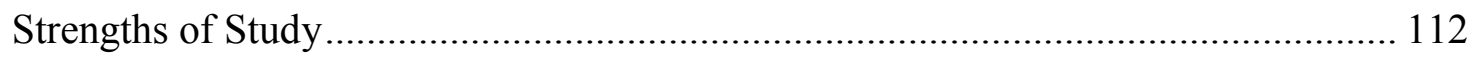

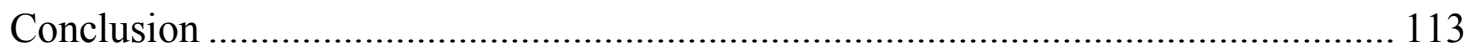

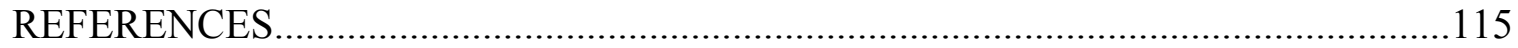

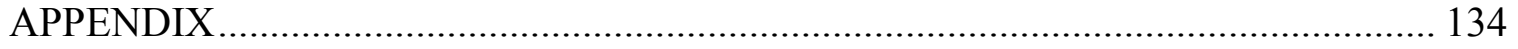

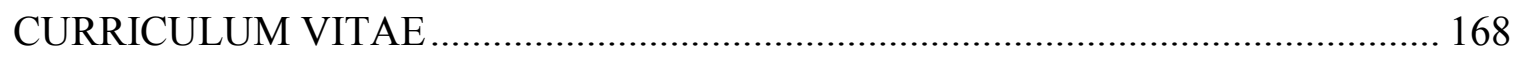




\section{LIST OF TABLES}

Table 1. Definitions of Outcome Measures from the Child Behavioral Checklist (CBCL) ... 51

Table 2. Sample Size, Odds Ratio and Corresponding Power Levels .................................... 60

Table 3. Distribution and Percentages of Outcome Variables ............................................... 62

Table 4. Distribution and Percentages of Fly Ash Found in Home ......................................... 62

Table 5. Sample Characteristics by Social Problems for Aim $1(\mathrm{~N}=158) \ldots \ldots \ldots \ldots \ldots \ldots \ldots \ldots \ldots \ldots . . . . .64$

Table 6. Sample Characteristics by Thought Problems for Aim $1(\mathrm{~N}=158)$.......................... 66

Table 7. Sample Characteristics by Obsessive-compulsive Problems ( $\mathrm{N}=158) \ldots \ldots \ldots \ldots \ldots \ldots \ldots . . . .68$

Table 8. Sample Characteristics by Total Fly Ash Exposure $(\mathrm{N}=158)$.................................. 69

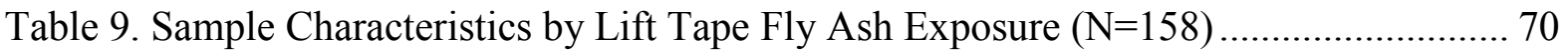

Table 10. Sample Characteristics by Filter Fly Ash Exposure $(\mathrm{N}=158)$................................. 71

Table 11. Univariate Logistic Regression Models of Outcome Variables with Total Fly

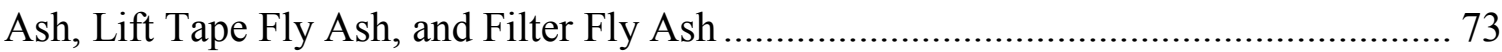

Table 12. Adjusted Odds Ratio (OR) for Social Problems Outcome Stratified by Fly Ash

Exposure, Adjusting for Child Level Covariates ........................................................... 75

Table 13. Adjusted Odds Ratio (OR) for Social Problems Outcome Stratified by Fly Ash

Exposure, Adjusting for Mother Level Covariates ……………..................................... 76

Table 14. Adjusted Odds Ratio (OR) for Social Problems Outcome Stratified by Fly Ash

Exposure, Adjusting for Child \& Mother Level Covariates ............................................ 77

Table 15. Adjusted Odds Ratio (OR) for Thought Problems Outcome Stratified by Fly

Ash Exposure, Adjusting for Child Level Covariates ................................................... 78 
Table 16. Adjusted Odds Ratio (OR) for Thought Problems Outcome Stratified by Fly Ash Exposure, Adjusting for Mother Level Covariates 79

Table 17. Adjusted Odds Ratio (OR) for Thought Problems Outcome Stratified by Fly Ash Exposure, Adjusting Child \& Mother Level Covariates 80

Table 18. Adjusted Odds Ratio (OR) for Obsessive-Compulsive Problems Outcome

Stratified by Fly Ash Exposure, Adjusting for Child Level Covariates 81

Table 19. Adjusted Odds Ratio (OR) for Obsessive-Compulsive Problems Outcome

Stratified by Fly Ash Exposure, Adjusting for Mother Level Covariates 82

Table 20. Adjusted Odds Ratio (OR) for Obsessive-Compulsive Problems Outcome

Stratified by Fly Ash Exposure, Adjusting for Child \& Mother Level Covariates 83

Table 21. Concentration and Distribution of Nail Metal Levels ....................................... 85

Table 22. Distribution of Rank Quartiles and Percentages .............................................. 86

Table 23. Logistic regression- Individual Nail Metal Exposure (Social Problems) .............. 87

Table 24. Logistic regression- Individual Nail Metal Exposure (Thought Problems) .......... 87

Table 25. Logistic Regression- Individual Nail Metal Exposure (Obsessive-Compulsive

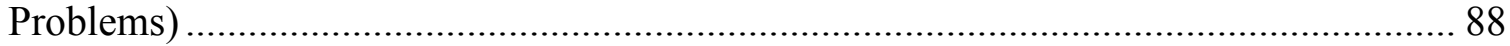

Table 26. Adjusted Odds Ratio of Metal Exposure, Outcomes, and Child Level

Covariates 90

Table 27. Adjusted Odds Ratio of Metal Exposure, Outcomes, and Mother Level

Covariates 91

Table 28. Adjusted Odds Ratio of Metal Exposure, Outcomes, and Child and Mother

Level Covariates 92

Table 29. Metal Sum Measures 93 
Table 30. Logistic Regression with Sum of All Metal Tertiles and Social Problems

Table 31. Logistic Regression with Sum of All Metal Tertiles and Thought Problems 94

Table 32. Logistic Regression with Sum of All Metal Tertiles and ObsessiveCompulsive Problems 95

Table 33. Pearson Correlation of Nail Metal Concentrations and Filter Metal Concentrations 96

Table 34. Spearman Correlation of Nail Metal Concentrations and Filter Metal Concentrations 97

Table 35. Adjusted Odds Ratio of Aluminum Exposure, Child Level Covariates, and Outcomes 134

Table 36. Adjusted Odds Ratio of Aluminum Exposure, Mother Level Covariates, and Outcomes 135

Table 37. Adjusted Odds Ratio of Aluminum Exposure, Child and Mother Level Covariates, and Outcomes 136

Table 38. Adjusted Odds Ratio of Copper Exposure, Child Level Covariates, and Outcomes 137

Table 39. Adjusted Odds Ratio of Copper Exposure, Mother Level Covariates, and Outcomes 138

Table 40. Adjusted Odds Ratio of Copper Exposure, Child and Mother Level Covariates, and Outcomes. 139

Table 41. Adjusted Odds Ratio of Iron Exposure, Child Level Covariates, and Outcomes. 140 Table 42. Adjusted Odds Ratio of Iron Exposure, Mother Level Covariates, and Outcomes 
Table 43. Adjusted Odds Ratio of Iron Exposure, Child and Mother Level Covariates, and Outcomes.

Table 44. Adjusted Odds Ratio of Zinc Exposure, Child Level Covariates, and Outcomes 143

Table 45. Adjusted Odds Ratio of Zinc Exposure, Mother Level Covariates, and

Outcomes

Table 46. Adjusted Odds Ratio of Zinc Exposure, Child and Mother Level Covariates, and Outcomes.

Table 47. Adjusted Odds Ratio of Nickel Exposure, Child Level Covariates, and Outcomes

Table 48. Adjusted Odds Ratio of Nickel Exposure, Mother Level Covariates, and Outcomes

Table 49. Adjusted Odds Ratio of Nickel Exposure, Child and Mother Level Covariates, and Outcomes

Table 50. Adjusted Odds Ratio of Silicon Exposure, Child Level Covariates, and

Outcomes

Table 51. Adjusted Odds Ratio of Silicon Exposure, Mother Level Covariates, and Outcomes

Table 52. Adjusted Odds Ratio of Silicon Exposure, Child and Mother Level Covariates, and Outcomes.

Table 53. Adjusted Odds Ratio of Chromium Exposure, Child Level Covariates, and Outcomes

Table 54. Adjusted Odds Ratio of Chromium Exposure, Mother Level Covariates, and Outcomes 
Table 55. Adjusted Odds Ratio of Chromium Exposure, Child and Mother Level

Covariates, and Outcomes

Table 56. Logistic Regression with Social Problems, Aluminum Exposure and Variables

Identified from Purposeful Selection Modeling 155

Table 57. Logistic Regression with Thought Problems, Aluminum Exposure and

Variables Identified from Purposeful Selection Modeling .....

Table 58. Logistic Regression with Obsessive-Compulsive Problems, Aluminum

Exposure and Variables Identified from Purposeful Selection Modeling 156

Table 59. Logistic Regression with Social Problems, Copper Exposure and Variables

Identified from Purposeful Selection Modeling

Table 60. Logistic Regression with Thought Problems, Copper Exposure and Variables

Identified from Purposeful Selection Modeling

Table 61. Logistic Regression with Obsessive-Compulsive Problems, Copper Exposure

and Variables Identified from Purposeful Selection Modeling 158

Table 62. Logistic Regression with Social Problems, Iron Exposure and Variables

Identified from Purposeful Selection Modeling 158

Table 63. Logistic Regression with Thought Problems, Iron Exposure and Variables

Identified from Purposeful Selection Modeling

Table 64. Logistic Regression with Obsessive-Compulsive Problems, Iron Exposure and

Variables Identified from Purposeful Selection Modeling....

Table 65. Logistic Regression with Social Problems, Zinc Exposure and Variables Identified from Purposeful Selection Modeling 
Table 66. Logistic Regression with Thought Problems, Zinc Exposure and Variables Identified from Purposeful Selection Modeling 160

Table 67. Logistic Regression with Obsessive-Compulsive Problems, Zinc Exposure and Variables Identified from Purposeful Selection Modeling... 160

Table 68. Logistic Regression with Social Problems, Titanium Exposure and Variables Identified from Purposeful Selection Modeling 161

Table 69. Logistic Regression with Thought Problems, Titanium Exposure and Variables Identified from Purposeful Selection Modeling 162

Table 70. Logistic Regression with Obsessive-Compulsive Problems, Titanium Exposure and Variables Identified from Purposeful Selection Modeling ... 162

Table 71. Logistic Regression with Social Problems, Nickel Exposure and Variables Identified from Purposeful Selection Modeling 163

Table 72. Logistic Regression with Thought Problems, Nickel Exposure and Variables Identified from Purposeful Selection Modeling 163

Table 73. Logistic Regression with Obsessive-Compulsive Problems, Nickel Exposure and Variables Identified from Purposeful Selection Modeling 164

Table 74. Logistic Regression with Social Problems, Silicon Exposure and Variables Identified from Purposeful Selection Modeling 164

Table 75. Logistic Regression with Thought Problems, Silicon Exposure and Variables Identified from Purposeful Selection Modeling 165

Table 76. Logistic Regression with Obsessive-Compulsive Problems, Silicon Exposure and Variables Identified from Purposeful Selection Modeling 165 
Table 77. Logistic Regression with Social Problems, Chromium Exposure and Variables Identified from Purposeful Selection Modeling ………………………...................... 166

Table 78. Logistic Regression with Thought Problems, Chromium Exposure and Variables Identified from Purposeful Selection Modeling ..... 166

Table 79. Logistic Regression with Obsessive-Compulsive Problems, Chromium

Exposure and Variables Identified from Purposeful Selection Modeling ...... 167 


\section{LIST OF FIGURES}

Figure 1. Indoor Sampling Equipment Set Up..................................................... 43

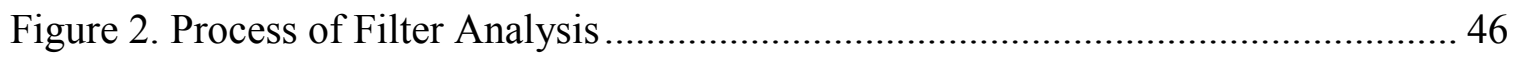

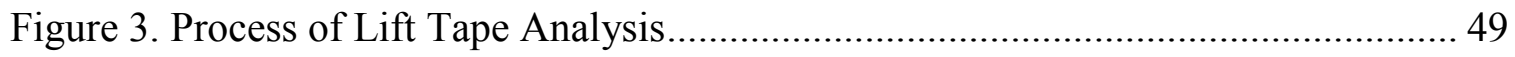

Figure 4. Scatter plots of Nail and Filter Metal Levels for Manganese, Chromium,

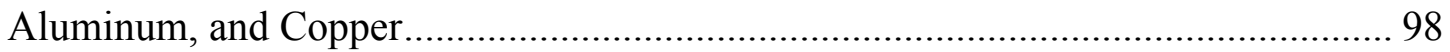

Figure 5. Scatter plots of Nail and Filter Metal Levels for Iron, Zinc, Titanium,

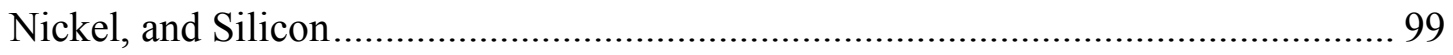

Figure 6. Log-Transformed Scatter plots of Nail and Filter Metal Levels for

Manganese, Chromium, Aluminum, and Copper ............................................. 100

Figure 7. Log Transformed Scatter plots of Nail and Filter Metal Levels for Iron,

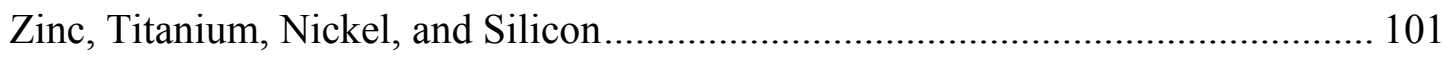




\section{SUMMARY OF STUDY}

Coal plants are major sources of coal combustion residuals like fly ash and heavy metals, and Kentucky ranks near the top, of states in the amount of coal ash generated and stored in the United States. Fly ash, a product generated from the combustion of coal, has been identified as a potential health hazard. Fly ash may contain metals like lead, chromium, and aluminum, which have been associated with Autism Spectrum Disorders (ASD). Metals also contain neuro-developmental and reproductive toxins that influence the growth of the neural tube and other structures necessary for proper brain development, which could result in fetal damage, birth defects, developmental delays, learning, and behavioral problems like those in ASD.

Autism Spectrum Disorders are disorders that affect the functioning of the brain and central nervous system, characterized by impaired social interaction, repetitive behaviors, and restricted interests. Children on the autistic spectrum have impaired socialization, thought and obsessive-compulsive problems, which are indicative of repeated awkward behaviors and restricted interests. Children with ASD range from the severely affected to the highly functional, with high functioning children possessing cognitive skills well above the average range compared to others. Even though high functioning children might perform well in school, their lack of social interaction and ability to communicate, affects their ability to participate in activities involving other kids.

In this study, social problems, thought problems, and obsessive-compulsive problems are used as scales to measures autism spectrum disorders, assessed by the Child 
Behavioral Checklist (CBCL). Even though the CBCL does not directly measure autism, studies have shown patterns of elevation on measures on the CBCL that are indicative of an autism spectrum disorder. These measures include social problems, thought problems, and obsessive-compulsive problems, which were used in this dissertation to capture ASD. The purpose of this study is to explore the relationship between fly ash and metals from particulate matter and social, thought, and obsessive-compulsive problems underlying autism. 


\section{SPECIFIC AIMS}

Specific Aim 1: To determine if children aged 6-14 exposed to fly ash residing within a 10-mile radius of two coal ash storage facilities in Louisville, KY have greater social, thought, and obsessive-compulsive problems as measured using the Child Behavior Checklist.

Specific Aim 2: To assess if children with higher metal concentrations in their body have higher scores of social, thought, and obsessive-compulsive problems based on the Child Behavioral Checklist.

Specific Aim 3: To determine whether child's nail metal concentrations are correlated with concentrations of metals found on the in-home filters. 


\section{Coal Ash Information}

\section{BACKGROUND}

\section{Coal Ash Composition}

Coal is an abundant fossil fuel used for the generation of over $40 \%$ of the electricity used globally and 30\% of the world's energy needs (1). In the United States, coal powered plants account for about $30 \%$ of electricity generation (2). Coal powered plants generated over 110 million tons of coal combustion residues (coal ash) in 2012 (3), about 130 million tons in 2014 (4), and about 107 million tons in 2016 (5). Coal ash is a term used to describe the combustion residue produced during the burning of coal in coal powered plants (4). Even though coal ash has many applications, only about $1 / 4$ of generated coal ash is actually recycled or utilized, while the rest becomes a source of pollution and is often disposed in landfills or waterways (6-8). In the United States, disposal of coal combustion products currently occurs at more than 310 landfills and 735 large ponds, known as surface impoundments (9). Most of the generated coal ash is stored in landfills and ponds, which are often positioned close to residential areas of underserved communities, constituting a public health threat to residents.

Coal ash is comprised of small particles that may contain heavy metals, radioactive elements and polycyclic aromatic hydrocarbons $(10,11)$. Studies report that arsenic (12), lead (13), uranium (14) and benzo-pyrene (15) have been found in coal ash samples. Coal ash includes bottom ash, boiler slag, flue gas desulfurization material, and 
fly ash. Bottom ash, a coarse angular particle is composed of a mass of ash particles from coal furnaces that are too large to be carried in flue gas, hence, it forms smoke stacks in the bottom of the coal furnace (16). Just like bottom ash, boiler slag also known as molten bottom ash, consists of heavier particles and it is collected via a wet-bottom boiler, and cooled down with water to form a molten mass (17). The large size of bottom ash and boiler slag, as well as their low leaching features, reduces the chance of inhalation, hence, research studies are often not focused on this (17). Flue gas desulfurization is a gas that is left over when sulfur and oxides are removed from coal power plants (4). Flue gas desulfurization residues are composed mainly of gypsum and materials similar to those that make up fly ash (18).

\section{Fly Ash}

Fly ash constitutes the majority of coal ash representing about $78 \%$ of the total product (17). Fly ash is a fine silt of spherical powdery particle with diameters $\leq 10 \mu \mathrm{m}$ $\left(\mathrm{PM}_{10}\right)$, usually gray in color with a refractory property $(19,20)$. The color of fly ash can vary from tan to gray, depending on the amount of carbon in the coal that has been burned. The toxicity of fly ash is ascertained by the geochemical properties, burning processes, and composition of the coal it is derived from $(1,10-13)$. Fly ash is composed mainly of silica, some oxides and trace elements (17). Heavy metals like lead and mercury are commonly found as well (17). The chemical properties of fly ash are also dependent on the type of coal burned, how the coal is burned and how it is stored (20). This determines the heating value, ash content, geological origin and chemical composition of fly ash. 
During coal combustion, fly ash ascends in the boiler and is captured by air pollution control devices called "scrubbers" (16). After fly ash is collected from the air pollution control devices, they are transported to landfills and ponds for disposal or storage. Fly ash contains twice the amount of metals in coal ash, making fly ash an even more toxic pollutant (21). Since fly ash contains small particles, unused fly ash disposed in landfills can be very contaminating, lead to air pollution and numerous health threats (22-24). In addition to the threat of air pollution from fugitive dust, fly ash can leach from stored landfills, polluting water, air, plants, and soil. Krgovic et al.'s study on leaching of minor and major elements during transport and storage of coal ash obtained from power plants shows possible leaching of lead, arsenic, and cadmium, which are heavy metals known to have adverse health and environmental effects (25). Reports of deterioration from ground water contamination and coal spillage caused by improper handling of coal products have been made in various areas (26). EPA reports show concentration of arsenic and other metals that exceed their standards for drinking water (26).

\section{Coal Ash Regulations and Storage}

In 2015, the Environmental Protection Agency (EPA) released its final Coal Combustion Residuals (CCR) Rule that set requirements for the disposal of coal ash from coal-fired power plants (27). Prior to December 2014, there were no EPA rules regulating the storage and disposal of coal ash. The ruling was made because of studies that showed the possible harmful effects that could result from improper disposal and storage of coal ash. There were occurrences of large spills in Kingston, Tennessee and Eden, New York which led to damage of property and environmental pollution (4). Collapse of the dike 
used to contain coal ash in Tennessee Valley Authority at Kingston Tennessee, resulted in spillage of over 4 million meter cubed of coal ash into nearby rivers and surrounding areas. Elevations of various neurotoxic and teratogenic metals and compounds especially methyl mercury- a toxic organic source of mercury, were reported in the area (28-30). The new rule addresses regulation of ponds and landfills, plant's location, safety practices, ground water protection, transfer of particles into air as dust, and rules for ash impoundment sites (9). In addition, the rule requires facilities to document and make public any information or changes they make regarding the ruling (9). The rule provides a comprehensive and more rigorous design, monitoring, operating, corrective action, closure, and post-closure requirements for CCR landfills and surface impoundments. As a result of this rule, many landfills and ponds will most likely be closed and/or replaced with those that meet the EPA's requirements. The CCR rule is applicable to old, new, and existing facilities and does not apply to plants and facilities that are already closed or no longer being used to generate energy.

The Coal Combustion Residuals (CCR) Rule is established under the Resource Conservation and Recovery Act (RCRA) which is the public law that creates the basis for the proper management of hazardous and non-hazardous solid waste. The RCRA under subtitle D classifies coal ash as a non-hazardous waste. The RCRA also sets forth criteria of standards for ponds and landfills that requires all facilities to comply (31). The key requirements of the ruling include structural integrity, hydraulic and air criteria, ground water monitoring and corrective action, and standards of the location. Structural integrity involves conducting frequent hazard classification assessments for possible damage that could occur if there was a problem with an impoundment. It also involves routine 
assessment of structural stability and routine safety assessment to determine if the disposal units meet minimum safety standards (9). The hydraulic criteria require routine assessment of the hydraulic capacities and its assessment. Ground water monitoring criteria require the use of liners to protect groundwater, mandate ground water cleanup, and enforce the closure of unlined impoundments that pollute water and those that do not meet structural integrity criteria (9). For meeting location standards, restrictions are in place to ensure that landfills cannot be built or placed in sensitive areas, such as wetlands and earthquake zones.

\section{Coal ash and Kentucky}

Kentucky is ranked number one in the list of states that generate the most toxic air pollution from power plants (32). Kentucky produces over 9 million tons of coal ash, and ranks 5th in the United States for production of coal ash (33). A 2007 risk assessment conducted by the EPA reported that Kentucky has a total of 43 ponds and 17 landfills. Of these, 10 ponds and landfills are unlined. Four of the unlined landfills and ponds have no ground water monitoring system, while eight of them have no leachate collection system (34). Overall, Kentucky has the third largest coal ash storage in the United States, with a capacity of 64,000 acre-feet $(33,34)$. Plants of interest to the study are those located in Louisville, Kentucky, both which are located in proximity to residential areas. Residents have made claims in the past of observing fly ash like particles in their cars, doors, yards, etc. The plants of interest are the Cane Run plant and the Mill Creek plant.

\section{Cane Run plant}

The Cane Run plant is Louisville Gas and Electric (LG\&E) company's electric generation stem, located in West Louisville. The Cane Run plant sits along the Ohio 
River located in southwest Jefferson County. The plant began operations in 1954 and has made updates over time; most currently in Cane Run plant unit 7, which became commercially available in 2015 (35). The newest Cane Run plant- unit 7 is the first natural gas combined cycle generating power plant in Kentucky. Prior to development of unit 7, coal high in sulfur was used as the primary fuel source and over a million tons was burned annually (35). Sulfur which is hazardous when burned in coal, has tendency to cause harm to the environment (36). Even though the most recent plant uses natural gas as a result of cost of complying to updated air pollution regulations, emission of toxic waste is still bound to happen.

While Cane Run no longer burns coal to produce energy, the landfill and coal ash ponds are yet to be completely covered, which can cause fugitive dust to be blown by wind to residential areas (37). Cane Run's landfill stores by-products of coal ash and has been estimated to produce wastes with an elevation of about 560 feet (38). Cane Run's main ash pond has been ranked as highly hazardous by the EPA (39). The rating for highly hazardous implies that collapse or failure of the unit will result in potential loss of life (39). EPA's recent ruling recognized that improper disposal of coal ash could cause harm, and rules are in place to ensure proper disposal of coal ash products, including control of leakage and blowing of waste products into the air. LG\&E plans to cap and close the Cane Run landfill, but has not provided a timeline for when this action will be taken (40). Closure of a landfill or pond must be completed either by leaving the waste in place and installing a final cover system or through removal of the wastes and decontamination of the unit. Closure of landfills could involve dewatering the ash, lining 
the water ponds, and installing a cap over the site to prevent rainwater from filtering into the material and increasing the risk of groundwater pollution (9).

\section{Mill Creek Plant}

The Mill Creek generating power station is owned by LG\&E. It is the largest coal-ash generating power plant in Kentucky, with a capacity of about 1400 megawatts (MW) (41). The Mill Creek plant sits on 544 acres of land, near the Ohio River, located in southwest Louisville, Kentucky. The plant was constructed as a result of increased demand in energy supply, which led to a need for an additional plant that could generate energy. The plant started functioning in 1972 to meet this increased demand (41). The Mill Creek plant consists of four coal-operated electric generating units. Units 1 and 2 began operation in 1972 and unit 3 in 1978. The latest addition is unit 4, which began operation in 1982. Unlike the Cane Run plant, the Mill Creek plant still uses coal as source of fuel and generates coal combustion residual by-products like fly ash, boiler, slag, bottom ash and gypsum. The Mill Creek plant consumes about 4.8 million tons of coal per year (41). Waste products from the plant are disposed in the main landfills or ash pounds (42). In addition to the major large ash pond, there are four smaller ones which supply and receive water, suspended materials, and sedimentation, which discharges into the Ohio River. The Mill Creek main ash pond is located on the North side of the power plant and faces the East side of the Ohio river (42). Fly ash that is generated from the power plant is collected using electrostatic precipitators and then placed in the on-site landfill, while bottom ash is washed off to the ash pond (42). Mill Creek has demonstrated damage to ground water moving off to the Ohio river, and heavy metals like arsenic have been found, which exceeds state and federal levels (43). 
In 1982, the Kentucky Division of Waste Management (KDWM) initially provided a permit for a 185 -acre coal by-product landfill, however, expansions have been made over time to increase the size of the landfill (43). Another 79-acre ash pond was built in 1972, in addition to commissioning of the four smaller ponds (43). KDWM did not require a liner for the landfill in the first expansion in 1990. The second expansion of the landfill made use of clay liners, which limits the seepage of metals, however, the clay is subject to deterioration from factors like desiccation (43). The KDWM assigned the Mill Creek main ash pond a "high hazard" classification because of its proximity to residential areas. The main pond is located less than 150 feet to a school in the area and can cause harm to people who live in the area (42). According to LG\&E, the ponds at Mill Creek are expected to be closed by 2020 . This closure statement was made in response to the EPA's Disposal of Coal Combustion Residuals from Electric Utilities Rule (44). LG\&E also made a statement about investing more than $\$ 300$ million dollars in additional environmental improvements.

\section{Content of coal ash/fly ash and relationship with health in general}

Fly ash can enter the body through inhalation, ingestion, eye, and skin exposure. There are both long and short terms effects of exposure to fly ash. One of the most entry routes for fly ash into the body is via inhalation. Fly ash consists of very tiny particles which when inhaled, can penetrate deep into the lungs leading to inflammation of cells, irritation of the mucous membrane of the respiratory tract, and accompanying immune system response and reactions (45). Fly ash contains silica in the form of silicon dioxide which is capable of attaching firmly in the lungs, and continued exposure to fly ash may result in pulmonary fibrosis, chronic bronchitis, silicosis, and other diseases (45). In a 
case study by Cho et al., a 48 year old man without history of respiratory problems developed acute lung disease after prolonged and intensive exposure to fly ash (45).

Fly ash is a form of particulate matter in the size range of PM10. Particulate matter is part of air pollution, and is made up of extremely small particles and liquid droplets found in the air we breathe. Particulate matter comes in various sizes, including PM2.5 (particulate matter with a diameter of 2.5 microns or less) and PM10 (particulate matter with a diameter of 10 microns or less) $(46,47)$. Particulate matter contains heavy metals like lead, mercury, and chromium and can cause harm (48-50). Particulate matter is an environmental pollutant and has been ranked as the $13^{\text {th }}$ leading cause of mortality worldwide, with about 800,000 premature deaths (47). Particulate matter has also been linked with impaired cardiovascular, brain, respiratory, and pulmonary health (47).

\section{Heavy Metals Often Found in Fly Ash}

Heavy metals found in fly ash have the ability to disrupt vital biochemical processes required for proper functioning of the body $(51,52)$. As a result, the production of chemically reactive chemicals which contain oxygen in turn disrupts enzymatic activities leading to malfunction of body processes $(51,53)$.

Heavy metals like arsenic can bind to compounds like thiols to disrupt enzyme action. Arsenic is one of the most toxic metals found in fly ash and it is a hazardous environmental pollutant. The Agency for Toxic Substances and Disease Registry (ATSDR) classifies arsenic as a carcinogen (54). Arsenic can get into the body via drinking water, inhalation or skin absorption. Studies have shown that chronic exposure to arsenic is associated with heart disease (55), diabetes (56), bladder cancer (57), lung cancer, (37) and impairments in children's intellectual function (58). A study conducted 
in Bangladesh showed that children with higher concentrations of arsenic in urine had higher odds of developing pneumonia compared to children with low level urine arsenic levels (OR :1.88; 95 \% CI: 1.01, 3.53) (59).

Lead is another toxic metal found in fly ash. Lead is found in water, air, soil, and in lead paints. Children are particularly at risk for lead effects because of their relatively greater body surface area, leading their bodies to absorb relatively greater proportions of the chemical compared to adults (60). Children are also more likely to put items that might have lead in their mouths and play in soil that has lead in it (60). Lead exposure can result in impaired learning, slow growth, behavioral problems, lower IQ and hyperactivity in children (60). Chronic lead exposure can also affect adults and result in health problems like hypertension, hearing problem, and male reproductive organ impairment (61). The industrial use of lead has decreased over time following reports of adverse health effects of lead exposure in recent years.

Mercury is a neurotoxin and the third most regularly released toxic substance from waste facilities $(62,63)$. Mercury exists in different forms - as organic, elemental, and inorganic. All these forms are toxic. These various forms can be exposed to humans via food contamination, air pollution, industrial, occupational and agricultural activities (64). Mercury has a low excretion rate, a little of it is excreted while the rest is absorbed by different organs in the body (e.g. kidney and liver) to produce neurotoxic and deteriorating effects $(64,65)$. The effects of mercury on neuro-behavioral development in early years have also been reported $(51,66)$.

Cadmium and chromium found in fly ash can have toxic effects on health. Cadmium from coal ash dust can be inhaled from fly ash stored in uncovered landfills. 
Cadmium exposure can result in osteoporosis and is also related to cancer and hypertension (61). Other cadmium effects include kidney problems, which result in increased urinary protein (67). About 300,000 workers are exposed to chromium and its compounds in the workplace (64). Even though chromium is most absorbed via inhalation, reports of skin inflammation after chronic exposure to chromium have been documented by some researchers $(64,68)$.

\section{Additional Trace Metals/Elements found in Fly Ash}

Elemental analysis of fly ash showed presence of aluminum, copper, iron, manganese, nickel, zinc, and titanium $(19,69)$. Aluminum is one of the neurotoxic elements found in fly ash $(69,70)$. Aluminum is ubiquitous and is one of the most abundant elements on the earth making aluminum exposure possible (70). Aluminum can be found in various consumer products including body deodorants, antacids, and also is naturally present in water, soil, and air (71). The concentration of aluminum accumulates over time with age and can be found in the brain, implying that older people are more likely to have high aluminum content compared to younger people which is why a possible link between aluminum and Alzheimer's disease is implied (70). Aluminum is also released to the environment via coal power plants (71). Aluminum is a biologically reactive element and has the ability to destroy cellular functions which will result in neurological deficits. A case-control study by Mohammed et al showed that levels of aluminum were higher among children with autism compared to children without autism, and was examined using hair samples (72).

Copper is an essential element that naturally occurs throughout the earth's crust (in water, air, and soil). Copper can be used for water treatment and in agricultural 
products and it is used to create products like copper wires, pipes, and coins (73).

Exposure to copper can result in redness of eyes, eye irritation and pain, and skin irritation. Copper or copper fumes and dust can be absorbed into the body via inhalation and ingestion, and can result in lung damage and pulmonary fibrosis (73). Ingestion or inhalation of large doses of copper can result in renal failure, liver damage, or even death (73).

Iron is an important component of hemoglobin, which aids in transportation of oxygen to cells, tissues, organs, and systems where they are needed (74). Iron is an essential element that is used in many consumer products like multivitamins that are used to prevent anemia (74). Iron deficiency (anemia) can result in cognitive and attention deficits. When iron levels are low in the body, levels of iron dependent enzymes (enzymes which catalyze a wide range of oxygen reactions, and involved in many cellular metabolic pathways) reduce which can result in problems with cognitive functions (75). On the other hand, excess levels of iron in the body can result in central nervous system problems and Parkinson's disease (75).

Manganese is a trace element, that functions in many enzyme actions, and that occurs naturally in the environment (76). Low levels of manganese is considered a nutritional element which is essential to human health. Even though manganese deficiency is rare, health problems like impaired growth and developmental abnormalities can occur (76). Chronic exposure to manganese can occur by inhalation and can result in manganese poisoning which can result in various psychiatric and motor problems (76).

Nickel, an abundant natural element in the earth's crust can be found in ocean floors (77). One of the major characteristics of nickel is that it readily forms alloys or can 
easily be remerged with elements like zinc, iron, chromium, and copper. These alloys can be used to make jewelry and coins. Coal burning power plants and other industries that make use of nickel can release nickel into the environment where it affixes to dust particles that end up settling in the ground (77). Furthermore, people can also be exposed to nickel by eating food that contains nickel, by skin exposure, touching nickel products, by drinking water that contains nickel, or by working in industries that use nickel and nickel containing products. Lung cancer and chronic bronchitis can result from nickel exposure especially among chronically exposed people like those who work in places that use nickel (77). Some people are allergic to nickel and could experience skin irritation when wearing jewelry that contains nickel or during ear piercing using nickel made jewelry. A study by Brandoa et al carried out to determine the prevalence of children who have metal allergies, found that children whose ears were pierced were 2.8 times more likely to react to nickel than children without pierced ear (Odds Ratio: 2.8; P-value= 0.031) (78).

Zinc is also one of the most abundant elements in the earth's crust, and just like nickel, it can combine with many elements to form zinc compounds which are used in industries to make things like zinc roofing sheets, ceramics, rubber, staining textiles, and conserving timber (79). More common exposures of zinc include use in consumer products like deodorants, multivitamin supplements, diaper rash lotions, antidandruff shampoos, and acne treatment products (79). Coal burning can increase levels of zinc in the air (79). Levels of zinc in the soil can increase as a result of dumping of zinc waste products, while air levels can increase when industrial activities like coal burning releases zinc particles in the air which then attaches to dust particles and settles over the ground 
and water systems (79). Deficiency of zinc is a problem just as much as chronic exposure of zinc. Deficiency of zinc can result in birth defects while over consumption of zinc can result in pancreatic damage (79).

Titanium is ranked $9^{\text {th }}$ as one of the most abundant elements in the earth's crust which naturally occurs in combination with either oxygen or iron (80). About $5 \%$ of the world's titanium mineral production goes to actually making titanium while the rest goes to making titanium dioxide (80). Titanium dioxide can be found in consumer products like body lotions and sunscreens (81). Inhalation or chronic exposure to titanium dioxide can result in cell death, DNA damage, and inflammation of lung and throat cells (81). Inhaled titanium dioxide can transfer to the central nervous system crossing the blood brain barrier through the olfactory pathway (82). Inhalation of titanium dioxide occurs primarily in occupational settings where titanium oxide powders and products are consistently used. Exposure can also occur via ingesting food products like cheese, ice cream, and pharmaceutical products (82).

\section{Other Hazardous Contents of Fly Ash}

Various radioactive elements are found in coal, and as a result, fly ash contains varying amount of radioactive elements or radionucleotides, depending on the type of coal and its geochemical properties (83). Soil samples from the Tennessee Kingston spill showed high levels of radioactive radium compared to soil samples from an unaffected area $(84,85)$. Uranium which is the most significant source of radon gas is redistributed in the environment when coal is burned. Radioactive elements are also retained when coal is burned and products like fugitive dust (particulate matter) are formed. These radioactive elements undergo radioactive decay, and are transported to the lungs, resulting in lung 
cancer and substituting the calcium content in bones (86). Populations in proximity to ash storage sites are exposed to increased doses of radioactive elements and pose a health threat to them (87). Products from coal combustion like fly ash are often recycled and used as building materials for homes, this activity poses a risk of increasing levels of radioactive elements in homes that were built with these coal product materials (88).

Polyaromatic hydrocarbons (PAH) are comprised of different chemicals that are formed during incomplete combustion of coal (89). PAHs in coal are the major source of organic pollution, and exert toxic effects via various actions. PAHs are commonly found in air, water, and soil $(90,91)$. PAHs are able to bind to DNA to form DNA-adducts, a biomarker that has been linked to cancer $(92,93)$. A study of New York children born to non-smoking mothers followed starting in utero to age 8 found prenatal exposure to $\mathrm{PAH}$ to be associated with neurodevelopmental problems in children $(93,94)$. Similarly, a high risk of cancer was observed in a cohort of workers in various industries exposed to PAH $(93,95)$.

\section{Coal Ash Effects on Worker's Health}

Landfill workers who handle the transportation, disposal, and recycling of coal ash are at increased risk of health hazards due to exposure to these metals, particulate matter, and PAHs found in fly ash. About $36 \%$ of generated fly ash is disposed in landfills, $21 \%$ is stored in pond or wet impoundments, while the remaining are recycled or used in industrial applications (86). Transmission routes could be via exposure before combustion, during combustion, and after combustion. Some exposure can occur in all the different transmission routes. A worker can be exposed to particulate matter before coal is completely combusted and afterward to post-combustion products, like fly ash 
(96). An occupational study of the effect of chronic exposure to heavy metals and fly ash on workers found that power plant workers had higher level of arsenic and mercury compared to non-occupational workers (51). Significant positive correlations were also found between arsenic and zinc (51).

\section{Coal ash and fly ash effect on children's health}

Children are considered a vulnerable population because they exhibit behaviors that increase their risk of exposure. Children tend to play on the ground and ingest items they come in contact with. Children also breathe in more air, making their exposure to pollution greater than that of adults. Children's lungs do not completely develop till late teen years, and developing organs like the lungs are more susceptible to toxic effects and environmental pollutants. In addition, children absorb more pollutants than adults and are more likely to retain them over time because they tend to spend more time outside. Children tend to be mouth breathers as well (not just nasal breathers) which increases their ventilation rate, thereby increasing the amount of pollutants taken up by the lungs. Undeveloped immune system could also pose health risks in children $(97,98)$. These behaviors and processes in kids can increase their chances of being exposed to coal ash via ingestion, inhalation or skin absorption.

According to the EPA, 25\% of residents in proximity to electric power plants are children (31). Studies have shown that children prenatally exposed to coal ash containing lead and polyaromatic hydrocarbons have decreased language, motor, and social progress $(3,99,100)$. Tang et al assessed the effects of prenatal exposure to coal-burning pollutants on children's development in China, and found that exposure to pollutants from power plants harmed the development of children living in the study region (100). 
Particulate matter exposure is also associated with decreased lung function (101) and increased asthma risk in children (102). There is increasing evidence of the adverse effects of prenatal exposure to air pollutants from the combustion of coal. A recent study on autism spectrum disorder and air pollution before, during and after pregnancy showed that increased maternal exposure to $\mathrm{PM}_{2.5}$ during third trimester of pregnancy was associated with a greater likelihood of a child having an autism spectrum disorder (103). Studies have also found an inverse relationship between children's intelligence scores, IQ scores, and memory test scores with manganese and arsenic exposure (104).Various heavy metals have also been shown to impact children's cognitive functions and abilities (105).

Several studies have demonstrated that long term exposure to heavy metal pollutants, such as arsenic, cadmium, mercury, lead, and arsenic, during pregnancy and the early years of life is associated with increased incidence of children developmental problems like autism (106-108). Heavy metals with adverse health effects on the immune system can lead to the abnormal secretion and activation of cytokines. Exposure to cytokines and other heavy metals during the critical period of development may interfere with the immune and nervous system, leading to the development of behavioral issues $(106,108)$. Children with autism retain mercury in their body due to impairments in detoxification pathways (63). 


\section{Autism Information}

\section{Overview of Autism Spectrum Disorders}

Autism Spectrum Disorder (ASD), also known as "autism" is a

neurodevelopmental disorder characterized by impaired social interaction, communication deficits, repetitive behaviors, and restricted interests $(106,109)$. Initially, autism disorders were recognized as distinct subtypes and diagnosed separately under the Pervasive Developmental Disorder category, and included autistic disorder, childhood disintegrative disorder, pervasive developmental disorder-not otherwise specified (PDDNOS) and Asperger syndrome (110,111). These conditions all combined are now referred to as autism spectrum disorder. Each individual on the spectrum is unique, and some have special skills with specific school subjects, music, visual capabilities, etc. Children with autism can display unusual ways of learning, and they are more likely to repeat certain behaviors and have difficulties when required to change their usual daily activities.

Children on the spectrum could also range from those highly affected by it to those who might be considered autistic but are still very functional. The high functioning children usually possess cognitive skills within or above the average range compared to their peers. Even though these children might perform well in school, their lack of social interaction will restrict them from participating in activities involving other kids (112). It is difficult for children with autism to blend in with daily activities of the society because people (teacher, friends) they encounter might not understand the gap caused by ASD between their abilities, and awkwardness. The varying spectrums of autism throughout a person's developmental stages present some of the greatest difficulties for researchers. Also, the prevalence rates of autism have changed overtime from having a low incidence 
to describing it as a disorder that is not uncommon. Thus, autism has gained publicity, resulting in the recognition of autism as a problem and highlighting the importance of autism research.

\section{Social and Communication Deficits and Autism}

Social skills are vital skills used to navigate through life and are developed and improved by constantly interacting with the social world (113). Social skills guide individuals on how to engage, interact, and participate with others in different social contexts and can be expressed verbally or non-verbally. Social deficits results in lack of interaction with others and affects emotional, social and cognitive development (114). Deficits in social functioning are the principal features of a child with an autism spectrum disorder, however, children on the autism spectrum display varying degrees of social deficits/skills (114). Children with social deficits become oblivious of people's feelings and struggle to understand it. They find it difficult to respond to faces and the various emotions that goes with each face that is made. Children on the autistic spectrum with social deficits find the social world to be fearsome, unnatural, and stressful. As a result, they prefer to stay isolated, avoid meeting other people, and will not perform an activity without being prompted. The high functioning children who might be social, sometimes lack the appropriate words to use to initiate a conversation. Also, social behaviors and cues that are deemed appropriate at one age might become inappropriate at another age and it is common for children on the ASD spectrum to struggle with this transition (115). Overall, children with impaired social functioning, struggle to comprehend social nuances, social cues, and require direct, systematic instruction to be able to function properly. The negative impacts of social impairments in children with autism spectrum 
disorder is extensive, therefore, it is important to find effective ways to facilitate development of social functioning and understanding among children.

\section{Behavioral Deficits and Autism}

Behavioral problems experienced by children with ASD are manifested as thought problems, repetitive behaviors, having restricted interests, and compulsive behaviors. While some children without ASD may display some of these behaviors during different levels of development, not all children will pervasively demonstrate these behaviors. Restricted and repetitive behaviors form a group of behaviors characterized by repetition in an undeviating manner, and a longing for sameness in a setting (116). Restrictive behavior is characterized by sticking to interests and activities, and emphasis is that aspects of the environment stay the same, while repetition is displayed by recurring stereotypic movements, speech, and routines (116). Children exhibit these behaviors when they have social fears and difficulty with expressing emotions. They may require prompting for various activities and may interminably repeat some behaviors in an order that soothes them and only children who display these symptoms can relate to the behavior, and order of repetition. Repetitive behaviors, obsessions, and routines can be a source of relief and pleasure for children with autism because it helps them to cope with day to day living. Children who have these behavioral deficits find it difficult to adjust to new routines which can result in display of aggressive behaviors.

\section{Diagnosis of ASD}

Autism has been shown to have its root from early childhood during brain development, and usually continues until adulthood (117). Diagnosing autism is not easy since there are no blood or medical tests. A combination of judgment of qualified 
professionals with expertise in use of standardized instruments, such as validated questionnaires, in addition to information from the parents is used to identify or diagnose a child with autism. Physician diagnosis is often based on a child's development level and behavior. It is possible for a child to be diagnosed below 2 years of age, but a diagnosis at two years is considered to be very reliable, however most children receive a diagnosis at a much older age (118). According to the U.S. Centers for Disease Control and Prevention (CDC), diagnosing autism takes two steps. The first is a developmental screening stage which is a short test to determine if a child is at the learning level where they should be, and learning the basic skills they should as determined by a Pediatrician (118). The physician asks parents questions, and observes how the child learns, behaves, speaks, and moves. The second step involves a thorough comprehensive diagnostic evaluation, where the child's behavior and development is further assessed by a physician /specialist. It is recommended that all children should be screened for autism during regular doctor visits at 18 months and 24 months.

Autism/autism disorder is diagnosed mainly using two international classification systems, ICD-10 and DSM-IV. Both describe behavioral criteria and specify the expected onset age. ICD-10 is more commonly used in the United Kingdom and is endorsed by the World Health Organization (WHO). The American Psychiatric Association issues the Diagnostic and Statistical Manual of Mental Disorders (DSM), which provides standardized criteria to help diagnose ASD. Autism was first operationalized in DSM-III (third edition), and was strongly influenced by Michael Rutter who is described as the father of child psychology. His definition involved conceptualization of restricted interest, impaired social and communication development occurring before 30 months of 
age $(110,119)$. The ensuing revisions in the fourth edition (DSM-IV) and $10^{\text {th }}$ revision of the International Classification of Diseases (ICD-10) describes autism as a pervasive developmental disorder, which implies that autism comprises of various features like impairments in communication, social interaction, and restricted, repetitive, and stereotyped behaviors. The most recent version- DSM-V was published in May 2013, replacing DSM-IV with controversial changes. DSM-V has incorporated the term autism spectrum disorder without a description of different subtypes. DSM-V's features of autism spectrum disorder includes difficulty in social communication and social interaction; and restricted and repetitive behavior, interests, or activities. The new criteria using DSM-V provides improved descriptions of key features with emphasis on the dimensional nature of autism $(110,120)$. DSM-V is more robust than DSM-IV and will identify different populations of individuals, although it can produce overlapping results (121).

The Child Behavioral Checklist (CBCL) developed by Thomas Achenbach is a commonly used questionnaire for assessing behavioral problems in children. The CBCL is an extensively standardized parent or teacher completed checklist of competencies and behavioral problems of children between ages 6 and 18. CBCL assessment includes statements regarding the child's behavior and uses a Likert Scale: $0=$ Not true, $1=$ Somewhat or sometimes true, $2=$ Very true or often true. The CBCL has scales to reflect scores associated with the DSM-IV which includes capturing social problems, compulsive problems, etc. (122). Even though the CBCL is designed to assess many psychological problems found in children, it does not exactly capture autism just by itself. However, there are patterns of elevation on measures on the CBCL that are 
indicative of an autism spectrum disorder (122). Increased elevations in social, thought, attention problems scales, could be indicative of an autism spectrum disorder (122). Studies that used the CBCL to compare children with autism versus children with ADHD found that significantly elevated scores for withdrawn, social, and thought problem scales differentiated children in these two groups $(123,124)$. The scorings on the CBCL are indicative of behaviors that commonly occur together, and similar questions are used to capture scales of different behavior. In a case control study conducted by Narzisi et al, the CBCL was used to effectively distinguish children with autism versus children with other psychiatric disorders (123). The CBCL has also been proposed for use in diagnosing children with ASD in clinical settings. The CBCL and its many forms have been used globally for research purposes, has been translated into over 70 languages, has been considered as valid and reliable in assessing behavioral functioning of kids, and has been used in thousands of publications.

\section{Prevalence of Autism}

The prevalence of autism varies by geographic region and time periods based on changes in diagnostic criteria. Recent worldwide median estimate ranges from $0.62 \%$ to $0.70 \%(121,125)$. According to the CDC, 1 in 68 children have been recognized to have autism spectrum disorders (126). The National Health Interview Survey, a nationwide household survey conducted by the CDC in 2014 found the prevalence of ASD among children aged 3 to 17 years to be 22.4 per 1000 . Another large nationally representative survey conducted between 2011 and 2012 (National Survey of Children's Health) reported the prevalence of ASD among children 6-17 years of age to be 20 per 1,000 $(127,128)$. Recent large population-based surveys suggest an increasing trend in the 
prevalence of ASD over the past two decades, however, some investigators believe that this perceived trend is likely a reflection of increased recognition and changes in diagnostic criteria.

\section{Risk Factors of ASD}

There are no established causes of autism, however, genetic factors, environmental factors, or a complex interaction between the two could play a role in the development of autism (106).

\section{Gender}

There is consensus that ASD is more common in males than females. Large population studies suggest that males are 2 to 3 times more likely to be affected by ASD compared to females $(110,129-132)$. In the United States, a survey of 11 sites in the Autism and Developmental Disabilities Monitoring Network (ADDM), found that ASD is 4.5 times more common in boys aged 8 years than girls aged 8 years (127). Some investigators speculate that sex differences in the prevalence of ASD may be related to under-recognition of ASD in females and diagnostic bias towards males.

\section{Race}

ASD affects individuals of all racial and ethnic backgrounds, but recent large population-based surveys indicate disparities in the prevalence of ASD by race and ethnicity in the United States. The 2012 ADDM surveillance study found that nonHispanic white children aged 8 years had a prevalence of ASD that was $20 \%, 40 \%$ and $50 \%$ higher than prevalence rates among non-Hispanic black children, Asian/Pacific Islander children, and Hispanic children, respectively. Similarly, the 2009-2010 National Survey of Children with Special Health Care Needs (NSCSHCN) found an estimated 
ASD prevalence for non-Hispanic white children of 15.3 per 1000 , nearly $50 \%$ and $300 \%$ higher than the corresponding rates for non-Hispanic black children $(10.4$ per 1,000), and Hispanic children living in households where the primary language was not English (5.2 per 1,000), respectively (127). These findings may be related to lack of awareness of ASD among minority populations and disparities associated with barriers in access to diagnostic and treatment services that is commonly seen among minority ethnicities in the United States (127).

\section{Smoking}

Exposure to cigarette smoke is one the risk factors for morbidity and mortality among both parents and their children. Smoking can inhibit the transfer of nutrients needed for the proper development of a child (133). A large population based cohort study investigating the risk of obsessive-compulsive problems and perinatal activities found that smoking during pregnancy was associated with increased risk of developing obsessive-compulsive disorders (Hazard ratio: 1.27; 95\% CI, 1.02-1.58) (134). Beyond exposure to smoke before birth, environmental smoke exposure has been linked with deficits in children's neurodevelopment and behaviors of a child (135).

\section{Genes}

There is a complex interaction between genetic and environmental factors, and association with autism. Studies have shown strong genetic connections- a 'twin study' conducted in the U.K. found that if one of an identical twin had ASD, then there is increased chance $(60 \%)$ of the other twin also having it. With the twin study, it was also possible that one of an identical twin could have autism but the other would not, indicating the influence of possible environmental factors. Studies have also shown that 
autism has $80 \%$ inheritability rate and this inheritability has an interplay with environmental factors $(110,136)$.

\section{Parent age}

Sandin et al showed that increased maternal and paternal age is a consistent and dose-dependent risk factor for autism: relative risk for developing autism increased as maternal age increased (137). Another major study published in 2008 by the Journal of Epidemiology showed that compared to mothers and fathers aged 25-29 years, there was a greater risk of autism if the mother was $\geq 35$ years $(\mathrm{OR}=1.30,95 \% \mathrm{CI}: 1.1-1.6)$ and father was $\geq 40$ years $(\mathrm{OR}=1.40,95 \% \mathrm{CI}: 1.1-1.8)$ (137). The study also reported that the first-born child of a household is most likely to be affected by autism spectrum disorders; whereas first born child of two older parents are 3 times more likely to develop autism than the children born after the first of mothers aged 20-34 years of age and fathers less than 40 years of age (137).

\section{Nutrient}

Complications that can affect the neurodevelopment of the fetus during pregnancy have been found to increase the risk of ASD (138), however, taking folic acid supplement before and after conception may be a protective factor (139). Micronutrients are essential for neurogenesis and the development of the neuro-network. Children with ASD have been found to have decreased levels of vitamin B complex, and some fat soluble vitamins (A,D,E) (140). 


\section{Socioeconomic Status}

Population indicators of socioeconomic status (SES), such as income, parental education, and occupation, are strongly correlated with the health and development of children (141).

\section{Selective Serotonin Reuptake Inhibitors (SSRI)}

ASDs are often characterized by impaired social interaction, communication deficits, repetitive behaviors, and can be further characterized based on other factors or disorders that simultaneously occurs with it. About $70 \%$ of ASD presents itself with other co-occurring conditions or comorbid factors like psychiatric, developmental, or other medical issues (110). For example, stereotyped and repetitive behavior characteristic of ASD is synonymous to compulsive behaviors present in obsessive compulsive disorders. As a result, SSRI (a class of drugs) used in treatment of obsessive compulsive disorders amongst other developmental disorders like depression and anxiety comorbid with ASD, are prescribed as intervention treatments for children with ASD $(142,143)$. Various conflicting results have been found regarding benefits, effects, dangers, etc. of SSRI being used for ASD. Some studies showed a positive effect of SSRI in aggression and anxiety, while some have found no evidence of a positive effect (143). 


\section{Environmental Factors for Autism and Neurobehavioral Disorders}

In addition to the afore mentioned risk factors, environmental factors may play a role in the development of autism and neurobehavioral disorders. This section discusses major environmental factors.

\section{Particulate Matter}

Traffic related air pollution has an association with neurobehavioral performance in general. Studies have investigated the social impact of exposure to particulate matter among school children. Children exposed to air pollution particles have lower school attendance and academic achievement rates $(105,144)$ which affects their social functioning. A longitudinal cohort study by Margolis et al found that prenatal exposure to air pollutants affects social competence in later stages of the child's life resulting in social problems (145). Results from the study by Margolis et al showed a positive association between presence of air pollutants social problem (P-value $<0.04)$ (145).

Some studies have shown a positive association between air pollution exposure and development of ASD. A component of the Nurse's Health Study conducted in 2011, set out to examine air pollution exposure during pregnancy using distance of residence to major roadways. Comparing 304 cases of ASD and 259 controls, the study reported that mothers of children with ASD were more likely to have lived near a freeway during their third trimester (OR: 2.22, CI: 1.16, 4.42) or at the time of delivery (OR: 1.86, CI: 1.04, 4.42) (146). Exposure to particulate matter $2.5\left(\mathrm{PM}_{2.5}\right)$ during pregnancy was also associated with increased odds of autism spectrum disorders with an OR of 1.57 (95\% CI: 1.22-2.03) among women with the same address before and after pregnancy (103). 


\section{Heavy metals}

Heavy metals are considered neurotoxins, developmental and reproductive toxins, which can cause fetal damage, birth defects, delay in development, behavioral and learning disabilities. These metals influence brain functioning, proper growth of the neural tube, and formation of structures necessary for proper brain development $(147,148)$. Children are considered a vulnerable group of the population because they exhibit behaviors that will increase their risk of exposure. Children can be exposed to heavy metals via fertilizers, chemical products, industrial paint, and living close to power plants which emit toxic waste. Some children might still live in older homes built with lead paint and may eat lead in soil or eat lead chips.

Antisocial behavior has been linked with exposure to metals like manganese and lead which are abundantly present in the earth's crust (149). Exposure to high levels of manganese has also been associated with development of obsessive-compulsive behavioral symptoms among adults (149). A group of pediatricians and neurologists found that children who were referred to them for evaluation of antisocial and violent behaviors were children who had received treatment for lead poisoning in the past $(149,150)$. Studies have showed lead and cadmium exposure to be associated with aggressive behaviors, learning disabilities, and poorer achievement in schools $(75,149,151,152)$. Exposure to arsenic in drinking water has also been associated with cognitive/intellectual function $(149,153)$ of which social cognition is part of, which deals with thoughts, beliefs, and processes on how the world works. People with intellectual deficits, can also experience problems with unrestrained aggression behaviors (154). A cross-sectional study which used the Child Behavioral Checklist to measure various 
behaviors, and the association of these behaviors with metals found that hair levels of cadmium, lead, and zinc accounted for up to $15 \%$ of the variation in social problems, thought problems, attention problems, and aggressive behaviors (155). These results indicate that there is a relationship between exposure to these metals and increased probability of these behaviors among the school age children been studied (155).

Mercury, a neurotoxin has been found to be the third most regularly released toxic substance from waste facilities, which implies increased exposure rates as well. When levels of lead and mercury were assessed among children with ASD in a case-control study, blood lead and mercury levels were found to be correlated with the severity of the social impairment measures using scales that are used to distinguish autism from other behavioral problems (156). Conflicting results have also been reported regarding the association between mercury and autism spectrum disorders- some researchers have reported positive associations $(157,158)$, some negative(159), and some null results $(160,161)$. Windham et al. found three times the amount of mercury in the urine of autistic children compared to non-autistic children $(147,162)$. Autistic children may be less likely to detoxify heavy metals, and this predisposes them to neural damage, which is consistent with autistic behavioral traits like social impairments, thought and compulsive problems $(147,148)$. In addition, mothers with chronic metal exposure and content in their bodies could pass it on to their fetus or during breast feeding (147).

\section{Distance to Pollutant Source}

An even greater factor that increases the likelihood of ASD is proximity to exposure or pollutant sources. It has also been shown that high levels of air pollutants is associated with poor birth outcomes, immunologic changes, and decreased cognitive 
abilities $(146,163,164)$. Volk et al. in their study showed that children with autism were more likely to live at residences that had the highest quartile of exposure to traffic-related air pollution, during gestation (AOR: 1.98; 95\% CI, 1.20-3.31) and during the first year

of life (AOR: 3.10; 95\% CI, 1.76-5.57), compared to control children (146). Additionally, proximity to sources of airborne pollutants, including industrial facilities with mercury exposure (63), and agricultural pesticides during pregnancy (165) have been associated with ASD diagnosis. An association was also found between the risk of autism and an early life residence within 309 miles of a freeway in the Childhood Autism Risks from Genetics and Environment study $(146,166)$.

\section{Pesticides}

Agricultural products like pesticides comprised of organophosphates and organochlorines have been shown to have neurotoxic effects in humans (167). Some of these neurotoxic pesticides are still in use despite its neurotoxicity. Various studies have explored the relationship between pesticide exposure and ASD. A case-control study published in the Childhood Autism and Risks from Gene \& Environment (CHARGE) study, examined the relationship between prenatal proximity to pesticide fields and diagnosis of autism later in life. The study found that children of mothers who lived less than a mile from the pesticide field were 6.1 times more likely to develop autism compared to children of mothers who lived farther away from the pesticide field (OR: 6.1; 95\% C.I: 2.4-15.3) (168). Further studies are needed to provide more insight on the relationship between pesticide and $\mathrm{ASD}$, since the case control is limited by retrospective data. 


\section{Endocrine disrupting chemicals}

Prenatal exposure to endocrine disrupting chemicals like Bisphenol A (BPA) and polychlorinated biphenyls (PCB) can disrupt early brain development. Even though many endocrine disruptors have been banned, some are still being used like BPA which is found in many plastics, canned foods, receipts, etc. Study of the associations between PCB and ASD are inconsistent. In a case-control study by Kardas et al., higher serum BPA concentrations were reported among cases, suggesting that endocrine disruptors could play a critical role in the pathogenesis of ASD $(140,169)$. However, studies conducted by other researchers $(170,171)$, did not find any association with the scale that measures autism features such as social, repetitive, and stereotypic behaviors, and measures of BPA in maternal urine or blood. Disruption of the function of the endocrine system as a result of environmental exposures, can also result in abnormal immune responses during pregnancy which can eventually result in ASD (106).

\section{Possible Biological Mechanism}

Heavy metals with adverse health effects on the immune system can lead to the abnormal secretion and activation of factors that can interfere with communication of cells. Exposure to heavy metals during the critical period of development may interfere with the immune and nervous system leading to the development of autism spectrum disorders and other behavioral issues $(106,108)$. The immune system plays a critical role in the gene-environment complex of autism development. Goines et al showed that mercury can affect functioning of the immune system and also lead to an increase in the intracellular calcium content (172). Children with autism retain mercury in their body due to impairments in detoxification pathways (63). Lead can also affect the functioning of 
the immune system - high levels of lead in the body can inhibit how fast the immune system responds, thereby increasing the likelihood of infection $(106,172)$. Concentrations of lead in the highest quartile had significantly higher ASD prevalence than lead concentrations in the lowest quartile (PR: 1.36: 95\% CI: 1.18-1.57) (109). A case-control study by Price et al, found that mothers of children with ASD were more frequently exposed to lead compared to mothers of children without ASD $(66,106)$. Children who are already susceptible to the ASD gene have a higher sensitivity to effects of environmental toxins, and exposure to these toxins can stimulate ASD or further increase its risk. Exposure to these environmental toxins obstruct chemical signals or transmission of neuronal electrical activity, resulting in nerve damage (106).

\section{Gaps in Knowledge}

There are limited studies on relationship between fly ash and behavioral problems in children and questions remain regarding the etiology and risk factors of ASD. Results will provide important insight into the role of environmental metal exposures and coal ash exposure in the diagnosis of ASD, and improve understanding of the potential pathophysiologic mechanisms responsible for social problems, thought problems, and obsessive-compulsive problems associated with ASD in children. Findings from this study may also inform the development of effective public health prevention approaches that will address primary prevention of exposure to metals among children in Louisville. 


\section{METHODS}

This dissertation was developed from an on-going five-year study (2015-2020) funded by the National Institutes of Health (NIEHS), (Grant Number: R01ES024757) to the Principal Investigator, Kristina Zierold, $\mathrm{PhD}$, who has expertise in community-based environmental research. The collection of data for the parent study began in Fall 2015 and is on-going. While the grant proposed to assess the relationship between fly ash and neurobehavioral performance and symptoms, the specific aims and methodologies utilized in this dissertation are different from those posed in the original grant application. This dissertation specifically assesses three neurobehavioral outcomes: social problems, thought problems, and obsessive-compulsive problems in children. This dissertation is based on analyses of data collected as of November 2017, but more data is being collected in the on-going study.

As a graduate research assistant for the study, I had the opportunity to participate in the following study-related activities since July 2015: participant recruitment, consenting and assenting participants, preparation of samples and equipment for field work, setting up and taking down equipment for air sampling, lift sampling, preparation of samples for laboratory analysis, data management, data quality assurance, data analysis, and involvement in media campaigns by demonstrating equipment during television interviews. Additionally, I was solely responsible for re-contacting participants to derive education status as a socioeconomic status measure to be utilized in this dissertation. 


\section{Recruitment Area}

To achieve the overall aims of the ongoing study, 300 children between ages 6 to 14 who live within a 10 -mile radius from the center of the two power plants in Louisville, Kentucky are being recruited. This dissertation is based on the subsample (Aim $1=158$, Aims 2 and 3=134) recruited as of November 2017 and does not include the final total sample. One of the power plants (Cane Run) now uses natural gas for generation of electricity, but still stores coal ash products on site while the second plant (Mill Creek) still burns coal to produce electricity. A Geographic Information Systems (GIS) sampling strategy was used for recruitment. Five buffer zones of incremental 2-mile radius distance from the center of the power plants were created using (GIS), as described by Allpress et al. (173). To account for the effect of wind direction, distance from the plants, and exposures from both sites, the buffer zones were further stratified into four quadrants to designate 20 sampling units. The use of buffer zones and quadrants ensured that participants were representative of the study area and ensured that a balanced number of participants are recruited from each zone. Since exposures in the home may vary based on season, comparable numbers of children were recruited in each of the seasons (fall, spring, summer, and winter).

\section{Participant Recruitment}

At study initiation, a door-to-door approach for participant recruitment was proposed and started. The study team focused on different sampling units and passed out flyers and brochures with information on how to enroll in the study. The study team was made up of the principal investigator of the grant, three co-investigators, and five graduate research assistants. Flyers and brochures were placed in door handles, door protectors, under door mats, and other visible areas for the potential participants. In good 
weather (no rain) flyers were also placed on car windshields in residential and commercial parking lots e.g., grocery stores. Additionally, study team members spoke with potential participants when they were outside or available during the times when flyers and brochures were distributed. When door-to-door recruitment of participants slowed down, the study team then explored other recruitment options, like mailing and social media.

Mail

In 2017, Dr. Zierold obtained lists of addresses from LeadsPlease.com and InfoUSA. Both these companies sell customized addresses and mailing lists. To optimize efficiency of study participant recruitment, addresses targeted areas with children residing within the zip codes and sampling units of the study. A letter describing the study with the school logo was sent in addition to the flyers used during door to door recruitment. Although previous studies have suggested that in-person recruitment tends to be more effective compared with mailed contact (174), results were similar for both methods in this study. Mailings were usually done 3-4 times a year and total of 800 to 1,000 letters were sent out each mailing.

\section{Social Media and Media}

During the third year of the study, in spring 2017, the University of Louisville's communications department developed a media campaign and a corresponding website (https://louisville.edu/sphis/research/study-recruitment/coal-ash-and-childrens-health). The media campaign resulted in a press release that led to several newspapers, national radio, and local television stations being interested in the study. One large newspaper article was written in the Courier Journal, the main Louisville newspaper that described 
the study in detail. In addition, two Louisville television interviews/taped segments were conducted, where details of the study were provided, including a description of the deliverables of the study, incentives of the study, and a demonstration of study equipment to viewers. The two interviews aired at various times and bolstered recruitment yield. Information on how to contact the principal investigator was also provided in local news websites.

In an attempt to use snowballing recruitment methods, participants that mentioned knowing other interested people were provided with the study web link and additional flyers. The participants were encouraged to pass flyers to those persons as well as other people they knew. Some participants, without the study team's knowledge shared study information and weblinks on personal and group social media (e.g. Facebook) accounts.

\section{Congressmen and Women}

In spring 2017, Dr, Zierold contacted congressmen and congresswomen and asked that they include the flyer or community letter in their email announcements. Many ignored the request, but three representatives included the study information in their email letters. With this method, several participants were recruited. Other recruitment strategies, such as connecting through parent teacher associations and churches, might be explored before the current study ends if yield of recruitment using present strategies decreases.

\section{Inclusion and Exclusion Criteria}

Participants were included in the study if they resided in the current study zone for at least two years, were ages 6 to 14 years old, and willing to complete all aspects of the study (both parent and child component). Children with genetic disorders (Down 
Syndrome, Fragile X Syndrome, Williams Syndrome, etc.) were excluded from the study.

Parents who were unwilling to smoke outside during the one-week sampling period were also excluded, thus their children were also excluded.

\section{Consenting/Assenting of Participants}

Interested participants who received information via any of the recruitment methods, called the principal investigator (PI) to schedule a time for consenting the parents and assenting the child. During the phone call, the PI ensured that inclusion and exclusion criteria are met and briefly explained what is required from the parent and child. If the parent was still interested during the phone call, the PI scheduled a Sunday time for consenting/assenting.

The consent folder included a contact sheet that collected the names, addresses, phone numbers, and child's age which specifically connected the participant's information to their identification number. Two consent forms for the parent to agree to participate, two consent forms for the parent giving the child permission to participate, and two child assent forms were included. Two copies were provided so that the participant and PI could both get signed copies of the consents and assents. Parent and study team member signed the consent forms while the child signed the assent forms. All children enrolled in the study must assent to participate. If the child refused to participate, data collection did not continue.

In addition to the consent/assent forms, three questionnaires (Environmental Health History Questionnaire, Home Cleaning Questionnaire, and the Child Behavioral Checklist), a daily activity diary, a letter asking about stimulant use (a letter with listed ADHD medications), a calendar that would be filled in with reminder dates, and instructions on how to cut toenails were included. The PI or a member of the study team 
obtained the consent providing information on the study purpose, procedures, risk and benefits, compensation and confidentiality. The participant was also informed that the study is voluntary and that they could stop the study at any time. Questions by the participants were addressed and contact information on how to contact the PI, the University's human subjects' protection office, and an outside body for very serious complaints were provided. If the participant was still interested, consent and assent forms were signed.

All documents used for consenting and assenting were approved by the Institutional Review Board (IRB) of the University of Louisville (IRB 14.1069). Overall, the parent was required to complete the questionnaires, allow air sampling in their home, allow the study team to take lift samples in their child's bedroom, help the child with collection of nails, agree to a home visit by the study nurse, and allow the study's coinvestigator, a child psychologist, to administer neurobehavioral testing. The child was required to collect nails, participate in neurobehavioral testing, and allow the study nurse to take their height, weight, blood pressure, and oxygen levels. The study team member or PI scheduled appointments for neurobehavioral testing and the take down of air sampling equipment. After scheduling the appointments, the air sampling equipment were set up in the main area of the house. Neurobehavioral testing was usually conducted during the week of the consent while the sampling equipment was taken down the week after consenting occurred. Once the air sampling equipment was taken down, parents were directly contacted by the study nurse to schedule an available time for taking the child's vitals and to conduct the environmental home assessment and pediatric health history. 


\section{Exposure Assessment}

The exposure assessment used in this study involved various components and is detailed below.

\section{Indoor Air Sampling (Filters)}

Assessment of fly ash and PM10 was carried out using an SKC Inc. Personal Modular Impactor (PMI) for PM10. The PMI is a light weight impactor sampler with an easily removable compact disc enclosing the polycarbonate filter, with an oiled substrate that prevents particles from bouncing and flying around. The PMI was connected to an SKC recommended pump- AirChek XR5000 Sample Pump, using tygon tubing as seen in Figure 1.

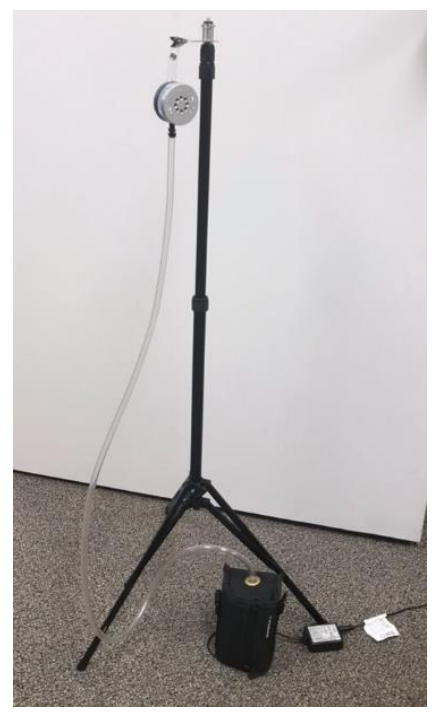

Figure 1. Indoor Sampling Equipment Set Up

Pumps were calibrated using a MesaLabs DryCal Defender 510 to ensure pump readings were within $\pm 5 \%$ of 3 Liters/minute. Flow readings with the defender were taken three times, before the sampler was placed in a home and when the sampler was removed from the home. The flow rate was also checked during the week to ensure that the flowrate is near the $3 \mathrm{~L} / \mathrm{min}$. The average initial and final flow rates were used to 
calculate the concentration of PM10 that was collected on the filter. The PMI was placed on an erectable stand along with the pump (shown in Figure 1) in the main activity room of participant's homes, and were placed within the breathing zone (3-3.5 feet) of the child for a one-week sampling period. Prior to the sampling week, filters were weighed three times before being placed in the impactors, and the average was used as the initial mass. After the one-week sampling period, the filters were weighed three times for determination of the final mass. The final filter mass was based on subtraction of the average final mass from the average initial mass. Using the average differences in flow rates and the final sample mass, concentration of PM10 was determined. Filters were placed in a filter holder and stored in a desiccator until they were ready to be taken to Elemental Analysis, Inc, in Lexington, Kentucky, the laboratory that specializes in a variety of testing techniques. Proton Induced X-ray Emission (PIXE) was then used to assess the distribution of the elements in the PM10 collected on the filters. Additionally, Scanning Electron Microscopy and Energy-Dispersive X-ray Spectrometry (SEM/EDX) was used to determine the presence or absence of fly ash and the elements in the fly ash.

\section{Analysis of Filters}

PIXE provides a non-destructive analysis that can be used to determine the concentration of 72 inorganic elements on the periodic table, from Sodium to Uranium (175). In PIXE, X-ray spectrums are created as a result of bombardment of energetic protons in the inner shell electrons of the target atoms. Collisions cause kinetic energy to be transferred to the inner shell electrons of the target atom, and X-ray production depends on both the total number of incident protons and the proton energy. The inner shells are then left empty so that it can be filled using energies from emitted X-rays. The 
energy of the X-ray that is released is comparable to and distinctively characteristic to the element they originate from, while the number of $\mathrm{X}$-rays emitted is proportional to the mass of the element being analyzed (175). In this study, PIXE was used to analyze elemental concentrations of the PM10 on the filters and for the nail samples.

Once the PIXE analysis was completed, the filters were analyzed for fly ash presence by Elemental Analysis Inc.in Lexington, Kentucky. A sliver of the filter was removed for analysis by Scanning Electron Microscopy (SEM), which is used to determine presence or absence of fly ash while Energy-Dispersive X-ray Spectrometry (EDX) is used to determine the elements found in the examined fly ash. Since fly ash is spherical, it is easy to assess compared to other particles that are generally irregularly shaped. SEM is a nondestructive visual method of analysis that uses high energy resolution and focused electron beam to produce high resolution images of surface topography. The scanning beams or primary electrons generate energy, which allows for the detection of secondary electrons. The strength of these secondary electrons is mainly governed by the surface topography of the sample. The sample surface can thus be constructed by measuring the strength of the secondary electrons as a function of the position of the scanning primary electron beam (176). EDX identifies the content of the particles in fly ash as a result of $\mathrm{x}$ rays produced when hit with the electron beam. EDX helps with determining the characteristics of the surface sample from SEM and provides a quantitative elemental information. SEM-EDX is a primary method for surface analysis because it allows for detailed visualization of the particle and its composition, and generates resolutions of high magnitude superior to other microscopes. The process of filter analysis is shown below in Figure 2. 


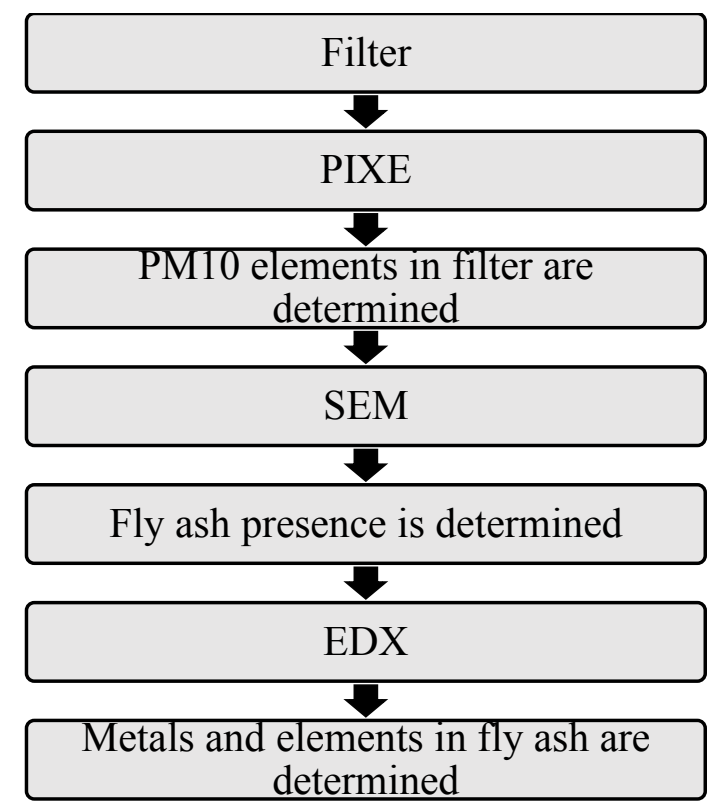

Figure 2. Process of Filter Analysis

\section{Toenail and Finger Nail Samples (Metal Body Burden)}

Concentration of metals in the body was assessed via finger and toe nail samples. Human nails are made up of keratin proteins that represent dietary intakes and multiple exposures of individuals. Nails can vary by age, individual behaviors, gender, and diet. The growth rate also varies based on age, gender, metabolic rate, and health conditions (177). Finger nails takes about 6 months to grow out, hence grow faster compared to toenails which takes about 12 months to grow out. Therefore, nail clippings represent a long term exposure time frame (178-180). In this study, finger nails and toenails were combined since children in the study are chronically exposed. Nails are suitable for use because it is a non-invasive method of assessing exposure, they are easy to collect, store and analyze, and are less likely to be contaminated. A limitation to using nails is the possibility of contamination via nail polish, dirt, and nail clippers, however, contamination can be controlled by using effective cleaning methods. 
After consenting and assenting, participants were provided with two containers to collect nails. Parents were provided with instructions on how to cut nails and nail clippers. Parents were also shown a sample of a $150 \mathrm{mg}$ nail in a container, to have an idea of the quantity of nails that was required. During the consenting/assenting process, a first sample of nails was collected from the child. Additional clippings were collected by picking them up in mailboxes, every couple of weeks. When parents thought that they had collected a sufficient quantity of nails, they informed the PI who scheduled a time for pick up (usually on Sunday) and asked parents to leave the collected nails in the mailbox. Sunday was the selected day of nail pick up because mail was not delivered on Sundays in the study area, hence, the nail containers did not interfere with the mailman's job. The PI or the study team picked up the nails from the mailboxes and left an additional container for further collection. This method ensured that no one had to be home for more nail collection and was less intrusive to the participants. The mailbox nail collection was carried out intermittently until the desired quantity was derived.

A total nail mass of $150 \mathrm{mg}$ was required which was collected over several weeks or months depending on the growth rate of the child's nails and response to the PI phone calls. In general, it took 3-6 clippings of nails to get the mass needed. Nails were weighed to ensure each participant had at least a total mass of $150 \mathrm{mg}$. Once the desired nail quantity had been reached, nails were washed with acetone and two rinses of deionized water. The nails were left to dry and placed in a new container. The dry nails were then weighed again and then taken to the lab (Elemental Analysis, Inc) for PIXE analysis. At the lab, nails were frozen and ground up into fine particles, and bound with a binding 
agent into a pellet. PIXE (described in previous section) was then used to analyze the elemental concentrations in the pellets.

\section{Lift Tape}

To determine the presence or absence of fly ash, lift tape sampling was also utilized. Lift sampling is a technique used to collect and remove settled dust particles from surfaces like headboards, desks, shelves, etc. Stick-to-It Lift Tape (SKC Inc.) was used in the study. The tape is a bendable microscopic slide with an adhesive area that can be used for sampling inorganic dust contamination on surfaces. Lift sampling was carried out in the child's bedroom. The adhesive part of the plastic was placed on window sills, headboards, dressers, children's desks or favorite toys. The dust particles collected by lift tapes were first examined using Optical Microscopy (OM), a technique that uses visible light and lenses to magnify images of small samples, thereby producing a detailed morphology and detail of the particle. Particles that appear smooth and spherical were believed to be fly ash and were sent to the PI for further confirmation. SEM/EDX was then used to further analyze the particles deemed to be fly ash. The process of lift sampling is shown in Figure 3 below. 


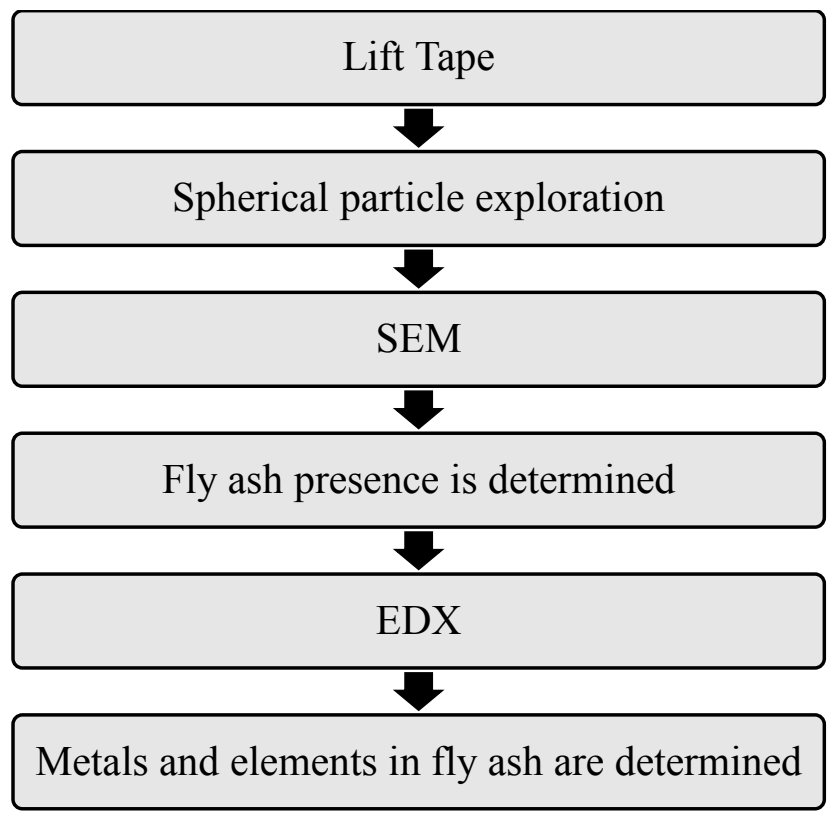

Figure 3. Process of Lift Tape Analysis

\section{Assessment of ASD measures (Outcome Assessment) \\ Child Behavioral Checklist}

The Child Behavioral Checklist (CBCL) is a commonly used standardized questionnaire completed by a caregiver for the assessment of behavioral, emotional, and social problems in children (122). The CBCL is available in various forms and for various age-groups. In this study, the parent reported form for children ages 4 to 18 was administered, which covered the ages 6 to 14 range of participants in this study. The various items and scales on the CBCL describe specific behaviors that parents respond to, based on behavioral individualities of the child. The parent rates the regularity of each behavior based on a three-point Likert Scale: $0=$ Not true, $1=$ Somewhat or sometimes true, $2=$ Very true or often true. The CBCL has scales to reflect scores associated with the DSM-IV which includes capturing social problems, thought problems, and compulsive problems (122). 
The first part of the CBCL requires parents to provide information on their child's social competency. These questions cover information on the child's hobbies and activities that the child is involved in, number of close friends, and school performance. The next set of questions on the CBCL are associated with problems on eight syndrome scales which include: anxious/depressed, withdrawn/depressed, somatic complaints, social problems, attention problems, rule-breaking behavior, and aggressive behavior. Measures are also provided on three summary scales, which includes internalizing problems, externalizing problems, and total problems. Six DSM-Oriented scales are also assessed on the CBCL (affective problems, anxiety problems, somatic problems, attention deficit/ hyperactivity problems, oppositional defiant problems, and conduct problems). The last group of scales measured on the CBCL includes sluggish cognitive tempo, obsessive-compulsive problems, and post-traumatic stress problems.

The measures of interest for this dissertation were social problem, thought problems, and obsessive-compulsive problems. As shown in Table 1 below, questions that address behaviors on social problems include questions on dependency, loneliness, getting along with people, jealousy, clumsiness, and speech problems. For thought problems the CBCL includes questions on whether the child has thoughts to harm self, is hearing things, is twitching, picking on skin, seeing things, stores up things, sleep walks, and has sleep problems. The obsessive-compulsive scale entails questions on stubbornness and temper of child. 
Table 1. Definitions of Outcome Measures from the Child Behavioral Checklist (CBCL)

\begin{tabular}{c|l} 
Outcomes & Questions and Definitions \\
\hline Social Problems & Clings to adults or too dependent \\
& Complains of loneliness \\
& Does not get along with other kids \\
& Easily jealous \\
& Feels other are out to get him/her \\
& Gets hurt a lot, accident prone \\
& Gets teased a lot \\
& Not liked by other kids \\
& Poorly coordinated or clumsy \\
& Prefers being with younger kids \\
& Speech problem \\
\hline Thought Problems & Cannot get his/her mind off certain thoughts/obsessions \\
& Deliberately harms self or attempts suicide \\
& Nervous movements or twitching \\
& Picks nose, skin, or other body parts \\
& Plays with own sex parts in public \\
& Plays with own sex parts too much \\
& Repeats certain acts over and over/compulsions \\
& Sees things that are not there \\
& Sleeps less than most kids \\
& Stores up too many things that he/she does not need \\
& Strange behavior \\
& Strange ideas \\
& Talks or walks in sleep \\
\hline \multirow{2}{*}{ Obsessive- } & Cannot get his/her mind off certain thoughts/obsessions \\
& Fears he/she might think or do something bad \\
& Feels he/she has to be perfect \\
& Feels too guilty \\
Repeats certain acts over and over/compulsions & Strange behavior \\
Strange ideas
\end{tabular}

The CBCL produces raw scores that can only be used to compare number of problems on individual scales experienced by a child. However, the number of items in every scale varies making it difficult to compare raw scores across different scales. Therefore, raw scores are converted to T-scores, which utilize a metric that is similar on all the scales making it possible to compare the relative number of problems experienced 
by each individual. T-scores on the CBCL are adjusted for age and gender and produce categorizations of normal, borderline, or clinical borderline range, which means that Tscores are separated to reflect whether a child has the problem being assessed. A t-score of 60 is indicative of a problem as measured by the appropriate scale (social problems, thought problems, obsessive-compulsive problems).

Parents of children who score in the clinical or borderline significant range for the scales of the CBCL were contacted by the study's child psychologist, for a structured interview. The structured interviews were conducted using guidelines of the Structured Clinical Interview for Diagnosis of DSM Disorders (SCID). During the interview, the child psychologist gained more insight into the behavioral problems of the child and made recommendations for treatment, based on diagnosis. The CBCL is generally used and has established psychometric features. Reports have shown the mean test-retest reliabilities for the CBCL to range from 0.95 to 1.00 , and internal consistency has ranged from 0.78 to $0.97(181)$.

\section{Assessment of Covariates (via Questionnaires)}

Covariates used in this dissertation were derived from various questionnaires used in the study. The questionnaires included are the Environmental Health History Questionnaire, Pediatric Health History Form, and Environmental Home Exposure Assessment. All questionnaires used in the study are described below.

\section{Environmental Health History Questionnaire}

The Environmental Health History Questionnaire (EHQ) is an in-depth questionnaire that assesses pollutants that children or parents have been exposed to in the past. The questionnaire was developed by the PI of the parent study as there was an 
unavailability of an existing questionnaire that addressed the problems pertinent to the study in a comprehensive way. The PI developed the questionnaires using resources such as the pediatric environmental history form, guidelines on how to derive environmental history from the American Academy of Pediatrics and the Agency for Toxic Substances and Disease Registry, and an article titled 'The rapid questionnaire of environmental exposures to pregnant women".

The environmental health history questionnaire consists of multiple choice options, yes/no/not sure, and open-ended/fill in the gap questions. EHQ consists of questions addressing current and previous addresses of the child, child behaviors, cleaning method and supplies used in cleaning, use of pesticides, insecticides, herbicides, where and how food and water are derived and the cooking environment, hobbies done at home by both parents and children, occupation of the parent, proximity to hazardous sites, questions about exposures that might have occurred during pregnancy, and questions about other places the child spends time. The EHQ was given at the time of consenting/assenting and was left with the parents to fill out. It was collected on the day when neurobehavioral testing occurred or when the samplers were taken down.

\section{The Pediatric Health History Form and Environmental Home Assessment}

The home visit by the study nurse was conducted after all samples, questionnaires, and neurobehavioral testing had been completed. The nurse administered the child health history form and conducted an environmental home assessment to assess for more confounders. The environmental home assessment used the pediatric environmental home assessment (PEHA) tool which is publicly available and meant to aid with identifying potential environmental hazards in the home. It includes questions on 
the general characteristics of the home, indoor pollutants the child might be exposed to such as presence of molds, lead based paint, smoke, etc., home environment, sleep environment, and home safety (182).

The Pediatric Health History form focuses on the child's health history and some parent information. The Pediatric Health History was developed by the PI and nurse coinvestigator, using examples of pediatric health histories. It includes questions on immunization records, height, weight, blood pressure and oxygen levels, past and present health conditions of the child, marital status of the parent, and question about the mother when pregnant. The nurse went through the questionnaires with the parent during her visit, which lasted about 40 to 60 minutes.

The covariates of interest for this dissertation included gender, age, ethnicity, child school performance, mother's depression, mother's use of cigarette during pregnancy, smoking in the home, age mother had the child, education level of parent, and marital status.

\section{Variable Definition and Statistical Analysis}

This section discusses how the variables used in this dissertation were defined and the analysis used to address the specific aims. SAS v.9.4 was employed for all analyses.

\section{Demographic Information}

Demographic information of importance for this dissertation included age, race/ethnicity, gender, and education status. Other covariates of interest included: smoking status, whether child was born preterm, maternal age at birth of child, marital status of parent, child school performance, mother's depression status, and whether or not the mother was smoking during pregnancy. Among the potential confounders, age of 
child was analyzed as a continuous variable of which medians and inter-quartile ranges were reported for cross-tabulations. Race/ethnicity was classified as Non-Hispanic White versus other races, while gender was classified as Male versus Female. Education status, which was derived by calling participants in the study was dichotomized as college degree or higher versus less than a college degree. A dichotomized response was derived for smoking status, which represented smoking status of either or both parents in the home. Preterm birth status was categorized as child being born at $<=36$ weeks versus $>36$ weeks. Maternal age at birth of child was derived by subtracting child's age from mother's current age which was further dichotomized to $<=35$ years of age versus $>35$ years of age. Child school performance was dichotomized as high performance in school versus low performance in school. Maternal depression status was analyzed as a yes/no, derived in response to "what medical problems do people in the child's family have", which addressed mother's medical problem of which depression was listed. Marital status was dichotomized as married versus not married. Finally, maternal smoke status during pregnancy was dichotomized, based on the response provided by mothers asking if they used cigarettes/cigars/pipe, during pregnancy.

Crosstabulation of outcomes, predictors, and covariates were examined for potential associations. The Chi-square test was used for all dichotomized variables, while the Wilcoxon rank test was used for non-normally distributed continuous variables.

\section{Outcome Categorization}

Social, thought, and obsessive-compulsive scales from the CBCL were used as dichotomized variables. The dichotomized variables were categorized as 1 for scores $\leq 59$ indicating "normal" and group 2 for scores $>59$ indicating problem scores within the clinical or borderline clinical range. Outcome categorization was based on quantitative 
scales that reflect meaningful qualitative differences of normal versus borderline/clinical. The outcome was the same for specific aims 1 and 2 and thus, the same categorizations were used.

\section{Exposure Categorizations}

Specific aim 1: The main exposure for specific aim 1 was fly ash, which is a dichotomized variable. Fly ash (yes/no) was determined by presence of fly ash on either the lift tape or the filter. Analysis addressed filter fly ash, lift tape fly ash, and combined filter and lift tape fly ash.

Specific aim 2: The main exposure for specific aim 2 was the metals found in toenails and fingernails, which included Aluminum, Copper, Zinc, Manganese, Iron, Nickel, Titanium, Silicon, and Chromium. All metals were categorized into quartiles for analysis of individual and total metal exposure.

Specific aim 3: Metals (Aluminum, Copper, Zinc, Manganese, Iron, Nickel, Titanium, Silicon, and Chromium) found in nails and filters were examined as continuous variables.

\section{Identification of Confounders}

Purposeful selection of variables was first employed for model building. This was carried out using a SAS macro as described in Bursac et al (183). The macro provided an algorithm and a systematic approach that guided the selection of confounders. The first stage in utilized model selection involved a univariate logistic regression used to assess the relationship between the outcomes (social, thought, obsessive-compulsive), exposures, and covariates. The univariate associations with a significant association $(\mathrm{P} \leq 0.25)$ were used in multivariate logistic regression models. In the multivariate models, variables that were not significant at $\mathrm{P}>0.10$ were removed. If adding or removing a 
covariate resulted in a change in the beta coefficient for exposure by more than $10 \%$, then the covariate was considered as a potential confounder, and was retained in the model for assessment. Tables derived using the purposeful selection strategy are found in the appendix (Tables 56-79). After employing a systematic approach to selection of variables, a decision was made to include all covariates in the models based on theory, previous research, and biological plausibility.

\section{Analyses by Specific Aims}

Aim 1: Specific Aim 1: To determine if children aged 6-14 exposed to fly ash residing within a 10-mile radius of two coal ash storage facilities in Louisville, KY had greater social, thought, and obsessive-compulsive problems as measured using the Child

\section{Behavior Checklist.}

\section{Analysis Description for Aim 1}

Logistic regression was used to assess whether fly ash was associated with social problems, thought problems, and obsessive-compulsive problems in univariate models. The relationship between fly ash and social, thought, and obsessive-compulsive problems were explored using three multivariable logistic regression models for each outcome. All the covariates in this study were grouped into child level and mother level covariates. Child level covariates were covariates specific to the child while mother level covariates were specific to the mother (e.g. mother's age at birth of child, maternal smoking, etc.). The first model adjusted for child level covariates such as gender, age, ethnicity, and smoke exposure in the home, while the second model controlled for mother level covariates such as mother's age at birth of child, depression status, marital status, and 
mother's use of cigarette during pregnancy. The third model adjusted for both the child and mother level covariates; hence, it included all the covariates in models 1 and 2.

Aim 2: Specific Aim 2: To assess if children with higher metal concentrations in their body had higher scores of social, thought, and obsessive-compulsive problems based on the Child Behavioral Checklist.

\section{Analysis Description for Aim 2}

A nonparametric statistic using rank sum quartiles was used to assess the relationship between each metal and social, thought, and obsessive-compulsive problems (184). To derive the ranks and quartiles, each metal was sorted according to their measured concentrations from lowest to highest. To ensure that the metals are measured on a common scale that can be aggregated to assess cumulative effects of exposures, the metal concentrations were ranked from the lowest to the highest and integer numbers were assigned as part of the rank statistical procedure, and categorized into quartiles. The use of quartiles enables the visualization of trends that might exist within each metal especially since the metal concentrations are skewed. Participants with concentrations in the lowest quartile were considered as the referent group.

Univariate logistic regression was used to assess whether each metal (Aluminum, Iron, Copper, Zinc, Manganese, Titanium, Nickel, Silicon, and Chromium) quartile was associated with the outcomes. Unadjusted odds ratios, confidence intervals, and tests for trend were calculated. The quartiles of the metal concentrations and covariates were used to build the final logistic regression model for this aim.

The logistic regression model was then $\operatorname{logit}(\mathrm{p})=\log (\mathrm{p} /(1-\mathrm{p}))=\beta_{0}+\beta_{1} * \mathrm{Q}_{2}+$

$\beta_{2}{ }^{*} \mathrm{Q}_{3}+\beta_{3}{ }^{*} \mathrm{Q}_{4}+\sum_{i=1}^{p} \beta_{i} X_{i}$, where $\mathrm{p}$ indicated the probability of social problems, thought 
problems, or obsessive-compulsive problems. The variables $\mathrm{Q}_{2}, \mathrm{Q}_{3}$, and $\mathrm{Q}_{4}$ were indicator variables for a subject being in the $2^{\text {nd }}, 3^{\text {rd }}$, and $4^{\text {th }}$ quartiles of the metal concentration, respectively. The $\beta_{i} X_{i}$ terms encompass the effect of additional covariates, where $p$ is the total number of additional covariates included in the model. In addition to including the metal concentration quartiles as indicator variables, a linear trend model was fitted by scoring each quartile at the median metal concentration for the quartile.

In addition to a model for each metal, an overall metal exposure rank was obtained by aggregating the ranks across all the metals. This total metal exposure rank summation was then categorized into tertiles and evaluated for an association with the outcomes in univariate models. A dichotomized social, thought, and obsessivecompulsive problems variable were used with the derived quartiles for unadjusted logistic regression model.

Aim 3: To determine whether child's nail metal concentrations were correlated with concentrations of metals found on the in-home filters.

\section{Analyses Description for Aim 3}

The metals that were assessed in the filters are the same as those found in nails (aluminum, iron, copper, zinc, manganese, titanium, nickel, silicon, and chromium). Cross tabulations between body metal and filter concentrations were carried out, and Pearson and Spearman correlation coefficients were determined. Correlation plots were created for all metals to visually display the correlation between body metal burden and filter metal content. Outliers were removed accordingly and minimized by logtransforming the metal concentrations. 


\section{Power and Sample Size}

The available sample size for this dissertation analysis ranges from 134 to 158 , based on the number of participants with complete data. Studies that explored the relationship between Autism Spectrum Disorders (ASD) and air pollution/heavy metals, have found effect sizes ranging from 1.9 to $3.1(109,146,166)$. The estimated prevalence of ASD among 8 year old children in the U.S is 14.7/1000 (185). Based on the sample size of 158 participants for Aim 1, and 134 participants for Aim 2, Table 2 shows the power to detect an odds ratio ranging from 1.9 to 3.1 with type 1 error set at 0.05 . Power was calculated using SAS v 9.4.

Table 2. Sample Size, Odds Ratio and Corresponding Power Levels

\begin{tabular}{l|l|l}
\hline Sample Size & Odds Ratio & Power \\
\hline 158 & 1.9 & 0.36 \\
\hline 158 & 2.2 & 0.51 \\
\hline 158 & 3.1 & 0.85 \\
\hline 134 & 1.9 & 0.31 \\
\hline 134 & 2.2 & 0.45 \\
\hline 134 & 3.1 & 0.78 \\
\hline
\end{tabular}

In this dissertation, there was lack of sufficient power to detect meaningful differences in analysis that produced an odds ratio of $<3.1$. Addition of more participants would assure an adequate power to detect statistical and meaningful differences with pertinent results. 


\section{RESULTS}

At the time this dissertation was written, 183 participants had been recruited into the study. However, not all data sources were complete at the time the analyses were conducted. For example, fly ash results and toenail/fingernails results were not available for some participants because they were not yet assayed, or results returned from the laboratory. Thus, given the available data, Aim 1 is based on a sample size of 158 participants and Aims 2 and 3 a sample size of 134 participants.

\section{Aim 1 Results}

\section{Demographics using Aim 1 Sample Size}

Tables 3 and 4 show the number and percentage of the outcome and exposure variables. Table 3 displays the distributions of the outcome variables which include social, thought, and obsessive-compulsive problems. There were 33 (22\%), 43 (27\%), and $44(28 \%)$ children with social, thought, and obsessive-compulsive problems respectively. Table 4 displays the distribution of the exposure variable, fly ash, which is derived from filter and lift tape samples. Fly ash was found in $63(40 \%)$ of the filters and $97(61 \%)$ of the lift tapes. In addition, total fly ash, defined as whether fly ash was found on the filter or on the lift tape, was found in homes of 117 participants, representing about $74 \%$ of fly ash exposure. 
Table 3. Distribution and Percentages of Outcome Variables

\begin{tabular}{lcc}
\cline { 2 - 3 } Outcome & $\begin{array}{c}\text { Frequency } \\
(\text { Total N = 158) }\end{array}$ & Percent \\
\hline Social Problems & 33 & \\
$\quad$ Yes & 125 & 21.89 \\
$\quad$ No & 43 & 79.11 \\
\hline Thought Problems & 115 & 27.22 \\
$\quad$ Yes & & 72.78 \\
$\quad$ No & & \\
\hline Obsessive-Compulsive & 44 & 27.85 \\
Problems & 114 & 72.85 \\
$\quad$ Yes & & \\
$\quad$ No & & \\
\hline
\end{tabular}

Table 4. Distribution and Percentages of Fly Ash Found in Home

\begin{tabular}{lcc}
\cline { 2 - 3 } Exposure & $\begin{array}{c}\text { Frequency } \\
\text { (Total N = 158) }\end{array}$ & Percent \\
\hline Total Fly Ash & 117 & 74.05 \\
$\quad$ Yes & 41 & 25.95 \\
$\quad$ No & 97 & 61.39 \\
\hline Fly ash in Lift Tape & 61 & 38.61 \\
$\quad$ Yes & & \\
No & 63 & 39.87 \\
\hline Fly ash in Filter & 95 & 60.13 \\
Yes & & \\
No & &
\end{tabular}

Table 5 presents the sample characteristics of demographic variables ('Total N" column). Of the 158 children in the study, $55 \%$ were males. The median age was 11 (IQR: 5). The racial/ethnic composition was $83 \%$ Non-Hispanic White and $17 \%$ other racial groups encompassing Blacks, Hispanics, Asians, and Mixed-race children. A larger portion of the children $(85 \%)$ had high performance in school compared to children with low school performance. Approximately $26 \%$ of the children in the study were born preterm ( $<=36$ weeks gestation) while $24 \%$ of participants were exposed to smoking in the home. A majority of parent participants had less than college degree (55\%), were 
younger than 35 years of age (77\%), married (70\%), and reported no diagnosis of maternal depression (70\%).

Table 5 also displays cross tabulation results between social problems and the variables of interest in the study. Most of the demographic variables did not have a significant association with social problems, however, child's age, mom smoking during pregnancy, and child's school performance had significant associations with social problems. Children with social problems had a higher median age (12 years) compared to children without social problems $(10$ years, $\mathrm{P}<0.001)$. Children without social problems also had a higher percentage of high performance in school (90\%) compared to children with social problems $(66 \%, \mathrm{P}=0.0004)$. The percentage of children who have social problems and low school performance was about 34\%. Maternal smoking during pregnancy was present in $31 \%$ of the children with social problems compared to only $11 \%$ of children without social problems $(\mathrm{P}=0.007)$. Ethnicity approached a statistically significant level with Non-Hispanic White children being more likely to have social problems compared to children from other races (other races includes African American, Hispanic, and Biracial children $)(\mathrm{P}=0.080)$. 
Table 5. Sample Characteristics by Social Problems for Aim $1(\mathrm{~N}=158)$

\begin{tabular}{|c|c|c|c|c|}
\hline \multirow[b]{3}{*}{ Variable } & \multicolumn{4}{|c|}{ Social Problems } \\
\hline & \multirow[b]{2}{*}{$\begin{array}{l}\text { Total } \\
\mathbf{N}(\%)\end{array}$} & $\begin{array}{c}\text { No } \\
(\mathbf{n}=125)\end{array}$ & $\begin{array}{c}\text { Yes } \\
(\mathbf{n}=\mathbf{3 3})\end{array}$ & \multirow[b]{2}{*}{ P-value } \\
\hline & & $\mathbf{N}(\%)$ & $\mathbf{N}(\%)$ & \\
\hline Gender of Child & & & & 0.946 \\
\hline Female & $71(44.9)$ & $56(44.80)$ & $15(45.45)$ & \\
\hline Male & $87(55.1)$ & $69(55.20)$ & $18(54.55)$ & \\
\hline Age of Child ${ }^{a}$ & & & & $<0.001$ \\
\hline 6 to 14 years old & $11(5)$ & $10(5)$ & $12(4)$ & \\
\hline Ethnicity of Child & & & & 0.080 \\
\hline Other & $26(17.0)$ & $24(19.67)$ & $2(6.45)$ & \\
\hline White & $127(83.0)$ & $98(80.33)$ & $29(93.55)$ & \\
\hline School Performance & & & & 0.0004 \\
\hline High & $134(85.4)$ & $113(90.40)$ & $21(65.63)$ & \\
\hline Low & $23(14.7)$ & $12(9.60)$ & $11(34.38)$ & \\
\hline Resident Smokes & & & & 0.622 \\
\hline No & $117(76.0)$ & $93(76.86)$ & $24(72.73)$ & \\
\hline Yes & $37(24.0)$ & $28(23.14)$ & $9(27.27)$ & \\
\hline Child Born Preterm & & & & \\
\hline No & $113(74.3)$ & $90(74.38)$ & $23(74.19)$ & 0.983 \\
\hline Yes & $39(25.7)$ & $31(25.62)$ & $8(25.81)$ & \\
\hline Parent Education & & & & \\
\hline$<$ College degree & $62(54.9)$ & $49(55.06)$ & $13(54.17)$ & 0.938 \\
\hline$>=$ College degree & $51(45.1)$ & $40(44.94)$ & $11(45.83)$ & \\
\hline Mom Smoked During & & & & \\
\hline Pregnancy & & & & 0.007 \\
\hline No & $124(84.9)$ & $104(88.89)$ & $20(68.97)$ & \\
\hline Yes & $22(15.07)$ & $13(11.11)$ & $9(31.03)$ & \\
\hline Age Mother Had Child & & & & 0.927 \\
\hline$<35$ years old & $114(76.5)$ & $92(76.67)$ & $22(75.86)$ & \\
\hline$>=35$ years old & $35(23.5)$ & $28(23.33)$ & $7(24.14)$ & \\
\hline Parent Marital Status & & & & 0.143 \\
\hline Not married & $46(30.1)$ & $33(27.27)$ & $13(40.63)$ & \\
\hline Married & $107(69.9)$ & $88(72.73)$ & $19(59.38)$ & \\
\hline Mom Depression & & & & 0.224 \\
\hline No & $106(70.2)$ & $87(72.50)$ & $19(61.29)$ & \\
\hline Yes & $45(29.8)$ & $33(27.50)$ & $12(38.71)$ & \\
\hline
\end{tabular}

${ }^{a}$ Age is reported as median (Interquartile range, IQR).

* P-values were derived using chi-square tests and the Wilcoxon test (age)

*Numbers may not add up to the total sample size of 158 as a result of missing data. 
Table 6 describes the sample characteristics of demographic variables and covariates stratified by thought problems. Overall, 43 (27\%) children had thought problems. There is a statistically significant association between age and thought problems $(\mathrm{P}<0.001)$. Older children were more likely to have thought problems than younger children. The median age for children with thought problems is 12 years which is higher than the median age for children without thought problems (age 10 years, $\mathrm{P}<0.001)$. There was a statistically significant association between child school performance and thought problems $(\mathrm{P}=0.003)$. High performance in school was seen in $90 \%$ of children without thought problems compared to $71 \%$ of children with thought problems. The percentage of children who have thought problems and low school performance was approximately $29 \%$. Mothers that smoked during pregnancy accounted for $26 \%$ of the children with thought problems ( $\mathrm{P}=0.024)$. A borderline statistically significant relationship was derived between thought problems and mothers who reported depression as a health problem $(\mathrm{P}=0.055)$. 
Table 6. Sample Characteristics by Thought Problems for Aim 1 (N=158)

\begin{tabular}{|c|c|c|c|c|}
\hline \multirow[b]{3}{*}{ Variable } & \multicolumn{4}{|c|}{ Thought Problems } \\
\hline & \multirow[b]{2}{*}{$\begin{array}{l}\text { Total } \\
\mathbf{N}(\%)\end{array}$} & $\begin{array}{c}\text { No } \\
(\mathrm{n}=115)\end{array}$ & $\begin{array}{c}\text { Yes } \\
(n=43)\end{array}$ & \multirow[b]{2}{*}{ P-value } \\
\hline & & & $\mathbf{N}(\%)$ & \\
\hline Gender of Child & & & & 0.186 \\
\hline Female & $71(44.9)$ & $48(41.74)$ & $23(53.49)$ & \\
\hline Male & $87(55.1)$ & $67(58.26)$ & $20(46.51)$ & \\
\hline Age of Child ${ }^{a}$ & & & & $<0.001$ \\
\hline 6 to 14 years old & $11(5)$ & $11(5)$ & $12(4)$ & \\
\hline Ethnicity of Child & & & & 0.339 \\
\hline Other & $26(17.0)$ & $21(18.75)$ & $65(12.20)$ & \\
\hline White & $127(83.0)$ & $91(81.25)$ & $36(87.80)$ & \\
\hline School Performance & & & & 0.003 \\
\hline High & $134(85.4)$ & $104(90.4)$ & $30(71.43)$ & \\
\hline Low & $23(14.7)$ & $11(9.6)$ & $12(28.57)$ & \\
\hline Resident Smokes & & & & 0.359 \\
\hline No & $117(76.0)$ & $88(77.88)$ & $29(70.73)$ & \\
\hline Yes & $37(24.0)$ & $25(22.12)$ & $12(29.27)$ & \\
\hline Child Born Preterm & & & & 0.299 \\
\hline No & $113(74.3)$ & $85(76.58)$ & $28(68.29)$ & \\
\hline Yes & $39(25.7)$ & $26(23.42)$ & $13(31.71)$ & \\
\hline Parent Education & & & & 0.938 \\
\hline$<$ College degree & $62(54.9)$ & $49(55.06)$ & $13(54.17)$ & \\
\hline$>=$ College degree & $51(45.1)$ & $40(44.94)$ & $11(45.83)$ & \\
\hline Mom Smoked During & & & & 0.024 \\
\hline Pregnancy & & & & \\
\hline No & $124(84.9)$ & $96(88.89)$ & $28(73.68)$ & \\
\hline Yes & $22(15.1)$ & $12(11.11)$ & $10(26.32)$ & \\
\hline Age Mother Had Child & & & & 0.681 \\
\hline$<35$ years old & $114(76.5)$ & $84(75.68)$ & $30(78.95)$ & \\
\hline$>=35$ years old & $35(23.5)$ & $27(24.32)$ & $8(21.05)$ & \\
\hline Parent Marital Status & & & & 0.349 \\
\hline Not married & $46(30.1)$ & $31(27.90)$ & $15(35.71)$ & \\
\hline Married & $107(69.9)$ & $80(72.07)$ & 27 (64.29) & \\
\hline Mom Depression & & & & 0.055 \\
\hline No & $106(70.2)$ & $82(74.55)$ & $24(58.54)$ & \\
\hline Yes & $45(29.8)$ & $28(25.45)$ & $17(41.46)$ & \\
\hline
\end{tabular}

${ }^{a} \mathrm{Age}$ is reported as median (Interquartile range, IQR).

* P-values were derived using chi-square tests and the Wilcoxon test (age)

*Numbers may not add up to the total sample size of 158 as a result of missing data. 
Table 7 describes the sample characteristics of demographic variables and covariates stratified by obsessive-compulsive problems. Overall, 44 children $(28 \%)$ had obsessive-compulsive problems. Children with obsessive-compulsive problems had a higher median age (12 years) compared to children without obsessive-compulsive problems (11 years, $\mathrm{P}<0.001$ ). Non-Hispanic White children were more likely to have obsessive-compulsive problems compared to children from other races ( $95 \%$ versus $5 \%$, $\mathrm{P}=0.016)$. There is a statistically significant association between child school performance and obsessive-compulsive problems $(\mathrm{P}=0.003)$. High performance in school was seen in $90 \%$ of children without obsessive-compulsive problems compared to $72 \%$ of children with obsessive-compulsive problems. The percentage of children who have obsessive-compulsive problems and low school performance was approximately $28 \%$. Mothers that smoked during pregnancy accounted for $25 \%$ of the children with obsessive-compulsive problems ( $\mathrm{P}=0.039)$. A borderline statistically significant relationship was derived between obsessive-compulsive problems and mothers who reported depression as a health problem $(\mathrm{P}=0.056)$. 
Table 7. Sample Characteristics by Obsessive-compulsive Problems ( $\mathrm{N}=158)$

\begin{tabular}{|c|c|c|c|c|}
\hline \multirow[b]{3}{*}{ Variable } & \multicolumn{4}{|c|}{$\begin{array}{l}\text { Obsessive-Compulsive } \\
\text { Problems }\end{array}$} \\
\hline & \multirow[b]{2}{*}{$\begin{array}{l}\text { Total } \\
\text { N }(\%)\end{array}$} & $\begin{array}{c}\text { No } \\
(n=114)\end{array}$ & $\begin{array}{c}\text { Yes } \\
(n=44)\end{array}$ & \multirow[b]{2}{*}{ P-value } \\
\hline & & $\mathbf{N}(\%)$ & $\mathbf{N}(\%)$ & \\
\hline Gender of Child & & & & 0.783 \\
\hline Female & $71(44.9)$ & $52(45.61)$ & $19(43.18)$ & \\
\hline Male & $87(55.1)$ & $62(54.39)$ & $25(56.82)$ & \\
\hline Age of Child ${ }^{a}$ & & & & $<0.001$ \\
\hline 6 to 14 years old & $11(5)$ & $11(5)$ & $12(5)$ & \\
\hline Ethnicity of Child & & & & 0.016 \\
\hline Other & $26(17.0)$ & $24(21.43)$ & $2(4.88)$ & \\
\hline White & $127(83.0)$ & $88(78.57)$ & $39(95.12)$ & \\
\hline School Performance & & & & 0.004 \\
\hline High & $134(85.4)$ & $103(90.35)$ & $31(72.09)$ & \\
\hline Low & $23(14.7)$ & $11(9.65)$ & $12(27.91)$ & \\
\hline Resident Smokes & & & & 0.098 \\
\hline No & $117(76.0)$ & $89(79.46)$ & $28(66.67)$ & \\
\hline Yes & $37(24.0)$ & $23(20.54)$ & $14(33.33)$ & \\
\hline Child Born Preterm & & & & 0.841 \\
\hline No & $113(74.3)$ & $83(74.77)$ & $30(73.17)$ & \\
\hline Yes & $39(25.7)$ & $28(25.23)$ & $11(26.83)$ & \\
\hline Parent Education & & & & 0.938 \\
\hline$<$ College degree & $62(54.9)$ & $49(55.06)$ & $13(54.17)$ & \\
\hline$>=$ College degree & $51(45.1)$ & $40(44.94)$ & $11(45.83)$ & \\
\hline Mom Smoked During & & & & 0.039 \\
\hline Pregnancy & & & & \\
\hline No & $124(84.9)$ & $94(88.68)$ & $30(75.00)$ & \\
\hline Yes & $22(15.1)$ & $12(11.32)$ & $10(25.00)$ & \\
\hline Age Mother Had Child & & & & 0.974 \\
\hline$<35$ years old & $114(76.5)$ & $85(76.58)$ & $29(76.32)$ & \\
\hline$>=35$ years old & $35(23.5)$ & $26(23.42)$ & $9(23.68)$ & \\
\hline Parent Marital Status & & & & 0.588 \\
\hline Not married & $46(30.1)$ & $32(28.83)$ & $14(33.33)$ & \\
\hline Married & $107(69.9)$ & $79(71.17)$ & $28(66.67)$ & \\
\hline Mom Depression & & & & 0.056 \\
\hline No & $106(70.2)$ & $82(74.55)$ & $24(58.54)$ & \\
\hline Yes & $45(29.8)$ & $28(25.45)$ & $17(41.46)$ & \\
\hline
\end{tabular}

${ }^{a}$ Age is reported as median (Interquartile range, IQR).

* P-values were derived using chi-square tests and the Wilcoxon test (age)

*Numbers may not add up to the total sample size of 158 as a result of missing data 
Tables 8-10 shows the sample characteristics by total fly ash, lift tape fly ash, and filter fly ash. A statistically significant association was only observed for filter fly ash and child born preterm (Table 10).

Table 8. Sample Characteristics by Total Fly Ash Exposure $(\mathrm{N}=158)$

\begin{tabular}{|c|c|c|c|c|}
\hline \multirow[b]{3}{*}{ Variable } & \multicolumn{4}{|c|}{ Total Fly Ash } \\
\hline & \multirow[b]{2}{*}{$\begin{array}{c}\text { Total } \\
\text { N (\%) } \\
\end{array}$} & $\begin{array}{c}\text { No } \\
(n=125)\end{array}$ & $\begin{array}{c}\text { Yes } \\
(\mathbf{n}=33)\end{array}$ & \multirow[b]{2}{*}{ P-value } \\
\hline & & $\mathbf{N}(\%)$ & $\mathbf{N}(\%)$ & \\
\hline Gender of Child & & & & 0.603 \\
\hline Female & $71(44.9)$ & $17(41.46)$ & $54(46.15)$ & \\
\hline Male & $87(55.1)$ & $24(58.54)$ & $63(53.85)$ & \\
\hline Age of Childa & & & & 0.871 \\
\hline 6 to 14 years old & $11(5)$ & $11(5)$ & $11(5)$ & \\
\hline Ethnicity of Child & & & & 0.498 \\
\hline Other & $26(17.0)$ & $8(20.51)$ & $18(15.79)$ & \\
\hline White & $127(83.0)$ & $31(79.49)$ & $96(84.21)$ & \\
\hline School Performance & & & & 0.605 \\
\hline High & $134(85.4)$ & $36(87.80)$ & $98(84.48)$ & \\
\hline Low & $23(14.7)$ & $5(12.20)$ & $18(15.52)$ & \\
\hline Resident Smokes & & & & 0.552 \\
\hline No & $117(76.0)$ & $31(79.49)$ & $86(74.78)$ & \\
\hline Yes & $37(24.0)$ & $8(20.51)$ & $29(25.22)$ & \\
\hline Child Born Preterm & & & & 0.397 \\
\hline No & $113(74.3)$ & $27(69.23)$ & $86(76.11)$ & \\
\hline Yes & $39(25.7)$ & $12(30.77)$ & $27(23.89)$ & \\
\hline Parent Education & & & & 0.742 \\
\hline$<$ College degree & $62(54.9)$ & $15(57.69)$ & $47(54.02)$ & \\
\hline$>=$ College degree & $51(45.1)$ & $11(42.31)$ & $40(45.98)$ & \\
\hline Mom Smoked During & & & & \\
\hline Pregnancy & & & & 0.885 \\
\hline No & $124(84.9)$ & $32(84.21)$ & $92(85.19)$ & \\
\hline Yes & $22(15.1)$ & $6(15.79)$ & $16(14.81)$ & \\
\hline Age Mother Had Child & & & & 0.681 \\
\hline$<35$ years old & $114(76.5)$ & $30(78.95)$ & $84(75.68)$ & \\
\hline$>=35$ years old & $35(23.5)$ & $8(21.05)$ & $27(24.32)$ & \\
\hline Parent Marital Status & & & & 0.485 \\
\hline Not married & $46(30.1)$ & $10(25.64)$ & $36(31.58)$ & \\
\hline Married & $107(69.9)$ & $29(74.36)$ & $78(68.42)$ & \\
\hline Mom Depression & & & & 0.510 \\
\hline No & $106(70.2)$ & $29(74.36)$ & $77(68.75)$ & \\
\hline Yes & $45(29.8)$ & $10(25.64)$ & $35(31.25)$ & \\
\hline
\end{tabular}


Table 9. Sample Characteristics by Lift Tape Fly Ash Exposure (N=158)

\begin{tabular}{|c|c|c|c|c|}
\hline \multirow{4}{*}{ Variable } & \multirow{4}{*}{ Total N (\%) } & \multicolumn{2}{|c|}{ Lift Tape Fly Ash } & \multirow{4}{*}{ P-value } \\
\hline & & $\begin{array}{c}\text { No } \\
(n=125)\end{array}$ & $\begin{array}{c}\text { Yes } \\
(n=33)\end{array}$ & \\
\hline & & \multirow[b]{2}{*}{$\mathbf{N}(\%)$} & \multirow[b]{2}{*}{$\mathbf{N}(\%)$} & \\
\hline & & & & \\
\hline Gender of Child & & & & 0.428 \\
\hline Female & $71(44.9)$ & $25(40.98)$ & $46(47.42)$ & \\
\hline Male & $87(55.1)$ & $36(59.02)$ & $51(52.58)$ & \\
\hline Age of Child ${ }^{a}$ & & & & 0.642 \\
\hline 6 to 14 years old & $11(5)$ & $11(4)$ & $11(5)$ & \\
\hline Ethnicity of Child & & & & 0.189 \\
\hline Other & $26(17.0)$ & $13(22.03)$ & $13(13.83)$ & \\
\hline White & $127(83.0)$ & $46(77.97)$ & $81(86.17)$ & \\
\hline School Performance & & & & 0.977 \\
\hline High & $134(85.4)$ & $52(85.25)$ & $82(85.42)$ & \\
\hline Low & $23(14.7)$ & $9(14.75)$ & $14(14.58)$ & \\
\hline Resident Smokes & & & & 0.648 \\
\hline No & $117(76.0)$ & $46(77.97)$ & $71(74.74)$ & \\
\hline Yes & $37(24.0)$ & $13(22.03)$ & $24(25.26)$ & \\
\hline Child Born Preterm & & & & 0.958 \\
\hline No & $113(74.3)$ & $44(74.58)$ & $69(74.19)$ & \\
\hline Yes & $39(25.7)$ & $15(25.42)$ & $24(25.81)$ & \\
\hline Parent Education & & & & 0.578 \\
\hline$<$ College degree & $62(54.9)$ & $20(51.28)$ & $42(56.76)$ & \\
\hline$>=$ College degree & $51(45.1)$ & $19(48.72)$ & $32(43.24)$ & \\
\hline Mom Smoked During & & & & \\
\hline Pregnancy & & & & 0.090 \\
\hline No & $124(84.9)$ & $44(75.57)$ & $80(88.89)$ & \\
\hline Yes & $22(15.1)$ & $12(21.43)$ & $10(11.11)$ & \\
\hline Age Mother Had Child & & & & 0.520 \\
\hline$<35$ years old & $114(76.5)$ & $46(79.31)$ & $68(74.73)$ & \\
\hline$>=35$ years old & $35(23.5)$ & $12(20.69)$ & $23(25.27)$ & \\
\hline Parent Marital Status & & & & 0.176 \\
\hline Not married & $46(30.1)$ & $14(23.73)$ & $32(34.04)$ & \\
\hline Married & $107(69.9)$ & $45(76.27)$ & $62(65.96)$ & \\
\hline Mom Depression & & & & 0.117 \\
\hline No & $106(70.2)$ & $45(77.59)$ & $61(65.59)$ & \\
\hline Yes & $45(29.8)$ & $13(22.41)$ & $32(34.41)$ & \\
\hline
\end{tabular}


Table 10. Sample Characteristics by Filter Fly Ash Exposure (N=158)

\begin{tabular}{|c|c|c|c|c|}
\hline \multirow[b]{3}{*}{ Variable } & \multirow[b]{3}{*}{ Total N (\%) } & \multicolumn{3}{|c|}{ Filter Fly Ash $(\mathrm{N}=158)$} \\
\hline & & $\begin{array}{c}\text { No } \\
(n=125)\end{array}$ & $\begin{array}{c}\text { Yes } \\
(\mathbf{n}=33)\end{array}$ & \\
\hline & & $\mathbf{N}(\%)$ & $\mathbf{N}(\%)$ & P-value \\
\hline Gender of Child & & & & 0.451 \\
\hline Female & $71(44.9)$ & $45(47.37)$ & $26(41.27)$ & \\
\hline Male & $87(55.1)$ & $50(52.63)$ & $37(58.73)$ & \\
\hline Age of Child ${ }^{\mathrm{a}}$ & & & & 0.084 \\
\hline 6 to 14 years old & $11(5)$ & $10(5)$ & $12(5)$ & \\
\hline Ethnicity of Child & & & & 0.839 \\
\hline Other & $26(17.0)$ & $15(16.48)$ & $11(17.74)$ & \\
\hline White & $127(83.0)$ & $76(83.52)$ & $51(82.26)$ & \\
\hline School Performance & & & & 0.415 \\
\hline High & $134(85.4)$ & $82(87.23)$ & $52(82.54)$ & \\
\hline Low & $23(14.7)$ & $12(12.77)$ & $11(17.46)$ & \\
\hline Resident Smokes & & & & 0.233 \\
\hline No & $117(76.0)$ & $73(79.35)$ & $44(70.97)$ & \\
\hline Yes & $37(24.0)$ & $19(20.65)$ & $18(29.03)$ & \\
\hline Child Born Preterm & & & & 0.040 \\
\hline No & $113(74.3)$ & $63(68.48)$ & $50(83.33)$ & \\
\hline Yes & $39(25.7)$ & $29(31.52)$ & $10(16.67)$ & \\
\hline Parent Education & & & & 0.739 \\
\hline$<$ College degree & $62(54.9)$ & $37(53.62)$ & $25(56.82)$ & \\
\hline$>=$ College degree & $51(45.1)$ & $32(46.38)$ & $19(43.18)$ & \\
\hline Mom Smoked During & & & & \\
\hline Pregnancy & & & & 0.223 \\
\hline No & $124(84.9)$ & $79(87.78)$ & $45(80.36)$ & \\
\hline Yes & $22(15.1)$ & $11(12.22)$ & $11(19.64)$ & \\
\hline Age Mother Had Child & & & & 0.721 \\
\hline$<35$ years old & $114(76.5)$ & $69(77.53)$ & $45(75.00)$ & \\
\hline$>=35$ years old & $35(23.5)$ & $20(22.47)$ & $15(25.00)$ & \\
\hline Parent Marital Status & & & & 0.729 \\
\hline Not married & $46(30.1)$ & $27(29.03)$ & $19(31.67)$ & \\
\hline Married & $107(69.9)$ & $66(70.97)$ & $41(68.33)$ & \\
\hline Mom Depression & & & & 0.605 \\
\hline No & $106(70.2)$ & $66(71.74)$ & $40(67.80)$ & \\
\hline Yes & $45(29.8)$ & $26(28.26)$ & $19(32.20)$ & \\
\hline
\end{tabular}




\section{Summary of Demographic Results}

Age, child school performance, and maternal smoking during pregnancy were all significantly associated with social, thought, and obsessive-compulsive problems. These results were expected because these variables have been identified as risk factors for autism spectrum disorders. An association was observed between child born preterm and filter fly ash.

\section{Regression Results}

Table 11 displays the cross-tabulation results of the outcomes versus total fly ash, lift tape fly ash, and filter fly ash. Table 7 also shows the unadjusted logistic regression results of each outcome and total fly ash, lift tape fly ash, and filter fly ash exposure. There was no statistically significant association between social problems and exposure to total fly ash $(\mathrm{OR}=1.39,95 \%$ C.I $=0.55-3.49)$, fly ash from lift tape $(\mathrm{OR}=1.13,95 \%$ $\mathrm{CI}=0.51-2.50)$, and fly ash from filter $(\mathrm{OR}=1.34,95 \% \mathrm{CI}=0.62-2.90)$. Decreased odds were observed for the association between thought problems and all fly ash exposure categories. Finally, non-significant associations were observed between obsessivecompulsive problems and all fly ash measures. 
Table 11. Univariate Logistic Regression Models of Outcome Variables with Total Fly Ash, Lift Tape Fly Ash, and Filter Fly Ash

\begin{tabular}{|c|c|c|c|c|c|}
\hline \multirow[t]{2}{*}{ Variable } & & & \multirow[t]{2}{*}{ OR } & \multirow[t]{3}{*}{$95 \% \mathrm{CI}$} & \multirow[t]{2}{*}{ P-value } \\
\hline & \multicolumn{2}{|c|}{ Social Problems } & & & \\
\hline & No & Yes & & & \\
\hline & $\mathrm{N}(\%)$ & $\mathrm{N}(\%)$ & & & \\
\hline Total Fly Ash & & & & & 0.487 \\
\hline No & $34(27.2)$ & $7(21.2)$ & 1.00 & Referent & \\
\hline Yes & $91(72.8)$ & $26(78.8)$ & 1.39 & $0.55-3.49$ & \\
\hline Lift Tape Fly Ash & & & & & 0.766 \\
\hline No & $49(39.2)$ & $12(36.4)$ & 1.00 & Referent & \\
\hline Yes & $76(60.8)$ & $21(63.6)$ & 1.13 & $0.51-2.50$ & \\
\hline Filter Fly Ash & & & & & 0.462 \\
\hline No & $77(61.6)$ & $18(54.6)$ & 1.00 & Referent & \\
\hline Yes & $48(38.4)$ & $15(45.4)$ & 1.34 & $0.62-2.90$ & \\
\hline \multicolumn{6}{|c|}{ Thought Problems } \\
\hline & No & Yes & & & \\
\hline & $\mathrm{N}(\%)$ & $\mathrm{N}(\%)$ & & & \\
\hline Total Fly Ash & & & & & 0.249 \\
\hline No & $27(23.5)$ & $14(32.6)$ & 1.00 & Referent & \\
\hline Yes & $88(76.5)$ & $29(67.4)$ & 0.64 & $0.29-1.37$ & \\
\hline Lift Tape Fly Ash & & & & & 0.108 \\
\hline No & $40(34.8)$ & $21(48.8)$ & 1.00 & Referent & \\
\hline Yes & $75(65.2)$ & $22(51.2)$ & 0.56 & $0.28-1.14$ & \\
\hline Filter Fly Ash & & & & & 0.958 \\
\hline No & $69(60.0)$ & $26(60.5)$ & 1.00 & Referent & \\
\hline Yes & $46(40.0)$ & $17(39.5)$ & 0.98 & $0.48-2.01$ & \\
\hline \multicolumn{6}{|c|}{ Obsessive-Compulsive Problems } \\
\hline & No & Yes & & & \\
\hline & $\mathrm{N}(\%)$ & $\mathrm{N}(\%)$ & & & \\
\hline Total Fly Ash & & & & & 0.522 \\
\hline No & $28(24.6)$ & $13(29.6)$ & 1.00 & Referent & \\
\hline Yes & $86(75.4)$ & $31(70.5)$ & 0.78 & $0.36-1.69$ & \\
\hline Lift Tape Fly Ash & & & & & 0.273 \\
\hline No & $41(36.0)$ & $20(45.5)$ & 1.00 & Referent & \\
\hline Yes & $73(64.0)$ & $24(54.5)$ & 0.67 & $0.33-1.37$ & \\
\hline Filter Fly Ash & & & & & 0.869 \\
\hline No & $69(60.5)$ & $26(59.1)$ & 1.00 & Referent & \\
\hline Yes & $45(39.5)$ & $18(40.9)$ & 1.06 & $0.52-2.16$ & \\
\hline
\end{tabular}

\section{Social Problems Regression}

Tables 12-14 report the results of the adjusted logistic regression for social problems. Three types of multivariable models were used- adjusting for child covariates, mother covariates, and both. Table 12 reports the results of the logistic regression models 
for social problems and total fly ash, lift tape fly ash and lift tape fly ash exposure while controlling for child level covariates. No statistically significant associations were found between social problems and total fly ash, lift tape fly ash, and filter fly ash exposures.

For the significant covariates, each additional year of age was associated with $23 \%$ increased odds of having social problems $(\mathrm{AOR}=1.23,95 \% \mathrm{CI}=1.02-1.49)$ in the total fly ash and lift tape fly ash models, and $22 \%$ in the filter fly ash model (AOR=1.22, $95 \% \mathrm{CI}=1.01-1.48)$. For the total fly ash model, children with low school performance were 3.43 times more likely to have social problems compared to children with high performance in school (AOR=3.43,95\% CI=1.11-10.6). For the lift tape fly ash model, children with low school performance were 3.47 times more likely to have social problems compared to children with high performance in school (AOR $=3.47,95 \%$ $\mathrm{CI}=1.12-10.8)$. For the filter fly ash model, children with low school performance were 3.29 times more likely to have social problems compared to children with high performance in school $(\mathrm{AOR}=3.29,95 \% \mathrm{CI}=1.06-10.2)$. 
Table 12. Adjusted Odds Ratio (OR) for Social Problems Outcome Stratified by Fly Ash Exposure, Adjusting for Child Level Covariates

\begin{tabular}{lcccccc} 
& Total & 95\% CI & $\begin{array}{c}\text { Lift } \\
\text { Tape } \\
\text { OR }\end{array}$ & 95\% CI & Filter & 95\% CI \\
& OR & & OR & \\
\hline $\begin{array}{l}\text { Exposure Measure } \\
\quad \text { No }\end{array}$ & 1.00 & Referent & 1.00 & Referent & 1.00 & Referent \\
$\quad$ Yes & 1.22 & $0.43-3.45$ & 0.98 & $0.40-2.43$ & 1.40 & $0.56-3.51$ \\
\hline Age of Child & & & & & & \\
$\quad$ 6-14 years old & 1.23 & $1.02-1.49$ & 1.23 & $1.02-1.49$ & 1.22 & $1.01-1.48$ \\
& & & & & & \\
\hline Gender of Child & & & & & & \\
$\quad$ Female & 1.00 & Referent & 1.00 & Referent & 1.00 & Referent \\
$\quad$ Male & 0.93 & $0.38-2.24$ & 0.91 & $0.38-2.21$ & 0.88 & $0.36-2.14$ \\
\hline $\begin{array}{l}\text { Ethnicity of Child } \\
\text { Other }\end{array}$ & 1.00 & Referent & 1.00 & Referent & 1.00 & Referent \\
$\quad$ White & 2.48 & $0.52-11.7$ & 2.54 & $0.53-12.2$ & 2.51 & $0.53-11.8$ \\
\hline $\begin{array}{l}\text { Smoke Exposure } \\
\quad \text { No }\end{array}$ & 1.00 & Referent & 1.00 & Referent & 1.00 & Referent \\
$\quad$ Yes & 0.98 & $0.35-2.72$ & 0.98 & $0.35-2.72$ & 0.97 & $0.35-2.69$ \\
\hline Child Born Preterm & & & & & & \\
$\quad$ No & 1.00 & Referent & 1.00 & Referent & 1.00 & Referent \\
$\quad$ Yes & 1.16 & $0.44-3.08$ & 1.14 & $0.43-2.72$ & 1.26 & $0.46-3.45$ \\
\hline $\begin{array}{l}\text { School } \\
\text { Performance }\end{array}$ & & & & & & \\
$\quad \begin{array}{l}\text { High } \\
\text { Low }\end{array}$ & 1.00 & Referent & 1.00 & Referent & 1.00 & Referent \\
\hline
\end{tabular}

Table 13 shows the results of the adjusted logistic regression model of total fly ash, lift tape fly ash, filter fly ash, and social problems using mother level covariates. There was not a statistically significant increase in a risk of social problems for children exposed to filter fly ash compared to children not exposed to filter fly ash ( $\mathrm{AOR}=1.34$, $95 \% \mathrm{CI}=0.50-3.61)$. Increased non-significant odds ratios were observed for mother smoking during pregnancy, mother's depression, and education status for all fly ash categories. 
Table 13. Adjusted Odds Ratio (OR) for Social Problems Outcome Stratified by Fly Ash Exposure, Adjusting for Mother Level Covariates

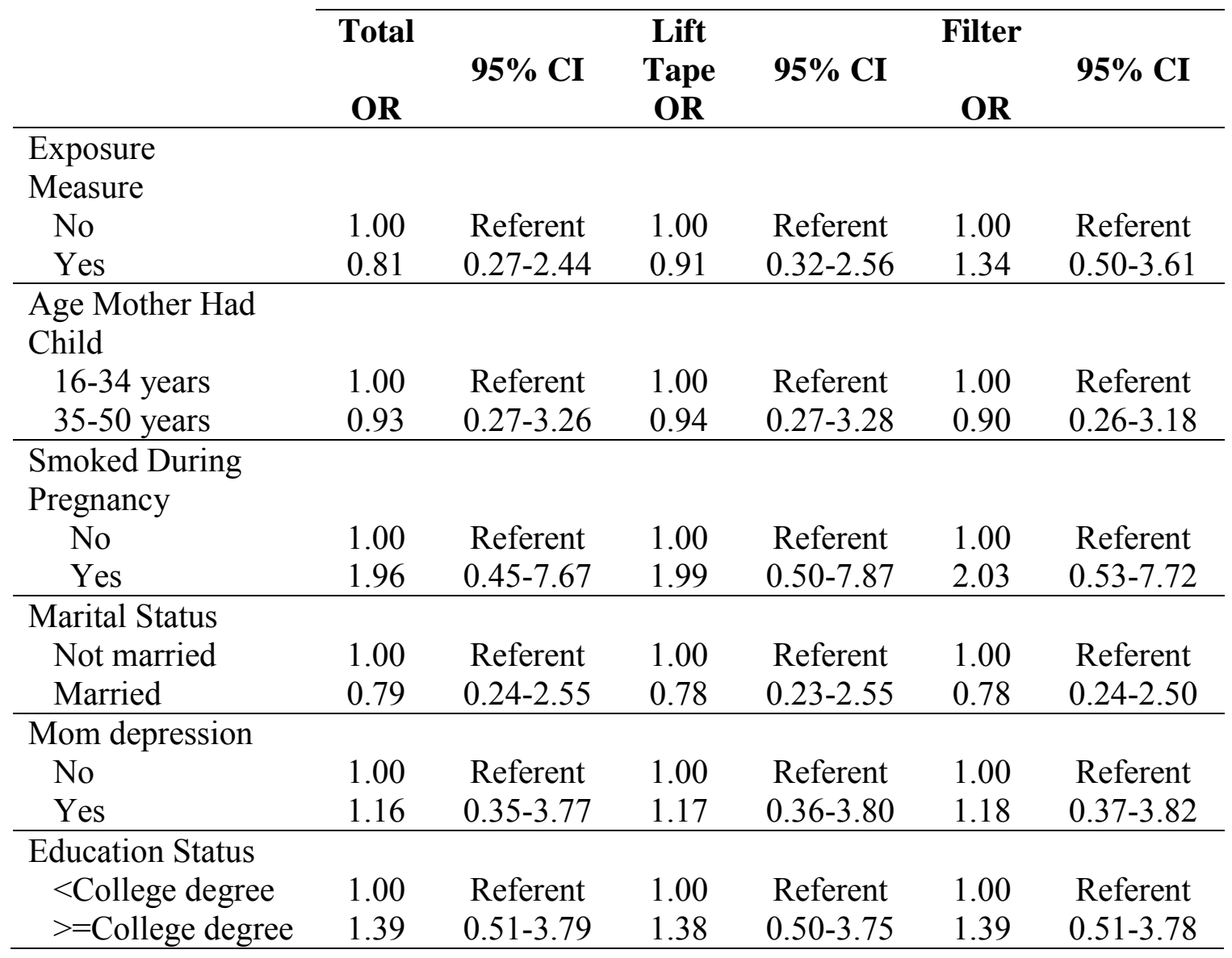

Table 14 displays the results from the adjusted logistic regression model of social problems, total fly ash, lift tape fly ash, and filter fly ash using both child and mother level covariates. In this table, an increased but non-statistically significant odds ratio $(\mathrm{AOR}=1.30,95 \% \mathrm{CI}=0.39-4.32)$ was observed for filter fly ash exposure but not total fly ash or lift tape fly ash. Also, each additional year of age was associated with $44 \%$ increased odds of having social problems $(\mathrm{AOR}=1.44,95 \% \mathrm{CI}=1.08-1.91)$ for total fly ash. Each additional year of age was also associated with $42 \%$ increased odds of having social problems for lift tape fly ash $(\mathrm{AOR}=1.42,95 \% \mathrm{CI}=1.07-1.88)$ and $41 \%$ increased odds for filter fly ash (AOR=1.41, 95\% CI=1.06-1.86). 
Table 14. Adjusted Odds Ratio (OR) for Social Problems Outcome Stratified by Fly Ash Exposure, Adjusting for Child \& Mother Level Covariates

\begin{tabular}{|c|c|c|c|c|c|c|}
\hline \multirow[t]{2}{*}{ Variable } & \multicolumn{2}{|l|}{ Total } & \multirow{2}{*}{$\begin{array}{c}\text { Lift } \\
\text { Tape } \\
\text { OR }\end{array}$} & \multicolumn{3}{|c|}{ Filter } \\
\hline & OR & $95 \% \mathrm{CI}$ & & $95 \% \mathrm{CI}$ & OR & $95 \% \mathrm{CI}$ \\
\hline \multicolumn{7}{|l|}{ Exposure } \\
\hline No & 1.00 & Referent & 1.00 & Referent & 1.00 & Referent \\
\hline Yes & 0.60 & $0.18-2.03$ & 0.83 & $0.25-2.72$ & 1.30 & $0.39-4.32$ \\
\hline \multicolumn{7}{|l|}{ Age of Child } \\
\hline $6-14$ years & 1.44 & $1.08-1.91$ & 1.42 & $1.07-1.88$ & 1.41 & $1.06-1.86$ \\
\hline \multicolumn{7}{|l|}{ Gender of Child } \\
\hline Female & 1.00 & Referent & 1.00 & Referent & 1.00 & Referent \\
\hline Male & 0.97 & $0.30-3.12$ & 0.95 & $0.30-3.01$ & 0.94 & $0.30-2.98$ \\
\hline \multicolumn{7}{|l|}{ Ethnicity of Child } \\
\hline Other & 1.00 & Referent & 1.00 & Referent & 1.00 & Referent \\
\hline White & 1.78 & $0.31-10.2$ & 1.75 & $0.30-10.3$ & 1.61 & $0.28-9.31$ \\
\hline \multicolumn{7}{|l|}{ Smoke Exposure } \\
\hline No & 1.00 & Referent & 1.00 & Referent & 1.00 & Referent \\
\hline Yes & 0.56 & $0.12-2.61$ & 0.56 & $0.12-2.65$ & 0.53 & $0.11-2.53$ \\
\hline \multicolumn{7}{|l|}{ Child Born Preterm } \\
\hline No & 1.00 & Referent & 1.00 & Referent & 1.00 & Referent \\
\hline Yes & 1.05 & $0.27-3.98$ & 1.12 & $0.30-4.14$ & 1.24 & $0.31-4.92$ \\
\hline \multicolumn{7}{|l|}{ School Performance } \\
\hline High & 1.00 & Referent & 1.00 & Referent & 1.00 & Referent \\
\hline Low & 2.84 & $0.47-17.2$ & 2.68 & $0.43-16.5$ & 2.61 & $0.42-16.2$ \\
\hline \multicolumn{7}{|l|}{ Age Mother Had } \\
\hline \multicolumn{7}{|l|}{ Child } \\
\hline $16-34$ years & 1.00 & Referent & 1.00 & Referent & 1.00 & Referent \\
\hline $35-50$ years & 0.56 & $0.12-2.65$ & 0.58 & $0.12-2.70$ & 0.56 & $0.12-2.65$ \\
\hline \multicolumn{7}{|l|}{ Smoked During } \\
\hline \multicolumn{7}{|l|}{ Pregnancy } \\
\hline No & 1.00 & Referent & 1.00 & Referent & 1.00 & Referent \\
\hline Yes & 2.45 & $0.48-12.4$ & 2.55 & $0.48-13.4$ & 2.79 & $0.55-14.1$ \\
\hline \multicolumn{7}{|l|}{ Marital Status } \\
\hline Not married & 1.00 & Referent & 1.00 & Referent & 1.00 & Referent \\
\hline Married & 0.88 & $0.24-3.27$ & 0.86 & $0.23-3.18$ & 0.87 & $0.24-3.16$ \\
\hline \multicolumn{7}{|l|}{ Mom depression } \\
\hline No & 1.00 & Referent & 1.00 & Referent & 1.00 & Referent \\
\hline Yes & 1.14 & $0.32-4.12$ & 1.16 & $0.32-4.19$ & 1.13 & $0.32-4.07$ \\
\hline \multicolumn{7}{|l|}{ Education Status } \\
\hline$<$ College degree & 1.00 & Referent & 1.00 & Referent & 1.00 & Referent \\
\hline$>=$ College degree & 1.59 & $0.50-5.03$ & 1.55 & $0.49-4.89$ & 1.58 & $0.50-4.94$ \\
\hline
\end{tabular}




\section{Thought Problems Regression}

Tables 15-17 show the results for the logistic regression for fly ash exposure and thought problems. Table 15 reports the results of the logistic regression models for thought problems and total fly ash, lift tape fly ash, and filter fly ash exposures while controlling for child level covariates. There was no association between filter fly ash and thought problems $(\mathrm{AOR}=1.04,95 \% \mathrm{CI}=0.48-2.36)$. Though not statistically significant, increased odds were derived for age, ethnicity, child exposed to smoking, child born preterm, and school performance.

Table 16 reports the results of the logistic regression models for thought problems and total fly ash, lift tape fly ash, and filter fly ash exposures while controlling for mother level covariates. Decreased odds were observed for the relationship between all fly ash sources and thought problems. Though not statistically significant, increased odds were derived for age mother had child, marital status, mom depression, and education status for all fly ash categories.

Table 17 displays the results from the adjusted logistic regression model of thought problems and total fly ash, lift tape fly ash, and filter fly ash using both child and mother level covariates. Decreased odds ratios were observed for all fly ash categories.

Table 15. Adjusted Odds Ratio (OR) for Thought Problems Outcome Stratified by Fly Ash Exposure, Adjusting for Child Level Covariates

\begin{tabular}{lcccccc} 
& Total & $\mathbf{9 5 \%}$ CI & $\begin{array}{c}\text { Lift } \\
\text { Tape } \\
\text { OR }\end{array}$ & 95\% CI & Filter & 95\% CI \\
& OR & & OR & \\
\hline Exposure Measure & & & & & & \\
$\quad$ No & 1.00 & Referent & 1.00 & Referent & 1.00 & Referent \\
$\quad$ Yes & 0.51 & $0.21-1.23$ & 0.41 & $0.18-0.92$ & 1.04 & $0.48-2.36$ \\
\hline Age of Child & & & & & &
\end{tabular}



6-14 years
1.10
$0.94-1.29$
1.10
$0.92-1.29$
1.10
$0.94-1.29$

\begin{tabular}{lcccccc}
\hline $\begin{array}{l}\text { Gender of Child } \\
\text { Female } \\
\text { Male }\end{array}$ & 1.00 & Referent & 1.00 & Referent & 1.00 & Referent \\
& 0.58 & $0.26-1.30$ & 0.55 & $0.24-1.24$ & 0.62 & $0.28-1.37$ \\
\hline $\begin{array}{l}\text { Ethnicity of Child } \\
\quad \text { Other }\end{array}$ & 1.00 & Referent & 1.00 & Referent & 1.00 & Referent \\
$\quad$ White & 1.90 & $0.57-6.36$ & 2.17 & $0.63-7.42$ & 1.73 & $0.52-5.68$ \\
\hline $\begin{array}{l}\text { Smoke Exposure } \\
\text { No }\end{array}$ & 1.00 & Referent & 1.00 & Referent & 1.00 & Referent \\
$\quad$ Yes & 1.30 & $0.52-3.26$ & 1.33 & $0.53-3.34$ & 1.26 & $0.51-3.11$ \\
\hline Child Born Preterm & & & & & & \\
$\quad$ No & 1.00 & Referent & 1.00 & Referent & 1.00 & Referent \\
$\quad$ Yes & 1.57 & $0.66-3.74$ & 1.69 & $0.71-4.02$ & 1.68 & $0.70-4.03$ \\
\hline $\begin{array}{l}\text { School Performance } \\
\text { High }\end{array}$ & 1.00 & Referent & 1.00 & Referent & 1.00 & Referent \\
Low & 2.68 & $0.93-7.73$ & 2.52 & $0.86-7.38$ & 2.55 & $0.89-7.34$ \\
\hline
\end{tabular}

Table 16. Adjusted Odds Ratio (OR) for Thought Problems Outcome Stratified by Fly Ash Exposure, Adjusting for Mother Level Covariates

\begin{tabular}{lcccccc} 
& Total & 95\% CI & $\begin{array}{c}\text { Lift } \\
\text { Tape } \\
\text { OR }\end{array}$ & 95\% CI & Filter & 95\% CI \\
& OR & & OR & \\
\hline $\begin{array}{l}\text { Exposure Measure } \\
\quad \text { No }\end{array}$ & 1.00 & Referent & 1.00 & Referent & 1.00 & Referent \\
$\quad$ Yes & 0.37 & $0.13-1.04$ & 0.37 & $0.14-1.02$ & 0.64 & $0.23-1.76$ \\
\hline Age Mother Had & & & & & & \\
Child & & & & & & \\
$\quad$ 16-34 years & 1.00 & Referent & 1.00 & Referent & 1.00 & Referent \\
$\quad$ 35-50 years & 1.24 & $0.38-4.09$ & 1.31 & $0.40-4.32$ & 1.26 & $0.39-4.09$ \\
\hline $\begin{array}{l}\text { Smoked During } \\
\text { Pregnancy }\end{array}$ & & & & & & \\
$\quad$ No & 1.00 & Referent & 1.00 & Referent & 1.00 & Referent \\
$\quad$ Yes & 0.92 & $0.20-4.36$ & 0.85 & $0.18-3.99$ & 1.22 & $0.28-5.33$ \\
\hline $\begin{array}{l}\text { Marital Status } \\
\quad \text { Not married }\end{array}$ & 1.00 & Referent & 1.00 & Referent & 1.00 & Referent \\
$\quad$ Married & 2.26 & $0.58-8.70$ & 2.00 & $0.52-7.77$ & 2.28 & $0.61-8.60$ \\
\hline Mom depression & & & & & & \\
$\quad$ No & 1.00 & Referent & 1.00 & Referent & 1.00 & Referent \\
$\quad$ Yes & 2.55 & $0.82-7.99$ & 2.69 & $0.85-8.48$ & 2.50 & $0.82-7.67$ \\
\hline Education Status & & & & & & \\
$\quad<$ College degree & 1.00 & Referent & 1.00 & Referent & 1.00 & Referent \\
$\quad>=$ College degree & 1.49 & $0.55-4.05$ & 1.35 & $0.50-3.66$ & 1.39 & $0.52-3.73$ \\
\hline
\end{tabular}


Table 17. Adjusted Odds Ratio (OR) for Thought Problems Outcome Stratified by Fly Ash Exposure, Adjusting Child \& Mother Level Covariates

\begin{tabular}{|c|c|c|c|c|c|c|}
\hline & $\begin{array}{c}\text { Total } \\
\text { OR }\end{array}$ & $95 \% \mathrm{CI}$ & $\begin{array}{c}\text { Lift } \\
\text { Tape } \\
\text { OR }\end{array}$ & $95 \% \mathrm{CI}$ & $\begin{array}{c}\text { Filter } \\
\text { OR }\end{array}$ & $95 \% \mathrm{CI}$ \\
\hline \multicolumn{7}{|l|}{ Exposure Measure } \\
\hline No & 1.00 & Referent & 1.00 & Referent & 1.00 & Referent \\
\hline Yes & 0.27 & $0.09-0.85$ & 0.25 & $0.08-0.83$ & 0.60 & $0.19-1.89$ \\
\hline \multicolumn{7}{|l|}{ Age of Child } \\
\hline $6-14$ years & 1.17 & $0.91-1.49$ & 1.14 & $0.89-1.46$ & 1.19 & $0.94-1.50$ \\
\hline \multicolumn{7}{|l|}{ Gender of Child } \\
\hline Female & 1.00 & Referent & 1.00 & Referent & 1.00 & Referent \\
\hline Male & 0.45 & $0.15-1.38$ & 0.42 & $0.13-1.28$ & 0.48 & $0.16-1.43$ \\
\hline \multicolumn{7}{|l|}{ Ethnicity of Child } \\
\hline Other & 1.00 & Referent & 1.00 & Referent & 1.00 & Referent \\
\hline White & 1.42 & $0.28-7.14$ & 1.45 & $0.29-7.14$ & 1.15 & $0.26-5.12$ \\
\hline \multicolumn{7}{|l|}{ Smoke Exposure } \\
\hline No & 1.00 & Referent & 1.00 & Referent & 1.00 & Referent \\
\hline Yes & 0.55 & $0.12-2.53$ & 0.65 & $0.14-3.02$ & 0.49 & $0.11-2.23$ \\
\hline \multicolumn{7}{|l|}{ Child Born Preterm } \\
\hline No & 1.00 & Referent & 1.00 & Referent & 1.00 & Referent \\
\hline Yes & 1.71 & $0.50-5.85$ & 1.95 & $0.57-6.72$ & 1.57 & $0.46-5.39$ \\
\hline \multicolumn{7}{|l|}{ School Performance } \\
\hline High & 1.00 & Referent & 1.00 & Referent & 1.00 & Referent \\
\hline Low & 2.81 & $0.52-15.2$ & 2.18 & $0.39-12.3$ & 3.14 & $0.58-17.1$ \\
\hline \multicolumn{7}{|l|}{ Age Mother Had } \\
\hline \multicolumn{7}{|l|}{ Child } \\
\hline $16-34$ years & 1.00 & Referent & 1.00 & Referent & 1.00 & Referent \\
\hline $35-50$ years & 1.04 & $0.25-4.25$ & 1.15 & $0.28-4.76$ & 0.99 & $0.25-3.95$ \\
\hline \multicolumn{7}{|l|}{ Smoked During } \\
\hline \multicolumn{7}{|l|}{ Pregnancy } \\
\hline No & 1.00 & Referent & 1.00 & Referent & 1.00 & Referent \\
\hline Yes & 1.42 & $0.24-8.58$ & 1.16 & $0.19-6.96$ & 1.88 & $0.36-9.81$ \\
\hline \multicolumn{7}{|l|}{ Marital Status } \\
\hline Not married & 1.00 & Referent & 1.00 & Referent & 1.00 & Referent \\
\hline Married & 2.91 & $0.65-13.0$ & 2.56 & $0.57-11.5$ & 2.82 & $0.69-11.5$ \\
\hline \multicolumn{7}{|l|}{ Mom depression } \\
\hline No & 1.00 & Referent & 1.00 & Referent & 1.00 & Referent \\
\hline Yes & 2.48 & $0.69-8.86$ & 2.94 & $0.79-11.5$ & 2.30 & $0.66-7.99$ \\
\hline \multicolumn{7}{|l|}{ Education Status } \\
\hline$<$ College degree & 1.00 & Referent & 1.00 & Referent & 1.00 & Referent \\
\hline$>=$ College degree & 1.31 & $0.43-4.00$ & 1.10 & $0.36-3.35$ & 1.29 & $0.44-3.81$ \\
\hline
\end{tabular}




\section{Obsessive-Compulsive Regression}

Tables 18-20 show the results for exposure to fly ash and obsessive-compulsive problems. Table 18 reports the results of the logistic regression models for obsessivecompulsive problems and total fly ash, lift tape fly ash, and filter fly ash exposures while controlling for child level covariates. No significant association was observed between filter fly ash and obsessive-compulsive problems ( $\mathrm{AOR}=1.15,95 \% \mathrm{CI}=0.49-2.69)$. Each additional year of age was associated with $21 \%$ increased odds of having obsessivecompulsive problems $(\mathrm{AOR}=1.21,95 \% \mathrm{CI}=1.02-1.44)$ for total fly ash, lift tape fly ash, and filter fly ash. Increased non-significant odds were observed for total fly ash for gender, child exposed to smoking, child born preterm, and school performance. Increased non-significant odds were observed for lift tape and filter fly ash for gender, ethnicity, child exposed to smoking, child born preterm, and school performance.

Table 18. Adjusted Odds Ratio (OR) for Obsessive-Compulsive Problems Outcome Stratified by Fly Ash Exposure, Adjusting for Child Level Covariates

\begin{tabular}{lcccccc} 
& Total & $\mathbf{9 5 \%}$ CI & $\begin{array}{c}\text { Lift } \\
\text { Tape } \\
\text { OR }\end{array}$ & 95\% CI & Filter & 95\% CI \\
& OR & & OR & \\
\hline $\begin{array}{l}\text { Exposure Measure } \\
\text { No }\end{array}$ & 1.00 & Referent & 1.00 & Referent & 1.00 & $\begin{array}{c}\text { Referent } \\
0.49-2.69\end{array}$ \\
$\quad$ Yes & 0.96 & $0.38-2.43$ & 0.69 & $0.30-1.58$ & 1.15 & 0.45 \\
\hline $\begin{array}{l}\text { Age of Child } \\
\text { 6-14 years }\end{array}$ & 1.21 & $1.02-1.44$ & 1.21 & $1.02-1.44$ & 1.21 & $1.02-1.43$ \\
& & & & & & \\
\hline $\begin{array}{l}\text { Gender of Child } \\
\quad \text { Female }\end{array}$ & 1.00 & Referent & 1.00 & Referent & 1.00 & Referent \\
$\quad$ Male & 1.31 & $0.57-3.02$ & 1.27 & $0.55-2.93$ & 1.30 & $0.57-2.99$ \\
\hline $\begin{array}{l}\text { Ethnicity of Child } \\
\quad \text { Other Ethnicity }\end{array}$ & 1.00 & Referent & 1.00 & Referent & 1.00 & Referent \\
$\quad$ White & 0.80 & $0.80-17.7$ & 4.14 & $0.87-19.8$ & 3.73 & $0.80-17.4$ \\
\hline $\begin{array}{l}\text { Smoke Exposure } \\
\quad \text { No }\end{array}$ & 1.00 & Referent & 1.00 & Referent & 1.00 & Referent \\
$\quad$ Yes & 1.95 & $0.79-4.78$ & 1.99 & $0.81-4.90$ & 1.93 & $0.79-4.75$ \\
\hline
\end{tabular}




\begin{tabular}{lcccccc}
\hline Child Born Preterm & & & & & & \\
No & 1.00 & Referent & 1.00 & Referent & 1.00 & Referent \\
Yes & 1.05 & $0.42-2.60$ & 1.05 & $0.42-2.61$ & 1.09 & $0.43-2.79$ \\
\hline School Performance & & & & & & \\
High & 1.00 & Referent & 1.00 & Referent & 1.00 & Referent \\
Low & 2.78 & $0.93-8.30$ & 2.69 & $0.90-8.07$ & 2.72 & $0.90-8.17$ \\
\hline
\end{tabular}

Table 19 shows the results of the adjusted logistic regression model of total fly ash, lift tape fly ash, filter fly ash, and obsessive-compulsive problems using mother level covariates. Though not significant, children exposed to fly ash as measured by filter were more likely to have obsessive-compulsive problems compared to unexposed children $(\mathrm{AOR}=1.61,95 \% \mathrm{CI}=0.66-3.94)$.

Table 19. Adjusted Odds Ratio (OR) for Obsessive-Compulsive Problems Outcome Stratified by Fly Ash Exposure, Adjusting for Mother Level Covariates

\begin{tabular}{lcccccc} 
& Total & 95\% CI & $\begin{array}{c}\text { Lift } \\
\text { Tape } \\
\text { OR }\end{array}$ & 95\% CI & Filter & 95\% CI \\
& OR & & OR & \\
\hline $\begin{array}{l}\text { Exposure Measure } \\
\quad \text { No }\end{array}$ & 1.00 & Referent & 1.00 & Referent & 1.00 & Referent \\
$\quad$ Yes & 0.99 & $0.35-2.79$ & 0.62 & $0.24-1.57$ & 1.61 & $0.66-3.94$ \\
\hline $\begin{array}{l}\text { Age Mother Had } \\
\text { Child }\end{array}$ & & & & & & \\
$\quad$ 16-34 years & 1.00 & Referent & 1.00 & Referent & 1.00 & Referent \\
$\quad$ 35-50 years & 1.55 & $0.54-4.49$ & 1.60 & $0.55-4.67$ & 1.50 & $0.51-4.37$ \\
\hline $\begin{array}{l}\text { Smoked During } \\
\text { Pregnancy }\end{array}$ & & & & & & \\
$\quad$ No & 1.00 & Referent & 1.00 & Referent & 1.00 & Referent \\
$\quad$ Yes & 1.36 & $0.35-5.27$ & 1.17 & $0.29-4.65$ & 1.35 & $0.36-5.07$ \\
\hline $\begin{array}{l}\text { Marital Status } \\
\quad \text { Not married }\end{array}$ & 1.00 & Referent & 1.00 & Referent & 1.00 & Referent \\
$\quad$ Married & 1.58 & $0.50-4.96$ & 1.48 & $0.46-4.23$ & 1.56 & $0.50-4.89$ \\
\hline Mom depression & & & & & & \\
$\quad$ No & 1.00 & Referent & 1.00 & Referent & 1.00 & Referent \\
$\quad$ Yes & 1.76 & $0.62-5.00$ & 1.79 & $0.63-5.15$ & 1.76 & $0.62-5.03$ \\
\hline Education Status & & & & & & \\
$\quad<$ College degree & 1.00 & Referent & 1.00 & Referent & 1.00 & Referent \\
$\quad$ > College degree & 1.02 & $0.41-2.53$ & 1.00 & $0.40-2.49$ & 1.03 & $0.41-2.55$ \\
\hline
\end{tabular}


Table 20 displays the results from the adjusted logistic regression model of obsessive-compulsive problems and total fly ash, lift tape fly ash, and filter fly ash using both child and mother level covariates. In this table, total fly ash and lift tape yielded decreased odds for the association with obsessive-compulsive problems. However, filter fly ash yielded an increased odds ratio $(\mathrm{AOR}=1.46,95 \% \mathrm{CI}=0.51-4.16)$. Each additional year of age was associated with a $30 \%$ increased odds of having obsessive-compulsive problems $(\mathrm{OR}=1.30,95 \% \mathrm{CI}=1.03-1.65)$ for total fly ash and lift tape fly ash, and $28 \%$ increased odds for filter fly ash $(\mathrm{AOR}=1.28,95 \% \mathrm{CI}=1.01-1.62)$. For total fly ash, children with low school performance were 5.3 times more likely to have obsessivecompulsive problems compared to children with high performance in school $(\mathrm{OR}=5.26$, $95 \% \mathrm{CI}=1.08-25.5)$.

Table 20. Adjusted Odds Ratio (OR) for Obsessive-Compulsive Problems Outcome Stratified by Fly Ash Exposure, Adjusting for Child \& Mother Level Covariates

\begin{tabular}{|c|c|c|c|c|c|c|}
\hline Variable & $\begin{array}{l}\text { Total } \\
\text { OR }\end{array}$ & $95 \% \mathrm{CI}$ & $\begin{array}{c}\text { Lift } \\
\text { Tape } \\
\text { OR }\end{array}$ & $95 \% \mathrm{CI}$ & $\begin{array}{c}\text { Filter } \\
\text { OR }\end{array}$ & $95 \% \mathrm{CI}$ \\
\hline \multicolumn{7}{|c|}{ Exposure Measure } \\
\hline No & 1.00 & Referent & 1.00 & Referent & 1.00 & Referent \\
\hline Yes & 0.92 & $0.29-2.29$ & 0.61 & $0.21-1.77$ & 1.46 & $0.51-4.16$ \\
\hline \multicolumn{7}{|l|}{ Age of Child } \\
\hline $6-14$ years & 1.30 & $1.03-1.65$ & 1.30 & $1.02-1.65$ & 1.28 & $1.01-1.62$ \\
\hline \multicolumn{7}{|c|}{ Gender of Child } \\
\hline Female & 1.00 & Referent & 1.00 & Referent & 1.00 & Referent \\
\hline Male & 1.40 & $0.49-4.03$ & 1.34 & $0.46-3.89$ & 1.39 & $0.48-1.01$ \\
\hline \multicolumn{7}{|c|}{ Ethnicity of Child } \\
\hline Other & 1.00 & Referent & 1.00 & Referent & 1.00 & Referent \\
\hline White & 2.14 & $0.40-11.3$ & 2.38 & $0.43-13.0$ & 1.99 & $0.37-10.6$ \\
\hline \multicolumn{7}{|c|}{ Smoke Exposure } \\
\hline No & 1.00 & Referent & 1.00 & Referent & 1.00 & Referent \\
\hline Yes & 1.15 & $0.32-4.16$ & 1.21 & $0.33-4.46$ & 1.17 & $0.32-4.27$ \\
\hline \multicolumn{7}{|c|}{ Child Born Preterm } \\
\hline No & 1.00 & Referent & 1.00 & Referent & 1.00 & Referent \\
\hline Yes & 0.90 & $0.26-3.09$ & 0.90 & $0.26-3.13$ & 1.03 & $0.29-3.69$ \\
\hline \multicolumn{7}{|c|}{ School Performance } \\
\hline High & 1.00 & Referent & 1.00 & Referent & 1.00 & Referent \\
\hline Low & 5.26 & $1.08-25.5$ & 4.84 & $0.97-24.1$ & 4.91 & $0.99-24.3$ \\
\hline
\end{tabular}




\begin{tabular}{lllllll}
$\begin{array}{l}\text { Age Mother Had } \\
\text { Child }\end{array}$ & & & & & & \\
$\quad \begin{array}{l}\text { 16-34 years } \\
\text { 35-50 years }\end{array}$ & 1.00 & Referent & 1.00 & Referent & 1.00 & Referent \\
$\begin{array}{l}\text { Smoked During } \\
\text { Pregnancy }\end{array}$ & 1.01 & $0.27-3.83$ & 1.04 & $0.27-3.97$ & 1.00 & $0.26-3.79$ \\
$\quad$ No & 1.00 & Referent & 1.00 & Referent & 1.00 & Referent \\
$\quad \begin{array}{l}\text { Yes } \\
\text { Marital Status }\end{array}$ & 0.99 & $0.19-5.09$ & 0.87 & $0.16-4.60$ & 1.00 & $0.20-5.06$ \\
$\quad$ Not married & 1.00 & Referent & 1.00 & Referent & 1.00 & Referent \\
$\quad$ Married & 2.05 & $0.55-7.60$ & 1.90 & $0.50-7.21$ & 2.06 & $0.55-7.65$ \\
$\begin{array}{l}\text { Mom depression } \\
\quad \text { No }\end{array}$ & 1.00 & Referent & 1.00 & Referent & 1.00 & Referent \\
$\quad$ Yes & 1.24 & $0.38-4.07$ & 1.33 & $0.40-4.44$ & 1.22 & $0.37-4.05$ \\
$\begin{array}{l}\text { Education Status } \\
\quad \text { College degree }\end{array}$ & 1.00 & Referent & 1.00 & Referent & 1.00 & Referent \\
$\quad>=$ College degree & 1.38 & $0.49-3.93$ & 1.33 & $0.47-3.78$ & 1.37 & $0.48-3.89$ \\
\hline
\end{tabular}

Summary of Aim 1 Regression Results

Aim 1 focused on assessing the relationship between fly ash measures and social, thought, and obsessive-compulsive disorders. Fly ash exposure was assessed as lift tape fly ash, filter fly ash, and total fly ash which is measured as a combination of fly ash found in filters and lift tapes taken from the home. No statistically significant associations were found between fly ash measures and outcomes. Child school performance and maternal smoke were mostly identified as confounders. However, all covariates were included in model regardless of confounder determination based on statistical tests. Included variables were variables identified as risk factors for Autism Spectrum Disorders based on literature. 


\section{Aim 2 Results}

The association between metal concentrations and social, thought, and obsessivecompulsive problems were explored in Aim 2. Aim 2 results are based on a sample size of 134 participants. Table 21 shows the number of nails (fingernails and toenails) with each metal, the mean concentration, and the measures of spread of the concentrations of metals found in nails. Copper, iron, zinc, and silicon $(\mathrm{N}=134)$, were the elements most commonly found in the nails collected from children.

Table 21. Concentration and Distribution of Nail Metal Levels

\begin{tabular}{lccccc}
\hline Element & $\begin{array}{c}\text { Total } \\
\mathrm{N}=134\end{array}$ & $\begin{array}{c}\text { Mean } \\
\text { Concentration } \\
(\mathrm{ppm})\end{array}$ & Std. Dev & $\begin{array}{c}\text { Minimum } \\
\text { Concentration } \\
(\mathrm{ppm})\end{array}$ & $\begin{array}{c}\text { Maximum } \\
\text { Concentration } \\
(\mathrm{ppm})\end{array}$ \\
\hline Aluminum & 124 & 182 & 108 & 71 & 705 \\
Copper & 134 & 4.96 & 2.19 & 1.43 & 14.0 \\
Iron & 134 & 93.5 & 66 & 22.0 & 430 \\
Manganese & 28 & 4.66 & 2.02 & 2.30 & 11.0 \\
Zinc & 134 & 87.7 & 19.3 & 56.0 & 204 \\
Titanium & 71 & 30.1 & 22.1 & 11.0 & 133 \\
Nickel & 95 & 3.44 & 4.18 & 0.70 & 28.0 \\
Silicon & 134 & 406 & 422 & 43 & 3000 \\
Chromium & 93 & 7.37 & 3.95 & 2.70 & 25.0 \\
\hline
\end{tabular}

\section{Individual Metal Quartile Derivation}

Table 22 shows the number and percentage of metals in each quartile. As described earlier, each metal was ranked according to their measured concentration and quartiles were derived by stratifying the cumulative exposure rank. 
Table 22. Distribution of Rank Quartiles and Percentages

\begin{tabular}{lccccc}
\hline Element & Total & $\begin{array}{c}\text { First Quartile } \\
\text { N }(\%)\end{array}$ & $\begin{array}{c}\text { Second Quartile } \\
\text { N }(\%)\end{array}$ & $\begin{array}{c}\text { Third } \\
\text { Quartile } \\
\text { N }(\%)\end{array}$ & $\begin{array}{c}\text { Fourth Quartile } \\
\text { N }(\%)\end{array}$ \\
\hline Aluminum & 124 & $24(19.35)$ & $38(30.65)$ & $32(25.81)$ & $30(24.19)$ \\
Copper & 134 & $31(23.13)$ & $35(26.12)$ & $35(26.12)$ & $33(24.63)$ \\
Iron & 134 & $32(23.88)$ & $35(26.12)$ & $36(26.87)$ & $31(23.13)$ \\
Manganese & 28 & $7(25.00)$ & $7(25.00)$ & $7(25.00)$ & $7(25.00)$ \\
Zinc & 134 & $33(24.63)$ & $32(23.88)$ & $37(27.61)$ & $32(23.88)$ \\
Titanium & 71 & $15(21.13)$ & $20(28.17)$ & $21(29.58)$ & $15(21.13)$ \\
Nickel & 95 & $21(22.11)$ & $25(26.32)$ & $27(28.42)$ & $22(23.16)$ \\
Silicon & 134 & $33(24.63)$ & $34(25.37)$ & $34(25.37)$ & $33(24.63)$ \\
Chromium & 93 & $20(21.51)$ & $26(27.96)$ & $25(26.88)$ & $22(23.66)$ \\
\hline
\end{tabular}

Our study is exploratory and statistical calculations such as p-values and confidence intervals are meant for descriptive purposes only and have no inferential content. Table 23 reports logistic regression results of each metal and social problems, using the first quartile as a reference category. The first quartile was used as reference because the first quartile constitutes the participants with the least concentration of each metal. A significant association was observed for the highest versus lowest quartile of copper exposure $\left(\mathrm{OR}=5.44,95 \% \mathrm{CI}=1.07-27.6, P_{\text {trend }}=0.034\right)$. Children exposed to copper levels in the highest quartile are more likely to have social problems compared to children in the lowest copper quartile. The trend test for zinc approached a statistically significant level $\left(P_{\text {trend }}=0.071\right)$ and showed increased odds ratio in the third and fourth quartiles. An increased odds ratio was also observed across the quartiles for Nickel, however, it failed to reach statistical significance. 
Table 23. Logistic regression- Individual Nail Metal Exposure (Social Problems)

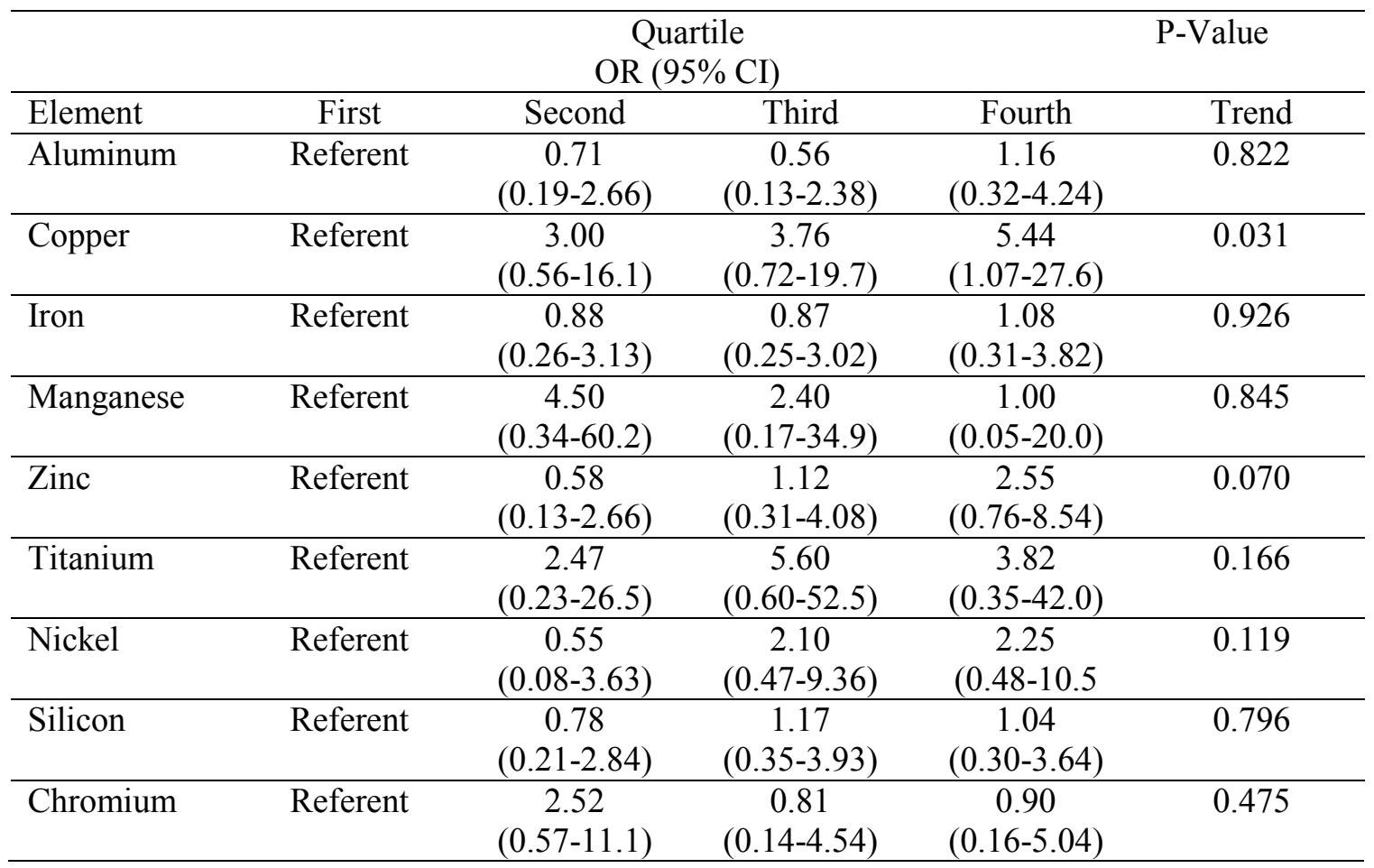

Table 24 displays the logistic regression results of nail metal quartiles and thought problems. There was no statistically significant association between thought problems and the metals.

Table 24. Logistic regression- Individual Nail Metal Exposure (Thought Problems)

\begin{tabular}{lccccc}
\hline & & \multicolumn{2}{c}{ Quartile } & & P- \\
& & Second & Th\% CI $)$ & Value \\
\hline Element & First & 0.86 & 0.73 & Fourth & Trend \\
\hline Aluminum & Referent & $(0.24-3.09)$ & $(0.19-2.89)$ & $(0.64-7.55)$ & 0.172 \\
& & 1.44 & 1.28 & 1.56 & 0.531 \\
\hline Copper & Referent & $(0.45-4.65)$ & $(0.39-4.22)$ & $(0.48-5.06)$ & \\
& & 0.37 & 0.73 & 0.80 & 0.941 \\
& Referent & $(0.11-1.23)$ & $(0.25-2.12)$ & $(0.27-2.41)$ & \\
\hline Iron & & 1.88 & 1.88 & 1.88 & 0.604 \\
& Referent & $(0.20-17.3)$ & $(0.20-17.3)$ & $(0.20-17.3)$ & \\
\hline Zinc & Referent & 0.43 & 0.77 & 0.77 & 0.838 \\
& & $(0.13-1.45)$ & $(0.27-2.21)$ & $(0.26-2.28)$ & \\
\hline Titanium & Referent & 0.71 & 1.60 & 1.60 & 0.376 \\
& & $(0.12-4.11)$ & $(0.33-7.77)$ & $(0.29-8.90)$ & \\
\hline Nickel & Referent & 0.61 & 2.13 & 1.98 & 0.132 \\
\hline
\end{tabular}




\begin{tabular}{lccccc}
\hline & & $(0.12-3.09)$ & $(0.55-8.21)$ & $(0.48-8.13)$ & \\
\hline Silicon & Referent & 0.81 & 0.54 & 1.88 & 0.326 \\
& & $(0.26-2.56)$ & $(0.16-1.86)$ & $(0.64-5.47)$ & \\
\hline Chromium & Referent & 1.20 & 0.80 & 1.50 & 0.714 \\
& & $(0.29-4(.99)$ & $(0.17-3.71)$ & $(0.34-6.35)$ & \\
\hline
\end{tabular}

Similar to Table 24, there were no statistically significant associations between the individual metals and obsessive-compulsive problems as shown in Table 25.

Table 25. Logistic Regression- Individual Nail Metal Exposure (Obsessive-Compulsive Problems)

\begin{tabular}{lccccc}
\hline & \multicolumn{4}{c}{ Quartile } & \\
\hline Element & First & Second & Third & Fourth & Trend \\
\hline Aluminum & Referent & 1.79 & 2.38 & 1.52 & 0.525 \\
& & $(0.49-6.51)$ & $(0.64-8.84)$ & $(0.39-5.97)$ & \\
\hline Copper & Referent & 1.02 & 1.64 & 1.29 & 0.781 \\
& & $(0.32-3.22)$ & $(0.52-4.96)$ & $(0.41-4.01)$ & \\
\hline Iron & Referent & 1.02 & 0.85 & 0.78 & 0.608 \\
& & $(0.35-2.96)$ & $(0.29-2.50)$ & $(0.25-2.44)$ & \\
\hline Manganese & Referent & 0.53 & 0.53 & $<0.001$ & 0.098 \\
& & $(0.06-4.19)$ & $(0.06-4.91)$ & $(<0.001->99$ & \\
\hline Zinc & Referent & 1.04 & 1.38 & 1.04 & 0.814 \\
& & $(0.34-3.22)$ & $(0.47-3.99)$ & $(0.34-3.22)$ & \\
\hline Titanium & Referent & 1.18 & 1.10 & 0.75 & 0.766 \\
& & $(0.27-5.24)$ & $(0.25-4.86)$ & $(0.14-4.17)$ & \\
\hline Nickel & Referent & 0.85 & 1.79 & 1.98 & 0.201 \\
& & $(0.18-3.92)$ & $(0.46-7.02)$ & $(0.48-8.13)$ & \\
\hline Silicon & Referent & 1.71 & 0.96 & 0.88 & 0.568 \\
& & $(0.59-4.93)$ & $(0.31-2.96)$ & $(0.28-2.78)$ & \\
\hline Chromium & Referent & 1.20 & 2.00 & 0.63 & 0.847 \\
& & $(0.29-4.99)$ & $(0.50-8.00)$ & $(0.12-3.25)$ & \\
\hline
\end{tabular}

Table 26 displays logistic regression results for social, thought, and obsessive compulsive-problems adjusted for child level covariates which includes age of child, gender of child, ethnicity of child, child exposed to smoking, child born preterm, and school performance. Complete results that show the odds ratios for child level covariates can be found in the appendix. After adjusting for child level covariates, children exposed 
to copper levels in the highest quartile were 5.89 times more likely to have social problems compared to children in the lowest copper quartile, though not statistically significant $(\mathrm{OR}=5.89,95 \% \mathrm{CI}=0.99-35.1)$. Associations between the rest of the metals and outcomes all had low confident limit levels less than 1 , which indicates a nonsignificant relationship. 
Table 26. Adjusted Odds Ratio of Metal Exposure, Outcomes, and Child Level Covariates

\begin{tabular}{|c|c|c|c|c|c|c|}
\hline & $\begin{array}{c}\text { Social } \\
\text { Problems }\end{array}$ & $95 \% \mathrm{CI}$ & $\begin{array}{l}\text { Thought } \\
\text { Problems }\end{array}$ & $95 \% \mathrm{CI}$ & $\begin{array}{l}\text { Obsessive } \\
\text { Compulsive } \\
\text { Problems }\end{array}$ & $95 \% \mathrm{CI}$ \\
\hline \multicolumn{7}{|l|}{ Aluminum } \\
\hline 1st Quartile & 1.00 & Referent & 1.00 & Referent & 1.00 & Referent \\
\hline $2^{\text {nd }}$ Quartile & 0.43 & $0.08-2.23$ & 0.44 & $0.08-2.32$ & 1.36 & $0.27-6.90$ \\
\hline 3rd Quartile & 0.35 & $0.06-2.07$ & 0.72 & $0.13-4.11$ & 2.61 & $0.51-13.4$ \\
\hline 4th Quartile & 1.46 & $0.29-7.42$ & 3.67 & $0.72-18.8$ & 2.37 & $0.42-13.5$ \\
\hline \multicolumn{7}{|l|}{ Copper } \\
\hline 1st Quartile & 1.00 & Referent & 1.00 & Referent & 1.00 & Referent \\
\hline 2nd Quartile & 3.38 & $0.57-20.1$ & 1.42 & $0.37-5.47$ & 1.47 & $0.39-5.57$ \\
\hline 3rd Quartile & 2.66 & $0.45-15.9$ & 0.96 & $0.24-3.88$ & 1.52 & $0.42-5.48$ \\
\hline 4th Quartile & 5.89 & $0.99-35.1$ & 1.52 & $0.37-6.26$ & 1.32 & $0.33-5.32$ \\
\hline \multicolumn{7}{|l|}{ Iron } \\
\hline 1st Quartile & 1.00 & Referent & 1.00 & Referent & 1.00 & Referent \\
\hline 2nd Quartile & 0.79 & $0.17-3.58$ & 0.29 & $0.06-1.36$ & 0.83 & $0.22-3.11$ \\
\hline 3rd Quartile & 0.95 & $0.22-4.14$ & 1.08 & $0.29-3.97$ & 1.00 & $0.28-3.65$ \\
\hline 4th Quartile & 1.60 & $0.33-7.67$ & 1.29 & $0.31-5.44$ & 1.04 & $0.25-4.31$ \\
\hline \multicolumn{7}{|l|}{ Zinc } \\
\hline 1st Quartile & 1.00 & Referent & 1.00 & Referent & 1.00 & Referent \\
\hline 2nd Quartile & 0.49 & $0.09-2.60$ & 0.33 & $0.08-1.35$ & 0.96 & $0.26-3.52$ \\
\hline 3rd Quartile & 0.71 & $0.15-3.35$ & 0.51 & $0.14-1.85$ & 1.40 & $0.39-5.00$ \\
\hline 4th Quartile & 3.29 & $0.75-14.5$ & 0.57 & $0.15-2.15$ & 1.26 & $0.31-5.07$ \\
\hline \multicolumn{7}{|l|}{ Titanium } \\
\hline 1st Quartile & 1.00 & Referent & 1.00 & Referent & 1.00 & Referent \\
\hline 2nd Quartile & 2.67 & $0.11-65.9$ & 0.50 & $0.06-4.46$ & 0.93 & $0.16-5.30$ \\
\hline 3rd Quartile & 12.4 & $0.59-261$ & 2.10 & $0.28-15.6$ & 0.86 & $0.15-4.75$ \\
\hline 4th Quartile & 9.75 & $0.34-284$ & 0.91 & $0.09-9.47$ & 0.46 & $0.05-4.39$ \\
\hline \multicolumn{7}{|l|}{ Nickel } \\
\hline 1st Quartile & 1.00 & Referent & 1.00 & Referent & 1.00 & Referent \\
\hline 2nd Quartile & 0.56 & $0.07-4.29$ & 0.67 & $0.11-4.06$ & 0.81 & $0.15-4.31$ \\
\hline 3rd Quartile & 1.59 & $0.30-8.35$ & 1.57 & $0.33-7.38$ & 0.97 & $0.21-4.51$ \\
\hline 4th Quartile & 1.35 & $0.23-8.11$ & 0.86 & $0.15-4.90$ & 1.14 & $0.21-6.19$ \\
\hline \multicolumn{7}{|l|}{ Silicon } \\
\hline 1st Quartile & 1.00 & Referent & 1.00 & Referent & 1.00 & Referent \\
\hline 2nd Quartile & 0.46 & $0.09-2.22$ & 0.70 & $0.17-2.84$ & 1.72 & $0.49-6.07$ \\
\hline 3rd Quartile & 1.00 & $0.27-3.71$ & 0.53 & $0.13-2.15$ & 0.96 & $0.28-3.34$ \\
\hline 4th Quartile & 1.12 & $0.26-4.92$ & 3.64 & $0.91-14.5$ & 1.08 & $0.27-4.28$ \\
\hline \multicolumn{7}{|l|}{ Chromium } \\
\hline 1st Quartile & 1.00 & Referent & 1.00 & Referent & 1.00 & Referent \\
\hline 2nd Quartile & 2.53 & $0.49-13.1$ & 1.24 & $0.24-6.37$ & 1.38 & $0.27-7.06$ \\
\hline 3rd Quartile & 0.33 & $0.04-2.91$ & 0.51 & $0.08-3.32$ & 1.98 & $0.38-10.4$ \\
\hline 4th Quartile & 0.54 & $0.06-4.71$ & 1.68 & $0.29-9.78$ & 0.33 & $0.03-3.26$ \\
\hline
\end{tabular}

*Manganese results were removed as a result of insufficient sample size for analysis. 
Table 27 displays logistic regression results for social, thought, and obsessive compulsive-problems adjusted for mother level covariates which includes parental age at birth of child, maternal smoke during pregnancy, marital status, maternal depression, and education status. Complete results that show the odds ratios for mother level covariates can be found in the appendix. After adjusting for mother level covariates, the lower confidence level approached 1 implying a borderline significant association between copper exposure and thought problems. Children exposed to copper levels in the second quartile were 5.61 times more likely to have social problems compared to children in the lowest copper quartile, however, the association was not significant $(\mathrm{OR}=5.61,95 \% \mathrm{CI}=$ $0.95-33.1)$.

Table 27. Adjusted Odds Ratio of Metal Exposure, Outcomes, and Mother Level Covariates

\begin{tabular}{lcc|cc|cc}
\hline & $\begin{array}{c}\text { Social } \\
\text { Problems }\end{array}$ & $95 \%$ CI & $\begin{array}{c}\text { Thought } \\
\text { Problems }\end{array}$ & $95 \%$ CI & $\begin{array}{c}\text { Obsessive } \\
\text { Compulsive } \\
\text { Problems }\end{array}$ & \\
\hline Aluminum & & & & & & \\
1st Quartile & 1.00 & Referent & 1.00 & Referent & 1.00 & Referent \\
2 nd Quartile $^{\text {3rd Quartile }}$ & 0.50 & $0.10-2.60$ & 1.36 & $0.21-9.00$ & 2.86 & $0.45-18.2$ \\
4th Quartile & 0.34 & $0.05-2.52$ & 0.79 & $0.09-7.28$ & 4.82 & $0.69-33.7$ \\
\hline Copper & 0.42 & $0.07-2.60$ & 2.36 & $0.36-15.7$ & 1.18 & $0.15-9.18$ \\
1st Quartile & 1.00 & Referent & 1.00 & Referent & 1.00 & Referent \\
2nd Quartile & 3.20 & $0.53-19.3$ & 5.61 & $0.95-33.1$ & 1.12 & $0.26-4.83$ \\
3rd Quartile & 1.29 & $0.19-8.71$ & 1.81 & $0.29-11.5$ & 1.26 & $0.32-4.70$ \\
4th Quartile & 3.97 & $0.67-23.7$ & 2.84 & $0.43-18.9$ & 1.59 & $0.37-6.82$ \\
\hline Iron & & & & & & \\
1st Quartile & 1.00 & Referent & 1.00 & Referent & 1.00 & Referent \\
2nd Quartile & 0.84 & $0.20-3.54$ & 0.62 & $0.13-2.82$ & 2.59 & $0.68-9.96$ \\
3rd Quartile & 0.50 & $0.10-2.48$ & 0.69 & $0.15-3.14$ & 0.76 & $0.17-3.42$ \\
4th Quartile & 0.53 & $0.10-2.81$ & 0.99 & $0.20-4.88$ & 0.85 & $0.17-4.14$ \\
\hline Zinc & & & & & & \\
1st Quartile & 1.00 & Referent & 1.00 & Referent & 1.00 & Referent \\
2nd Quartile & 0.48 & $0.10-2.44$ & 0.52 & $0.11-2.30$ & 0.55 & $0.13-2.21$ \\
3rd Quartile & 0.57 & $0.11-2.87$ & 0.70 & $0.16-3.07$ & 0.96 & $0.25-3.69$ \\
4th Quartile & 1.11 & $0.25-4.95$ & 0.46 & $0.09-2.32$ & 0.67 & $0.16-2.76$ \\
\hline Nickel & & & & & & \\
1st Quartile & 1.00 & Referent & 1.00 & Referent & 1.00 & Referent \\
\hline
\end{tabular}




\begin{tabular}{ccc|cc|cc}
\hline 2nd Quartile & 0.24 & $0.02-3.63$ & 0.58 & $0.06-5.56$ & 0.41 & $0.06-2.98$ \\
3rd Quartile & 2.55 & $0.31-20.8$ & 1.83 & $0.26-13.1$ & 1.15 & $0.19-6.84$ \\
4th Quartile & 3.36 & $0.33-33.8$ & 1.43 & $0.15-13.2$ & 0.73 & $0.09-5.90$ \\
\hline Silicon & & & & & & \\
1st Quartile & 1.00 & Referent & 1.00 & Referent & 1.00 & Referent \\
2nd Quartile & 0.73 & $0.15-3.69$ & 1.04 & $0.21-5.12$ & 3.67 & $0.87-15.5$ \\
3rd Quartile & 0.94 & $0.22-4.08$ & 0.23 & $0.02-2.19$ & 1.52 & $0.36-6.36$ \\
4th Quartile & 0.49 & $0.10-2.34$ & 2.24 & $0.57-8.78$ & 0.67 & $0.15-2.97$ \\
\hline Chromium & & & & & & \\
1st Quartile & 1.00 & Referent & 1.00 & Referent & 1.00 & Referent \\
2nd Quartile & 2.00 & $0.36-11.3$ & 0.72 & $0.13-4.04$ & 0.96 & $0.15-6.10$ \\
3rd Quartile & 0.22 & $0.02-2.57$ & 0.19 & $0.02-2.07$ & 0.72 & $0.13-3.97$ \\
4th Quartile & 0.40 & $0.03-4.58$ & 1.15 & $0.18-7.27$ & 0.32 & $0.03-3.88$ \\
\hline
\end{tabular}

*Manganese and Titanium results were removed as a result of insufficient sample size for analysis.

Table 28 displays logistic regression results for social, thought, and obsessive compulsive-problems adjusted for both child and mother level covariates which includes age of child, gender of child, ethnicity of child, child exposed to smoking, child born preterm, school performance, parental age at birth of child, maternal smoke during pregnancy, marital status, maternal depression, and education status. Odds ratio results for controlling for both child and mother level covariates can be found in the appendix. No significant association was derived between the metals and the outcomes.

Table 28. Adjusted Odds Ratio of Metal Exposure, Outcomes, and Child and Mother Level Covariates

\begin{tabular}{lcc|cc|cc}
\hline & $\begin{array}{c}\text { Social } \\
\text { Problems }\end{array}$ & $95 \%$ CI & $\begin{array}{c}\text { Thought } \\
\text { Problems }\end{array}$ & $95 \%$ CI & $\begin{array}{c}\text { Obsessive } \\
\text { Compulsive } \\
\text { Problems }\end{array}$ & \\
\hline Aluminum & & & & & & \\
1st Quartile & 1.00 & Referent & 1.00 & Referent & 1.00 & Referent \\
2 $^{\text {nd }}$ Quartile & 0.36 & $0.05-2.68$ & 0.91 & $0.10-8.65$ & 2.44 & $0.29-20.7$ \\
3rd Quartile & 0.23 & $0.02-3.18$ & 1.66 & $0.11-25.7$ & 6.21 & $0.58-66.6$ \\
4th Quartile & 0.25 & $0.02-3.45$ & 2.64 & $0.24-28.9$ & 1.23 & $0.10-15.9$ \\
\hline Copper & & & & & & \\
1st Quartile & 1.00 & Referent & 1.00 & Referent & 1.00 & Referent \\
2nd Quartile & 4.94 & $0.65-37.6$ & 5.15 & $0.66-40.0$ & 1.57 & $0.30-8.33$ \\
3rd Quartile & 1.19 & $0.13-10.6$ & 1.40 & $0.18-11.3$ & 1.25 & $0.26-6.00$ \\
4th Quartile & 6.11 & $0.68-55.0$ & 2.24 & $0.22-22.5$ & 1.44 & $0.23-9.05$ \\
\hline Iron & & & & & & \\
1st Quartile & 1.00 & Referent & 1.00 & Referent & 1.00 & Referent \\
\hline
\end{tabular}




\begin{tabular}{|c|c|c|c|c|c|c|}
\hline 2nd Quartile & 1.51 & $0.23-9.69$ & 0.57 & $0.07-4.87$ & 3.08 & $0.57-16.7$ \\
\hline 3rd Quartile & 1.12 & $0.17-7.39$ & 1.75 & $0.27-11.5$ & 1.25 & $0.21-7.48$ \\
\hline 4th Quartile & 0.68 & $0.06-6.95$ & 1.88 & $0.22-16.4$ & 1.21 & $0.16-9.34$ \\
\hline \multicolumn{7}{|l|}{ Zinc } \\
\hline 1st Quartile & 1.00 & Referent & 1.00 & Referent & 1.00 & Referent \\
\hline 2nd Quartile & 0.49 & $0.08-3.03$ & 0.26 & $0.03-1.97$ & 0.38 & $0.07-1.95$ \\
\hline 3rd Quartile & 0.40 & $0.06-2.74$ & 0.44 & $0.08-2.61$ & 0.75 & $0.16-3.59$ \\
\hline 4th Quartile & 1.25 & $0.23-6.75$ & 0.20 & $0.03-1.52$ & 0.62 & $0.12-3.17$ \\
\hline \multicolumn{7}{|l|}{ Nickel } \\
\hline 1st Quartile & 1.00 & Referent & 1.00 & Referent & 1.00 & Referent \\
\hline 2nd Quartile & 0.11 & $0.00-3.64$ & 0.52 & $0.04-7.50$ & 0.61 & $0.07-5.13$ \\
\hline 3rd Quartile & 6.68 & $0.36-122$. & 2.23 & $0.21-24.0$ & 0.89 & $0.11-7.01$ \\
\hline 4th Quartile & 8.44 & $0.18-400$ & 0.47 & $0.02-12.8$ & 1.09 & $0.06-21.6$ \\
\hline \multicolumn{7}{|l|}{ Silicon } \\
\hline 1st Quartile & 1.00 & Referent & 1.00 & Referent & 1.00 & Referent \\
\hline 2nd Quartile & 0.62 & $0.09-4.20$ & 0.81 & $0.12-5.51$ & 3.40 & $0.64-18.1$ \\
\hline 3rd Quartile & 1.16 & $0.23-5.83$ & 0.26 & $0.02-2.85$ & 1.71 & $0.36-8.12$ \\
\hline 4th Quartile & 0.39 & $0.05-3.12$ & 4.99 & $0.80-31.1$ & 0.61 & $0.09-3.93$ \\
\hline \multicolumn{7}{|l|}{ Chromium } \\
\hline 1st Quartile & 1.00 & Referent & 1.00 & Referent & 1.00 & Referent \\
\hline 2nd Quartile & 4.59 & $0.47-44.6$ & 1.06 & $0.12-9.41$ & 10.8 & $0.39-301$ \\
\hline 3rd Quartile & $<0.001$ & $<0.0->99$ & $<0.001$ & $<0.0->99$ & 0.63 & $0.05-7.69$ \\
\hline 4th Quartile & 0.24 & $0.01-8.97$ & 1.53 & 0.15-15.9 & 0.02 & $<0.0-176$ \\
\hline
\end{tabular}

\section{Quartile Sum of All Metals}

An aggregate value (Table 29) of all the ranked metals were derived and categorized into tertiles for assessment of total metal score effect on social problems, thought problems, and obsessive-compulsive problems. In SAS, average ranks are taken by default to combat the issue of ties.

Table 29. Metal Sum Measures

\begin{tabular}{l|c|c|c|c|c|c|c|c|c}
\hline Element & N & Mean & $\begin{array}{c}\text { Media } \\
\mathbf{n}\end{array}$ & IQR & Q1 & Q2 & Q3 & Min & Max \\
\hline $\begin{array}{l}\text { Metal } \\
\text { Aggregate }\end{array}$ & 144 & 1599 & 1158 & 1486 & 923 & 1158 & 2410 & 324 & 4165 \\
\hline
\end{tabular}


Table 30 displays the logistic regression result found between total nail sum and social problems. No significant association was observed between total metal exposure quartiles and social problems.

Table 30. Logistic Regression with Sum of All Metal Tertiles and Social Problems

\begin{tabular}{lrccc}
\hline & \multicolumn{3}{c}{ Quartile, OR (95\% CI) } & P-Value \\
\hline Element & First & Second & Third & Trend \\
Aggregate & Referent & $2.20(0.89-5.52)$ & $1.97(0.79-4.90)$ & 0.160 \\
\hline
\end{tabular}

For Table 31, children exposed to a quartile sum of all metals in the third tertile were more likely to have thought problems compared to children exposed to all metals in the lowest tertile $(\mathrm{OR}=30.2,95 \% \mathrm{CI}=8.14-112)$. The odds of having thought problems for children exposed to all metals in the second tertile was 8.80 times the odds for those in the lowest tertile $(\mathrm{OR}=8.80,95 \% \mathrm{CI}=2.38-32.5)$. A significant linear trend of odds ratios was observed (Ptrend $<0.001$ ), showing a dose-response relationship between exposure to sum of all metals and thought problems. A significant association was also achieved between aggregate metal tertiles and thought problems in adjusted models.

Table 31. Logistic Regression with Sum of All Metal Tertiles and Thought Problems

\begin{tabular}{lcccc}
\hline & \multicolumn{2}{c}{ Quartile, OR $(95 \% \mathrm{CI})$} & P-Value \\
\hline Element & First & Second & Third & Trend \\
Aggregate & Referent & $8.80(2.38-32.5)$ & $30.2(8.14-112)$ & $<0.001$ \\
\hline
\end{tabular}

Table 32 displays logistic regression results of sum of all metal quartiles and obsessive-compulsive problems. There was no statistically significant association between obsessive-compulsive problems and exposure to all metals in the second quartile versus the first quartile. Reduced odds ratio were observed in the second and third quartiles of sum of all metals for obsessive-compulsive problems. 
Table 32. Logistic Regression with Sum of All Metal Tertiles and Obsessive-Compulsive Problems

\begin{tabular}{lrccc}
\hline & \multicolumn{3}{c}{ Quartile, OR (95\% CI) } & P-Value \\
\hline Element & First & Second & Third & Trend \\
Aggregate & Referent & $0.81(0.35-1.85)$ & $0.33(0.13-0.84)$ & 0.019 \\
\hline
\end{tabular}

\section{Summary of Aim 2 Results}

In Aim 2, a significant association was derived between copper levels and social problems. In univariate models, a significant association was found between copper exposure and social problems. Children exposed to copper levels in the highest quartile are more likely to have social problems compared to children in the lowest copper quartile $(\mathrm{OR}=5.44,95 \% \mathrm{CI}=1.07-27.6, \mathrm{P}$ for trend $=0.031)$. In multivariate models controlling for child level covariates, a borderline significant odds ratio was derived between copper exposure and social problems. No significant associations were derived in multivariable models between thought problems, obsessive-compulsive problems, and copper exposure. Also, no other metals had significant associations with the outcomes. 


\section{Aim 3 Results}

The purpose of Aim 3 was to determine if the concentrations of nail metals were correlated with concentrations of metals found on the in-home filters. Table 33 reports the Pearson correlation of nail metal concentrations and filter metal concentrations using raw and log transformed metal concentrations. Significant correlation coefficients above 0.5 were found between manganese nail versus manganese filter and chromium nail versus chromium filter. Manganese nail and manganese filter was highly correlated with a positive correlation value $(\mathrm{r}=0.63, \mathrm{p}=0.027)$. As filter chromium levels increased, nail chromium level also increased $(\mathrm{r}=0.63, \mathrm{p}=0.005)$.

Table 33. Pearson Correlation of Nail Metal Concentrations and Filter Metal Concentrations

\begin{tabular}{l|c}
\hline Raw Data & Correlation Coefficient (P-Value) \\
\hline Aluminum Nail vs Aluminum Filter & $0.30(0.0005)$ \\
\hline Copper Nail vs Copper Filter & $0.10(0.276)$ \\
\hline Iron Nail vs Iron Filter & $0.30(0.0005)$ \\
\hline Manganese Nail vs Manganese Filter & $0.63(0.027)$ \\
\hline Zinc Nail vs Zinc Filter & $0.04(0.602)$ \\
\hline Titanium Nail vs Titanium Filter & $0.04(0.792)$ \\
\hline Nickel Nail vs Nickel Filter & $-0.24(0.097)$ \\
\hline Silicon Nail vs Silicon Filter & $0.30(0.0005)$ \\
\hline Chromium Nail vs Chromium Filter & $0.63(0.005)$ \\
\hline Log-Transformed Data & \\
\hline Aluminum Nail vs Aluminum Filter & $0.16(0.077)$ \\
\hline Copper Nail vs Copper Filter & $0.22(0.012)$ \\
\hline Iron Nail vs Iron Filter & $0.20(0.024)$ \\
\hline Manganese Nail vs Manganese Filter & $0.58(0.049)$ \\
\hline Zinc Nail vs Zinc Filter & $0.06(0.504)$ \\
\hline Titanium Nail vs Titanium Filter & $0.16(0.302)$ \\
\hline Nickel Nail vs Nickel Filter & $-0.31(0.025)$ \\
\hline Silicon Nail vs Silicon Filter & $0.35(<0.001)$ \\
\hline Chromium Nail vs Chromium Filter & $0.58(0.012)$ \\
\hline
\end{tabular}

Spearman correlation coefficients were derived to corroborate the results found in

Table 33. Table 34 reports the Spearman correlation of nail metal concentrations and 
filter metal concentrations. Similar to Pearson results, a significant positive correlation was found between manganese nail and manganese filter $(\mathrm{r}=0.58, \mathrm{p}=0.050)$.

Table 34. Spearman Correlation of Nail Metal Concentrations and Filter Metal Concentrations

\begin{tabular}{l|c}
\hline Raw Data & Correlation Coefficient (P-Value) \\
\hline Aluminum Nail vs Aluminum Filter & $0.10(0.252)$ \\
\hline Copper Nail vs Copper Filter & $0.23(0.008)$ \\
\hline Iron Nail vs Iron Filter & $0.16(0.063)$ \\
\hline Manganese Nail vs Manganese Filter & $0.58(0.047)$ \\
\hline Zinc Nail vs Zinc Filter & $0.06(0.481)$ \\
\hline Titanium Nail vs Titanium Filter & $0.22(0.147)$ \\
\hline Nickel Nail vs Nickel Filter & $-0.20(0.160)$ \\
\hline Silicon Nail vs Silicon Filter & $0.30(0.004)$ \\
\hline Chromium Nail vs Chromium Filter & $0.37(0.132)$ \\
\hline Log-Transformed Data & \\
\hline Aluminum Nail vs Aluminum Filter & $0.10(0.252)$ \\
\hline Copper Nail vs Copper Filter & $0.23(0.008)$ \\
\hline Iron Nail vs Iron Filter & $0.16(0.063)$ \\
\hline Manganese Nail vs Manganese Filter & $0.58(0.047)$ \\
\hline Zinc Nail vs Zinc Filter & $0.06(0.481)$ \\
\hline Titanium Nail vs Titanium Filter & $0.22(0.147)$ \\
\hline Nickel Nail vs Nickel Filter & $-0.20(0.160)$ \\
\hline Silicon Nail vs Silicon Filter & $0.30(0.0004)$ \\
\hline Chromium Nail vs Chromium Filter & $0.37(0.132)$ \\
\hline
\end{tabular}

Scatters plots were used in this Aim to provide a great visualization of the data. Figures 4 and 5 show the correlation plots of the nail and filter metal concentrations. The presented results might be robust as a result of the effects of outliers. Log-transformation was carried out to minimize the effect of outliers as shown in Figures 6 and 7. 


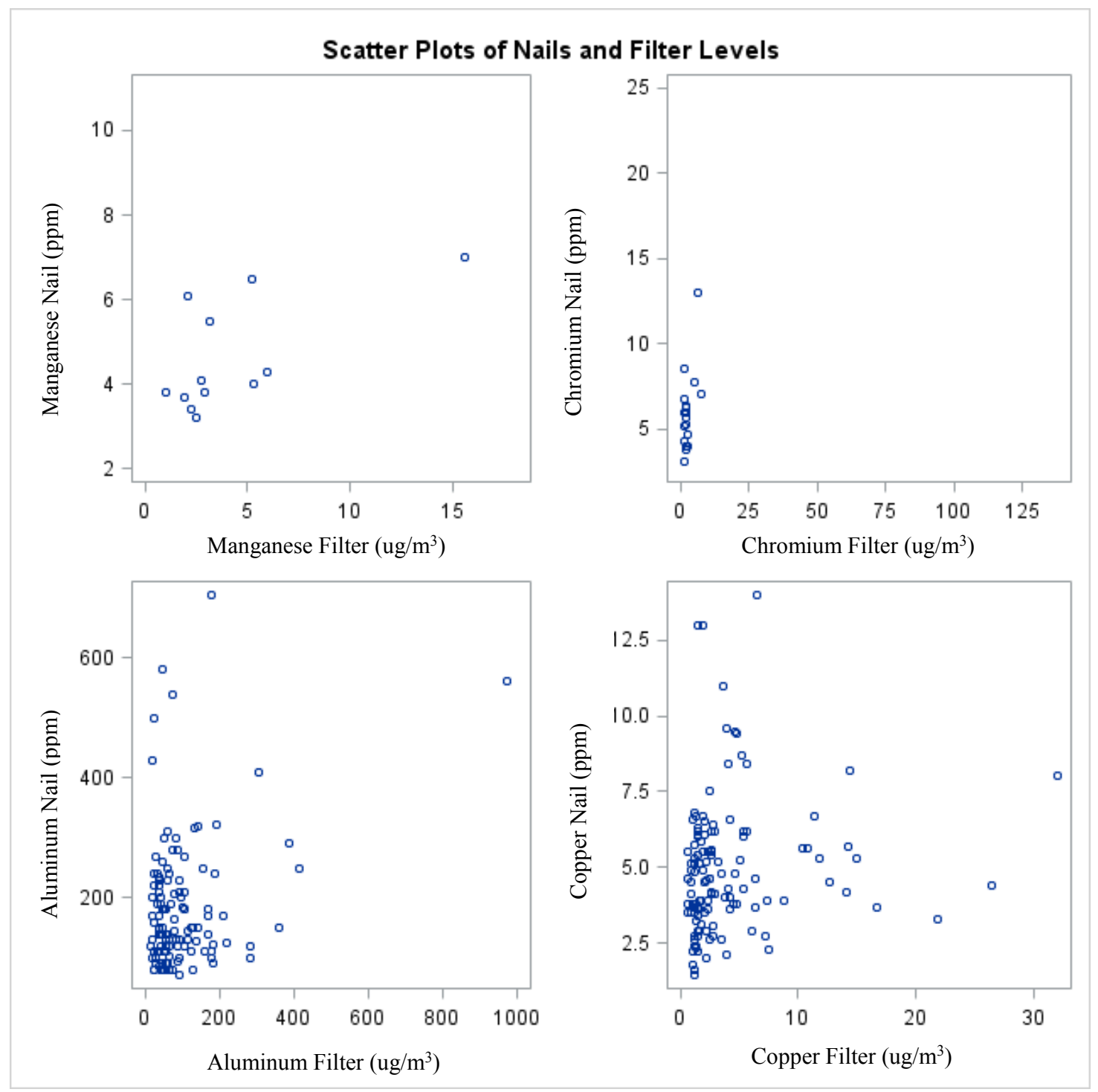

Figure 4. Scatter plots of Nail and Filter Metal Levels for Manganese, Chromium, Aluminum, and Copper 


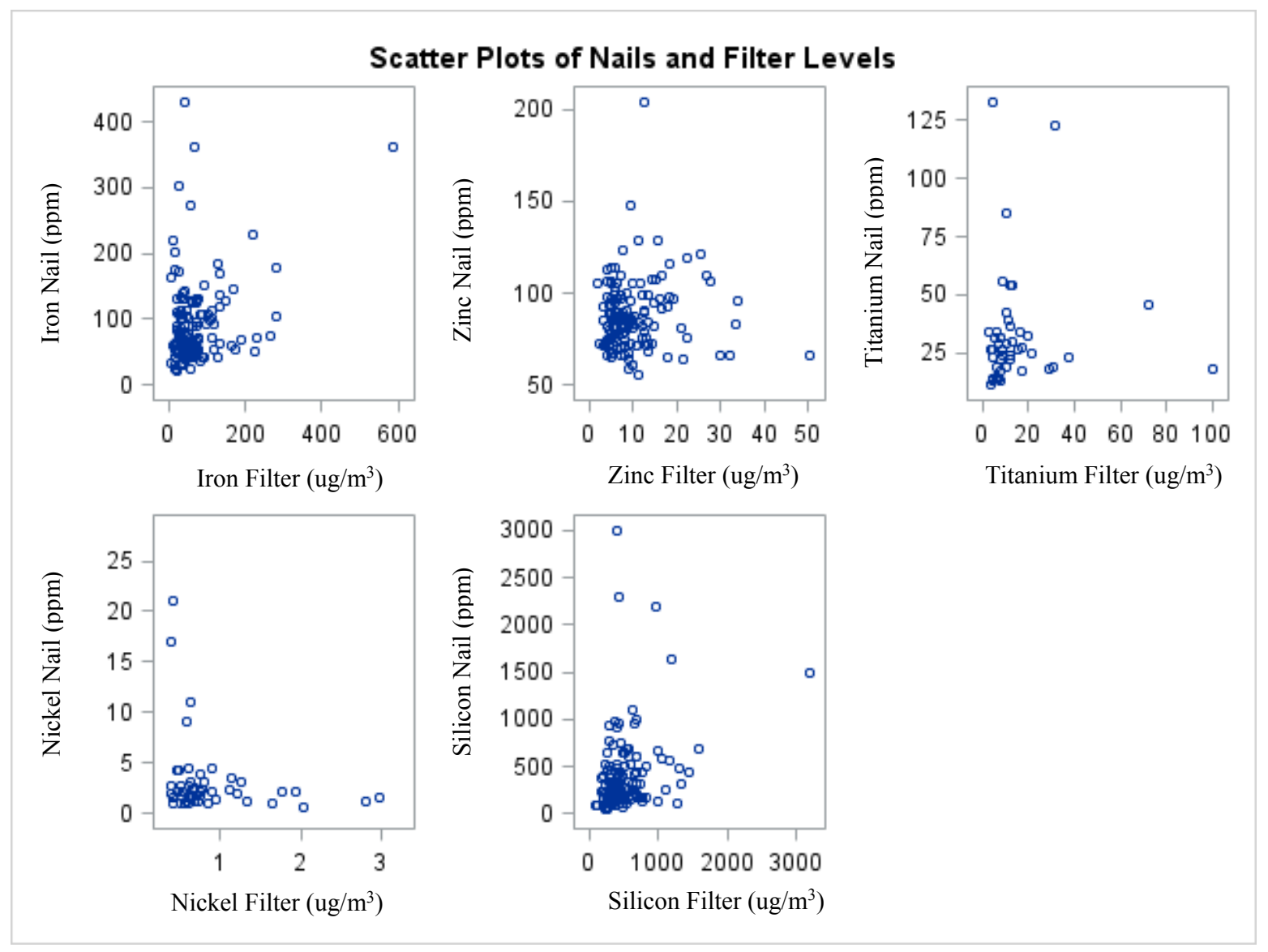

Figure 5. Scatter plots of Nail and Filter Metal Levels for Iron, Zinc, Titanium, Nickel, and Silicon 

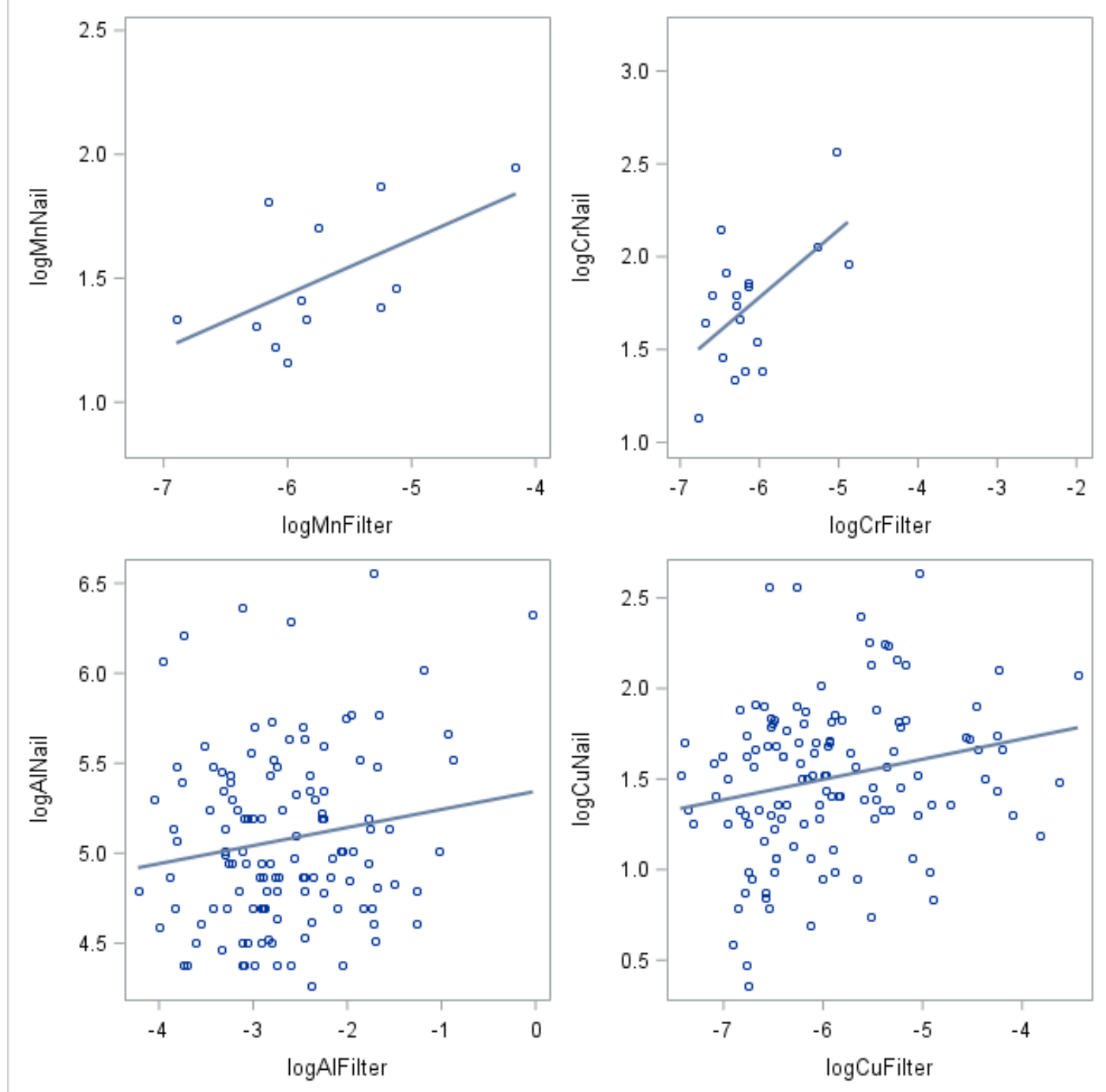

Figure 6. Log-Transformed Scatter plots of Nail and Filter Metal Levels for Manganese, Chromium, Aluminum, and Copper 

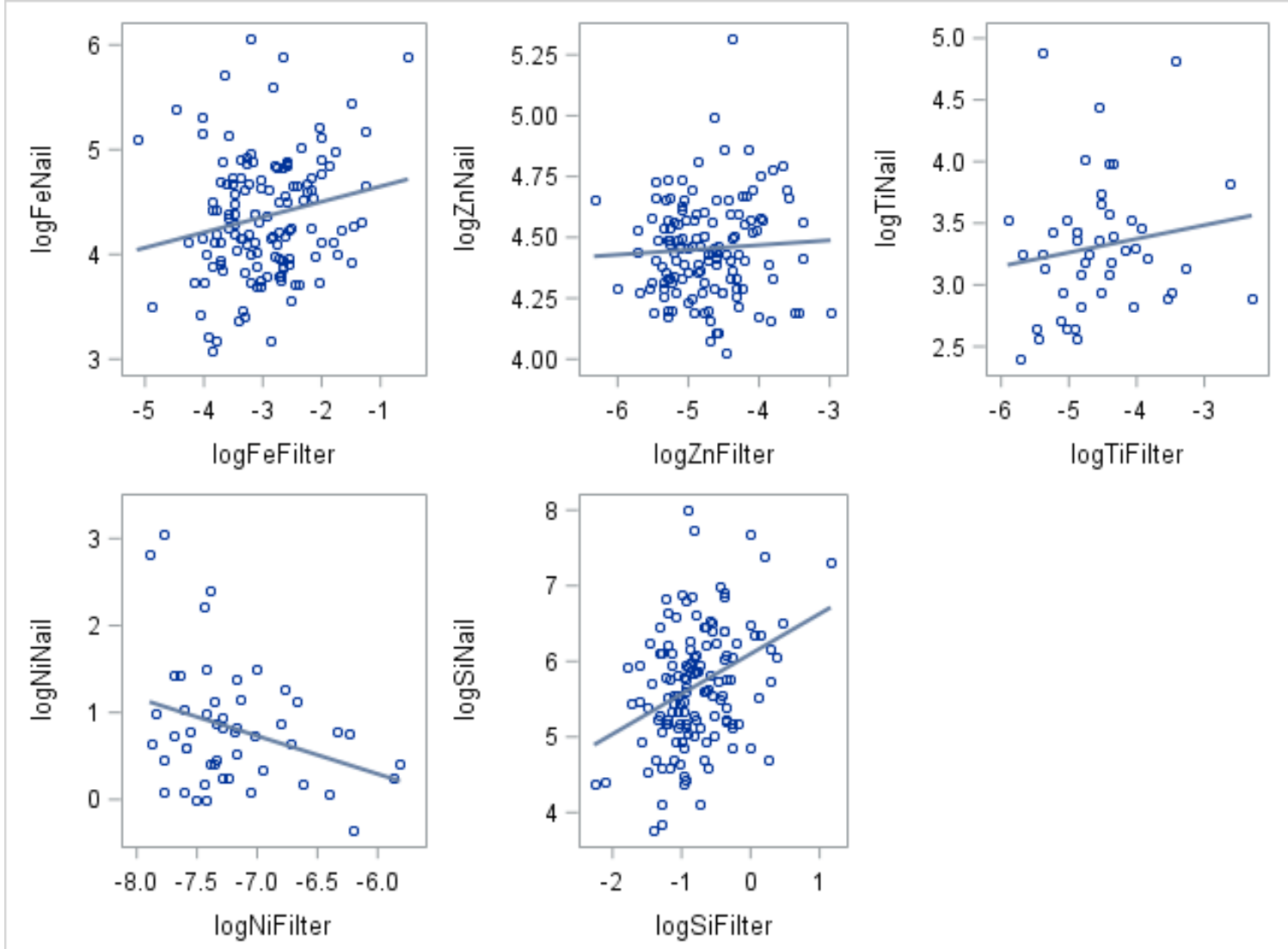

Figure 7. Log Transformed Scatter plots of Nail and Filter Metal Levels for Iron, Zinc, Titanium, Nickel, and Silicon

\section{Summary of Aim 3 Results}

Scatter plots derived with raw data appeared to be highly skewed with outliers. As a result, $\log$ transformations were conducted to reduce the skewness of the data. As shown in the graphs above, scatter plots derived with log transformed data, better displayed the linearity that exists between nail versus filter metals with a significant positive correlation. Overall, a positive correlation was found between manganese found in filter versus those found in the nails for both Spearman and Pearson correlation results. Further description of results will be provided in the discussion section below. 


\section{DISCUSSION}

In this study, the associations between fly ash, metals found in fly ash, and behaviors underlying autism spectrum disorders were examined. Social problems, thought problems, and obsessive-compulsive problems were used as proxies for autism spectrum disorders. Social problems were found in $22 \%$ of children. Thought problems and obsessive-compulsive problems were each found in $27 \%$ of the children in the study. The prevalence of social, thought, and obsessive-compulsive problems in this study were much higher than the estimated rates of $7.9 \%, 2.4 \%$, and $3 \%$ provided by previous studies (186-188). A hypothesis that could explain the differences in prevalence could be that children in this study are chronically exposed to pollution and live in close proximity to factors that could exacerbate their behavioral functioning compared to children in other populations. On the other hand, it is possible that our recruitment process resulted in selection bias whereby enrolled participants were more likely to report these problems than children in other communities. Over a child's lifetime, even minor levels of these behavioral impairments in somewhat healthy children can have harmful outcome (170). The evaluation of the association between fly ash and social, thought, and obsessivecompulsive problems are summarized below.

\section{Relationship between Fly Ash Measures and Outcomes}

There was no statistical association between the outcomes and fly ash measures (Specific Aim 1). In models with child-level covariates that assessed the association between fly ash exposure and the health outcomes, the findings of an increased odds 
ratios were more prominent for filter fly ash than lift tape fly ash. This was not true for lift tape sample. Fly ash on the filter is representative of exposures in the home during the one-week sampling period, while fly ash on the lift tape is representative of exposures from home; however, there is no clear timeframe associated with this exposure method. Fly ash on the filters may be a better measure since they collect particles that are in the air and may be inhaled, whereas lift tape samples represent dust that has settled, unless the dust on the sampled objects is stirred up via cleaning or movement of objects.

Fly ash sizes captured on the filters and lift tape samples may also vary. Fly ash particles are in the range of particulate matter from as small as PM2.5 to as large and coarse as $8 \mu \mathrm{m}$ diameter and greater (189). Filters are encased in PM10 impactors, hence, captured fly ash is in the form of particulate matter in the size range of PM10. These smaller sized particles are more likely to be inhaled by the child and affect their health.

Lift tape on the other hand captures fly ash of various sizes. Fly ash on the lift tape samples could range from small sizes (PM10) to very large sizes. In one study by Ilker that assessed particles on life tape, particle sizes from $20 \mu \mathrm{m}$ to $100 \mu \mathrm{m}$ were identified (190). In a study that used lift tape sampling to determine the presence of fly ash outside of homes located close to a power plant, heavy and non-uniform particles were observed using scanning electron microscopy (191). Filters capture smaller fly ash sizes (189) compared to lift tapes. It is likely that the large size of fly ash from lift tape could reduce the chance of inhalation. Particles of smaller sizes are more likely to be inhaled and can penetrate deeper into the lungs, leading to immune system responses and reactions (45). 
Exposure to PM10 was previously found to be associated with autism spectrum disorders and respiratory problems in children $(146,192)$. Also, previous studies showed that breathing in particles of PM2.5 is associated with respiratory health problems, cardiovascular problems, and autism spectrum disorders (146,193-195). Few studies have assessed the relationship between overall fly ash exposure and behavioral problems in children. Tang et al. assessed the effects of prenatal exposure to coal-burning pollutants on children's development in China, and found that exposure to pollutants from power plants harmed the development of children living in the study region (100). Results from this dissertation reflect preliminary results as data is still being collected. It is possible that a larger sample size from our study may improve our statistical power and reveal disparate results.

\section{Copper Body Burden}

This study evaluated a number of metals for an association with behavioral problems; however, only results for copper based on nail samples was statistically significant. Overall, findings from this research suggest that increased copper levels may be associated with the development of social problems in children ( $\mathrm{OR}=5.44,95 \%$ $\mathrm{CI}=1.07-27.6)$. Copper is an essential element that naturally occurs in the environment and is well known as one of the elements required for essential body functions such as central nervous system development, cellular respiration and connective tissues formation (196). Copper deficiency is associated with myelopathy, a disease of the spinal cord (197). However, at high concentrations, copper may be hazardous to health. Previous studies have shown a significant association between high copper levels and poor working memory in male school children (198). Similar to the findings from this research, a study that examined levels of trace elements in autistic children found that 
children with autism had high copper levels in their hair and nails compared to children who do not have autism (199). Lack of social skills is one of the major features displayed in children with autism spectrum disorders. As in our study, Priya et al reported that the nail and hair levels of copper were correlated with the degree of severity of the autism, i.e. the higher the copper levels, the more severe the autism spectrum of the child (199).

Findings from this research study are consistent with prior studies that show that excess copper levels can be toxic, and can result in impairments in neurobehavioral performance like learning disorders, nervousness, depression, irritability, and autism $(196,199)$. A possible pathway by which copper exerts its deleterious effects is through the functioning of ceruloplasmin, the major copper carrying enzyme in the blood. Since children with autism are commonly subjected to oxidative stress, the levels of ceruloplasmin are decreased in children with autism $(199,200)$, hence greater copper exposure may occur. Further research is needed to explore the pathways of behaviors underlying autism and copper exposure. According to the Environmental Protection Agency (EPA), copper levels greater than 1.3mg should not be contained in drinking water, while the Occupational Safety and Health Administration (OSHA), has set standards not to exceed $1.0 \mathrm{mg} / \mathrm{m} 3$ and $0.1 \mathrm{mg} /$ cubic meter $(\mathrm{mg} / \mathrm{m} 3)$ for copper dust and copper fumes, respectively (201).

\section{Relationship of Aggregate of All Metals and Outcomes}

Cumulative exposure to various metals may be strongly involved in the development of neurobehavioral problems in children (202). In particular, results showed that exposure to an aggregate of all metals was most strongly associated with thought problems with a linear dose-response relationship ( $\mathrm{OR}=8.80$ for tertile 2 ; $\mathrm{OR}=30.2$ for

tertile 3; Ptrend $<0.001$ ). Various exposure pathways exist for residents who live close to 
an air pollution facility. Children can be exposed to multiple metals via ingestion and consumption of food, water, soil, or contaminated objects, dermal contacts, and inhalation of dust particles (203). These study findings confirm those of previous studies, which reported an association between exposure to multiple metals and evidence for behavioral deficits $(202,204,205)$. A study by Moon showed that an aggregate metal exposure could have more of an effect compared to an individual metal exposure (206). Findings from this dissertation on the effect of the sum of all metals could raise concerns because individually most of the metals did not have a significant association with thought problems, but did when an aggregate was used. It is possible that an additive or synergistic relationship exists between thought problems and an aggregate of all metals. Further research is needed to explore the mechanism and pathways by which a cumulative exposure to metals could result in behavioral problems in children.

\section{Body and Home Metal Correlation}

Additionally, the association between nail and filter concentrations was evaluated. There was no statistically significant correlation for many of the metals studied in this dissertation. This finding is somewhat unexpected, because increased environmental exposures should lead to increased metal levels in the body. Filter and nail manganese concentrations were however, significantly correlated $(\mathrm{r}=0.63, \mathrm{p}=0.027)$. As filter metal levels increased, nail metal levels also increased. Nail and filter chromium were also found to be significantly correlated with each other $(r=0.63, p=0.005)$. Sung et al. found elevated body lead and cadmium concentrations among individuals who resided in proximity to industrial complexes (207). Some of the common modes of absorption of these metals are inhalation, ingestion, and skin exposure. Outdoor sources of air pollution 
can migrate into the home and as its level accumulates, it will lead to increased absorption, and hence, increased body metal levels $(208,209)$.

The metals that were not correlated could be explained as being poorly absorbed by the body. Aluminum and iron are examples of elements that are poorly absorbed, so environmental levels of these metals might not be accurately reflected in their body measures (210,211). Additionally, children can be in various environments where they may be exposed to metals that might not be present in the home and thus not captured on the filters. There are also various exposure routes, pathways, and child behaviors that could introduce metals into the body other than those captured on the filter in the home environment (212). In addition, the filter measures only reflect short term exposure, while nail measures are a better biomarker of cumulative long-term exposure. Further, the body has mechanisms for metabolizing and/or excreting excess amounts of some metals (e.g. $\mathrm{Cu}$ ), which would also reduce the correlation between filter and nail concentrations. Another issue may be measurement error for either or both filter and nail concentrations of some metals.

\section{Relationship between Significant Covariates and Outcomes}

In multiple models, our results determined the following covariates to be important in the relationship between fly ash and behaviors underlying ASD: child's age, child's school performance, maternal smoking during pregnancy, and maternal depression. These variables were also part of the covariates deemed to be important predictors in the relationship between metal exposures and social, thought and obsessivecompulsive problems in the purposeful selection modeling shown in the appendix (Tables 56-79). 
Age was found to have a significant relationship with social problems, thought problems, and obsessive-compulsive problems $(\mathrm{P}<0.001)$ in the cross-tabulation tables (Tables 6-8). Variability in the age of the child can lead to differential presentation of ASD features. Signs and features of ASD are not always reliably present at birth, but emerge via a series of atypical behaviors. Identification of ASD can occur as early as 2 years (213). Although improvements might be seen overtime, ASD among children who are severely affected persists till later in life, resulting in problems with social communication and the awkward behaviors associated with the disease (213). Social, thought, and obsessive-compulsive problems may be general symptoms, and not specific to ASD. These outcomes could also be associated with non-ASD neurological problems. School performance was a significant covariate in models that assessed the relationship between fly ash measures and social problems. School performance in the child-level model was identified as a significant covariate for the association between social problems and all three exposure measures: total fly ash $(\mathrm{AOR}=3.43,95 \% \mathrm{CI}=1.11$ 10.6); lift tape fly ash ( $\mathrm{AOR}=3.47,95 \% \mathrm{CI}=1.12-10.8)$; and filter fly ash ( $\mathrm{AOR}=3.29$, 95\% CI=1.06-10.2). School performance was significant in the multivariate logistic regression models that explored the relationship between copper quartiles and social, thought, and obsessive-compulsive problems while controlling for child level covariates. The following results were obtained for school performance in social problems versus copper quartile $(\mathrm{OR}=6.52,95 \% \mathrm{CI}=1.47-28.8)$, thought problems versus copper quartile $(\mathrm{OR}=5.83,95 \% \mathrm{CI}=1.47-23.1)$, and obsessive-compulsive problems versus copper quartile $(\mathrm{OR}=5.80,95 \% \mathrm{CI}=1.43-23.5)$ (See Appendix Table 38). 
A cross-sectional descriptive study reported that children with autism were significantly more likely to have learning difficulties compared to children without autism $(\mathrm{P}<0.001)$ (214). Similar results were also found in a study which assessed predictors of academic achievement among children with autism spectrum disorders. Miller et al found that children with ASD demonstrated an impairment with reading comprehension (215). Social impairments associated with ASD contribute to specific difficulties in academic attainment, particularly within the domain of reading comprehension. Poor reading comprehension capabilities displayed by children with ASD are not simply a product of inabilities to incorporate basic language skills, instead, this could be as a result of impairment in social understanding and poor social cognition $(215,216)$. School performance of children on the autism spectrum can range from those who might be considered autistic but are still very functional (mild impairment) to children with severely impaired performance. Regardless of the spectrum designation of the child, children with autism find it difficult to perform daily activities both at school and at home, which could in turn affect their performance in school (112). Some teachers and parents might not understand the deficits caused by ASD and therefore might find it difficult to assist an affected child.

Maternal smoking is a risk factor for a variety of neurodevelopmental disorders, for example antisocial behavior (217). In various models, increased effect values were found in the association between maternal cigarette smoking during pregnancy and social, thought, and obsessive-compulsive problems. Studies have suggested that there may be an association between behaviors underlying autism and maternal cigarette use during pregnancy. Maternal smoking during pregnancy has been linked with Attention 
Deficit Hyperactivity Disorders (ADHD). Exposure to nicotine from cigarettes during the developmental periods of growth has been shown to be associated with speech processing problems, ADHD and conduct disorders (218-220). A large population-based cohort study investigating the risk of obsessive-compulsive problems and perinatal activities found that smoking during pregnancy was associated with increased risk of developing obsessive-compulsive disorders (Hazard ratio: 1.27; 95\% CI, 1.02-1.58) (134).

In this study, mother's depression status was associated with an increased odds for social, thought, and obsessive-compulsive problems. Borderline statistical significance were found in cross tabulation models between maternal depression and thought problems on one hand, and maternal depression and obsessive-compulsive problems on another. This finding is consistent with other studies reporting that maternal depression is a risk factor for social, emotional, and cognitive development of a child $(221,222)$. Studies have also shown parental depression to be associated with behavioral problems, functional impairments, and increased rates of anxiety in children and adolescents (223).

\section{Limitations of Study}

This study has several limitations. First, this dissertation utilized data from an ongoing study, thus, the sample size was much smaller than the overall sample that will be collected in the parent study. Based on the power analyses employed in this dissertation, effect sizes of $>3.1$ are needed to obtain $80 \%$ power. Hence, power was low for all analyses where effect sizes of less than 3.1 were achieved.

A second limitation is the process of assessment of fly ash from the filters, which

could be inaccurate. Only a section of the filter was selected to undergo scanning electron 
microscopy (SEM), which limited the ability to measure fly ash presence in other parts of the filter. This might have greatly reduced the number of fly ash particles found on the filter and accurate quantification of total exposure. In addition, the derivation of fly ash only as a dichotomized variable disallowed the assessment of fly ash as a continuous variable.

A third limitation is related to the use of Proton Induced X-ray Emission (PIXE) to obtain the metals utilized in the study. PIXE analysis produces concentrations of up to 72 inorganic elements. Detection of both heavy metals and trace elements were anticipated. However, the limit of detection may have been too high to determine lowlevel concentrations. Other methods of analysis, such as Inductively Coupled PlasmaMass Spectrometry (ICP-MS) might be advantageous in future studies to assess lower concentrations. Fourth, even though this study assessed the metals found in particulate matter collected in the home, it is not possible to conclude that all the derived metals from the filter and lift tapes are unquestionably from fly ash. However, this is quite plausible given that the participants live within a 10-mile radius from two coal storage sites.

A fifth limitation of this study was that rank sums and quartiles in specific aim 2 were derived using the concentration of the metals of interest in this study (Aluminum, Copper, Zinc, Manganese, Iron, Nickel, Titanium, Silicon, and Chromium). However, derived quartiles were created based on the subjects in the sample, and do not represent standardized data for the normal range and categorizations of metal exposure. A sixth limitation was issues of missing data in the study from participants who did not complete all the components of the study. There was missing data especially with nail 
measures/concentrations. Participants (children) with slow nail growth did not have the required quantity of nails $(150 \mathrm{mg})$ ready to be sent to the lab in time for analysis and hence the sample sizes were lower. Different sample sizes were used for different aims since all data sources were not available. Thus, missing data further eroded the overall low statistical power for some analyses.

Another limitation may be the use of the Pediatric Health History Form and the Environmental Health Questionnaire for the assessment of the covariates. These questionnaires were used for the first time in the study and were not validated. However, these questionnaires were developed from other validated instruments like the Pediatric Environmental Health History, a screening environmental history tool (224).

A final limitation is with the assessment of the outcomes using the self-reported Child Behavioral Checklist (CBCL), which a parent or guardian completed. Since the CBCL is based on parental self-report there is the possibility of reporting bias - some parents/guardians could under or over report the responses they provided. In addition, after completing the CBCL, children with scores above the normal level on the different behavioral measures were contacted by the study psychologist for further evaluation of the child. This could be viewed as an advantage; however, some parents declined this offer for further evaluation of their child.

\section{Strengths of Study}

Some strengths of this study include a community engagement component, a relatively representative sample, use of multiple recruitment methods, and the use of multiple measures to assess exposure, especially biomarkers of body metal burden in nail concentrations. The community engagement component ensures that the needs of the community members are reflected in the study findings. Some participants were oblivious 
of the proximity of their home to the coal ash storage sites and indicated that they would have chosen a different place to live, if they were aware. Interacting with community members provided insight as to the underlying reasons for their choice of home, views of their neighborhood, and their opinion of the power station and its potential relationship with health problems.

Another strength of this study was the use of five buffer zones of 2-mile incremental radius to ensure that participants were fairly distributed in each of the sampling units and quadrants. In addition, a door-to-door method of recruitment was initially used, but when recruitment of participants slowed down, other methods of recruitment were adopted, which yielded more participants. This decision showed innovativeness and the flexibility of the study to adapt to various circumstances, albeit possibly at the risk of selection bias.

The use of multiple exposure assessment methods (nails, lift tapes, and filters), allowed for the derivation of home metal exposure, metal body burden, and exposures that might be present in the child's room. Use of these multiple methods facilitated the accurate characterization of the metal exposure of children in the study. There are limited studies exploring the association between fly ash and metals and neurobehavioral performance in children, especially in the Louisville, Kentucky and the United States at large. Findings from this study could result in the development of appropriate interventions and policies that protect the health of residents residing in neighborhoods exposed to coal ash.

\section{Conclusion}

In conclusion, pollutants such as fly ash and metals found in particulate matter may affect the behavior of children and need to be studied further. While the prevalence 
of autism spectrum disorders continues to rise, many questions remain unanswered as to the potential involvement of environmental toxicants such as coal ash in its development. Future research is needed to further elucidate the etiologic role of environmental exposures on neurobehavioral disorders, in general, as well as ASD. It is important to further understand developmental mechanisms of ASD to improve early detection and the development and implementation of appropriate interventions. Among the covariates measured in this study, age, maternal smoking during pregnancy, child school performance, and maternal depression had a relationship with social, thought, and obsessive-compulsive problems. Children in this study, who are underserved and live in areas where environmental justice issues are prevalent, could be more likely to be exposed to various neurotoxic pollutants. It is important to understand exposures linked to behaviors that can be targeted for intervention. These study findings, although limited, are relevant to environmental health. As more data is collected in the ongoing study, the associations detected in these preliminary results between exposure to fly ash and behaviors underlying ASD may become clear. 


\section{REFERENCES}

1. Yang Y, Chen B, Hower J, et al. Discovery and ramifications of incidental Magnéli phase generation and release from industrial coal-burning. Nat. Commun. [electronic article]. 2017;8.

(https://www.ncbi.nlm.nih.gov/pmc/articles/PMC5548795/). (Accessed October 17, 2017)

2. U.S Energy Information Administration. Electricity in the United States - Energy Explained, Your Guide To Understanding Energy - Energy Information Administration. 2016; (https://www.eia.gov/energyexplained/index.cfm?page=electricity_in_the_un ited_states). (Accessed October 17, 2017)

3. Zierold KM, Sears CG. Community views about the health and exposure of children living near a coal ash storage site. J. Community Health. 2015;40(2):357363.

4. US EPA O. Coal Ash Basics. (https://www.epa.gov/coalash/coal-ash-basics\#03). (Accessed October 25, 2016)

5. American Coal Ash Association. 2016 Coal Combustion Product (CCP)

Production and Use Survey Report. 2016;(https://www.acaausa.org/Portals/9/Files/PDFs/2016-Survey-Results.pdf)

6. Sommerville R, Blissett R, Rowson N, et al. Producing a synthetic zeolite from improved fly ash residue. Int. J. Miner. Process. 2013;124:20-25.

7. Blissett RS, Rowson NA. A review of the multi-component utilisation of coal fly ash. Fuel. 2012;97:1-23.

8. Franus W, Wiatros-Motyka MM, Wdowin M. Coal fly ash as a resource for rare earth elements. Environ. Sci. Pollut. Res. Int. 2015;22(12):9464-9474.

9. US EPA O. Frequent Questions about the Coal Ash Disposal Rule. (https://www.epa.gov/coalash/frequent-questions-about-coal-ash-disposal-rule). (Accessed February 24, 2017)

10. Research Triangle Institute. Human and Ecological Risk Assessment of Coal Combustion Wastes. Research Triangle Park, NC, USA: Research Triangle Institute; 2007. 
(http://content.sierraclub.org/coal/sites/content.sierraclub.org.coal/files/elp/docs/us -general_epa-coal-ash-report_2007-8-6.pdf)

11. Zierold KM, Sears CG. Are healthcare providers asking about environmental exposures? A community-based mixed methods study. J. Environ. Public Health. 2015;2015:189526.

12. Sandeep P, Sahu SK, Kothai P, et al. Leaching Behavior of Selected Trace and Toxic Metals in Coal Fly Ash Samples Collected from Two Thermal Power Plants, India. Bull. Environ. Contam. Toxicol. 2016;97(3):425-431.

13. Shim Y-S, Rhee S-W, Lee W-K. Comparison of leaching characteristics of heavy metals from bottom and fly ashes in Korea and Japan. Waste Manag. 2005;25(5):473-480.

14. Lei X, Qi G, Sun Y, et al. Removal of uranium and gross radioactivity from coal bottom ash by $\mathrm{CaCl} 2$ roasting followed by $\mathrm{HNO} 3$ leaching. J. Hazard. Mater. 2014;276:346-352.

15. Mizwar A, Priatmadi BJ, Abdi C, et al. Assessment of polycyclic aromatic hydrocarbons (PAHs) contamination in surface soil of coal stockpile sites in South Kalimantan, Indonesia. Environ. Monit. Assess. 2016;188(3):152.

16. American Coal Ash Association. Coal Combustion Product (CCP) Production \& Use Survey Report. 2016.(https://www.acaausa.org/Portals/9/Files/PDFs/2014ReportFinal.pdf)

17. Liberda EN, Chen LC. An evaluation of the toxicological aspects and potential doses from the inhalation of coal combustion products. J. Air Waste Manag. Assoc. 2013;63(6):671-680.

18. Punshon T, Knox AS, Adriano DC, et al. Flue Gas Desulfurization (FGD) Residue. In: Sajwan KS, Alva AK, Keefer RF, eds. Biogeochemistry of Trace Elements in Coal and Coal Combustion Byproducts. Springer US; 1999 (Accessed February 24, 2017):7-28.(http://link.springer.com/chapter/10.1007/978-1-4615-4155-4_2). (Accessed February 24, 2017)

19. Patra KC, Rautray TR, Tripathy BB, et al. Elemental analysis of coal and coal ASH by PIXE technique. Appl. Radiat. Isot. Data Instrum. Methods Use Agric. Ind. Med. 2012;70(4):612-616.

20. Ahmaruzzaman M. A review on the utilization of fly ash. Prog. Energy Combust. Sci. 36:327-363.

21. Spencer LLS, Drake LD. Hydrogeology of an Alkaline Fly Ash Landfill in Eastern Iowa. Ground Water. 1987;25(5):519-526. 
22. Cheerarot R, Jaturapitakkul C. A study of disposed fly ash from landfill to replace Portland cement. Waste Manag. 2004;24(7):701-709.

23. Ravi I. The surface chemistry of leaching coal fly ash. J. Hazard. Mater. 2002;93(3):321-329.

24. Brown P, Jones T, BéruBé K. The internal microstructure and fibrous mineralogy of fly ash from coal-burning power stations. Environ. Pollut. Barking Essex 1987. 2011;159(12):3324-3333.

25. Krgović R, Trifković J, Milojković-Opsenica D, et al. Leaching of Major and Minor Elements during the Transport and Storage of Coal Ash Obtained in Power Plant. Sci. World J. [electronic article]. 2014;2014. (http://www.ncbi.nlm.nih.gov/pmc/articles/PMC4101221/). (Accessed February 24, 2017)

26. Harkness JS, Sulkin B, Vengosh A. Evidence for Coal Ash Ponds Leaking in the Southeastern United States. Environ. Sci. Technol. 2016;50(12):6583-6592.

27. LG\&E. CCR Rule Compliance Data and Information | LG\&E and KU. (https://lgeku.com/environment/ccr-rule-compliance-data-and-information). (Accessed March 1, 2017)

28. Smith JG, Baker TF, Murphy CA, et al. Spatial and temporal trends in contaminant concentrations in Hexagenia nymphs following a coal ash spill at the Tennessee Valley Authority's Kingston Fossil Plant. Environ. Toxicol. Chem. 2016;35(5):1159-1171.

29. Deonarine A, Bartov G, Johnson TM, et al. Environmental impacts of the Tennessee Valley Authority Kingston coal ash spill. 2. Effect of coal ash on methylmercury in historically contaminated river sediments. Environ. Sci. Technol. 2013;47(4):2100-2108.

30. Ruhl L, Vengosh A, Dwyer GS, et al. Environmental impacts of the coal ash spill in Kingston, Tennessee: an 18-month survey. Environ. Sci. Technol. 2010;44(24):9272-9278.

31. EPA. Hazardous and Solid Waste Management System; Identification and Listing of Special Wastes: Disposal of Coal Combustion Residuals from Electric Utilities; Proposed Rule. Federal Register. 2010;75(118):35128-35264.

32. Erica Peterson. Kentucky Ranks First in Toxic Air Pollution from Power Plants. 893 WFPL. 2012;(http://wfpl.org/kentucky-ranks-first-toxic-air-pollution-powerplants/). (Accessed October 22, 2016)

33. U.S. EPA and United States Department of Energy (U.S. DOE). Coal Combustion Waste Management at Landfills and Surface Impoundments, 1994-2004. 2004; 
34. United States Environmental Protection Agency (U.S. EPA). Database of coal combustion waste surface impoundments (2009). Information collected by EPA from industry responses to Information Collection Request letters issued to the companies on March 9, 2009.

35. LG\&E. Cane Run Generating Station | LG\&E and KU. (https://lge-ku.com/ourcompany/community/neighbor-neighbor/cane-run-generating-station). (Accessed February 27, 2017)

36. Liu G, Peng Z, Yang P, et al. Sulfur in coal and its environmental impact from Yanzhou mining district, China. Chin. J. Geochem. 2001;20(3):273.

37. Bruggers J. Sixty years of coal burning ends at LG\&E plant. Cour.-J. (http://www.courier-journal.com/story/tech/science/environment/2015/07/06/lgeku-energy-dedicates-new-natural-gas-power-plant-cane-run-property/29762011/). (Accessed February 27, 2017)

38. Adnams K, Stellato A, Harris W. Assessment of Dam Safety Coal Combustion Surface Impoundments (Task 3) Draft Report. 2010;

39. US Environmental Protection Agency. Coal Combustion Residues (CCR): Surface Impoundments with High Hazard Potential Rating Fact Sheet. 2009;(https://nepis.epa.gov/Exe/ZyNET.exe/P10048EX.txt?ZyActionD=ZyDocum ent $\&$ Client $=$ EPA $\&$ Index $=2006 \% 20$ Thru $\% 202010 \&$ Docs $=\& Q$ uery $=\&$ Time $=\&$ End Time $=\&$ SearchMethod $=1 \&$ TocRestrict $=$ n $\&$ Toc $=\&$ TocEntry $=\& Q$ Field $=\& Q$ FieldY ear $=\& Q$ FieldMonth $=\& Q$ FieldDay $=\& U$ seQField $=\&$ IntQFieldOp $=0 \&$ ExtQFieldOp $=0 \&$ XmlQuery $=\&$ File $=\mathrm{D} \% 3 \mathrm{~A} \% 5$ CZYFILES $\% 5$ CINDEX $\% 20$ DATA $\% 5$ C06THR U10\%5CTXT\%5C00000009\%5CP10048EX.txt\&User=ANONYMOUS\&Passwor $\mathrm{d}=$ anonymous $\&$ SortMethod $=\mathrm{h} \% 7 \mathrm{C}-$

$\&$ MaximumDocuments $=1 \&$ FuzzyDegree $=0 \&$ ImageQuality $=\mathrm{r} 75 \mathrm{~g} 8 / \mathrm{r} 75 \mathrm{~g} 8 / \mathrm{x} 150 \mathrm{y} 15$ 0g16/i425\&Display $=$ hpfr\&DefSeekPage $=x \&$ SearchBack=ZyActionL\&Back=ZyA ctionS\&BackDesc=Results\%20page\&MaximumPages=1\&ZyEntry=1). (Accessed October 18, 2017)

40. Bruggers J. LG\&E to cap Cane Run coal ash. (http://www.courierjournal.com/story/tech/science/environment/2015/03/05/lge-makes-plans-closecap-louisville-ash-pond-landfill-cane-run-plant/24436013/). (Accessed February $28,2017)$

41. LG\&E. Mill Creek Generating Station | LG\&E and KU. (https://ge-ku.com/ourcompany/community/neighbor-neighbor/mill-creek-generating-station). (Accessed March 1, 2017)

42. Bowers R, Cormier S. Dam Safety Assessment Report of CCW Impoundments LG\&E Mill Creek Station. 2009;(https://archive.epa.gov/epawaste/nonhaz/industrial/special/fossil/web/pdf/mi ll-creek-draft.pdf) 
43. Stant J. IN HARM'S WAY: Lack Of Federal Coal Ash Regulations Endangers Americans And Their Environment. (http://earthjustice.org/sites/default/files/files/report-in-harms-way.pdf)

44. LG\&E. LG\&E to invest more than $\$ 300$ million in additional environmental improvements | LG\&E and KU. (https://lge-ku.com/newsroom/pressreleases/2016/01/11/lge-invest-more-300-million-additional-environmentalimprovements). (Accessed February 28, 2017)

45. Cho K, Cho YJ, Shrivastava DK, et al. Acute Lung Disease After Exposure to Fly Ash. Chest. 1994;106(1):309-311.

46. Valavanidis A, Fiotakis K, Vlachogianni T. Airborne particulate matter and human health: toxicological assessment and importance of size and composition of particles for oxidative damage and carcinogenic mechanisms. J. Environ. Sci. Health Part C Environ. Carcinog. Ecotoxicol. Rev. 2008;26(4):339-362.

47. Anderson JO, Thundiyil JG, Stolbach A. Clearing the Air: A Review of the Effects of Particulate Matter Air Pollution on Human Health. J. Med. Toxicol. 2012;8(2):166-175.

48. Chen LC, Lippmann M. Effects of metals within ambient air particulate matter (PM) on human health. Inhal. Toxicol. 2009;21(1):1-31.

49. Zereini F, Alt F, Messerschmidt J, et al. Concentration and distribution of heavy metals in urban airborne particulate matter in Frankfurt am Main, Germany. Environ. Sci. Technol. 2005;39(9):2983-2989.

50. Pal R, Mahima null, Gupta A, et al. Assessment of heavy metals in suspended particulate matter in Moradabad, India. J. Environ. Biol. 2014;35(2):357-361.

51. Zeneli L, Sekovanić A, Ajvazi M, et al. Alterations in antioxidant defense system of workers chronically exposed to arsenic, cadmium and mercury from coal flying ash. Environ. Geochem. Health. 2016;38(1):65-72.

52. Zeneli L, Daci-Ajvazi M, Daci NM, et al. Environmental Pollution and Relationship Between Total Antioxidant Capacity and Heavy Metals ( $\mathrm{Pb}, \mathrm{Cd}, \mathrm{Zn}$, $\mathrm{Mn}$, and Fe) in Solanum tuberosum L. and Allium cepa L. Hum. Ecol. Risk Assess. Int. J. 2013;19(6):1618-1627.

53. Leonard SS, Harris GK, Shi X. Metal-induced oxidative stress and signal transduction. Free Radic. Biol. Med. 2004;37(12):1921-1942.

54. Agency for Toxic Substance (ATSDR)s and Disease Registry. Toxic Substances Arsenic. (https://www.atsdr.cdc.gov/substances/toxsubstance.asp?toxid=3). (Accessed March 16, 2017) 
55. Wang C-H, Hsiao CK, Chen C-L, et al. A review of the epidemiologic literature on the role of environmental arsenic exposure and cardiovascular diseases. Toxicol. Appl. Pharmacol. 2007;222(3):315-326.

56. Coronado-González JA, Del Razo LM, García-Vargas G, et al. Inorganic arsenic exposure and type 2 diabetes mellitus in Mexico. Environ. Res. 2007;104(3):383389.

57. Silvera SAN, Rohan TE. Trace elements and cancer risk: a review of the epidemiologic evidence. Cancer Causes Control. 2007;18(1):7-27.

58. von Ehrenstein OS, Poddar S, Yuan Y, et al. Children's intellectual function in relation to arsenic exposure. Epidemiol. Camb. Mass. 2007;18(1):44-51.

59. George CM, Brooks WA, Graziano JH, et al. Arsenic exposure is associated with pediatric pneumonia in rural Bangladesh: a case control study. Environ. Health. 2015;14:83.

60. United States Environmental Protection Agency (U.S. EPA). Learn about Lead. (https://www.epa.gov/lead/learn-about-lead). (Accessed March 16, 2017)

61. Gottlieb B, Gollin Evans L. Coal Ash: The toxic threat to our health and environment. A Report From Physicians For Social Responsibility and EarthJustice. (http://www.psr.org/assets/pdfs/coal-ash.pdf)

62. Agency for Toxic Substance and Disease Registry (ATSDR). 2007 CERCLA Priority List of Hazardous Substances. 2007; (https://www.atsdr.cdc.gov/spl/previous/07list.html). (Accessed March 16, 2017)

63. Palmer RF, Blanchard S, Wood R. Proximity to point sources of environmental mercury release as a predictor of autism prevalence. Health Place. 2009;15(1):1824.

64. Tchounwou PB, Yedjou CG, Patlolla AK, et al. Heavy Metals Toxicity and the Environment. EXS. 2012;101:133-164.

65. Tchounwou PB, Ayensu WK, Ninashvili N, et al. Environmental exposure to mercury and its toxicopathologic implications for public health. Environ. Toxicol. 2003;18(3):149-175.

66. Thompson WW, Price C, Goodson B, et al. Early Thimerosal Exposure and Neuropsychological Outcomes at 7 to 10 Years. N. Engl. J. Med. 2007;357(13):1281-1292.

67. Satarug S, Baker JR, Urbenjapol S, et al. A global perspective on cadmium pollution and toxicity in non-occupationally exposed population. Toxicol. Lett. 2003;137(1-2):65-83. 
68. Shelnutt SR, Goad P, Belsito DV. Dermatological toxicity of hexavalent chromium. Crit. Rev. Toxicol. 2007;37(5):375-387.

69. Bilski J, McLean K, Soumaila F, et al. Aluminium in coal fly ash (FA), in plants grown on FA, and in the leachates from FA. Res. J. Chem. Environ. Sci. 2014;2(4):22-26.

70. Exley C. What is the risk of aluminium as a neurotoxin? Expert Rev. Neurother. 2014;14(6):589-591.

71. Agency for Toxic Substance (ATSDR)s and Disease Registry. Aluminum. (https://www.atsdr.cdc.gov/PHS/PHS.asp?id=1076\&tid=34). (Accessed November 1, 2017)

72. Mohamed FEB, Zaky EA, El-Sayed AB, et al. Assessment of Hair Aluminum, Lead, and Mercury in a Sample of Autistic Egyptian Children: Environmental Risk Factors of Heavy Metals in Autism. Behav. Neurol. 2015;2015:545674.

73. Open Chemistry Database, Pubchem. Copper. (https://pubchem.ncbi.nlm.nih.gov/compound/23978). (Accessed November 1, 2017)

74. Open Chemistry Database, Pubchem. Iron. (https://pubchem.ncbi.nlm.nih.gov/compound/23925). (Accessed November 1, 2017)

75. Watts DL. Trace Elements and Neuropsychological Problems as Reflected in Tissue Mineral Analysis (TMA) Patterns. Journal of Orthomolecular Medicine 1990;5(3):159-166.

76. Open Chemistry Database, Pubchem. Manganese. (https://pubchem.ncbi.nlm.nih.gov/compound/23930). (Accessed November 1, 2017)

77. Agency for Toxic Substance (ATSDR)s and Disease Registry (ATSDR). ATSDR ToxFAQs ${ }^{\text {TM: }}$ Nickel.

2005;(https://www.atsdr.cdc.gov/toxfaqs/TF.asp?id=244\&tid=44). (Accessed November 2, 2017)

78. Brandão MHT, Gontijo B, Girundi MA, et al. Ear piercing as a risk factor for contact allergy to nickel. J. Pediatr. (Rio J.). 2010;86(2):149-154.

79. Agency for Toxic Substances and Disease Registry (ATSDR). Public Health Statement: Zinc. (https://www.atsdr.cdc.gov/phs/phs.asp?id=300\&tid=54). (Accessed November 2, 2017) 
80. The National Institute for Occupational Safety and Health (NIOSH). Titanium. (https://www.cdc.gov/niosh/nioshtic-2/10003067.html). (Accessed November 2, 2017)

81. Wright $\mathrm{C}$, Iyer $\mathrm{AKV}$, Wang $\mathrm{L}$, et al. Effects of titanium dioxide nanoparticles on human keratinocytes. Drug Chem. Toxicol. 2017;40(1):90-100.

82. Skocaj M, Filipic M, Petkovic J, et al. Titanium dioxide in our everyday life; is it safe? Radiol. Oncol. 2011;45(4):227-247.

83. Osmanlioglu AE. Utilization of coal fly ash in solidification of liquid radioactive waste from research reactor. Waste Manag. Res. J. Int. Solid Wastes Public Clean. Assoc. ISWA. 2014;32(5):366-370.

84. Lauer NE, Hower JC, Hsu-Kim H, et al. Naturally Occurring Radioactive Materials in Coals and Coal Combustion Residuals in the United States. Environ. Sci. Technol. 2015;49(18):11227-11233.

85. Roper AR, Stabin MG, Delapp RC, et al. Analysis of naturally-occurring radionuclides in coal combustion fly ash, gypsum, and scrubber residue samples. Health Phys. 2013;104(3):264-269.

86. Lockwood A, Evans L. How Breathing Coal Ash is Hazardous to your Health. Earth Justice [electronic article]. 2014;(http://earthjustice.org/sites/default/files/files/Ash_In_Lungs_1.pdf)

87. Mahur AK, Kumar R, Mishra M, et al. An investigation of radon exhalation rate and estimation of radiation doses in coal and fly ash samples. Appl. Radiat. Isot. Data Instrum. Methods Use Agric. Ind. Med. 2008;66(3):401-406.

88. Papastefanou C. Escaping radioactivity from coal-fired power plants (CPPs) due to coal burning and the associated hazards: a review. J. Environ. Radioact. 2010;101(3):191-200.

89. Agency for Toxic Substances and Disease Registry (ATSDR). Toxic Substances Polycyclic Aromatic Hydrocarbons (PAHs). (https://www.atsdr.cdc.gov/substances/toxsubstance.asp?toxid=25). (Accessed March 16, 2017)

90. Abdel-Shafy HI, Mansour MSM. A review on polycyclic aromatic hydrocarbons: Source, environmental impact, effect on human health and remediation. Egypt. J. Pet. 2016;25(1):107-123.

91. Liu G, Niu Z, Van Niekerk D, et al. Polycyclic aromatic hydrocarbons (PAHs) from coal combustion: emissions, analysis, and toxicology. Rev. Environ. Contam. Toxicol. 2008;192:1-28. 
92. Veglia F, Matullo G, Vineis P. Bulky DNA adducts and risk of cancer: a metaanalysis. Cancer Epidemiol. Biomark. Prev. Publ. Am. Assoc. Cancer Res. Cosponsored Am. Soc. Prev. Oncol. 2003;12(2):157-160.

93. Wang J, Chen S, Tian M, et al. Inhalation Cancer Risk Associated with Exposure to Complex Polycyclic Aromatic Hydrocarbon Mixtures in an Electronic Waste and Urban Area in South China. Environ. Sci. Technol. 2012;46(17):9745-9752.

94. Perera F, Li TY, Lin C, et al. Effects of prenatal polycyclic aromatic hydrocarbon exposure and environmental tobacco smoke on child IQ in a Chinese cohort. Environ. Res. 2012;114:40-46.

95. Bosetti C, Boffetta P, La Vecchia C. Occupational exposures to polycyclic aromatic hydrocarbons, and respiratory and urinary tract cancers: a quantitative review to 2005. Ann. Oncol. Off. J. Eur. Soc. Med. Oncol. 2007;18(3):431-446.

96. Rohr AC, Campleman SL, Long CM, et al. Potential Occupational Exposures and Health Risks Associated with Biomass-Based Power Generation. Int. J. Environ. Res. Public. Health. 2015;12(7):8542-8605.

97. Salvi S. Health effects of ambient air pollution in children. Paediatr. Respir. Rev. 2007;8(4):275-280.

98. Bateson TF, Schwartz J. Children's response to air pollutants. J. Toxicol. Environ. Health A. 2008;71(3):238-243.

99. Liang F, Zhang G, Tan M, et al. Lead in Children's Blood Is Mainly Caused by Coal-Fired Ash after Phasing out of Leaded Gasoline in Shanghai. Environ. Sci. Technol. 2010;44(12):4760-4765.

100. Tang D, Li T, Liu JJ, et al. Effects of Prenatal Exposure to Coal-Burning Pollutants on Children's Development in China. Environ. Health Perspect. 2008;116(5):674679.

101. Nastos PT, Paliatsos AG, Anthracopoulos MB, et al. Outdoor particulate matter and childhood asthma admissions in Athens, Greece: a time-series study. Environ. Health. 2010;9(1):45.

102. Gehring U, Gruzieva O, Agius RM, et al. Air Pollution Exposure and Lung Function in Children: The ESCAPE Project. Environ. Health Perspect. 2013;121(11-12):1357-1364.

103. Raz R, Roberts AL, Lyall K, et al. Autism spectrum disorder and particulate matter air pollution before, during, and after pregnancy: a nested case-control analysis within the Nurses' Health Study II Cohort. Environ. Health Perspect. 2015;123(3):264-270. 
104. Wright RO, Amarasiriwardena C, Woolf AD, et al. Neuropsychological correlates of hair arsenic, manganese, and cadmium levels in school-age children residing near a hazardous waste site. NeuroToxicology. 2006;27(2):210-216.

105. Liu J, Lewis G. Environmental Toxicity and Poor Cognitive Outcomes in Children and Adults. J. Environ. Health. 2014;76(6):130-138.

106. Liu L, Zhang D, Rodzinka-Pasko JK, et al. Environmental risk factors for autism spectrum disorders. Nervenarzt. 2016;

107. Rossignol DA, Genuis SJ, Frye RE. Environmental toxicants and autism spectrum disorders: a systematic review. Transl. Psychiatry. 2014;4(2):e360.

108. Grandjean P, Landrigan PJ. Developmental neurotoxicity of industrial chemicals. Lancet Lond. Engl. 2006;368(9553):2167-2178.

109. Dickerson AS, Rahbar MH, Bakian AV, et al. Autism spectrum disorder prevalence and associations with air concentrations of lead, mercury, and arsenic. Environ. Monit. Assess. 2016;188(7):407.

110. Lai M-C, Lombardo MV, Baron-Cohen S. Autism. Lancet Lond. Engl. 2014;383(9920):896-910.

111. Autism Speaks. What Is Autism? || Autism Speaks. (https://www.autismspeaks.org/what-autism). (Accessed September 17, 2016)

112. Sansosti JM, Sansosti FJ. Inclusion for Students with High-Functioning Autism Spectrum Disorders: Definitions and Decision Making. Psychol. Sch. 2012;49(10):917-931.

113. White SW, Keonig K, Scahill L. Social Skills Development in Children with Autism Spectrum Disorders: A Review of the Intervention Research. J. Autism Dev. Disord. 2007;37(10):1858-1868.

114. Bellini S, Peters JK, Benner L, et al. A Meta-Analysis of School-Based Social Skills Interventions for Children With Autism Spectrum Disorders. Remedial Spec. Educ. 2007;28(3):153-162.

115. Holloway J, Healy O, Dwyer M, et al. Social Skills Deficits in Children with Autism Spectrum Disorders: Evidence Based Interventions. In: Patel VB, Preedy VR, Martin CR, eds. Comprehensive Guide to Autism. Springer New York; 2014 (Accessed August 16, 2017):11331158.(http://link.springer.com/referenceworkentry/10.1007/978-1-4614-47887_62). (Accessed August 16, 2017)

116. Leekam SR, Prior MR, Uljarevic M. Restricted and repetitive behaviors in autism spectrum disorders: a review of research in the last decade. Psychol. Bull. 2011;137(4):562-593. 
117. Kanner L. Autistic disturbances of affective contact. Acta Paedopsychiatr. 1968;35(4):100-136.

118. CDC. Autism Spectrum Disorder (ASD) | Screening and Diagnosis. CDC - Facts Autism Spectr. Disord. - NCBDDD.

(http://www.cdc.gov/ncbddd/autism/facts.html). (Accessed September 17, 2016)

119. Rutter M. Diagnosis and definition of childhood autism. J. Autism Child. Schizophr. 1978;8(2):139-161.

120. Lai M-C, Lombardo MV, Chakrabarti B, et al. Subgrouping the autism "spectrum": reflections on DSM-5. PLoS Biol. 2013;11(4):e1001544.

121. Harstad EB, Fogler J, Sideridis G, et al. Comparing Diagnostic Outcomes of Autism Spectrum Disorder Using DSM-IV-TR and DSM-5 Criteria. J. Autism Dev. Disord. 2015;45(5):1437-1450.

122. Mazefsky CA, Anderson R, Conner CM, et al. Child Behavior Checklist Scores for School-Aged Children with Autism: Preliminary Evidence of Patterns Suggesting the Need for Referral. J. Psychopathol. Behav. Assess. 2011;33(1):31-37.

123. Narzisi A, Calderoni S, Maestro S, et al. Child Behavior Check List $11 / 2-5$ as a Tool to Identify Toddlers with Autism Spectrum Disorders: A Case-Control Study. Res. Dev. Disabil. Multidiscip. J. 2013;34(4):1179-1189.

124. Ooi YP, Rescorla L, Ang RP, et al. Identification of autism spectrum disorders using the Child Behavior Checklist in Singapore. J. Autism Dev. Disord. 2011;41(9):1147-1156.

125. Saemundsen E, Magnússon P, Georgsdóttir I, et al. Prevalence of autism spectrum disorders in an Icelandic birth cohort. BMJ Open. 2013;3(6):e002748.

126. Center for Disease Control and Prevention (CDC). Facts About ASDs. Facts Autism Spectr. Disord. - NCBDDD. (http://www.cdc.gov/ncbddd/autism/facts.html). (Accessed October 2, 2017)

127. Zablotsky B, Black LI, Maenner MJ, et al. Estimated Prevalence of Autism and Other Developmental Disabilities Following Questionnaire Changes in the 2014 National Health Interview Survey. Natl. Health Stat. Rep. 2015;(87):1-20.

128. Mattila M-L, Kielinen M, Linna S-L, et al. Autism spectrum disorders according to DSM-IV-TR and comparison with DSM-5 draft criteria: an epidemiological study. J. Am. Acad. Child Adolesc. Psychiatry. 2011;50(6):583-592.e11.

129. Kim YS, Leventhal BL, Koh Y-J, et al. Prevalence of autism spectrum disorders in a total population sample. Am. J. Psychiatry. 2011;168(9):904-912. 
130. Christensen DL, Baio J, Van Naarden Braun K, et al. Prevalence and Characteristics of Autism Spectrum Disorder Among Children Aged 8 Years-Autism and Developmental Disabilities Monitoring Network, 11 Sites, United States, 2012. Morb. Mortal. Wkly. Rep. Surveill. Summ. Wash. DC 2002. 2016;65(3):1-23.

131. Idring S, Rai D, Dal H, et al. Autism Spectrum Disorders in the Stockholm Youth Cohort: Design, Prevalence and Validity. PLOS ONE. 2012;7(7):e41280.

132. Bailey A, Le Couteur A, Gottesman I, et al. Autism as a strongly genetic disorder: evidence from a British twin study. Psychol. Med. 1995;25(1):63-77.

133. Blood-Siegfried J, Rende EK. The Long-Term Effects of Perinatal Nicotine Exposure on Neurologic Development. J. Midwifery Womens Health. 2010;55(2):143-152.

134. Brander G, Rydell M, Kuja-Halkola R, et al. Association of Perinatal Risk Factors With Obsessive-Compulsive Disorder: A Population-Based Birth Cohort, Sibling Control Study. JAMA Psychiatry. 2016;73(11):1135-1144.

135. Hofhuis W, Jongste JC de, Merkus PJFM. Adverse health effects of prenatal and postnatal tobacco smoke exposure on children. Arch. Dis. Child. 2003;88(12):1086-1090.

136. Ronald A, Hoekstra RA. Autism spectrum disorders and autistic traits: a decade of new twin studies. Am. J. Med. Genet. Part B Neuropsychiatr. Genet. Off. Publ. Int. Soc. Psychiatr. Genet. 2011;156B(3):255-274.

137. Durkin MS, Maenner MJ, Newschaffer CJ, et al. Advanced parental age and the risk of autism spectrum disorder. Am. J. Epidemiol. 2008;168(11):1268-1276.

138. Gardener H, Spiegelman D, Buka SL. Prenatal risk factors for autism: comprehensive meta-analysis. Br. J. Psychiatry J. Ment. Sci. 2009;195(1):7-14.

139. Surén $\mathrm{P}$, Roth $\mathrm{C}$, Bresnahan $\mathrm{M}$, et al. Association between maternal use of folic acid supplements and risk of autism spectrum disorders in children. JAMA. 2013;309(6):570-577.

140. Fujiwara T, Morisaki N, Honda Y, et al. Chemicals, Nutrition, and Autism Spectrum Disorder: A Mini-Review. Front. Neurosci. [electronic article]. 2016;10. (http://www.ncbi.nlm.nih.gov/pmc/articles/PMC4837386/). (Accessed April 27, 2017)

141. Durkin MS, Maenner MJ, Meaney FJ, et al. Socioeconomic inequality in the prevalence of autism spectrum disorder: evidence from a U.S. cross-sectional study. PloS One. 2010;5(7):e11551. 
142. Reiersen AM, Handen B. Commentary on 'Selective serotonin reuptake inhibitors (SSRIs) for autism spectrum disorders (ASD).' Evid.-Based Child Health Cochrane Rev. J. 2011;6(4):1082-1085.

143. Williams K, Brignell A, Randall M, et al. Selective serotonin reuptake inhibitors (SSRIs) for autism spectrum disorders (ASD). Cochrane Database Syst. Rev. 2013;(8):CD004677.

144. Mohai P, Kweon B-S, Lee S, et al. Air pollution around schools is linked to poorer student health and academic performance. Health Aff. Proj. Hope. 2011;30(5):852-862.

145. Margolis AE, Herbstman JB, Davis KS, et al. Longitudinal effects of prenatal exposure to air pollutants on self-regulatory capacities and social competence. $J$. Child Psychol. Psychiatry. 2016;57(7):851-860.

146. Volk HE, Lurmann F, Penfold B, et al. Traffic-Related Air Pollution, Particulate Matter, and Autism. JAMA Psychiatry. 2013;70(1):71.

147. BLAUROCK-BUSCH E, AMIN OR, RABAH T. Heavy Metals and Trace Elements in Hair and Urine of a Sample of Arab Children with Autistic Spectrum Disorder. Maedica. 2011;6(4):247-257.

148. Geier DA, Kern JK, Garver CR, et al. Biomarkers of environmental toxicity and susceptibility in autism. J. Neurol. Sci. 2009;280(1-2):101-108.

149. Haynes EN, Chen A, Ryan P, et al. Exposure to airborne metals and particulate matter and risk for youth adjudicated for criminal activity. Environ. Res. [electronic article]. 2011;111(8). (https://www.ncbi.nlm.nih.gov/pmc/articles/PMC3883046/). (Accessed November 2, 2017)

150. Byers RK, Lord EE. Late effects of lead poisoning on mental development. Am Journal of Diseases of Children. 1943;66(5):66471-66494.

151. Evens A, Hryhorczuk D, Lanphear BP, et al. The impact of low-level lead toxicity on school performance among children in the Chicago Public Schools: a population-based retrospective cohort study. Environ. Health. 2015;14:21.

152. Thatcher RW, Lester ML, McAlaster R, et al. Effects of low levels of cadmium and lead on cognitive functioning in children. Arch. Environ. Health. 1982;37(3):159-166.

153. Wasserman GA, Liu X, Parvez F, et al. Water Arsenic Exposure and Children's Intellectual Function in Araihazar, Bangladesh. Environ. Health Perspect. 2004;112(13):1329-1333. 
154. Gautam P, Bhatia MS. Obsessive Compulsive Disorder with Intellectual Disability: A Diagnostic and Therapeutic Challenge. J. Clin. Diagn. Res. JCDR. 2015;9(9):VD01-VD02.

155. Bao Q-S, Lu C-Y, Song H, et al. Behavioural development of school-aged children who live around a multi-metal sulphide mine in Guangdong province, China: a cross-sectional study. BMC Public Health. 2009;9:217.

156. Alabdali A, Al-Ayadhi L, El-Ansary A. A key role for an impaired detoxification mechanism in the etiology and severity of autism spectrum disorders. Behav. Brain Funct. BBF. 2014;10:14.

157. Fido A, Al-Saad S. Toxic trace elements in the hair of children with autism. Autism Int. J. Res. Pract. 2005;9(3):290-298.

158. Adams JB, Romdalvik J, Ramanujam VMS, et al. Mercury, lead, and zinc in baby teeth of children with autism versus controls. J. Toxicol. Environ. Health A. 2007;70(12):1046-1051.

159. Holmes AS, Blaxill MF, Haley BE. Reduced levels of mercury in first baby haircuts of autistic children. Int. J. Toxicol. 2003;22(4):277-285.

160. Adams JB, Holloway CE, George F, et al. Analyses of toxic metals and essential minerals in the hair of Arizona children with autism and associated conditions, and their mothers. Biol. Trace Elem. Res. 2006;110(3):193-209.

161. Adams JB, Audhya T, McDonough-Means S, et al. Toxicological status of children with autism vs. neurotypical children and the association with autism severity. Biol. Trace Elem. Res. 2013;151(2):171-180.

162. Windham GC, Zhang L, Gunier R, et al. Autism spectrum disorders in relation to distribution of hazardous air pollutants in the san francisco bay area. Environ. Health Perspect. 2006;114(9):1438-1444.

163. Currie J, Neidell M, Schmieder JF. Air pollution and infant health: Lessons from New Jersey. J. Health Econ. 2009;28(3):688-703.

164. Hansen CA, Barnett AG, Pritchard G. The effect of ambient air pollution during early pregnancy on fetal ultrasonic measurements during mid-pregnancy. Environ. Health Perspect. 2008;116(3):362-369.

165. Shelton JF, Geraghty EM, Tancredi DJ, et al. Neurodevelopmental disorders and prenatal residential proximity to agricultural pesticides: the CHARGE study. Environ. Health Perspect. 2014;122(10):1103-1109.

166. Volk HE, Hertz-Picciotto I, Delwiche L, et al. Residential proximity to freeways and autism in the CHARGE study. Environ. Health Perspect. 2011;119(6):873877. 
167. Costa LG, Giordano G, Guizzetti M, et al. Neurotoxicity of pesticides: a brief review. Front. Biosci. J. Virtual Libr. 2008;13:1240-1249.

168. Roberts EM, English PB, Grether JK, et al. Maternal residence near agricultural pesticide applications and autism spectrum disorders among children in the California Central Valley. Environ. Health Perspect. 2007;115(10):1482-1489.

169. Kardas F, Bayram AK, Demirci E, et al. Increased Serum Phthalates (MEHP, DEHP) and Bisphenol A Concentrations in Children With Autism Spectrum Disorder: The Role of Endocrine Disruptors in Autism Etiopathogenesis. J. Child Neurol. 2016;31(5):629-635.

170. Miodovnik A, Engel SM, Zhu C, et al. Endocrine Disruptors and Childhood Social Impairment. Neurotoxicology. 2011;32(2):261-267.

171. Braun JM, Kalkbrenner AE, Just AC, et al. Gestational Exposure to EndocrineDisrupting Chemicals and Reciprocal Social, Repetitive, and Stereotypic Behaviors in 4- and 5-Year-Old Children: The HOME Study. Environ. Health Perspect. 2014;122(5):513-520.

172. Goines PE, Ashwood P. Cytokine dysregulation in autism spectrum disorders (ASD): possible role of the environment. Neurotoxicol. Teratol. 2013;36:67-81.

173. Allpress JL, Curry RJ, Hanchette CL, et al. A GIS-based method for household recruitment in a prospective pesticide exposure study. Int. J. Health Geogr. 2008;7:18.

174. Flynn A, Tremblay PF, Rehm J, et al. A modified random walk door-to-door recruitment strategy for collecting social and biological data relating to mental health, substance use, addiction, and violence problems in a Canadian community. Int. J. Alcohol Drug Res. 2013;2(2):7-16.

175. Elemental Analysis Inc. Proton Induced X-ray Emission (PIXE). In. Lexington, KY; 2016;

176. Surface Science Western. Scanning Electron Microscopy coupled with Energy Dispersive X-ray (SEM/EDX) Spectroscopy. In. London, Ontario: The Univeristy of Western Ontario. 2016;

177. He K. Trace Elements in Nails as Biomarkers in Clinical Research. Eur. J. Clin. Invest. 2011;41(1):98-102.

178. Slotnick MJ, Nriagu JO. Validity of human nails as a biomarker of arsenic and selenium exposure: A review. Environ. Res. 2006;102(1):125-139.

179. Parizanganeh A, Zamani A, Bijnavand V, et al. Human nail usage as a Bioindicator in contamination monitoring of heavy metals in Dizajabaad, Zanjan province-Iran. J. Environ. Health Sci. Eng. [electronic article]. 2014;12. 
(http://www.ncbi.nlm.nih.gov/pmc/articles/PMC4271415/). (Accessed January 22, 2017)

180. Yaemsiri S, Hou N, Slining MM, et al. Growth rate of human fingernails and toenails in healthy American young adults. J. Eur. Acad. Dermatol. Venereol. JEADV. 2010;24(4):420-423.

181. Storch EA, Murphy TK, Bagner DM, et al. Reliability and validity of the Child Behavior Checklist Obsessive-Compulsive Scale. J. Anxiety Disord. 2006;20(4):473-485.

182. Healthy Housing Solutions. Pediatric Environmental Home Assessment. (http://healthyhousingsolutions.com/wpcontent/uploads/2014/12/HHAPP_Ex_2_PEHA_Survey-Nov2013.pdf)

183. Bursac Z, Gauss CH, Williams DK, et al. Purposeful selection of variables in logistic regression. Source Code Biol. Med. 2008;3:17.

184. Cave M, Appana S, Patel M, et al. Polychlorinated biphenyls, lead, and mercury are associated with liver disease in American adults: NHANES 2003-2004. Environ. Health Perspect. 2010;118(12):1735-1742.

185. Boat TF, Wu JT, Disorders C to E the SSIDP for C with M, et al. Prevalence of Autism Spectrum Disorder. National Academies Press (US); 2015 (Accessed November 4, 2016).(https://www.ncbi.nlm.nih.gov/books/NBK332896/). (Accessed November 4, 2016)

186. Kakhi S, Soomro GM. Obsessive compulsive disorder in children and adolescents: duration of maintenance drug treatment. BMJ Clin. Evid. [electronic article]. 2015;2015. (https://www.ncbi.nlm.nih.gov/pmc/articles/PMC4456909/). (Accessed June 11, 2018)

187. Kalra SK, Swedo SE. Children with obsessive-compulsive disorder: are they just "little adults"? J. Clin. Invest. 2009;119(4):737-746.

188. Gritti A, Bravaccio C, Signoriello S, et al. Epidemiological study on behavioural and emotional problems in developmental age: prevalence in a sample of Italian children, based on parent and teacher reports. Ital. J. Pediatr. 2014;40:19.

189. Wang C, Seames WS, Gadgil M, et al. Comparison of Coal Ash Particle Size Distributions from Berner and Dekati Low Pressure Impactors. Aerosol Sci. Technol. 2007;41(12):1049-1062.

190. Kara İ. The influence of different skin types on GSR sampling by tape lifting for SEM analysis. Microsc. Res. Tech. 2017;80(12):1310-1314. 
191. RJ Lee Group. Surface Dust Study, RJ Lee Group Project Number: TLH104154, July 2011. (http://archives.wfpl.org/wp-content/uploads/2011/07/TLH104154Nuisance-dust-report-7-8-11-FINAL.pdf)

192. Hoek G, Pattenden S, Willers S, et al. PM10, and children's respiratory symptoms and lung function in the PATY study. Eur. Respir. J. 2012;40(3):538-547.

193. Talbott EO, Arena VC, Rager JR, et al. Fine particulate matter and the risk of autism spectrum disorder. Environ. Res. 2015;140:414-420.

194. Xing Y-F, Xu Y-H, Shi M-H, et al. The impact of PM2.5 on the human respiratory system. J. Thorac. Dis. 2016;8(1):E69-E74.

195. Schulze F, Gao X, Virzonis D, et al. Air Quality Effects on Human Health and Approaches for Its Assessment through Microfluidic Chips. Genes [electronic article]. 2017;8(10). (https://www.ncbi.nlm.nih.gov/pmc/articles/PMC5664094/). (Accessed June 11, 2018)

196. Madsen E, Gitlin JD. Copper and iron disorders of the brain. Annu. Rev. Neurosci. 2007;30:317-337.

197. Jaiser SR, Winston GP. Copper deficiency myelopathy. J. Neurol. 2010;257(6):869-881.

198. Zhou G, Ji X, Cui N, et al. Association between Serum Copper Status and Working Memory in Schoolchildren. Nutrients. 2015;7(9):7185-7196.

199. Priya MDL, Geetha A. Level of Trace Elements (Copper, Zinc, Magnesium and Selenium) and Toxic Elements (Lead and Mercury) in the Hair and Nail of Children with Autism. Biol. Trace Elem. Res. 2011;142(2):148-158.

200. El-Baz F, Mowafy ME, Lotfy A. Study of serum copper and ceruloplasmin levels in Egyptian autistic children. Egypt. J. Med. Hum. Genet. 2018;19(2):113-116.

201. Agency for Toxic Substances \& Disease Registry. Public Health Statement for Coppr.

2004;(https://www.atsdr.cdc.gov/phs/phs.asp?id=204\&tid=37\#bookmark05)

202. Sanders AP, Henn BC, Wright RO. Perinatal and Childhood Exposure to Cadmium, Manganese, and Metal Mixtures and Effects on Cognition and Behavior: A Review of Recent Literature. Curr. Environ. Health Rep. 2015;2(3):284-294.

203. Zhuang P, Lu H, Li Z, et al. Multiple Exposure and Effects Assessment of Heavy Metals in the Population near Mining Area in South China. PLOS ONE. 2014;9(4):e94484. 
204. Kordas K, Queirolo EI, Ettinger AS, et al. Prevalence and predictors of exposure to multiple metals in preschool children from Montevideo, Uruguay. Sci. Total Environ. 2010;408(20):4488-4494.

205. Henn BC, Coull BA, Wright RO. Chemical Mixtures and Children's Health. Curr. Opin. Pediatr. 2014;26(2):223-229.

206. Moon S-S. Additive effect of heavy metals on metabolic syndrome in the Korean population: the Korea National Health and Nutrition Examination Survey (KNHANES) 2009-2010. Endocrine. 2014;46(2):263-271.

207. Sung JH, Oh I, Kim A, et al. Environmental and Body Concentrations of Heavy Metals at Sites Near and Distant from Industrial Complexes in Ulsan, Korea. $J$. Korean Med. Sci. [electronic article]. 2017;33(5). (https://www.ncbi.nlm.nih.gov/pmc/articles/PMC5773847/). (Accessed May 6, 2018)

208. Zota AR, Schaider LA, Ettinger AS, et al. Metal sources and exposures in the homes of young children living near a mining-impacted Superfund site. J. Expo. Sci. Environ. Epidemiol. 2011;21(5):495-505.

209. Ghorani-Azam A, Riahi-Zanjani B, Balali-Mood M. Effects of air pollution on human health and practical measures for prevention in Iran. J. Res. Med. Sci. Off. J. Isfahan Univ. Med. Sci. [electronic article]. 2016;21. (https://www.ncbi.nlm.nih.gov/pmc/articles/PMC5122104/). (Accessed May 7, 2018)

210. Linder MC, Zerounian NR, Moriya M, et al. Iron and copper homeostasis and intestinal absorption using the Caco2 cell model. Biometals. 2003;16(1):145-160.

211. Jaishankar M, Tseten T, Anbalagan N, et al. Toxicity, mechanism and health effects of some heavy metals. Interdiscip. Toxicol. 2014;7(2):60-72.

212. Ferguson A, Penney R, Solo-Gabriele H. A Review of the Field on Children's Exposure to Environmental Contaminants: A Risk Assessment Approach. Int. J. Environ. Res. Public. Health [electronic article]. 2017;14(3). (https://www.ncbi.nlm.nih.gov/pmc/articles/PMC5369101/). (Accessed June 9, 2018)

213. Howlin P, Magiati I. Autism spectrum disorder: outcomes in adulthood. Curr. Opin. Psychiatry. 2017;30(2):69-76.

214. Montes G, Halterman JS. Characteristics of school-age children with autism. $J$. Dev. Behav. Pediatr. JDBP. 2006;27(5):379-385.

215. Miller LE, Burke JD, Troyb E, et al. Preschool Predictors of School-Age Academic Achievement in Autism Spectrum Disorder. Clin. Neuropsychol. 2017;31(2):382-403. 
216. Fitch A, Fein DA, Eigsti I-M. Detail and gestalt focus in individuals with optimal outcomes from Autism Spectrum Disorders. J. Autism Dev. Disord. 2015;45(6):1887-1896.

217. Tran PL, Lehti V, Lampi KM, et al. Smoking during pregnancy and risk of Autism Spectrum Disorder in a Finnish National Birth Cohort. Paediatr. Perinat. Epidemiol. 2013;27(3):266-274.

218. Langley K, Rice F, van den Bree MBM, et al. Maternal smoking during pregnancy as an environmental risk factor for attention deficit hyperactivity disorder behaviour. A review. Minerva Pediatr. 2005;57(6):359-371.

219. Nigg JT, Breslau N. Prenatal smoking exposure, low birth weight, and disruptive behavior disorders. J. Am. Acad. Child Adolesc. Psychiatry. 2007;46(3):362-369.

220. Cornelius MD, Day NL. Developmental consequences of prenatal tobacco exposure. Curr. Opin. Neurol. 2009;22(2):121-125.

221. Canadian Paediatric Society. Maternal depression and child development. Paediatr. Child Health. 2004;9(8):575-583.

222. Cummings EM, Davies PT. Maternal depression and child development. J. Child Psychol. Psychiatry. 1994;35(1):73-112.

223. England MJ, Sim LJ. Associations Between Depression in Parents and Parenting, Child Health, and Child Psychological Functioning. National Academies Press (US); 2009 (Accessed May 2, 2018).(https://www.ncbi.nlm.nih.gov/books/NBK215128/). (Accessed May 2, 2018)

224. National Environmental Educatiion Foundation. Pediatric Environmental History. $N E E F$. (https://www.neefusa.org/resource/pediatric-environmental-history). (Accessed November 4, 2016) 
APPENDIX

Table 35. Adjusted Odds Ratio of Aluminum Exposure, Child Level Covariates, and Outcomes

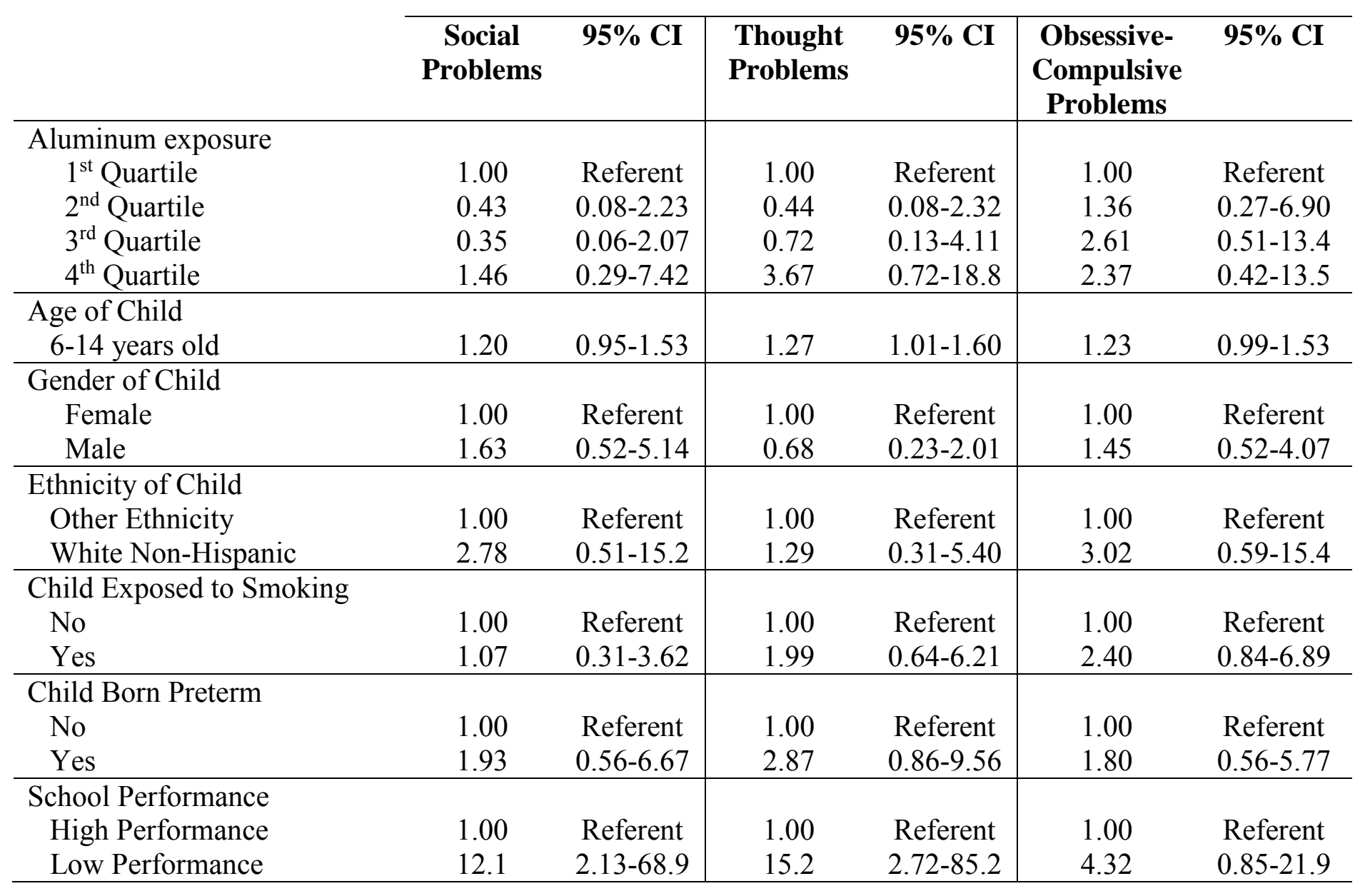


Table 36. Adjusted Odds Ratio of Aluminum Exposure, Mother Level Covariates, and Outcomes

\begin{tabular}{|c|c|c|c|c|c|c|}
\hline & $\begin{array}{c}\text { Social } \\
\text { Problems }\end{array}$ & $95 \%$ CI & $\begin{array}{l}\text { Thought } \\
\text { Problems }\end{array}$ & $95 \% \mathrm{CI}$ & $\begin{array}{c}\text { Obsessive } \\
\text { Compulsive } \\
\text { Problems } \\
\end{array}$ & $95 \% \mathrm{CI}$ \\
\hline $\begin{array}{l}\text { Aluminum exposure } \\
1^{\text {st }} \text { Quartile } \\
2^{\text {nd }} \text { Quartile } \\
3^{\text {rd }} \text { Quartile } \\
4^{\text {th }} \text { Quartile }\end{array}$ & $\begin{array}{l}1.00 \\
0.50 \\
0.34 \\
0.42\end{array}$ & $\begin{array}{l}\text { Referent } \\
0.10-2.60 \\
0.05-2.52 \\
0.07-2.60\end{array}$ & $\begin{array}{l}1.00 \\
1.36 \\
0.79 \\
2.36\end{array}$ & $\begin{array}{l}\text { Referent } \\
0.21-9.00 \\
0.09-7.28 \\
0.36-15.7\end{array}$ & $\begin{array}{l}1.00 \\
2.86 \\
4.82 \\
1.18\end{array}$ & $\begin{array}{l}\text { Referent } \\
0.45-18.2 \\
0.69-33.7 \\
0.15-9.18\end{array}$ \\
\hline $\begin{array}{l}\text { Age Mother Had Child } \\
16-34 \text { years } \\
\text { 35-50 years }\end{array}$ & $\begin{array}{l}1.00 \\
0.59 \\
\end{array}$ & $\begin{array}{c}\text { Referent } \\
0.11-3.19 \\
\end{array}$ & $\begin{array}{l}1.00 \\
1.10 \\
\end{array}$ & $\begin{array}{c}\text { Referent } \\
0.23-5.18 \\
\end{array}$ & $\begin{array}{l}1.00 \\
0.98 \\
\end{array}$ & $\begin{array}{c}\text { Referent } \\
0.26-3.69\end{array}$ \\
\hline $\begin{array}{l}\text { Smoked During Pregnancy } \\
\text { No } \\
\text { Yes }\end{array}$ & $\begin{array}{l}1.00 \\
2.45\end{array}$ & $\begin{array}{c}\text { Referent } \\
0.47-12.6\end{array}$ & $\begin{array}{l}1.00 \\
1.89 \\
\end{array}$ & $\begin{array}{c}\text { Referent } \\
0.37-9.61\end{array}$ & $\begin{array}{l}1.00 \\
3.49 \\
\end{array}$ & $\begin{array}{c}\text { Referent } \\
0.74-16.5\end{array}$ \\
\hline $\begin{array}{l}\text { Marital Status } \\
\text { Not married } \\
\text { Married } \\
\end{array}$ & $\begin{array}{l}1.00 \\
0.94\end{array}$ & $\begin{array}{c}\text { Referent } \\
0.19-4.78\end{array}$ & $\begin{array}{l}1.00 \\
1.20 \\
\end{array}$ & $\begin{array}{c}\text { Referent } \\
0.22-6.54\end{array}$ & $\begin{array}{l}1.00 \\
1.22 \\
\end{array}$ & $\begin{array}{c}\text { Referent } \\
0.26-5.66\end{array}$ \\
\hline $\begin{array}{l}\text { Mom depression } \\
\text { No } \\
\text { Yes }\end{array}$ & $\begin{array}{l}1.00 \\
0.68\end{array}$ & $\begin{array}{c}\text { Referent } \\
0.10-4.53\end{array}$ & $\begin{array}{l}1.00 \\
0.98\end{array}$ & $\begin{array}{c}\text { Referent } \\
0.17-5.82\end{array}$ & $\begin{array}{l}1.00 \\
1.28\end{array}$ & $\begin{array}{c}\text { Referent } \\
0.30-5.56\end{array}$ \\
\hline $\begin{array}{l}\text { Education Status } \\
\text { Less than college degree } \\
\text { College degree or higher }\end{array}$ & $\begin{array}{c}1.00 \\
1.32 \\
\end{array}$ & $\begin{array}{c}\text { Referent } \\
0.35-4.98\end{array}$ & $\begin{array}{l}1.00 \\
0.73\end{array}$ & $\begin{array}{c}\text { Referent } \\
0.20-2.65\end{array}$ & $\begin{array}{l}1.00 \\
0.61\end{array}$ & $\begin{array}{c}\text { Referent } \\
0.19-1.94\end{array}$ \\
\hline
\end{tabular}


Table 37. Adjusted Odds Ratio of Aluminum Exposure, Child and Mother Level Covariates, and Outcomes

\begin{tabular}{|c|c|c|c|c|c|c|}
\hline & $\begin{array}{c}\text { Social } \\
\text { Problems }\end{array}$ & $95 \% \mathrm{CI}$ & $\begin{array}{l}\text { Thought } \\
\text { Problems }\end{array}$ & $95 \% \mathrm{CI}$ & $\begin{array}{c}\text { Obsessive- } \\
\text { Compulsive } \\
\text { Problems } \\
\end{array}$ & $95 \% \mathrm{CI}$ \\
\hline \multicolumn{7}{|l|}{ Aluminum Exposure } \\
\hline 1st Quartile & 1.00 & Referent & 1.00 & Referent & 1.00 & Referent \\
\hline 2nd Quartile & 0.36 & $0.05-2.68$ & 0.91 & $0.10-8.65$ & 2.44 & $0.29-20.7$ \\
\hline 3rd Quartile & 0.23 & $0.02-3.18$ & 1.66 & $0.11-25.7$ & 6.21 & $0.58-66.6$ \\
\hline 4th Quartile & 0.25 & $0.02-3.45$ & 2.64 & $0.24-28.9$ & 1.23 & $0.10-15.9$ \\
\hline \multicolumn{7}{|l|}{ Age of Child } \\
\hline $6-14$ years & 1.23 & $0.84-1.80$ & 1.15 & $0.82-1.60$ & 1.10 & $0.83-1.47$ \\
\hline \multicolumn{7}{|l|}{ Gender of Child } \\
\hline Female & 1.00 & Referent & 1.00 & Referent & 1.00 & Referent \\
\hline Male & 2.13 & $0.43-10.4$ & 0.56 & $0.12-2.60$ & 1.40 & $0.36-5.51$ \\
\hline \multicolumn{7}{|l|}{ Ethnicity of Child } \\
\hline Other Ethnicity & 1.00 & Referent & 1.00 & Referent & 1.00 & Referent \\
\hline White Non-Hispanic & 2.38 & $0.29-19.6$ & 0.67 & $0.12-3.87$ & 1.65 & $0.27-10.2$ \\
\hline \multicolumn{7}{|c|}{ Child Exposed to Smoking } \\
\hline No & 1.00 & Referent & 1.00 & Referent & 1.00 & Referent \\
\hline Yes & 0.63 & $0.07-6.06$ & 0.64 & $0.08-5.27$ & 1.39 & $0.26-7.54$ \\
\hline \multicolumn{7}{|l|}{ Child Born Preterm } \\
\hline No & 1.00 & Referent & 1.00 & Referent & 1.00 & Referent \\
\hline Yes & 1.25 & $0.20-7.75$ & 3.04 & $0.51-18.1$ & 2.11 & $0.39-11.4$ \\
\hline \multicolumn{7}{|l|}{ School Performance } \\
\hline High Performance & 1.00 & Referent & 1.00 & Referent & 1.00 & Referent \\
\hline Low Performance & 3.12 & $0.14-68.3$ & 6.65 & $0.45-98.9$ & 1.87 & 0.18-19.9 \\
\hline \multicolumn{7}{|l|}{ Age Mother Had Child } \\
\hline $16-34$ years & 1.00 & Referent & 1.00 & Referent & 1.00 & Referent \\
\hline $35-50$ years & 0.36 & $0.04-3.50$ & 0.73 & $0.10-5.21$ & 0.62 & $0.13-3.02$ \\
\hline \multicolumn{7}{|c|}{ Smoked During Pregnancy } \\
\hline No & 1.00 & Referent & 1.00 & Referent & 1.00 & Referent \\
\hline Yes & 3.32 & $0.23-47.4$ & 3.06 & $0.30-30.9$ & 2.85 & $0.32-25.1$ \\
\hline
\end{tabular}




\begin{tabular}{lcc|cc|cc} 
Marital Status & & & & \\
$\quad$ Not married & 1.00 & Referent & 1.00 & Referent & 1.00 & Referent \\
$\quad$ Married & 0.81 & $0.13-5.06$ & 1.41 & $0.21-9.37$ & 1.32 & $0.24-7.34$ \\
\hline $\begin{array}{l}\text { Mom depression } \\
\quad \text { No }\end{array}$ & 1.00 & Referent & 1.00 & Referent & 1.00 & Referent \\
$\quad$ Yes & 0.59 & $0.08-4.64$ & 0.98 & $0.14-7.12$ & 1.34 & $0.26-6.81$ \\
\hline $\begin{array}{l}\text { Education Status } \\
\quad \text { Less than college degree }\end{array}$ & 1.00 & Referent & 1.00 & Referent & 1.00 & Referent \\
$\quad$ College degree or higher & 2.72 & $0.47-15.7$ & 0.87 & $0.18-4.14$ & 0.88 & $0.22-3.52$ \\
\hline
\end{tabular}

Table 38. Adjusted Odds Ratio of Copper Exposure, Child Level Covariates, and Outcomes

\begin{tabular}{|c|c|c|c|c|c|c|}
\hline & $\begin{array}{c}\text { Social } \\
\text { Problems }\end{array}$ & $95 \% \mathrm{CI}$ & $\begin{array}{l}\text { Thought } \\
\text { Problems }\end{array}$ & $95 \%$ CI & $\begin{array}{c}\text { Obsessive- } \\
\text { Compulsive } \\
\text { Problems } \\
\end{array}$ & $95 \% \mathrm{CI}$ \\
\hline \multicolumn{7}{|l|}{ Copper exposure } \\
\hline $1^{\text {st }}$ Quartile & 1.00 & Referent & 1.00 & Referent & 1.00 & Referent \\
\hline $2^{\text {nd }}$ Quartile & 3.38 & $0.57-20.1$ & 1.42 & $0.37-5.47$ & 1.47 & $0.39-5.57$ \\
\hline $3^{\text {rd }}$ Quartile & 2.66 & $0.45-15.9$ & 0.96 & $0.24-3.88$ & 1.52 & $0.42-5.48$ \\
\hline $4^{\text {th }}$ Quartile & 5.89 & $0.99-35.1$ & 1.52 & $0.37-6.26$ & 1.32 & $0.33-5.32$ \\
\hline \multicolumn{7}{|l|}{ Age of Child } \\
\hline 6-14 years old & 1.19 & $0.97-1.46$ & 1.14 & $0.95-1.37$ & 1.17 & $0.97-1.42$ \\
\hline \multicolumn{7}{|l|}{ Gender of Child } \\
\hline Female & 1.00 & Referent & 1.00 & Referent & 1.00 & Referent \\
\hline Male & 1.12 & $0.97-1.46$ & 0.53 & $0.21-1.39$ & 1.31 & 0.51-3.39 \\
\hline \multicolumn{7}{|l|}{ Ethnicity of Child } \\
\hline Other Ethnicity & 1.00 & Referent & 1.00 & Referent & 1.00 & Referent \\
\hline White Non-Hispanic & 2.30 & $0.44-12.0$ & 1.78 & $0.49-6.44$ & 4.26 & $0.86-21.2$ \\
\hline \multicolumn{7}{|c|}{ Child Exposed to Smoking } \\
\hline No & 1.00 & Referent & 1.00 & Referent & 1.00 & Referent \\
\hline Yes & 1.32 & $0.40-4.44$ & 1.68 & $0.59-4.77$ & 1.72 & $0.62-4.77$ \\
\hline Child Born Preterm & & & & & & \\
\hline
\end{tabular}




\begin{tabular}{lcc|rc|rr}
\hline No & 1.00 & Referent & 1.00 & Referent & 1.00 & Referent \\
Yes & 1.68 & $0.52-5.45$ & 2.39 & $0.86-6.68$ & 1.49 & $0.53-4.21$ \\
\hline School Performance & & & & & & \\
High Performance & 1.00 & Referent & 1.00 & Referent & 1.00 & Referent \\
Low Performance & 6.52 & $1.47-28.8$ & 5.83 & $1.47-23.1$ & 5.80 & $1.43-23.5$ \\
\hline
\end{tabular}

Table 39. Adjusted Odds Ratio of Copper Exposure, Mother Level Covariates, and Outcomes

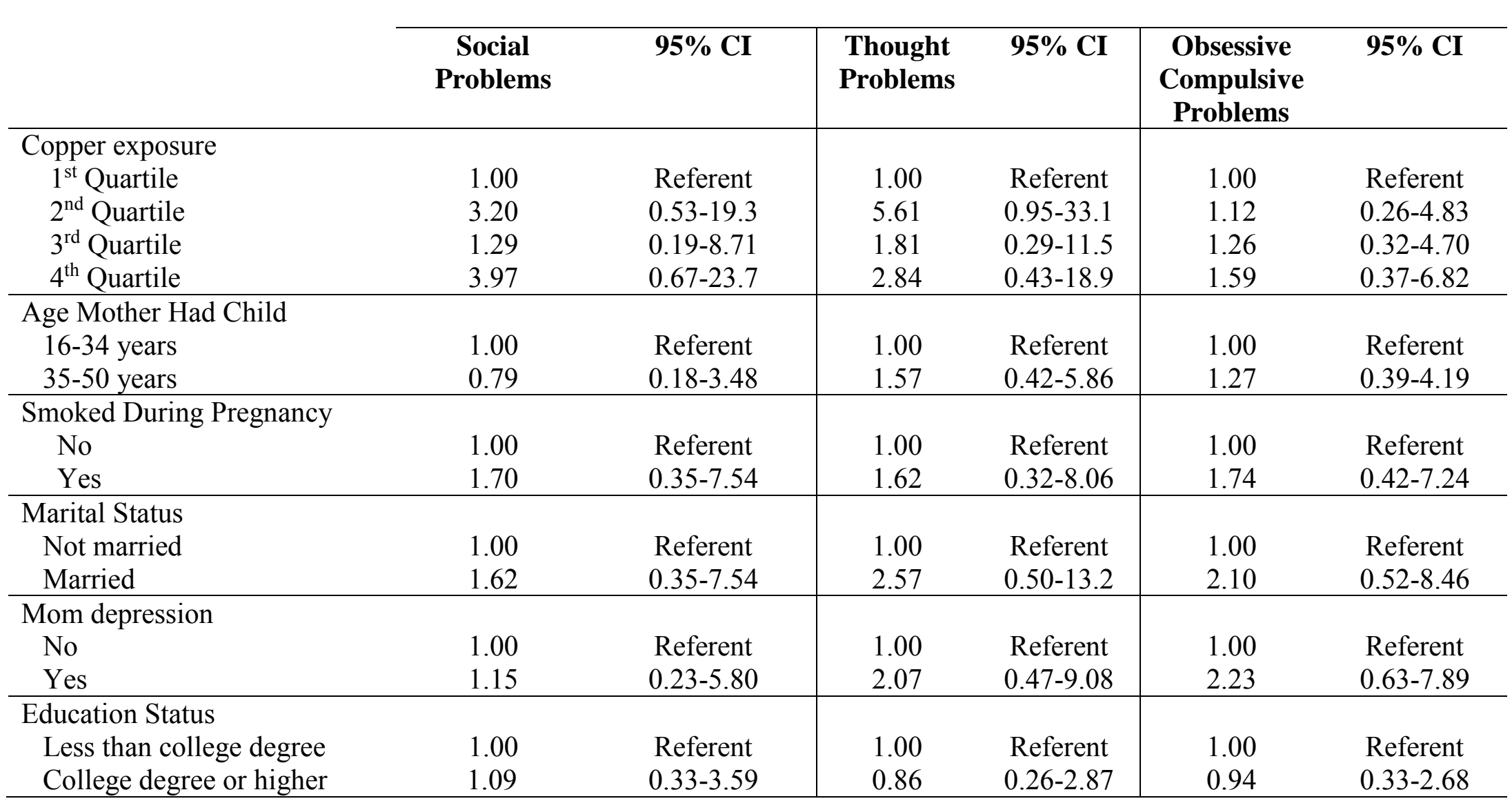


Table 40. Adjusted Odds Ratio of Copper Exposure, Child and Mother Level Covariates, and Outcomes

\begin{tabular}{|c|c|c|c|c|c|c|}
\hline & $\begin{array}{c}\text { Social } \\
\text { Problems }\end{array}$ & $95 \% \mathrm{CI}$ & $\begin{array}{l}\text { Thought } \\
\text { Problems }\end{array}$ & $95 \% \mathrm{CI}$ & $\begin{array}{l}\text { Obsessive- } \\
\text { Compulsive } \\
\text { Problems }\end{array}$ & $95 \% \mathrm{CI}$ \\
\hline \multicolumn{7}{|l|}{ Copper Exposure } \\
\hline 1st Quartile & 1.00 & Referent & 1.00 & Referent & 1.00 & Referent \\
\hline 2nd Quartile & 4.94 & $0.65-37.6$ & 5.15 & $0.66-40.0$ & 1.57 & $0.30-8.33$ \\
\hline 3rd Quartile & 1.19 & $0.13-10.6$ & 1.40 & $0.18-11.3$ & 1.25 & $0.26-6.00$ \\
\hline 4th Quartile & 6.11 & $0.68-55.0$ & 2.24 & $0.22-22.5$ & 1.44 & $0.23-9.05$ \\
\hline \multicolumn{7}{|l|}{ Age of Child } \\
\hline 6-14 years & 1.30 & $0.96-1.74$ & 1.22 & $0.91-1.64$ & 1.24 & $0.95-1.61$ \\
\hline \multicolumn{7}{|l|}{ Gender of Child } \\
\hline Female & 1.00 & Referent & 1.00 & Referent & 1.00 & Referent \\
\hline Male & 1.58 & $0.38-6.59$ & 0.50 & $0.11-2.15$ & 1.23 & $0.35-4.30$ \\
\hline \multicolumn{7}{|l|}{ Ethnicity of Child } \\
\hline Other Ethnicity & 1.00 & Referent & 1.00 & Referent & 1.00 & Referent \\
\hline White Non-Hispanic & 1.55 & $0.24-10.0$ & 1.17 & $0.21-6.48$ & 2.53 & $0.44-14.5$ \\
\hline \multicolumn{7}{|c|}{ Child Exposed to Smoking } \\
\hline No & 1.00 & Referent & 1.00 & Referent & 1.00 & Referent \\
\hline Yes & 1.36 & $0.20-9.50$ & 0.68 & $0.10-4.59$ & 1.44 & $0.30-6.97$ \\
\hline \multicolumn{7}{|l|}{ Child Born Preterm } \\
\hline No & 1.00 & Referent & 1.00 & Referent & 1.00 & Referent \\
\hline Yes & 1.50 & $0.31-7.26$ & 1.63 & $0.34-7.87$ & 1.13 & $0.27-4.79$ \\
\hline \multicolumn{7}{|l|}{ School Performance } \\
\hline High Performance & 1.00 & Referent & 1.00 & Referent & 1.00 & Referent \\
\hline Low Performance & 3.79 & $0.31-7.26$ & 5.50 & $0.72-42.2$ & 5.26 & $0.82-33.7$ \\
\hline \multicolumn{7}{|l|}{ Age Mother Had Child } \\
\hline $16-34$ years & 1.00 & Referent & 1.00 & Referent & 1.00 & Referent \\
\hline $35-50$ years & 0.75 & $0.12-4.82$ & 1.34 & $0.26-6.88$ & 0.99 & $0.22-4.35$ \\
\hline \multicolumn{7}{|c|}{ Smoked During Pregnancy } \\
\hline No & 1.00 & Referent & 1.00 & Referent & 1.00 & Referent \\
\hline Yes & 1.61 & $0.23-11.4$ & 2.42 & $0.35-16.8$ & 1.05 & $0.18-6.27$ \\
\hline
\end{tabular}




\begin{tabular}{|c|c|c|c|c|c|c|}
\hline $\begin{array}{c}\text { Marital Status } \\
\text { Not married } \\
\text { Married }\end{array}$ & $\begin{array}{l}1.00 \\
1.83\end{array}$ & $\begin{array}{c}\text { Referent } \\
0.32-10.3\end{array}$ & $\begin{array}{l}1.00 \\
3.03\end{array}$ & $\begin{array}{c}\text { Referent } \\
0.48-19.5\end{array}$ & $\begin{array}{l}1.00 \\
2.22\end{array}$ & $\begin{array}{c}\text { Referent } \\
10.8\end{array}$ \\
\hline \multicolumn{7}{|l|}{ Mom depression } \\
\hline No & 1.00 & Referent & 1.00 & Referent & 1.00 & Referent \\
\hline Yes & 1.55 & $0.25-9.57$ & 2.45 & $0.43-14.0$ & 2.01 & $0.47-8.63$ \\
\hline \multicolumn{7}{|l|}{ Education Status } \\
\hline Less than college degree & 1.00 & Referent & 1.00 & Referent & 1.00 & Referent \\
\hline College degree or higher & 1.45 & $0.37-5.75$ & 0.83 & $0.20-3.38$ & 1.46 & $0.43-4.97$ \\
\hline
\end{tabular}

Table 41. Adjusted Odds Ratio of Iron Exposure, Child Level Covariates, and Outcomes

\begin{tabular}{|c|c|c|c|c|c|c|}
\hline & $\begin{array}{c}\text { Social } \\
\text { Problems }\end{array}$ & $95 \%$ CI & $\begin{array}{l}\text { Thought } \\
\text { Problems }\end{array}$ & $95 \%$ CI & $\begin{array}{c}\text { Obsessive- } \\
\text { Compulsive } \\
\text { Problems } \\
\end{array}$ & $95 \% \mathrm{CI}$ \\
\hline $\begin{array}{c}\text { Iron exposure } \\
1^{\text {st }} \text { Quartile } \\
2^{\text {nd }} \text { Quartile } \\
3^{\text {rd }} \text { Quartile } \\
4^{\text {th }} \text { Quartile }\end{array}$ & $\begin{array}{l}1.00 \\
0.79 \\
0.95 \\
1.60\end{array}$ & $\begin{array}{l}\text { Referent } \\
0.17-3.58 \\
0.22-4.14 \\
0.33-7.67\end{array}$ & $\begin{array}{l}1.00 \\
0.29 \\
1.08 \\
1.29\end{array}$ & $\begin{array}{l}\text { Referent } \\
0.06-1.36 \\
0.29-3.97 \\
0.31-5.44\end{array}$ & $\begin{array}{l}1.00 \\
0.83 \\
1.00 \\
1.04\end{array}$ & $\begin{array}{l}\text { Referent } \\
0.22-3.11 \\
0.28-3.65 \\
0.25-4.31\end{array}$ \\
\hline $\begin{array}{l}\text { Age of Child } \\
6-14 \text { years old }\end{array}$ & 1.22 & $0.96-1.53$ & 1.18 & $0.96-1.46$ & 1.17 & 0.96-1.43 \\
\hline $\begin{array}{l}\text { Gender of Child } \\
\text { Female } \\
\text { Male } \\
\end{array}$ & $\begin{array}{l}1.00 \\
0.82 \\
\end{array}$ & $\begin{array}{l}\text { Referent } \\
0.29-2.31 \\
\end{array}$ & $\begin{array}{l}1.00 \\
0.41 \\
\end{array}$ & $\begin{array}{l}\text { Referent } \\
0.16-1.09 \\
\end{array}$ & $\begin{array}{l}1.00 \\
1.21 \\
\end{array}$ & $\begin{array}{c}\text { Referent } \\
0.48-3.06 \\
\end{array}$ \\
\hline $\begin{array}{l}\text { Ethnicity of Child } \\
\text { Other Ethnicity } \\
\text { White Non-Hispanic }\end{array}$ & $\begin{array}{l}1.00 \\
2.56\end{array}$ & $\begin{array}{c}\text { Referent } \\
0.47-13.8\end{array}$ & $\begin{array}{l}1.00 \\
2.38\end{array}$ & $\begin{array}{c}\text { Referent } \\
0.59-9.60\end{array}$ & $\begin{array}{l}1.00 \\
4.48\end{array}$ & $\begin{array}{c}\text { Referent } \\
0.88-22.8\end{array}$ \\
\hline $\begin{array}{l}\text { Child Exposed to Smoking } \\
\text { No } \\
\text { Yes }\end{array}$ & $\begin{array}{l}1.00 \\
1.12\end{array}$ & $\begin{array}{c}\text { Referent } \\
0.35-3.59\end{array}$ & $\begin{array}{l}1.00 \\
1.60\end{array}$ & $\begin{array}{c}\text { Referent } \\
0.56-4.61\end{array}$ & $\begin{array}{l}1.00 \\
1.81 \\
\end{array}$ & $\begin{array}{c}\text { Referent } \\
0.67-4.90\end{array}$ \\
\hline
\end{tabular}




\begin{tabular}{lll|lc|cc}
\hline Child Born Preterm & & & & & & \\
No & 1.00 & Referent & 1.00 & Referent & 1.00 & Referent \\
Yes & 1.95 & $0.61-6.29$ & 2.56 & $0.88-7.49$ & 1.54 & $0.54-4.37$ \\
\hline School Performance & & & & & & \\
High Performance & 1.00 & Referent & 1.00 & Referent & 1.00 & Referent \\
Low Performance & 7.81 & $1.72-35.6$ & 9.87 & $2.16-45.0$ & 6.24 & $1.47-26.6$ \\
\hline
\end{tabular}

Table 42. Adjusted Odds Ratio of Iron Exposure, Mother Level Covariates, and Outcomes

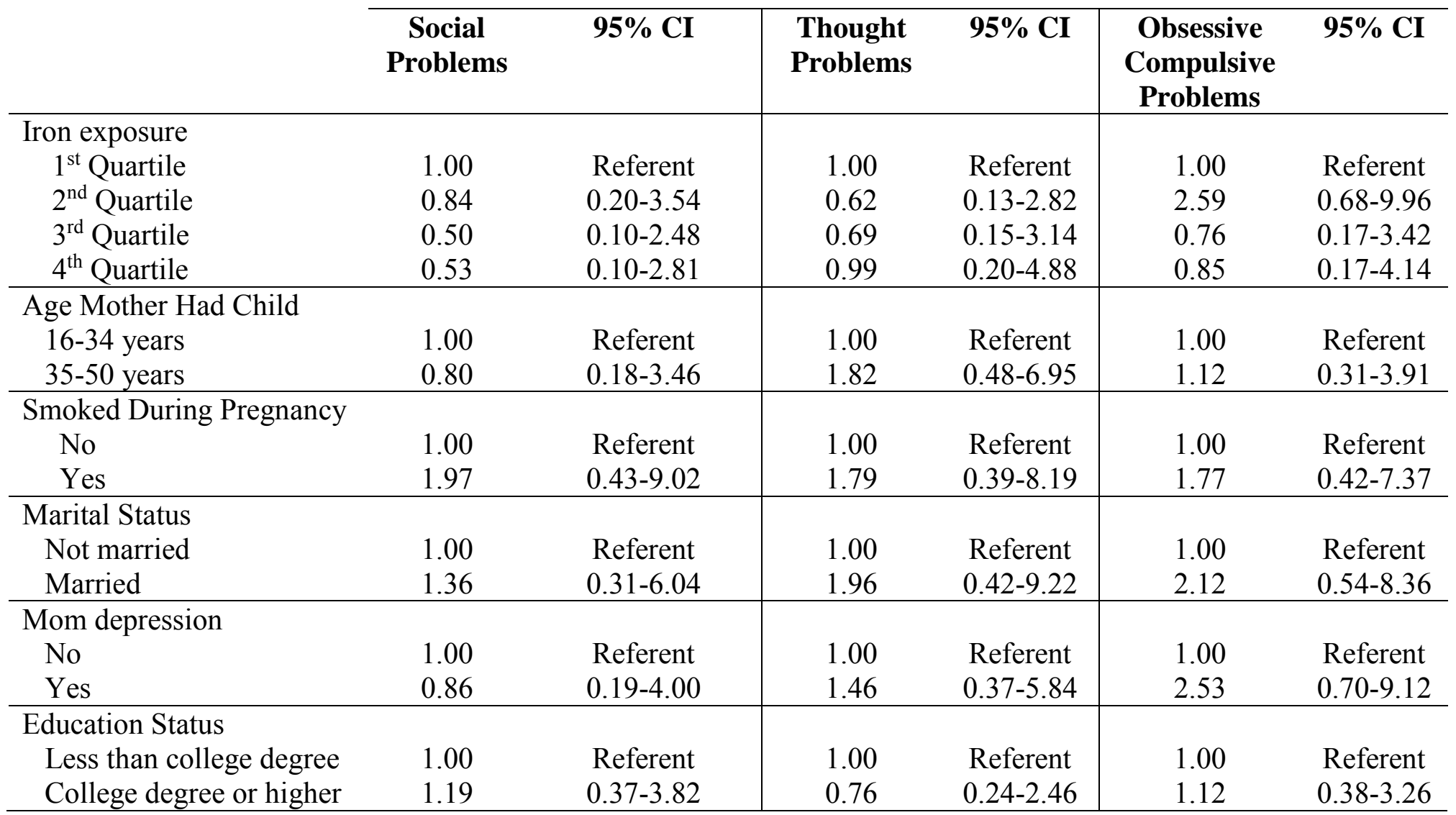


Table 43. Adjusted Odds Ratio of Iron Exposure, Child and Mother Level Covariates, and Outcomes

\begin{tabular}{|c|c|c|c|c|c|c|}
\hline & $\begin{array}{c}\text { Social } \\
\text { Problems }\end{array}$ & 95\% C.I & $\begin{array}{l}\text { Thought } \\
\text { Problems }\end{array}$ & $95 \% \mathrm{CI}$ & $\begin{array}{l}\text { Obsessive- } \\
\text { Compulsive } \\
\text { Problems }\end{array}$ & $95 \%$ CI \\
\hline \multicolumn{7}{|l|}{ Iron Exposure } \\
\hline 1st Quartile & 1.00 & Referent & 1.00 & Referent & 1.00 & Referent \\
\hline 2nd Quartile & 1.51 & $0.23-9.69$ & 0.57 & $0.07-4.87$ & 3.08 & $0.57-16.7$ \\
\hline 3rd Quartile & 1.12 & $0.17-7.39$ & 1.75 & $0.27-11.5$ & 1.25 & $0.21-7.48$ \\
\hline 4th Quartile & 0.68 & $0.06-6.95$ & 1.88 & $0.22-16.4$ & 1.21 & $0.16-9.34$ \\
\hline \multicolumn{7}{|l|}{ Age of Child } \\
\hline $6-14$ years & 1.26 & $0.92-1.74$ & 1.31 & $0.95-1.80$ & 1.24 & $0.93-1.64$ \\
\hline \multicolumn{7}{|l|}{ Gender of Child } \\
\hline Female & 1.00 & Referent & 1.00 & Referent & 1.00 & Referent \\
\hline Male & 0.95 & $0.23-3.86$ & 0.25 & $0.06-1.14$ & 1.17 & $0.32-4.25$ \\
\hline \multicolumn{7}{|l|}{ Ethnicity of Child } \\
\hline Other Ethnicity & 1.00 & Referent & 1.00 & Referent & 1.00 & Referent \\
\hline White Non-Hispanic & 1.49 & $0.22-9.92$ & 1.11 & $0.18-6.95$ & 1.78 & $0.30-10.6$ \\
\hline \multicolumn{7}{|c|}{ Child Exposed to Smoking } \\
\hline No & 1.00 & Referent & 1.00 & Referent & 1.00 & Referent \\
\hline Yes & 0.65 & $0.10-4.24$ & 0.58 & $0.09-3.72$ & 1.40 & $0.30-6.65$ \\
\hline \multicolumn{7}{|l|}{ Child Born Preterm } \\
\hline No & 1.00 & Referent & 1.00 & Referent & 1.00 & Referent \\
\hline Yes & 1.29 & $0.27-6.24$ & 2.09 & $0.40-11.0$ & 1.19 & $0.26-5.42$ \\
\hline \multicolumn{7}{|l|}{ School Performance } \\
\hline High Performance & 1.00 & Referent & 1.00 & Referent & 1.00 & Referent \\
\hline Low Performance & 1.85 & $0.16-21.2$ & 9.55 & $0.76-120.9$ & 2.99 & $0.37-24.3$ \\
\hline \multicolumn{7}{|l|}{ Age Mother Had Child } \\
\hline $16-34$ years & 1.00 & Referent & 1.00 & Referent & 1.00 & Referent \\
\hline $35-50$ years & 0.46 & $0.07-3.17$ & 1.64 & $0.27-9.81$ & 0.77 & $0.16-3.79$ \\
\hline \multicolumn{7}{|c|}{ Smoked During Pregnancy } \\
\hline No & 1.00 & Referent & 1.00 & Referent & 1.00 & Referent \\
\hline Yes & 2.47 & $0.34-18.0$ & 2.35 & $0.34-16.3$ & 1.05 & $0.16-6.87$ \\
\hline
\end{tabular}




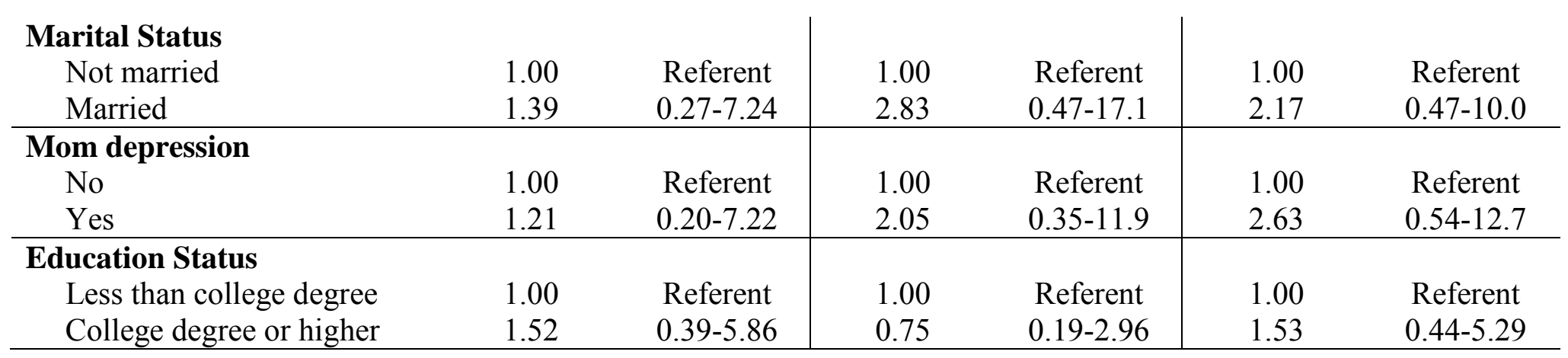

Table 44. Adjusted Odds Ratio of Zinc Exposure, Child Level Covariates, and Outcomes

\begin{tabular}{|c|c|c|c|c|c|c|}
\hline & $\begin{array}{c}\text { Social } \\
\text { Problems }\end{array}$ & $95 \% \mathrm{CI}$ & $\begin{array}{l}\text { Thought } \\
\text { Problems }\end{array}$ & $95 \% \mathrm{CI}$ & $\begin{array}{c}\text { Obsessive- } \\
\text { Compulsive } \\
\text { Problems }\end{array}$ & $95 \% \mathrm{CI}$ \\
\hline \multicolumn{7}{|l|}{ Zinc exposure } \\
\hline $1^{\text {st }}$ Quartile & 1.00 & Referent & 1.00 & Referent & 1.00 & Referent \\
\hline $2^{\text {nd }}$ Quartile & 0.49 & $0.09-2.60$ & 0.33 & $0.08-1.35$ & 0.96 & $0.26-3.52$ \\
\hline $3^{\text {rd }}$ Quartile & 0.71 & $0.15-3.35$ & 0.51 & $0.14-1.85$ & 1.40 & $0.39-5.00$ \\
\hline $4^{\text {th }}$ Quartile & 3.29 & $0.75-14.5$ & 0.57 & $0.15-2.15$ & 1.26 & $0.31-5.07$ \\
\hline \multicolumn{7}{|l|}{ Age of Child } \\
\hline 6-14 years old & 1.28 & $1.01-1.62$ & 1.12 & $0.92-1.36$ & 1.18 & $0.97-1.44$ \\
\hline \multicolumn{7}{|l|}{ Gender of Child } \\
\hline Female & 1.00 & Referent & 1.00 & Referent & 1.00 & Referent \\
\hline Male & 0.84 & $0.28-2.47$ & 0.42 & $0.16-1.10$ & 1.30 & $0.51-3.31$ \\
\hline \multicolumn{7}{|l|}{ Ethnicity of Child } \\
\hline Other Ethnicity & 1.00 & Referent & 1.00 & Referent & 1.00 & Referent \\
\hline White Non-Hispanic & 3.27 & $0.60-17.9$ & 2.10 & $0.57-7.77$ & 4.21 & $0.86-20.7$ \\
\hline \multicolumn{7}{|l|}{ Child Exposed to Smoking } \\
\hline No & 1.00 & Referent & 1.00 & Referent & 1.00 & Referent \\
\hline Yes & 1.18 & $0.35-3.95$ & 1.66 & $0.59-4.72$ & 1.75 & $0.64-4.76$ \\
\hline
\end{tabular}




\begin{tabular}{lcc|cc|cc}
\hline Child Born Preterm & & & & & & \\
No & 1.00 & Referent & 1.00 & Referent & 1.00 & Referent \\
Yes & 1.75 & $0.53-5.71$ & 2.51 & $0.89-7.11$ & 1.56 & $0.56-4.37$ \\
\hline School Performance & & & & & & \\
High Performance & 1.00 & Referent & 1.00 & Referent & 1.00 & Referent \\
Low Performance & 6.59 & $1.43-30.3$ & 6.85 & $1.72-27.3$ & 5.80 & $1.42-23.7$ \\
\hline
\end{tabular}

Table 45. Adjusted Odds Ratio of Zinc Exposure, Mother Level Covariates, and Outcomes

\begin{tabular}{|c|c|c|c|c|c|c|}
\hline & $\begin{array}{c}\text { Social } \\
\text { Problems }\end{array}$ & $95 \% \mathrm{CI}$ & $\begin{array}{l}\text { Thought } \\
\text { Problems }\end{array}$ & $95 \% \mathrm{CI}$ & $\begin{array}{c}\text { Obsessive } \\
\text { Compulsive } \\
\text { Problems } \\
\end{array}$ & $95 \%$ CI \\
\hline \multicolumn{7}{|l|}{ Zinc exposure } \\
\hline $1^{\text {st }}$ Quartile & 1.00 & Referent & 1.00 & Referent & 1.00 & Referent \\
\hline $2^{\text {nd }}$ Quartile & 0.48 & $0.10-2.44$ & 0.52 & $0.11-2.30$ & 0.55 & $0.13-2.21$ \\
\hline $3^{\text {rd }}$ Quartile & 0.57 & $0.11-2.87$ & 0.70 & $0.16-3.07$ & 0.96 & $0.25-3.69$ \\
\hline $4^{\text {th }}$ Quartile & 1.11 & $0.25-4.95$ & 0.46 & $0.09-2.32$ & 0.67 & $0.16-2.76$ \\
\hline \multicolumn{7}{|l|}{ Age Mother Had Child } \\
\hline $16-34$ years & 1.00 & Referent & 1.00 & Referent & 1.00 & Referent \\
\hline $35-50$ years & 1.07 & $0.24-4.76$ & 1.58 & $0.43-5.82$ & 1.33 & $0.40-4.48$ \\
\hline \multicolumn{7}{|l|}{ Smoked During Pregnancy } \\
\hline No & 1.00 & Referent & 1.00 & Referent & 1.00 & Referent \\
\hline Yes & 2.09 & $0.44-9.94$ & 1.88 & $0.40-8.94$ & 1.99 & $0.48-8.36$ \\
\hline \multicolumn{7}{|l|}{ Marital Status } \\
\hline Not married & 1.00 & Referent & 1.00 & Referent & 1.00 & Referent \\
\hline Married & 1.09 & $0.25-4.84$ & 2.05 & $0.44-9.56$ & 2.09 & $0.53-8.30$ \\
\hline \multicolumn{7}{|l|}{ Mom depression } \\
\hline No & 1.00 & Referent & 1.00 & Referent & 1.00 & Referent \\
\hline Yes & 0.78 & $0.16-3.71$ & 1.77 & $0.45-6.94$ & 2.22 & 0.64-7.69 \\
\hline \multicolumn{7}{|l|}{ Education Status } \\
\hline Less than college degree & 1.00 & Referent & 1.00 & Referent & 1.00 & Referent \\
\hline College degree or higher & 1.20 & $0.37-3.93$ & 0.90 & $0.28-2.90$ & 1.00 & $0.35-2.87$ \\
\hline
\end{tabular}


Table 46. Adjusted Odds Ratio of Zinc Exposure, Child and Mother Level Covariates, and Outcomes

\begin{tabular}{|c|c|c|c|c|c|c|}
\hline & $\begin{array}{c}\text { Social } \\
\text { Problems }\end{array}$ & $95 \% \mathrm{CI}$ & $\begin{array}{l}\text { Thought } \\
\text { Problems }\end{array}$ & $95 \% \mathrm{CI}$ & $\begin{array}{c}\text { Obsessive- } \\
\text { Compulsive } \\
\text { Problems } \\
\end{array}$ & $95 \% \mathrm{CI}$ \\
\hline \multicolumn{7}{|l|}{ Zinc Exposure } \\
\hline 1st Quartile & 1.00 & Referent & 1.00 & Referent & 1.00 & Referent \\
\hline 2nd Quartile & 0.49 & $0.08-3.03$ & 0.26 & $0.03-1.97$ & 0.38 & $0.07-1.95$ \\
\hline 3rd Quartile & 0.40 & $0.06-2.74$ & 0.44 & $0.08-2.61$ & 0.75 & $0.16-3.59$ \\
\hline 4th Quartile & 1.25 & $0.23-6.75$ & 0.20 & $0.03-1.52$ & 0.62 & $0.12-3.17$ \\
\hline \multicolumn{7}{|l|}{ Age of Child } \\
\hline 6-14 years & 1.31 & $0.96-1.79$ & 1.20 & $0.89-1.61$ & 1.23 & 0.93-1.61 \\
\hline \multicolumn{7}{|l|}{ Gender of Child } \\
\hline Female & 1.00 & Referent & 1.00 & Referent & 1.00 & Referent \\
\hline Male & 0.93 & $0.24-3.66$ & 0.18 & $0.04-0.92$ & 0.97 & $0.28-3.31$ \\
\hline \multicolumn{7}{|l|}{ Ethnicity of Child } \\
\hline Other Ethnicity & 1.00 & Referent & 1.00 & Referent & 1.00 & Referent \\
\hline White Non-Hispanic & 1.78 & $0.29-11.0$ & 0.83 & $0.16-4.34$ & 2.67 & $0.47-15.2$ \\
\hline \multicolumn{7}{|c|}{ Child Exposed to Smoking } \\
\hline No & 1.00 & Referent & 1.00 & Referent & 1.00 & Referent \\
\hline Yes & 0.69 & $0.11-4.34$ & 0.46 & $0.06-3.52$ & 1.39 & $0.31-6.34$ \\
\hline \multicolumn{7}{|l|}{ Child Born Preterm } \\
\hline No & 1.00 & Referent & 1.00 & Referent & 1.00 & Referent \\
\hline Yes & 1.10 & $0.23-5.41$ & 1.65 & $0.35-7.66$ & 1.12 & $0.26-4.97$ \\
\hline \multicolumn{7}{|l|}{ School Performance } \\
\hline High Performance & 1.00 & Referent & 1.00 & Referent & 1.00 & Referent \\
\hline Low Performance & 3.72 & $0.42-32.5$ & 5.69 & $0.64-50.9$ & 6.13 & $0.89-42.1$ \\
\hline \multicolumn{7}{|l|}{ Age Mother Had Child } \\
\hline $16-34$ years & 1.00 & Referent & 1.00 & Referent & 1.00 & Referent \\
\hline $35-50$ years & 0.67 & $0.10-4.36$ & 1.30 & $0.23-7.26$ & 1.02 & $0.23-4.56$ \\
\hline \multicolumn{7}{|c|}{ Smoked During Pregnancy } \\
\hline No & 1.00 & Referent & 1.00 & Referent & 1.00 & Referent \\
\hline Yes & 2.13 & $0.32-14.3$ & 3.48 & $0.38-31.7$ & 1.07 & $0.17-6.89$ \\
\hline
\end{tabular}




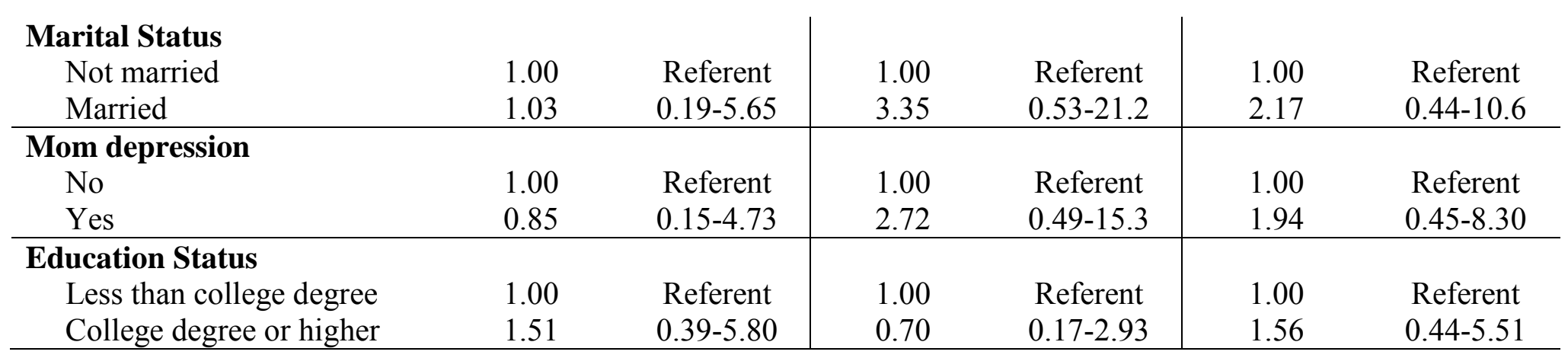

Table 47. Adjusted Odds Ratio of Nickel Exposure, Child Level Covariates, and Outcomes

\begin{tabular}{|c|c|c|c|c|c|c|}
\hline & $\begin{array}{c}\text { Social } \\
\text { Problems }\end{array}$ & $95 \% \mathrm{CI}$ & $\begin{array}{l}\text { Thought } \\
\text { Problems }\end{array}$ & $95 \% \mathrm{CI}$ & $\begin{array}{l}\text { Obsessive- } \\
\text { Compulsive } \\
\text { Problems }\end{array}$ & $95 \% \mathrm{CI}$ \\
\hline $\begin{array}{l}\text { Nickel exposure } \\
1^{\text {st }} \text { Quartile } \\
2^{\text {nd }} \text { Quartile } \\
3^{\text {rd }} \text { Quartile } \\
4^{\text {th }} \text { Quartile }\end{array}$ & $\begin{array}{l}1.00 \\
0.56 \\
1.59 \\
1.35\end{array}$ & $\begin{array}{l}\text { Referent } \\
0.07-4.29 \\
0.30-8.35 \\
0.23-8.11\end{array}$ & $\begin{array}{l}1.00 \\
0.67 \\
1.57 \\
0.86\end{array}$ & $\begin{array}{l}\text { Referent } \\
0.11-4.06 \\
0.33-7.38 \\
0.15-4.90\end{array}$ & $\begin{array}{l}1.00 \\
0.81 \\
0.97 \\
1.14\end{array}$ & $\begin{array}{l}\text { Referent } \\
0.15-4.31 \\
0.21-4.51 \\
0.21-6.19\end{array}$ \\
\hline $\begin{array}{l}\text { Age of Child } \\
6-14 \text { years old }\end{array}$ & 1.10 & $0.86-1.40$ & 1.08 & $0.86-1.35$ & 0.99 & 0.79-1.24 \\
\hline $\begin{array}{l}\text { Gender of Child } \\
\text { Female } \\
\text { Male } \\
\end{array}$ & $\begin{array}{l}1.00 \\
1.00 \\
\end{array}$ & $\begin{array}{l}\text { Referent } \\
0.29-3.46 \\
\end{array}$ & $\begin{array}{l}1.00 \\
0.90 \\
\end{array}$ & $\begin{array}{c}\text { Referent } \\
0.28-2.86 \\
\end{array}$ & $\begin{array}{l}1.00 \\
1.78 \\
\end{array}$ & $\begin{array}{r}\text { Referent } \\
0.56-5.69 \\
\end{array}$ \\
\hline $\begin{array}{l}\text { Ethnicity of Child } \\
\text { Other Ethnicity } \\
\text { White Non-Hispanic } \\
\end{array}$ & $\begin{array}{l}1.00 \\
1.65 \\
\end{array}$ & $\begin{array}{c}\text { Referent } \\
0.28-9.77 \\
\end{array}$ & $\begin{array}{l}1.00 \\
2.91 \\
\end{array}$ & $\begin{array}{c}\text { Referent } \\
0.49-17.2 \\
\end{array}$ & $\begin{array}{l}1.00 \\
3.00 \\
\end{array}$ & $\begin{array}{c}\text { Referent } \\
0.55-16.4\end{array}$ \\
\hline $\begin{array}{l}\text { Child Exposed to Smoking } \\
\text { No } \\
\text { Yes }\end{array}$ & $\begin{array}{l}1.00 \\
1.50\end{array}$ & $\begin{array}{c}\text { Referent } \\
0.37-6.15\end{array}$ & $\begin{array}{l}1.00 \\
1.42\end{array}$ & $\begin{array}{c}\text { Referent } \\
0.38-5.35\end{array}$ & $\begin{array}{l}1.00 \\
1.56\end{array}$ & $\begin{array}{c}\text { Referent } \\
0.43-5.71\end{array}$ \\
\hline
\end{tabular}




\begin{tabular}{lcc|rr|rr}
\hline Child Born Preterm & & & & & \\
No & 1.00 & Referent & 1.00 & Referent & 1.00 & Referent \\
Yes & 2.73 & $0.67-11.1$ & 2.80 & $0.75-10.5$ & 0.99 & $0.24-3.99$ \\
\hline School Performance & & & & & & \\
High Performance & 1.00 & Referent & 1.00 & Referent & 1.00 & Referent \\
Low Performance & 3.85 & $0.65-23.0$ & 5.74 & $0.98-33.7$ & 2.76 & $0.47-16.0$ \\
\hline
\end{tabular}

Table 48. Adjusted Odds Ratio of Nickel Exposure, Mother Level Covariates, and Outcomes

\begin{tabular}{|c|c|c|c|c|c|c|}
\hline & $\begin{array}{c}\text { Social } \\
\text { Problems }\end{array}$ & $95 \%$ CI & $\begin{array}{l}\text { Thought } \\
\text { Problems }\end{array}$ & $95 \%$ CI & $\begin{array}{c}\text { Obsessive } \\
\text { Compulsive } \\
\text { Problems } \\
\end{array}$ & $95 \% \mathrm{CI}$ \\
\hline $\begin{array}{c}\text { Nickel exposure } \\
1^{\text {st }} \text { Quartile } \\
2^{\text {nd }} \text { Quartile } \\
3^{\text {rd }} \text { Quartile } \\
4^{\text {th }} \text { Quartile }\end{array}$ & $\begin{array}{l}1.00 \\
0.24 \\
2.55 \\
3.36\end{array}$ & $\begin{array}{l}\text { Referent } \\
0.02-3.63 \\
0.31-20.8 \\
0.33-33.8\end{array}$ & $\begin{array}{l}1.00 \\
0.58 \\
1.83 \\
1.43\end{array}$ & $\begin{array}{c}\text { Referent } \\
0.06-5.56 \\
0.26-13.1 \\
0.15-13.2\end{array}$ & $\begin{array}{l}1.00 \\
0.41 \\
1.15 \\
0.73\end{array}$ & $\begin{array}{l}\text { Referent } \\
0.06-2.98 \\
0.19-6.84 \\
0.09-5.90\end{array}$ \\
\hline $\begin{array}{l}\text { Age Mother Had Child } \\
\text { 16-34 years } \\
35-50 \text { years }\end{array}$ & $\begin{array}{l}1.00 \\
0.59 \\
\end{array}$ & $\begin{array}{c}\text { Referent } \\
0.09-3.78\end{array}$ & $\begin{array}{l}1.00 \\
0.98\end{array}$ & $\begin{array}{c}\text { Referent } \\
0.20-4.83\end{array}$ & $\begin{array}{l}1.00 \\
1.86\end{array}$ & $\begin{array}{c}\text { Referent } \\
0.44-7.82\end{array}$ \\
\hline $\begin{array}{l}\text { Smoked During Pregnancy } \\
\text { No } \\
\text { Yes }\end{array}$ & $\begin{array}{l}1.00 \\
2.29 \\
\end{array}$ & $\begin{array}{c}\text { Referent } \\
0.28-18.4 \\
\end{array}$ & $\begin{array}{l}1.00 \\
1.81 \\
\end{array}$ & $\begin{array}{c}\text { Referent } \\
0.27-12.1\end{array}$ & $\begin{array}{l}1.00 \\
1.14 \\
\end{array}$ & $\begin{array}{c}\text { Referent } \\
0.18-7.19\end{array}$ \\
\hline $\begin{array}{l}\text { Marital Status } \\
\text { Not married } \\
\text { Married } \\
\end{array}$ & $\begin{array}{l}1.00 \\
1.54\end{array}$ & $\begin{array}{c}\text { Referent } \\
0.20-12.1\end{array}$ & $\begin{array}{l}1.00 \\
1.73\end{array}$ & $\begin{array}{c}\text { Referent } \\
0.25-11.9\end{array}$ & $\begin{array}{l}1.00 \\
2.36\end{array}$ & $\begin{array}{c}\text { Referent } \\
0.33-16.9\end{array}$ \\
\hline $\begin{array}{l}\text { Mom depression } \\
\text { No } \\
\text { Yes }\end{array}$ & $\begin{array}{l}1.00 \\
0.89 \\
\end{array}$ & $\begin{array}{c}\text { Referent } \\
0.11-6.89\end{array}$ & $\begin{array}{l}1.00 \\
1.48 \\
\end{array}$ & $\begin{array}{c}\text { Referent } \\
0.27-8.02 \\
\end{array}$ & $\begin{array}{l}1.00 \\
2.29 \\
\end{array}$ & $\begin{array}{c}\text { Referent } \\
0.46-11.3\end{array}$ \\
\hline $\begin{array}{l}\text { Education Status } \\
\text { Less than college degree } \\
\text { College degree or higher }\end{array}$ & $\begin{array}{l}1.00 \\
3.80\end{array}$ & $\begin{array}{c}\text { Referent } \\
0.80-18.0\end{array}$ & $\begin{array}{l}1.00 \\
0.97\end{array}$ & $\begin{array}{c}\text { Referent } \\
0.23-4.11\end{array}$ & $\begin{array}{l}1.00 \\
1.34\end{array}$ & $\begin{array}{c}\text { Referent } \\
0.36-5.06\end{array}$ \\
\hline
\end{tabular}


Table 49. Adjusted Odds Ratio of Nickel Exposure, Child and Mother Level Covariates, and Outcomes

\begin{tabular}{|c|c|c|c|c|c|c|}
\hline & $\begin{array}{c}\text { Social } \\
\text { Problems }\end{array}$ & $95 \% \mathrm{CI}$ & $\begin{array}{l}\text { Thought } \\
\text { Problems }\end{array}$ & $95 \% \mathrm{CI}$ & $\begin{array}{c}\text { Obsessive- } \\
\text { Compulsive } \\
\text { Problems } \\
\end{array}$ & $95 \% \mathrm{CI}$ \\
\hline \multicolumn{7}{|l|}{ Nickel Exposure } \\
\hline 1st Quartile & 1.00 & Referent & 1.00 & Referent & 1.00 & Referent \\
\hline 2nd Quartile & 0.11 & $0.003-3.64$ & 0.52 & $0.04-7.50$ & 0.61 & $0.07-5.13$ \\
\hline 3rd Quartile & 6.68 & $0.36-122.9$ & 2.23 & $0.21-24.0$ & 0.89 & $0.11-7.01$ \\
\hline 4th Quartile & 8.44 & $0.18-400.0$ & 0.47 & $0.02-12.8$ & 1.09 & $0.06-21.6$ \\
\hline \multicolumn{7}{|l|}{ Age of Child } \\
\hline $6-14$ years & 1.29 & $0.82-2.04$ & 1.17 & $0.81-1.69$ & 1.02 & $0.75-1.40$ \\
\hline \multicolumn{7}{|l|}{ Gender of Child } \\
\hline Female & 1.00 & Referent & 1.00 & Referent & 1.00 & Referent \\
\hline Male & 5.98 & $0.45-79.7$ & 0.84 & $0.11-6.38$ & 1.62 & 0.29-8.99 \\
\hline \multicolumn{7}{|l|}{ Ethnicity of Child } \\
\hline Other Ethnicity & 1.00 & Referent & 1.00 & Referent & 1.00 & Referent \\
\hline White Non-Hispanic & 0.34 & $0.03-3.96$ & 0.97 & $0.12-8.10$ & 1.42 & $0.20-11.7$ \\
\hline \multicolumn{7}{|c|}{ Child Exposed to Smoking } \\
\hline No & 1.00 & Referent & 1.00 & Referent & 1.00 & Referent \\
\hline Yes & 17.1 & $0.63-460.2$ & 3.05 & $0.27-35.3$ & 2.45 & $0.28-21.8$ \\
\hline \multicolumn{7}{|l|}{ Child Born Preterm } \\
\hline No & 1.00 & Referent & 1.00 & Referent & 1.00 & Referent \\
\hline Yes & 3.17 & $0.27-36.7$ & 4.53 & $0.57-35.9$ & 1.53 & $0.20-11.7$ \\
\hline \multicolumn{7}{|l|}{ School Performance } \\
\hline High Performance & 1.00 & Referent & 1.00 & Referent & 1.00 & Referent \\
\hline Low Performance & 0.41 & $0.01-12.6$ & 2.04 & $0.13-31.0$ & 2.36 & $0.16-34.4$ \\
\hline \multicolumn{7}{|l|}{ Age Mother Had Child } \\
\hline $16-34$ years & 1.00 & Referent & 1.00 & Referent & 1.00 & Referent \\
\hline $35-50$ years & 0.19 & $0.01-3.66$ & 0.47 & $0.05-4.13$ & 1.22 & $0.21-7.18$ \\
\hline \multicolumn{7}{|c|}{ Smoked During Pregnancy } \\
\hline No & 1.00 & Referent & 1.00 & Referent & 1.00 & Referent \\
\hline Yes & 1.35 & $0.09-20.4$ & 1.60 & $0.17-15.4$ & 0.29 & $0.02-4.49$ \\
\hline
\end{tabular}




\begin{tabular}{lcc|cc|cc} 
Marital Status & & & & \\
$\quad$ Not married & 1.00 & Referent & 1.00 & Referent & 1.00 & Referent \\
$\quad$ Married & 1.12 & $0.06-22.9$ & 1.17 & $0.10-14.4$ & 4.33 & $0.23-82.0$ \\
\hline $\begin{array}{l}\text { Mom depression } \\
\quad \text { No }\end{array}$ & 1.00 & Referent & 1.00 & Referent & 1.00 & Referent \\
$\quad$ Yes & 2.55 & $0.13-48.6$ & 5.14 & $0.45-59.4$ & 2.02 & $0.25-16.5$ \\
\hline $\begin{array}{l}\text { Education Status } \\
\quad \text { Less than college degree }\end{array}$ & 1.00 & Referent & 1.00 & Referent & 1.00 & Referent \\
$\quad$ College degree or higher & 14.3 & $1.15-178.4$ & 1.16 & $0.17-7.97$ & 2.14 & $0.36-12.2$ \\
\hline
\end{tabular}

Table 50. Adjusted Odds Ratio of Silicon Exposure, Child Level Covariates, and Outcomes

\begin{tabular}{|c|c|c|c|c|c|c|}
\hline & $\begin{array}{c}\text { Social } \\
\text { Problems }\end{array}$ & $95 \% \mathrm{CI}$ & $\begin{array}{l}\text { Thought } \\
\text { Problems }\end{array}$ & $95 \% \mathrm{CI}$ & $\begin{array}{c}\text { Obsessive- } \\
\text { Compulsive } \\
\text { Problems }\end{array}$ & $95 \% \mathrm{CI}$ \\
\hline \multicolumn{7}{|l|}{ Silicon exposure } \\
\hline $1^{\text {st }}$ Quartile & 1.00 & Referent & 1.00 & Referent & 1.00 & Referent \\
\hline $2^{\text {nd }}$ Quartile & 0.46 & $0.09-2.22$ & 0.70 & $0.17-2.84$ & 1.72 & $0.49-6.07$ \\
\hline $3^{\text {rd }}$ Quartile & 1.00 & $0.27-3.71$ & 0.53 & $0.13-2.15$ & 0.96 & $0.28-3.34$ \\
\hline $4^{\text {th }}$ Quartile & 1.12 & $0.26-4.92$ & 3.64 & $0.91-14.5$ & 1.08 & $0.27-4.28$ \\
\hline \multicolumn{7}{|l|}{ Age of Child } \\
\hline 6-14 years old & 1.19 & $0.95-1.50$ & 1.25 & $1.02-1.54$ & 1.16 & $0.95-1.41$ \\
\hline \multicolumn{7}{|l|}{ Gender of Child } \\
\hline Female & 1.00 & Referent & 1.00 & Referent & 1.00 & Referent \\
\hline Male & 0.82 & $0.29-2.30$ & 0.50 & $0.19-1.32$ & 1.29 & $0.51-3.24$ \\
\hline \multicolumn{7}{|l|}{ Ethnicity of Child } \\
\hline Other Ethnicity & 1.00 & Referent & 1.00 & Referent & 1.00 & Referent \\
\hline White Non-Hispanic & 2.49 & $0.48-13.0$ & 1.46 & $0.37-5.80$ & 4.42 & $0.91-21.6$ \\
\hline \multicolumn{7}{|c|}{ Child Exposed to Smoking } \\
\hline No & 1.00 & Referent & 1.00 & Referent & 1.00 & Referent \\
\hline Yes & 1.13 & $0.34-3.68$ & 1.47 & $0.49-4.44$ & 1.72 & $0.63-4.67$ \\
\hline
\end{tabular}




\begin{tabular}{lcc|cc|cc}
\hline Child Born Preterm & & & & & & \\
No & 1.00 & Referent & 1.00 & Referent & 1.00 & Referent \\
Yes & 1.93 & $0.61-6.15$ & 2.98 & $1.00-8.84$ & 1.51 & $0.54-4.23$ \\
\hline School Performance & & & & & & \\
High Performance & 1.00 & Referent & 1.00 & Referent & 1.00 & Referent \\
Low Performance & 6.64 & $1.54-28.6$ & 9.62 & $2.09-44.3$ & 6.14 & $1.47-25.7$ \\
\hline
\end{tabular}

Table 51. Adjusted Odds Ratio of Silicon Exposure, Mother Level Covariates, and Outcomes

\begin{tabular}{|c|c|c|c|c|c|c|}
\hline & $\begin{array}{c}\text { Social } \\
\text { Problems }\end{array}$ & $95 \%$ CI & $\begin{array}{c}\text { Thought } \\
\text { Problems }\end{array}$ & $95 \% \mathrm{CI}$ & $\begin{array}{c}\text { Obsessive } \\
\text { Compulsive } \\
\text { Problems } \\
\end{array}$ & $95 \% \mathrm{CI}$ \\
\hline $\begin{array}{l}\text { Silicon exposure } \\
1^{\text {st }} \text { Quartile } \\
2^{\text {nd }} \text { Quartile } \\
3^{\text {rd }} \text { Quartile } \\
4^{\text {th }} \text { Quartile }\end{array}$ & $\begin{array}{l}1.00 \\
0.73 \\
0.94 \\
0.49 \\
\end{array}$ & $\begin{array}{l}\text { Referent } \\
0.15-3.69 \\
0.22-4.08 \\
0.10-2.34 \\
\end{array}$ & $\begin{array}{l}1.00 \\
1.04 \\
0.23 \\
2.24\end{array}$ & $\begin{array}{l}\text { Referent } \\
0.21-5.12 \\
0.02-2.19 \\
0.57-8.78 \\
\end{array}$ & $\begin{array}{l}1.00 \\
3.67 \\
1.52 \\
0.67\end{array}$ & $\begin{array}{l}\text { Referent } \\
0.87-15.5 \\
0.36-6.36 \\
0.15-2.97 \\
\end{array}$ \\
\hline $\begin{array}{l}\text { Age Mother Had Child } \\
\text { 16-34 years } \\
\text { 35-50 years }\end{array}$ & $\begin{array}{l}1.00 \\
0.80 \\
\end{array}$ & $\begin{array}{c}\text { Referent } \\
0.18-3.57\end{array}$ & $\begin{array}{l}1.00 \\
2.20 \\
\end{array}$ & $\begin{array}{c}\text { Referent } \\
0.53-9.21\end{array}$ & $\begin{array}{l}1.00 \\
0.81 \\
\end{array}$ & $\begin{array}{c}\text { Referent } \\
0.23-2.87\end{array}$ \\
\hline $\begin{array}{l}\text { Smoked During Pregnancy } \\
\text { No } \\
\text { Yes }\end{array}$ & $\begin{array}{l}1.00 \\
2.18 \\
\end{array}$ & $\begin{array}{c}\text { Referent } \\
0.45-10.6\end{array}$ & $\begin{array}{l}1.00 \\
1.37 \\
\end{array}$ & $\begin{array}{c}\text { Referent } \\
0.28-6.64\end{array}$ & $\begin{array}{l}1.00 \\
2.81 \\
\end{array}$ & $\begin{array}{c}\text { Referent } \\
0.62-12.8 \\
\end{array}$ \\
\hline $\begin{array}{l}\text { Marital Status } \\
\text { Not married } \\
\text { Married }\end{array}$ & $\begin{array}{l}1.00 \\
1.22 \\
\end{array}$ & $\begin{array}{c}\text { Referent } \\
0.27-5.46\end{array}$ & $\begin{array}{l}1.00 \\
2.13 \\
\end{array}$ & $\begin{array}{c}\text { Referent } \\
0.42-10.8\end{array}$ & $\begin{array}{l}1.00 \\
2.87 \\
\end{array}$ & $\begin{array}{c}\text { Referent } \\
0.65-12.7\end{array}$ \\
\hline $\begin{array}{l}\text { Mom depression } \\
\text { No } \\
\text { Yes }\end{array}$ & $\begin{array}{l}1.00 \\
0.92 \\
\end{array}$ & $\begin{array}{c}\text { Referent } \\
0.20-4.34\end{array}$ & $\begin{array}{l}1.00 \\
1.33 \\
\end{array}$ & $\begin{array}{c}\text { Referent } \\
0.32-5.56\end{array}$ & $\begin{array}{l}1.00 \\
2.84 \\
\end{array}$ & $\begin{array}{c}\text { Referent } \\
0.78-10.4\end{array}$ \\
\hline $\begin{array}{l}\text { Education Status } \\
\text { Less than college degree } \\
\text { College degree or higher }\end{array}$ & $\begin{array}{l}1.00 \\
1.20\end{array}$ & $\begin{array}{c}\text { Referent } \\
0.38-3.82\end{array}$ & $\begin{array}{l}1.00 \\
0.78\end{array}$ & $\begin{array}{c}\text { Referent } \\
0.24-2.53\end{array}$ & $\begin{array}{l}1.00 \\
0.96\end{array}$ & $\begin{array}{c}\text { Referent } \\
0.33-2.84\end{array}$ \\
\hline
\end{tabular}


Table 52. Adjusted Odds Ratio of Silicon Exposure, Child and Mother Level Covariates, and Outcomes

\begin{tabular}{|c|c|c|c|c|c|c|}
\hline & $\begin{array}{c}\text { Social } \\
\text { Problems }\end{array}$ & $95 \%$ CI & $\begin{array}{l}\text { Thought } \\
\text { Problems }\end{array}$ & $95 \% \mathrm{CI}$ & $\begin{array}{c}\text { Obsessive- } \\
\text { Compulsive } \\
\text { Problems }\end{array}$ & $95 \%$ CI \\
\hline \multicolumn{7}{|l|}{ Silicon Exposure } \\
\hline 1st Quartile & 1.00 & Referent & 1.00 & Referent & 1.00 & Referent \\
\hline 2nd Quartile & 0.62 & $0.09-4.20$ & 0.81 & $0.12-5.51$ & 3.40 & $0.64-18.1$ \\
\hline 3rd Quartile & 1.16 & $0.23-5.83$ & 0.26 & $0.02-2.85$ & 1.71 & $0.36-8.12$ \\
\hline 4th Quartile & 0.39 & $0.05-3.12$ & 4.99 & $0.80-31.1$ & 0.61 & $0.09-3.93$ \\
\hline \multicolumn{7}{|l|}{ Age of Child } \\
\hline $6-14$ years & 1.23 & $0.90-1.68$ & 1.36 & $0.97-1.90$ & 1.21 & 0.91-1.59 \\
\hline \multicolumn{7}{|l|}{ Gender of Child } \\
\hline Female & 1.00 & Referent & 1.00 & Referent & 1.00 & Referent \\
\hline Male & 0.87 & $0.22-3.41$ & 0.39 & $0.09-1.64$ & 1.06 & $0.32-3.57$ \\
\hline \multicolumn{7}{|l|}{ Ethnicity of Child } \\
\hline Other Ethnicity & 1.00 & Referent & 1.00 & Referent & 1.00 & Referent \\
\hline White Non-Hispanic & 1.73 & $0.28-10.7$ & 0.65 & $0.11-3.76$ & 2.56 & $0.45-14.7$ \\
\hline \multicolumn{7}{|c|}{ Child Exposed to Smoking } \\
\hline No & 1.00 & Referent & 1.00 & Referent & 1.00 & Referent \\
\hline Yes & 0.64 & $0.10-4.09$ & 0.85 & $0.12-6.01$ & 0.96 & $0.21-4.47$ \\
\hline \multicolumn{7}{|l|}{ Child Born Preterm } \\
\hline No & 1.00 & Referent & 1.00 & Referent & 1.00 & Referent \\
\hline Yes & 1.29 & $0.27-6.15$ & 2.71 & $0.49-15.0$ & 0.80 & $0.17-3.69$ \\
\hline \multicolumn{7}{|l|}{ School Performance } \\
\hline High Performance & 1.00 & Referent & 1.00 & Referent & 1.00 & Referent \\
\hline Low Performance & 2.49 & $0.30-20.6$ & 7.49 & $0.87-64.6$ & 4.71 & $0.70-31.8$ \\
\hline \multicolumn{7}{|l|}{ Age Mother Had Child } \\
\hline $16-34$ years & 1.00 & Referent & 1.00 & Referent & 1.00 & Referent \\
\hline $35-50$ years & 0.57 & $0.09-3.52$ & 1.84 & $0.30-11.5$ & 0.66 & $0.15-2.97$ \\
\hline \multicolumn{7}{|c|}{ Smoked During Pregnancy } \\
\hline No & 1.00 & Referent & 1.00 & Referent & 1.00 & Referent \\
\hline Yes & 3.08 & $0.33-29.2$ & 0.92 & $0.11-7.92$ & 2.33 & 19.0 \\
\hline
\end{tabular}




\begin{tabular}{lcc|cc|cc}
$\begin{array}{l}\text { Marital Status } \\
\quad \text { Not married } \\
\text { Married }\end{array}$ & 1.00 & Referent & 1.00 & Referent & 1.00 & Referent \\
\hline $\begin{array}{l}\text { Mom depression } \\
\quad \text { No }\end{array}$ & 1.35 & $0.25-7.28$ & 3.46 & $0.53-22.5$ & 2.23 & $0.45-11.0$ \\
$\quad$ Yes & 1.00 & Referent & 1.00 & Referent & 1.00 & Referent \\
\hline $\begin{array}{l}\text { Education Status } \\
\text { Less than college degree }\end{array}$ & 1.14 & $0.20-6.43$ & 1.51 & $0.27-8.42$ & 2.63 & $0.58-11.9$ \\
$\quad$ College degree or higher & 1.00 & Referent & 1.00 & Referent & 1.00 & Referent \\
\hline
\end{tabular}

Table 53. Adjusted Odds Ratio of Chromium Exposure, Child Level Covariates, and Outcomes

\begin{tabular}{|c|c|c|c|c|c|c|}
\hline & $\begin{array}{c}\text { Social } \\
\text { Problems }\end{array}$ & $95 \% \mathrm{CI}$ & $\begin{array}{c}\text { Thought } \\
\text { Problems }\end{array}$ & $95 \% \mathrm{CI}$ & $\begin{array}{c}\text { Obsessive- } \\
\text { Compulsive } \\
\text { Problems }\end{array}$ & $95 \% \mathrm{CI}$ \\
\hline \multicolumn{7}{|l|}{ Chromium exposure } \\
\hline $1^{\text {st }}$ Quartile & 1.00 & Referent & 1.00 & Referent & 1.00 & Referent \\
\hline $2^{\text {nd }}$ Quartile & 2.53 & $0.49-13.1$ & 1.24 & $0.24-6.37$ & 1.38 & $0.27-7.06$ \\
\hline $3^{\text {rd }}$ Quartile & 0.33 & $0.04-2.91$ & 0.51 & $0.08-3.32$ & 1.98 & $0.38-10.4$ \\
\hline $4^{\text {th }}$ Quartile & 0.54 & $0.06-4.71$ & 1.68 & $0.29-9.78$ & 0.33 & $0.03-3.26$ \\
\hline \multicolumn{7}{|l|}{ Age of Child } \\
\hline 6-14 years old & 1.02 & $0.79-1.32$ & 1.24 & $0.97-1.58$ & 1.24 & $0.96-1.59$ \\
\hline \multicolumn{7}{|l|}{ Gender of Child } \\
\hline Female & 1.00 & Referent & 1.00 & Referent & 1.00 & Referent \\
\hline Male & 0.63 & $0.17-2.37$ & 0.41 & $0.12-1.40$ & 0.55 & $0.16-1.93$ \\
\hline \multicolumn{7}{|l|}{ Ethnicity of Child } \\
\hline Other Ethnicity & 1.00 & Referent & 1.00 & Referent & 1.00 & Referent \\
\hline White Non-Hispanic & 5.32 & $0.47-60.4$ & 1.44 & $0.28-7.28$ & 2.35 & $0.37-14.8$ \\
\hline \multicolumn{7}{|l|}{ Child Exposed to Smoking } \\
\hline No & 1.00 & Referent & 1.00 & Referent & 1.00 & Referent \\
\hline Yes & 1.71 & $0.38-7.70$ & 1.71 & $0.45-6.47$ & 2.04 & $0.50-8.24$ \\
\hline
\end{tabular}




\begin{tabular}{lcc|cc|cc}
\hline Child Born Preterm & & & & & \\
No & 1.00 & Referent & 1.00 & Referent & 1.00 & $\begin{array}{c}\text { Referent } \\
0.38-7.26\end{array}$ \\
Yes & 2.54 & $0.56-11.5$ & 6.09 & $1.44-25.8$ & 1.66 & \\
\hline School Performance & & & & & & \\
High Performance & 1.00 & Referent & 1.00 & Referent & 1.00 & Referent \\
Low Performance & 11.0 & $1.69-71.0$ & 7.82 & $1.37-44.6$ & 21.3 & $3.21-140.9$ \\
\hline
\end{tabular}

Table 54. Adjusted Odds Ratio of Chromium Exposure, Mother Level Covariates, and Outcomes

\begin{tabular}{|c|c|c|c|c|c|c|}
\hline & $\begin{array}{c}\text { Social } \\
\text { Problems }\end{array}$ & $95 \% \mathrm{CI}$ & $\begin{array}{c}\text { Thought } \\
\text { Problems }\end{array}$ & $95 \% \mathrm{CI}$ & $\begin{array}{c}\text { Obsessive } \\
\text { Compulsive } \\
\text { Problems } \\
\end{array}$ & 95\% CI \\
\hline \multicolumn{7}{|l|}{ Chromium exposure } \\
\hline $1^{\text {st }}$ Quartile & 1.00 & Referent & 1.00 & Referent & 1.00 & Referent \\
\hline $2^{\text {nd }}$ Quartile & 2.00 & $0.36-11.3$ & 0.72 & $0.13-4.04$ & 0.96 & $0.15-6.10$ \\
\hline $3^{\text {rd }}$ Quartile & 0.22 & $0.02-2.57$ & 0.19 & $0.02-2.07$ & 0.72 & $0.13-3.97$ \\
\hline $4^{\text {th }}$ Quartile & 0.40 & $0.03-4.58$ & 1.15 & $0.18-7.27$ & 0.32 & $0.03-3.88$ \\
\hline \multicolumn{7}{|l|}{ Age Mother Had Child } \\
\hline $16-34$ years & 1.00 & Referent & 1.00 & Referent & 1.00 & Referent \\
\hline $35-50$ years & 0.46 & $0.07-2.89$ & 0.94 & $0.18-5.04$ & 1.24 & $0.24-6.49$ \\
\hline \multicolumn{7}{|l|}{ Smoked During Pregnancy } \\
\hline No & 1.00 & Referent & 1.00 & Referent & 1.00 & Referent \\
\hline Yes & 1.55 & $0.18-13.6$ & 2.43 & $0.30-19.9$ & 0.45 & $0.04-5.85$ \\
\hline \multicolumn{7}{|l|}{ Marital Status } \\
\hline Not married & 1.00 & Referent & 1.00 & Referent & 1.00 & Referent \\
\hline Married & 1.21 & $0.19-7.54$ & 0.86 & $0.16-4.54$ & $>999$ & $<0.001->999$ \\
\hline \multicolumn{7}{|l|}{ Mom depression } \\
\hline No & 1.00 & Referent & 1.00 & Referent & 1.00 & Referent \\
\hline Yes & 1.68 & $0.30-9.46$ & 1.06 & $0.19-6.07$ & 2.14 & $0.36-12.8$ \\
\hline \multicolumn{7}{|l|}{ Education Status } \\
\hline Less than college degree & 1.00 & Referent & 1.00 & Referent & 1.00 & Referent \\
\hline College degree or higher & 1.23 & $0.29-5.26$ & 0.61 & $0.15-2.45$ & 1.66 & $0.41-6.75$ \\
\hline
\end{tabular}


Table 55. Adjusted Odds Ratio of Chromium Exposure, Child and Mother Level Covariates, and Outcomes

\begin{tabular}{|c|c|c|c|c|c|c|}
\hline & $\begin{array}{c}\text { Social } \\
\text { Problems }\end{array}$ & $95 \% \mathrm{CI}$ & $\begin{array}{l}\text { Thought } \\
\text { Problems }\end{array}$ & $95 \% \mathrm{CI}$ & $\begin{array}{c}\text { Obsessive- } \\
\text { Compulsive } \\
\text { Problems } \\
\end{array}$ & $95 \% \mathrm{CI}$ \\
\hline $\begin{array}{l}\text { Chromium Exposure } \\
\text { 1st Quartile } \\
\text { 2nd Quartile } \\
\text { 3rd Quartile } \\
\text { 4th Quartile }\end{array}$ & $\begin{array}{c}1.00 \\
4.59 \\
<0.001 \\
0.24\end{array}$ & $\begin{array}{c}\text { Referent } \\
0.47-44.6 \\
<0.001->999 \\
0.01-8.97\end{array}$ & $\begin{aligned} & 1.00 \\
& 1.06 \\
< & 0.001 \\
& 1.53\end{aligned}$ & $\begin{array}{c}\text { Referent } \\
0.12-9.41 \\
<0.001->999 \\
0.15-15.9\end{array}$ & $\begin{array}{l}1.00 \\
10.8 \\
0.63 \\
0.02\end{array}$ & $\begin{array}{c}\text { Referent } \\
0.39-301.2 \\
0.05-7.69 \\
<0.001-176.8\end{array}$ \\
\hline $\begin{array}{r}\text { Age of Child } \\
6-14 \text { years }\end{array}$ & 1.05 & $0.65-1.69$ & 1.12 & $0.74-1.72$ & 1.77 & $1.01-3.12$ \\
\hline $\begin{array}{l}\text { Gender of Child } \\
\text { Female } \\
\text { Male }\end{array}$ & $\begin{array}{l}1.00 \\
0.22\end{array}$ & $\begin{array}{c}\text { Referent } \\
0.02-2.94\end{array}$ & $\begin{array}{l}1.00 \\
0.19\end{array}$ & $\begin{array}{c}\text { Referent } \\
0.02-1.52\end{array}$ & $\begin{array}{l}1.00 \\
0.26\end{array}$ & $\begin{array}{c}\text { Referent } \\
0.03-2.56\end{array}$ \\
\hline $\begin{array}{c}\text { Ethnicity of Child } \\
\text { Other Ethnicity } \\
\text { White Non-Hispanic }\end{array}$ & $\begin{array}{l}1.00 \\
3.53\end{array}$ & $\begin{array}{c}\text { Referent } \\
0.20-61.7\end{array}$ & $\begin{array}{l}1.00 \\
0.80\end{array}$ & $\begin{array}{c}\text { Referent } \\
0.08-7.76\end{array}$ & $\begin{array}{l}1.00 \\
0.61\end{array}$ & $\begin{array}{c}\text { Referent } \\
0.04-8.36\end{array}$ \\
\hline $\begin{array}{l}\text { Child Exposed to Smoking } \\
\text { No } \\
\text { Yes }\end{array}$ & $\begin{array}{l}1.00 \\
0.44\end{array}$ & $\begin{array}{c}\text { Referent } \\
0.03-7.35\end{array}$ & $\begin{array}{l}1.00 \\
0.50\end{array}$ & $\begin{array}{c}\text { Referent } \\
0.04-6.28\end{array}$ & $\begin{array}{l}1.00 \\
0.31\end{array}$ & $\begin{array}{c}\text { Referent } \\
0.01-7.43\end{array}$ \\
\hline $\begin{array}{l}\text { Child Born Preterm } \\
\text { No } \\
\text { Yes }\end{array}$ & $\begin{array}{l}1.00 \\
1.24\end{array}$ & $\begin{array}{c}\text { Referent } \\
0.12-12.7 \\
\end{array}$ & $\begin{array}{l}1.00 \\
5.35\end{array}$ & $\begin{array}{c}\text { Referent } \\
0.56-51.6\end{array}$ & $\begin{array}{l}1.00 \\
0.18\end{array}$ & $\begin{array}{c}\text { Referent } \\
0.003-10.0\end{array}$ \\
\hline $\begin{array}{c}\text { School Performance } \\
\text { High Performance } \\
\text { Low Performance } \\
\end{array}$ & $\begin{array}{l}1.00 \\
12.3\end{array}$ & $\begin{array}{c}\text { Referent } \\
0.45-335.8\end{array}$ & $\begin{array}{l}1.00 \\
4.28\end{array}$ & $\begin{array}{c}\text { Referent } \\
0.19-99\end{array}$ & $\begin{array}{c}1.00 \\
665.7\end{array}$ & $\begin{array}{c}\text { Referent } \\
5.53->999\end{array}$ \\
\hline $\begin{array}{c}\text { Age Mother Had Child } \\
\text { 16-34 years } \\
\text { 35-50 years } \\
\end{array}$ & $\begin{array}{l}1.00 \\
0.34\end{array}$ & $\begin{array}{c}\text { Referent } \\
0.03-4.12\end{array}$ & $\begin{array}{l}1.00 \\
0.46\end{array}$ & $\begin{array}{c}\text { Referent } \\
0.05-4.56\end{array}$ & $\begin{array}{l}1.00 \\
8.60 \\
\end{array}$ & $\begin{array}{c}\text { Referent } \\
0.53-139.4\end{array}$ \\
\hline $\begin{array}{l}\text { Smoked During Pregnancy } \\
\text { No } \\
\text { Yes }\end{array}$ & $\begin{array}{l}1.00 \\
1.70\end{array}$ & $\begin{array}{c}\text { Referent } \\
0.11-27.6\end{array}$ & $\begin{array}{l}1.00 \\
2.39\end{array}$ & $\begin{array}{c}\text { Referent } \\
0.19-29.8\end{array}$ & $\begin{array}{l}1.00 \\
0.29\end{array}$ & $\begin{array}{c}\text { Referent } \\
0.01-8.16\end{array}$ \\
\hline
\end{tabular}




\begin{tabular}{lcc|cc|cc}
$\begin{array}{l}\text { Marital Status } \\
\quad \text { Not married } \\
\quad \text { Married }\end{array}$ & 1.00 & Referent & 1.00 & Referent & 1.00 & $\begin{array}{c}\text { Referent } \\
<0.01->999\end{array}$ \\
\hline $\begin{array}{l}\text { Mom depression } \\
\quad \text { No }\end{array}$ & 1.48 & $0.16-13.9$ & 2.10 & $0.24-18.3$ & $>999$ & Referent \\
$\quad$ Yes & 1.00 & Referent & 1.00 & Referent & 1.00 & $0.02-6.71$ \\
\hline $\begin{array}{l}\text { Education Status } \\
\quad \text { Less than college degree }\end{array}$ & 1.29 & $0.13-12.7$ & 1.79 & $0.17-18.6$ & 0.41 & Referent \\
$\quad$ College degree or higher & 1.00 & Referent & 1.00 & Referent & 1.00 & $0.88-238.3$ \\
\hline
\end{tabular}

Table 56. Logistic Regression with Social Problems, Aluminum Exposure and Variables Identified from Purposeful Selection Modeling

\begin{tabular}{lccc}
\cline { 2 - 4 } Variable & OR & 95\% CI & P-value \\
\hline Aluminum & & & \\
$1^{\text {st }}$ Quartile & 1.00 & Referent & \\
$2^{\text {nd }}$ Quartile & 0.41 & $0.08-2.21$ & 0.299 \\
$3^{\text {rd }}$ Quartile & 0.44 & $0.08-2.53$ & 0.356 \\
$4^{\text {th }}$ Quartile & 0.58 & $0.10-3.39$ & 0.547 \\
Age of Child & & & \\
$\quad$ 6-14 years & 1.08 & $0.84-1.39$ & 0.548 \\
Ethnicity of Child & & & \\
$\quad$ Other Races & 1.00 & Referent & 0.235 \\
$\quad$ White non-Hispanic & 2.78 & $0.52-15.0$ & \\
School Performance & & & \\
$\quad$ High Performance & 1.00 & Referent & 0.094 \\
$\quad$ Low Performance & 4.94 & $0.76-32.1$ & \\
Smoked During Pregnancy & & & \\
$\quad$ No & 1.00 & Referent & 0.018 \\
$\quad$ Yes & 4.86 & $1.32-18.0$ & \\
\hline
\end{tabular}


Table 57. Logistic Regression with Thought Problems, Aluminum Exposure and Variables Identified from Purposeful Selection Modeling

\begin{tabular}{lccc}
\cline { 2 - 4 } Variable & OR & 95\% CI & P-value \\
\hline Aluminum & & & \\
$1^{\text {st }}$ Quartile & 1.00 & Referent & \\
$2^{\text {nd }}$ Quartile & 0.53 & $0.11-2.68$ & 0.448 \\
$3^{\text {rd }}$ Quartile & 0.87 & $0.16-4.62$ & 0.868 \\
$4^{\text {th }}$ Quartile & 1.98 & $0.45-8.62$ & 0.363 \\
School Performance & & & \\
$\quad$ High Performance & 1.00 & Referent & 0.005 \\
$\quad$ Low Performance & 9.49 & $1.97-45.8$ & \\
Smoked During Pregnancy & & & \\
$\quad$ No & 1.00 & Referent & 0.050 \\
$\quad$ Yes & 3.30 & $1.00-10.9$ & \\
Preterm Birth & & & \\
$\quad$ No & 1.00 & Referent & 0.078 \\
$\quad$ Yes & 2.84 & $0.89-9.07$ & \\
\hline
\end{tabular}

Table 58. Logistic Regression with Obsessive-Compulsive Problems, Aluminum Exposure and Variables Identified from Purposeful Selection Modeling

\begin{tabular}{lccc}
\cline { 2 - 4 } Variable & OR & $\mathbf{9 5 \%}$ CI & P-value \\
\hline Aluminum & & & \\
$1^{\text {st }}$ Quartile & 1.00 & Referent & \\
$2^{\text {nd }}$ Quartile & 1.50 & $0.28-7.94$ & 0.634 \\
$3^{\text {rd }}$ Quartile & 2.51 & $0.48-13.2$ & 0.277 \\
$4^{\text {th }}$ Quartile & 1.13 & $0.18-7.17$ & 0.900 \\
Age of Child & & & \\
$\quad$ 6-14 years & 1.19 & $0.95-1.48$ & 0.130 \\
Smoke & & & \\
$\quad$ No & 1.00 & Referent & 0.409 \\
$\quad$ Yes & 1.64 & $0.51-5.27$ & \\
Ethnicity of Child & & & \\
$\quad \begin{array}{l}\text { Other Races } \\
\quad \text { White non-Hispanic }\end{array}$ & 1.00 & Referent & 0.105 \\
School Performance & 3.91 & $0.75-20.3$ & \\
$\quad \begin{array}{l}\text { High Performance } \\
\quad \text { Low Performance }\end{array}$ & 1.00 & Referent & 0.094 \\
Smoked During Pregnancy & 3.79 & $0.64-22.5$ & \\
$\quad$ No & & & \\
$\quad$ Yes & 1.00 & Referent & 0.133 \\
\hline
\end{tabular}


Table 59. Logistic Regression with Social Problems, Copper Exposure and Variables Identified from Purposeful Selection Modeling

\begin{tabular}{lccc} 
Variable & OR & 95\% CI & P-value \\
\hline Copper & & & \\
$1^{\text {st }}$ Quartile & 1.00 & Referent & \\
$2^{\text {nd }}$ Quartile & 3.77 & $0.61-23.4$ & 0.154 \\
$3^{\text {rd }}$ Quartile & 2.62 & $0.38-17.8$ & 0.326 \\
$4^{\text {th }}$ Quartile & 4.47 & $0.72-27.9$ & 0.109 \\
Age of Child & & & \\
$\quad$ 6-14 years & 1.14 & $0.92-1.41$ & 0.240 \\
Ethnicity of Child & & & \\
$\quad \begin{array}{l}\text { Other Races } \\
\quad \text { White non-Hispanic }\end{array}$ & 1.00 & Referent & 0.295 \\
School Performance & 2.45 & $0.46-13.2$ & \\
$\quad$ High Performance & & & \\
$\quad$ Low Performance & 1.00 & Referent & 0.039 \\
Smoked During Pregnancy & 5.09 & $1.09-23.8$ & \\
$\quad$ No & & & \\
$\quad$ Yes & 1.00 & Referent & 0.016 \\
$\quad$ & 4.40 & $1.32-14.6$ & \\
\hline
\end{tabular}

Table 60. Logistic Regression with Thought Problems, Copper Exposure and Variables Identified from Purposeful Selection Modeling

\begin{tabular}{lccc}
\cline { 2 - 4 } Variable & OR & 95\% CI & P-value \\
\hline Copper & & & \\
$1^{\text {st }}$ Quartile & 1.00 & Referent & \\
$2^{\text {nd }}$ Quartile & 1.84 & $0.50-6.73$ & 0.359 \\
$3^{\text {rd }}$ Quartile & 0.98 & $0.24-4.03$ & 0.972 \\
$4^{\text {th }}$ Quartile & 1.49 & $0.40-5.59$ & 0.558 \\
School Performance & & & \\
$\quad$ High Performance & 1.00 & Referent & 0.024 \\
$\quad$ Low Performance & 4.30 & $1.21-15.3$ & \\
Smoked During Pregnancy & & & \\
$\quad$ No & 1.00 & Referent & 0.035 \\
$\quad$ Yes & 3.20 & $1.09-9.42$ & \\
\hline
\end{tabular}


Table 61. Logistic Regression with Obsessive-Compulsive Problems, Copper Exposure and Variables Identified from Purposeful Selection Modeling

\begin{tabular}{lccc}
\cline { 2 - 4 } Variable & OR & 95\% CI & P-value \\
\hline Copper & & & \\
$1^{\text {st }}$ Quartile & 1.00 & Referent & \\
$2^{\text {nd }}$ Quartile & 1.46 & $0.39-5.49$ & 0.579 \\
$3^{\text {rd }}$ Quartile & 1.37 & $0.60-5.25$ & 0.643 \\
$4^{\text {th }}$ Quartile & 1.27 & $0.31-5.12$ & 0.739 \\
Age of Child & & \\
$\quad$ 6-14 years & 1.18 & $0.97-1.43$ & 0.091 \\
Smoke & & & \\
$\quad$ No & 1.00 & Referent & 0.585 \\
$\quad$ Yes & 1.37 & $0.45-4.19$ & \\
Ethnicity of Child & & & \\
$\quad \begin{array}{l}\text { Other Races } \\
\text { White non-Hispanic }\end{array}$ & 1.00 & Referent & 0.056 \\
School Performance & 4.90 & $0.96-25.0$ & \\
$\quad \begin{array}{l}\text { High Performance } \\
\quad \text { Low Performance }\end{array}$ & 1.00 & Referent & 0.011 \\
Smoked During Pregnancy & 6.91 & $1.55-30.7$ & \\
$\quad$ No & & & \\
$\quad$ Yes & 1.00 & Referent & 0.243 \\
\hline
\end{tabular}

Table 62. Logistic Regression with Social Problems, Iron Exposure and Variables Identified from Purposeful Selection Modeling

\begin{tabular}{|c|c|c|c|}
\hline Variable & OR & 95\% CI & P-value \\
\hline \multicolumn{4}{|l|}{ Iron } \\
\hline $1^{\text {st }}$ Quartile & 1.00 & Referent & \\
\hline $2^{\text {nd }}$ Quartile & 0.57 & $0.12-2.67$ & 0.474 \\
\hline $3^{\text {rd }}$ Quartile & 0.72 & $0.15-3.44$ & 0.679 \\
\hline $4^{\text {th }}$ Quartile & 0.84 & $0.16-4.42$ & 0.835 \\
\hline \multicolumn{4}{|l|}{ Age of Child } \\
\hline $6-14$ years & 1.13 & $0.88-1.41$ & 0.374 \\
\hline \multicolumn{4}{|l|}{ Ethnicity of Child } \\
\hline Other Races & 1.00 & Referent & 0.251 \\
\hline White non-Hispanic & 2.69 & $0.50-14.5$ & \\
\hline \multicolumn{4}{|l|}{ School Performance } \\
\hline High Performance & 1.00 & Referent & 0.037 \\
\hline Low Performance & 5.34 & $1.11-25.8$ & \\
\hline \multicolumn{4}{|c|}{ Smoked During Pregnancy } \\
\hline No & 1.00 & Referent & 0.019 \\
\hline Yes & 4.34 & $1.27-14.8$ & \\
\hline
\end{tabular}


Table 63. Logistic Regression with Thought Problems, Iron Exposure and Variables Identified from Purposeful Selection Modeling

\begin{tabular}{lccc}
\cline { 2 - 4 } Variable & OR & $\mathbf{9 5 \%}$ CI & P-value \\
\hline Iron & & & \\
$1^{\text {st }}$ Quartile & 1.00 & Referent & \\
$2^{\text {nd }}$ Quartile & 0.22 & $0.05-0.92$ & 0.039 \\
$3^{\text {rd }}$ Quartile & 0.62 & $0.18-2.10$ & 0.441 \\
$4^{\text {th }}$ Quartile & 0.58 & $0.17-2.01$ & 0.391 \\
School Performance & & & \\
$\quad$ High Performance & 1.00 & Referent & 0.009 \\
$\quad$ Low Performance & 5.89 & $1.53-22.7$ & \\
Smoked During Pregnancy & & & \\
$\quad$ No & 1.00 & Referent & 0.032 \\
$\quad$ Yes & 3.43 & $1.12-10.5$ & \\
\hline
\end{tabular}

Table 64. Logistic Regression with Obsessive-Compulsive Problems, Iron Exposure and Variables Identified from Purposeful Selection Modeling

\begin{tabular}{lccc} 
Variable & OR & $\mathbf{9 5 \%}$ CI & P-value \\
\hline $\begin{array}{l}\text { Iron } \\
1^{\text {st }} \text { Quartile }\end{array}$ & 1.00 & Referent & \\
$2^{\text {nd }}$ Quartile & 0.86 & $0.23-3.21$ & 0.820 \\
$3^{\text {rd }}$ Quartile & 0.93 & $0.25-3.51$ & 0.914 \\
$4^{\text {th }}$ Quartile & 0.81 & $0.18-3.58$ & 0.780 \\
Age of Child & & & \\
$\quad$ 6-14 years & 1.16 & $0.95-1.43$ & 0.156 \\
$\begin{array}{l}\text { Smoke } \\
\quad \text { No }\end{array}$ & & & \\
$\quad$ Yes & 1.00 & Referent & 0.548 \\
Ethnicity of Child & 1.39 & $0.47-4.11$ & \\
$\quad \begin{array}{l}\text { Other Races } \\
\text { White non-Hispanic }\end{array}$ & 1.00 & Referent & 0.052 \\
School Performance & 5.04 & $0.98-25.8$ & \\
$\quad$ High Performance & & & \\
$\quad$ Low Performance & 1.00 & Referent & 0.013 \\
Smoked During Pregnancy & 7.02 & $1.51-32.7$ & \\
$\quad \begin{array}{l}\text { No } \\
\quad \text { Yes }\end{array}$ & 1.00 & Referent & 0.251 \\
\hline
\end{tabular}


Table 65. Logistic Regression with Social Problems, Zinc Exposure and Variables Identified from Purposeful Selection Modeling

\begin{tabular}{lccc} 
Variable & OR & 95\% CI & P-value \\
\hline $\begin{array}{l}\text { Zinc } \\
1^{\text {st }} \text { Quartile }\end{array}$ & 1.00 & Referent & \\
$2^{\text {nd }}$ Quartile & 0.41 & $0.08-2.21$ & 0.297 \\
$3^{\text {rd }}$ Quartile & 0.63 & $0.12-3.23$ & 0.579 \\
$4^{\text {th }}$ Quartile & 2.83 & $0.62-12.9$ & 0.179 \\
Age of Child & & & \\
$\quad$ 6-14 years & 1.25 & $0.97-1.59$ & 0.081 \\
Ethnicity of Child & & & \\
$\quad$ Other Races & 1.00 & Referent & 0.217 \\
$\quad$ White non-Hispanic & 2.95 & $0.53-16.4$ & \\
School Performance & & & \\
$\quad$ High Performance & & & \\
$\quad$ Low Performance & 1.00 & Referent & 0.029 \\
Smoked During Pregnancy & 6.06 & $1.20-30.6$ & \\
$\quad$ No & & & \\
$\quad$ Yes & 1.00 & Referent & 0.024 \\
$\quad$ & 4.17 & $1.21-14.4$ & \\
\hline
\end{tabular}

Table 66. Logistic Regression with Thought Problems, Zinc Exposure and Variables Identified from Purposeful Selection Modeling

\begin{tabular}{lccc} 
Variable & OR & 95\% CI & P-value \\
\hline Zinc & & & \\
$1^{\text {st }}$ Quartile & 1.00 & Referent & \\
$2^{\text {nd }}$ Quartile & 0.33 & $0.09-1.26$ & 0.105 \\
$3^{\text {rd }}$ Quartile & 0.63 & $0.19-2.12$ & 0.455 \\
$4^{\text {th }}$ Quartile & 0.41 & $0.11-1.52$ & 0.183 \\
School Performance & & & \\
$\quad$ High Performance & 1.00 & Referent & 0.012 \\
$\quad$ Low Performance & 5.33 & $1.44-19.7$ & \\
Smoked During Pregnancy & & & \\
$\quad$ No & 1.00 & Referent & 0.016 \\
$\quad$ Yes & 4.01 & $1.29-12.4$ & \\
\hline
\end{tabular}

Table 67. Logistic Regression with Obsessive-Compulsive Problems, Zinc Exposure and Variables Identified from Purposeful Selection Modeling

\begin{tabular}{lccc}
\cline { 2 - 4 } Variable & OR & 95\% CI & P-value \\
\hline Zinc & & & \\
$1^{\text {st }}$ Quartile & 1.00 & Referent & \\
$2^{\text {nd }}$ Quartile & 0.89 & $0.24-3.32$ & 0.866 \\
$3^{\text {rd }}$ Quartile & 1.28 & $0.35-4.64$ & 0.710 \\
\hline
\end{tabular}




\begin{tabular}{lccc}
\hline $\begin{array}{l}4^{\text {th }} \text { Quartile } \\
\text { Age of Child } \\
\text { 6-14 years }\end{array}$ & 1.32 & $0.32-5.43$ & 0.705 \\
$\begin{array}{l}\text { Smoke } \\
\quad \text { No }\end{array}$ & 1.20 & $0.98-1.47$ & 0.087 \\
$\quad$ Yes & 1.00 & Referent & 0.562 \\
Ethnicity of Child & 1.38 & $0.46-4.10$ & \\
$\quad \begin{array}{l}\text { Other Races } \\
\quad \text { White non-Hispanic }\end{array}$ & 1.00 & Referent & 0.054 \\
$\begin{array}{l}\text { School Performance } \\
\quad \text { High Performance }\end{array}$ & 4.85 & $0.97-24.2$ & \\
$\quad$ Low Performance & 1.00 & Referent & 0.011 \\
$\begin{array}{l}\text { Smoked During Pregnancy } \\
\quad \text { No }\end{array}$ & 7.03 & $1.57-31.5$ & \\
$\quad$ Yes & 1.00 & Referent & 0.263 \\
\hline
\end{tabular}

Table 68. Logistic Regression with Social Problems, Titanium Exposure and Variables Identified from Purposeful Selection Modeling

\begin{tabular}{lccc}
\cline { 2 - 4 } Variable & OR & 95\% CI & P-value \\
\hline Titanium & & & \\
$1^{\text {st }}$ Quartile & 1.00 & Referent & \\
$2^{\text {nd }}$ Quartile & 1.39 & $0.06-29.3$ & 0.833 \\
$3^{\text {rd }}$ Quartile & 3.37 & $0.19-60.7$ & 0.411 \\
$4^{\text {th }}$ Quartile & 5.21 & $0.26-104.5$ & 0.281 \\
Gender of Child & & & \\
$\quad$ Female & 1.00 & Referent & 0.112 \\
$\quad$ Male & 5.27 & $0.68-40.9$ & \\
School Performance & & & \\
$\quad$ High Performance & 1.00 & Referent & 0.020 \\
$\quad$ Low Performance & 14.4 & $1.52-136$ & \\
Smoked During Pregnancy & & & \\
$\quad$ No & 1.00 & Referent & 0.016 \\
$\quad$ Yes & 8.66 & $1.50-50.0$ & \\
Preterm & & & \\
$\quad$ No & 1.00 & Referent & 0.118 \\
$\quad$ Yes & 4.58 & $0.68-30.9$ & \\
\hline
\end{tabular}


Table 69. Logistic Regression with Thought Problems, Titanium Exposure and Variables Identified from Purposeful Selection Modeling

\begin{tabular}{lccc} 
Variable & OR & 95\% CI & P-value \\
\hline Titanium & & & \\
$1^{\text {st }}$ Quartile & 1.00 & Referent & \\
$2^{\text {nd }}$ Quartile & 0.64 & $0.08-5.37$ & 0.683 \\
$3^{\text {rd }}$ Quartile & 1.03 & $0.13-8.08$ & 0.975 \\
$4^{\text {th }}$ Quartile & 1.19 & $0.14-10.5$ & 0.873 \\
School Performance & & & \\
$\quad$ High Performance & 1.00 & Referent & 0.030 \\
$\quad$ Low Performance & 7.65 & $1.22-48.0$ & \\
Smoked During Pregnancy & & & \\
$\quad$ No & 1.00 & Referent & 0.012 \\
$\quad$ Yes & 6.72 & $1.52-29.6$ & \\
\hline
\end{tabular}

Table 70. Logistic Regression with Obsessive-Compulsive Problems, Titanium Exposure and Variables Identified from Purposeful Selection Modeling

\begin{tabular}{lccc}
\cline { 2 - 4 } Variable & OR & 95\% CI & P-value \\
\hline $\begin{array}{l}\text { Titanium } \\
1^{\text {st }} \text { Quartile }\end{array}$ & 1.00 & Referent & \\
$2^{\text {nd }}$ Quartile & 1.12 & $0.19-6.58$ & 0.903 \\
$3^{\text {rd }}$ Quartile & 1.13 & $0.18-7.00$ & 0.895 \\
$4^{\text {th }}$ Quartile & 0.53 & $0.06-4.67$ & 0.566 \\
Age of Child & & & \\
$\quad$ 6-14 years & 1.18 & $0.91-1.53$ & 0.223 \\
Smoke & & & \\
$\quad$ No & 1.00 & Referent & 0.970 \\
$\quad$ Yes & 0.97 & $0.23-4.14$ & \\
Ethnicity of Child & & & \\
$\quad$ Other Races & 1.00 & Referent & 0.443 \\
$\quad$ White non-Hispanic & 2.43 & $0.25-23.4$ & \\
School Performance & & & \\
$\quad$ High Performance & 1.00 & Referent & 0.083 \\
$\quad$ Low Performance & 5.28 & $0.81-34.7$ & \\
Smoked During Pregnancy & & & \\
$\quad \begin{array}{l}\text { No } \\
\quad \text { Yes }\end{array}$ & 1.00 & Referent & 0.327 \\
\hline
\end{tabular}


Table 71. Logistic Regression with Social Problems, Nickel Exposure and Variables Identified from Purposeful Selection Modeling

\begin{tabular}{lccc}
\cline { 2 - 4 } Variable & OR & 95\% CI & P-value \\
\hline Nickel & & & \\
$1^{\text {st }}$ Quartile & 1.00 & Referent & \\
$2^{\text {nd }}$ Quartile & 0.61 & $0.06-5.81$ & 0.665 \\
$3^{\text {rd }}$ Quartile & 1.79 & $0.27-12.0$ & 0.549 \\
$4^{\text {th }}$ Quartile & 1.77 & $0.25-12.7$ & 0.569 \\
Ethnicity of Child & & & \\
$\quad$ Other Races & 1.00 & Referent & 0.921 \\
$\quad$ White non-Hispanic & 1.10 & $0.18-6.87$ & \\
School Performance & & & \\
$\quad$ High Performance & 1.00 & Referent & 0.309 \\
$\quad$ Low Performance & 2.85 & $0.38-21.4$ & \\
Smoked During Pregnancy & & & \\
$\quad$ No & 1.00 & Referent & 0.033 \\
$\quad$ Yes & 4.72 & $1.13-19.6$ & \\
Preterm & & & \\
$\quad$ No & 1.00 & Referent & 0.154 \\
$\quad$ Yes & 2.80 & $0.68-11.5$ & \\
\hline
\end{tabular}

Table 72. Logistic Regression with Thought Problems, Nickel Exposure and Variables Identified from Purposeful Selection Modeling

\begin{tabular}{lccc}
\cline { 2 - 4 } Variable & OR & 95\% CI & P-value \\
\hline Nickel & & & \\
$1^{\text {st }}$ Quartile & 1.00 & Referent & \\
$2^{\text {nd }}$ Quartile & 0.78 & $0.12-5.03$ & 0.794 \\
$3^{\text {rd }}$ Quartile & 1.82 & $0.36-9.31$ & 0.474 \\
$4^{\text {th }}$ Quartile & 1.33 & $0.24-7.30$ & 0.740 \\
School Performance & & & \\
$\quad$ High Performance & 1.00 & Referent & 0.050 \\
$\quad$ Low Performance & 5.22 & $1.00-27.3$ & \\
Smoked During Pregnancy & & & \\
$\quad$ No & 1.00 & Referent & 0.134 \\
$\quad$ Yes & 2.76 & $0.73-10.5$ & \\
Preterm & & & \\
$\quad$ No & 1.00 & Referent & 0.140 \\
$\quad$ Yes & 2.60 & $0.73-9.25$ & \\
\hline
\end{tabular}


Table 73. Logistic Regression with Obsessive-Compulsive Problems, Nickel Exposure and Variables Identified from Purposeful Selection Modeling

\begin{tabular}{lccc}
\cline { 2 - 4 } Variable & OR & 95\% CI & P-value \\
\hline Nickel & & & \\
$1^{\text {st }}$ Quartile & 1.00 & Referent & \\
$2^{\text {nd }}$ Quartile & 0.66 & $0.12-3.47$ & 0.620 \\
$3^{\text {rd }}$ Quartile & 0.61 & $0.12-3.15$ & 0.553 \\
$4^{\text {th }}$ Quartile & 0.76 & $0.14-4.24$ & 0.758 \\
Smoke & & & \\
$\quad$ No & 1.00 & Referent & 0.808 \\
$\quad$ Yes & 1.20 & $0.28-5.09$ & \\
Ethnicity of Child & & & \\
$\quad \begin{array}{l}\text { Other Races } \\
\text { White non-Hispanic }\end{array}$ & 1.00 & Referent & 0.200 \\
School Performance & 3.06 & $0.55-16.8$ & \\
$\quad \begin{array}{l}\text { High Performance } \\
\text { Low Performance }\end{array}$ & 1.00 & Referent & 0.131 \\
Smoked During Pregnancy & 4.32 & $0.65-28.8$ & \\
$\quad$ No & & & \\
$\quad$ Yes & 1.00 & Referent & 0.518 \\
\hline
\end{tabular}

Table 74. Logistic Regression with Social Problems, Silicon Exposure and Variables Identified from Purposeful Selection Modeling

\begin{tabular}{lccc} 
Variable & OR & 95\% CI & P-value \\
\hline $\begin{array}{l}\text { Silicon } \\
1^{\text {st }} \text { Quartile }\end{array}$ & 1.00 & Referent & \\
$2^{\text {nd }}$ Quartile & 0.54 & $0.11-2.62$ & 0.444 \\
$3^{\text {rd }}$ Quartile & 0.92 & $0.22-3.84$ & 0.913 \\
$4^{\text {th }}$ Quartile & 0.78 & $0.16-3.77$ & 0.752 \\
Age of Child & & & \\
$\quad$ 6-14 years & 1.11 & $0.88-1.41$ & 0.372 \\
Ethnicity of Child & & & \\
$\quad$ Other Races & 1.00 & Referent & 0.272 \\
$\quad$ White non-Hispanic & 2.52 & $0.49-13.0$ & \\
School Performance & & & \\
$\quad$ High Performance & & & \\
$\quad$ Low Performance & 1.00 & Referent & 0.054 \\
Smoked During Pregnancy & 4.54 & $0.98-21.0$ & \\
$\quad$ No & & & \\
$\quad$ Yes & 1.00 & Referent & 0.020 \\
$\quad$ & 4.44 & $1.27-15.5$ & \\
\hline
\end{tabular}


Table 75. Logistic Regression with Thought Problems, Silicon Exposure and Variables Identified from Purposeful Selection Modeling

\begin{tabular}{lccc} 
Variable & OR & 95\% CI & P-value \\
\hline Silicon & & & \\
$1^{\text {st }}$ Quartile & 1.00 & Referent & \\
$2^{\text {nd }}$ Quartile & 0.90 & $0.25-3.27$ & 0.878 \\
$3^{\text {rd }}$ Quartile & 0.33 & $0.07-1.59$ & 0.168 \\
$4^{\text {th }}$ Quartile & 1.95 & $0.59-6.40$ & 0.271 \\
School Performance & & & \\
$\quad$ High Performance & 1.00 & Referent & 0.009 \\
$\quad$ Low Performance & 5.96 & $1.55-22.9$ & \\
Smoked During Pregnancy & & & \\
$\quad$ No & 1.00 & Referent & 0.084 \\
$\quad$ Yes & 2.69 & $0.88-8.26$ & \\
\hline
\end{tabular}

Table 76. Logistic Regression with Obsessive-Compulsive Problems, Silicon Exposure and Variables Identified from Purposeful Selection Modeling

\begin{tabular}{lccc}
\cline { 2 - 4 } Variable & OR & 95\% C.I & P-value \\
\hline $\begin{array}{l}\text { Silicon } \\
1^{\text {st }} \text { Quartile }\end{array}$ & 1.00 & Referent & \\
$2^{\text {nd }}$ Quartile & 2.05 & $0.55-7.57$ & 0.284 \\
$3^{\text {rd }}$ Quartile & 1.07 & $0.29-3.99$ & 0.918 \\
$4^{\text {th }}$ Quartile & 0.90 & $0.21-3.89$ & 0.889 \\
Age of Child & & & \\
$\quad$ 6-14 years & 1.15 & $0.94-1.41$ & 0.170 \\
Smoke & & & \\
$\quad$ No & 1.00 & Referent & 0.656 \\
$\quad$ Yes & 1.28 & $0.43-3.80$ & \\
Ethnicity of Child & & & \\
$\quad$ Other Races & 1.00 & Referent & 0.048 \\
$\quad$ White non-Hispanic & 4.97 & $1.02-24.3$ & \\
School Performance & & & \\
$\quad$ High Performance & 1.00 & Referent & 0.013 \\
$\quad$ Low Performance & 7.09 & $1.51-33.2$ & \\
Smoked During Pregnancy & & & \\
$\quad \begin{array}{l}\text { No } \\
\quad \text { Yes }\end{array}$ & 1.00 & Referent & 0.158 \\
\end{tabular}


Table 77. Logistic Regression with Social Problems, Chromium Exposure and Variables Identified from Purposeful Selection Modeling

\begin{tabular}{|c|c|c|c|}
\hline Variable & OR & $95 \% \mathrm{CI}$ & P-value \\
\hline \multicolumn{4}{|l|}{ Chromium } \\
\hline $1^{\text {st }}$ Quartile & 1.00 & Referent & \\
\hline $2^{\text {nd }}$ Quartile & 1.68 & $0.31-9.04$ & 0.548 \\
\hline $3^{\text {rd }}$ Quartile & 0.23 & $0.02-2.41$ & 0.220 \\
\hline $4^{\text {th }}$ Quartile & 0.48 & $0.05-4.45$ & 0.515 \\
\hline \multicolumn{4}{|l|}{ Age of Child } \\
\hline $6-14$ years & 1.05 & $0.81-1.36$ & 0.727 \\
\hline \multicolumn{4}{|l|}{ Ethnicity of Child } \\
\hline Other Races & 1.00 & Referent & 0.196 \\
\hline White non-Hispanic & 4.62 & $0.46-46.9$ & \\
\hline \multicolumn{4}{|l|}{ School Performance } \\
\hline High Performance & 1.00 & Referent & 0.009 \\
\hline Low Performance & 11.6 & $1.81-74.4$ & \\
\hline \multicolumn{4}{|c|}{ Smoked During Pregnancy } \\
\hline No & 1.00 & Referent & 0.006 \\
\hline Yes & 9.04 & $1.89-43.1$ & \\
\hline
\end{tabular}

Table 78. Logistic Regression with Thought Problems, Chromium Exposure and Variables Identified from Purposeful Selection Modeling

\begin{tabular}{lccc}
\cline { 2 - 4 } Variable & OR & 95\% CI & P-value \\
\hline Chromium & & & \\
$1^{\text {st }}$ Quartile & 1.00 & Referent & \\
$2^{\text {nd }}$ Quartile & 0.78 & $0.17-3.65$ & 0.752 \\
$3^{\text {rd }}$ Quartile & 0.37 & $0.06-2.26$ & 0.283 \\
$4^{\text {th }}$ Quartile & 1.00 & $0.20-5.02$ & 0.996 \\
School Performance & & & \\
$\quad$ High Performance & 1.00 & Referent & 0.045 \\
$\quad$ Low Performance & 4.82 & $1.04-22.4$ & \\
Smoked During Pregnancy & & & \\
$\quad$ No & 1.00 & Referent & 0.015 \\
$\quad$ Yes & 5.32 & $1.39-20.4$ & \\
\hline
\end{tabular}


Table 79. Logistic Regression with Obsessive-Compulsive Problems, Chromium Exposure and Variables Identified from Purposeful Selection Modeling

\begin{tabular}{lccc}
\cline { 2 - 4 } Variable & OR & 95\% CI & P-value \\
\hline $\begin{array}{l}\text { Chromium } \\
1^{\text {st }} \text { Quartile }\end{array}$ & 1.00 & Referent & \\
$2^{\text {nd }}$ Quartile & 0.89 & $0.17-4.70$ & 0.893 \\
$3^{\text {rd }}$ Quartile & 1.72 & $0.34-8.80$ & 0.512 \\
$4^{\text {th }}$ Quartile & 0.28 & $0.03-2.92$ & 0.289 \\
Age of Child & & & \\
$\quad$ 6-14 years & 1.26 & $0.98-1.61$ & 0.071 \\
Smoke & & & \\
$\quad$ No & 1.00 & Referent & 0.669 \\
$\quad$ Yes & 1.38 & $0.32-5.96$ & \\
Ethnicity of Child & & & \\
$\quad \begin{array}{l}\text { Other Races } \\
\text { White non-Hispanic }\end{array}$ & 1.00 & Referent & 0.345 \\
School Performance & 2.43 & $0.39-15.2$ & \\
$\quad$ High Performance & & & \\
$\quad$ Low Performance & 1.00 & Referent & 0.002 \\
Smoked During Pregnancy & 27.4 & $3.51-215$ & \\
$\quad \begin{array}{l}\text { No } \\
\quad \text { Yes }\end{array}$ & 1.00 & Referent & 0.075 \\
$\quad$ & 4.67 & $0.86-25.4$ & \\
\hline
\end{tabular}




\title{
CURRICULUM VITAE
}

\author{
Chisom N. Odoh \\ University of Louisville \\ Department of Epidemiology and Population Health \\ Cell Phone: (281) 250-3236 \\ Email: chisom.odoh@gmail.com
}

\section{EDUCATION}

\section{University of Louisville, Louisville, KY (2018)}

Doctor of Philosophy (PhD) Public Health; Concentration- Epidemiology

Tennessee State University, Nashville, TN (2015)

Master of Public Health (MPH); Concentration- Behavioral Health Science and Health Education

Fisk University, Nashville, TN (2012)

Bachelor of Arts in Biology, Magna Cum Laude

\section{CERTIFICATIONS}

- Data Management in Clinical Trials

- Certified HIV/AIDS counselor

\section{WORK EXPERIENCE}

Graduate Research Assistant, Coal Ash Study

2015-2018

\section{University of Louisville, Louisville, KY}

- R01 Grant on a community-based research examining neurobehavioral performance in children ages 6-14 years old residing near coal burning power stations. Field work experience - recruitment skills (door to door, mailing, etc.), consenting, interaction with community members. Data collection, data entry, and data analysis.

- Setting up air samplers in participants' homes, biospecimen collection, gravimetric analysis, and laboratory skills. 
- Human Papilloma Virus (HPV) vaccine promotion project: Recruitment of participants, data management, data collection, data analysis, data entry, following up with participants, assisting with health education programs (biospecimen awareness, building trust in the community), creation of surveys using REDCap, literature reviews and developing manuscripts.

Health Promotion Assistant

Directors of Health Promotion and Education (DHPE)

Placement site: Pittsburgh Community Improvement Association, Atlanta, GA

- Three main projects were carried out: Program evaluation for a Minority Men's Oral Health and Dental Access Program (MOHDAP), provided resources for recent release incarcerated women in a Women's Health Intervention Study (WHIS), and conducted focus groups to discuss the perceptions of residents on the needs/assets of the community in a Community Resources Awareness Campaign.

Teaching Assistant and Graduate Assistant

Tennessee State University- Department of Public Health, Nashville, TN.

- Lectured HLSC 4010-01- Introduction to Biostatistics, an undergraduate course averaging 30 students per semester. Developed course work, quizzes, and in-class activities.

Bioinformatics Consultant

2013

Fisk University- Nashville, TN

- Developed a website hosting online tutorials/learning modules for bioinformatics knowledge, skills and activities. The modules included: DNA Structure and Visualization; Gene regulation and transcription factors; The use of WormBase and the WormBase genome browser; Using NCBI and BLAST to identify homology; Examining transcription factor binding sites; ChIP-Seq and RNA-Seq process.

Material Safety Data Sheet (MSDS) Implementation Assistant

2012-2013

Fisk University- Nashville, TN

- Built and maintained MSDS databases using web and paper-based resources. Sorted and categorized all the chemicals at Fisk University and ensured that chemicals and storage method are in compliance with the Occupational Safety and Health Administration (OSHA) and in Material Safety Data Sheet (MSDS) database. 
Fisk University- Nashville, TN

- Assessment of local community's knowledge and practice of sustainability and health issues using questionnaires and surveys, preparation, organization of training materials and supplies, and set-up and delivery of training sessions for elementary, middle and high school students.

Distant Learning Consultant

2012

Fisk University- Nashville, TN

- Developed a new research-oriented biochemistry lab practical for undergraduates, using bacterial expression of recombinant proteins that were later purified by affinity chromatography (on the micro scale) and then assessed via SDS-PAGE and Western Blot.

- Development of an online course in pharmacology for undergraduates aimed at students with an interest in medical school. This was evidenced by written literature review of deep learning and the impact of changes in pedagogy on student learning.

Teaching Assistant - Organic Chemistry Lecture and Lab Fisk University- Nashville, TN

- Provided support and guidance for an undergraduate Organic chemistry course and lab assessments for students inside and outside the classroom. Prepared solutions and assays required for class and analyzed the numerical trends of student performances to assist the instructor in implementing better teaching techniques. Mentored students on lab safety and lab techniques.

Student Environmental Health and Safety Assistant

Fisk University- Nashville, TN

2009-2012

- Recorded and tracked use of chemical inventory in the Chemistry department at Fisk University. Coordinated and conducted inspections, assessments, surveys, audits and evaluations to identify potential hazards and to ensure regulatory compliance.

\section{Undergraduate Research Projects}

Research Intern, Case Western Reserve University Cleveland, Ohio

- Investigated the effects of Dasatinib and Rapamycin on the viability of ErbB2+ cells, derived from an aggressive subtype of breast cancer and on $\mathrm{SKBr} 3$ cells using western blot and cell paraffinization. 
Research Assistant, Materials Science and Applications Group

Fisk University- Nashville, TN

- Investigated the electron transport properties of graphene, a surface material of potential value in biomedical applications.

- Compared production variables using Atomic Force Microscope and Raman spectroscopy to identify mass production protocols to achieve affordable but desirable standards.

\section{MEMBERSHIPS AND AFFILIATIONS}

- Member, National Institute of Science (NIS) - (2010-2013)

- Vice-President, International Students Organization - (2011-2012)

- Executive Board Member, Center for Community Health Solutions - (2012-2013)

- Member, Tennessee Public Health Association (TPHA) - (2013-2016)

- Member, Health Science Student Organization - (2014-2015)

- Member, Society for Epidemiologic Research (SER) - (2016-Present)

- Member, American Public Health Association (APHA) - (2017-Present)

\section{PUBLICATIONS}

1). Odoh C, Sanderson M, Williams EA, Hull PC. Operationalizing outcome measures of human papillomavirus vaccination among adolescents. Public Health. 2018 June; 159:129-132. Doi: 10.1016/j.puhe.2018.02.022. Epub 2018 Mar 30. PubMed PMID: 29609838; PubMed Central PMCID: PMC5984163.

2). Musa BM, Odoh C, Galadanci NA, Saidu H, Aliyu MH. Lower than expected elevated tricuspid regurgitant jet velocity in adults with sickle cell disease in Nigeria. International Health. 2018 Feb 9. doi: 10.1093/inthealth/ihx074. PubMed PMID: 29438485.

3). Nchako E, Bussell S, Nesbeth C, Odoh C. Barriers to the availability and accessibility of controlled medicines for chronic pain in Africa. International Health. 2018 Feb 13. doi 10.1093/inthealth/ihy002. PubMed PMID: 29447356.

4). Nchako E, Nesbeth C, Odoh C. Assessment of knowledge of Ebola virus disease management of medical residents in a tertiary medical college. Journal of Public Health and Epidemiology. 2017 Nov Vol. 9(11), pp. 286-291, doi: 10.5897/JPHE2017.0959.

5). Musa BM, Adamu AL, Galadanci NA, Zubayr B, Odoh C, Aliyu MH. Trends in prevalence of multi drug resistant tuberculosis in sub-Saharan Africa: A systematic review and meta-analysis. PLoS One. 2017 Sep 25;12(9):e0185105.

doi:10.1371/journal.pone.0185105. PubMed PMID: 28945771. 
6). Amole TG, Bello S, Odoh C, Aliyu MH, Iliyasu Z. Correlates of femaleperpetrated intimate partner violence in Kano, northern Nigeria. Journal of Interpersonal Violence. 2016 Jul;31(12):2240-54. doi: 10.1177/0886260515573576. PubMed PMID: 25731930 .

7). Iliyasu Z, Galadanci HS, Abubakar S, Auwal MS, Odoh C, Salihu HM, Aliyu MH. Phenotype of intimate partner violence among women experiencing infertility in Kano, Northwest Nigeria. International Journal of Gynecology and Obstetrics. 2016 Apr;133(1):32-6. doi: 10.1016/j.ijgo.2015.08.010. PubMed PMID: 26948339.

8). Aliyu MH, Blevins M, Parrish DD, Megazzini KM, Audet CM, Chan N, Odoh C, Gebi UI, Muhammad MY, Shepherd BE, Wester CW, Vermund SH. Pregnant women with HIV in rural Nigeria have higher rates of antiretroviral treatment initiation, but similar loss to follow-up as non-pregnant women and men. International Health. 2015 Nov;7(6):405-11. doi: 10.1093/inthealth/ihv032. Epub 2015 May 25. PubMed PMID: 26012740 .

9). Aliyu MH, Blevins M, Arinze F, Megazzini KM, Bussell S, Dunlap J, Odoh C, Gebi UI, Muhammad MY, Shepherd BE, Audet CM, Vermund SH, Wester CW. Enrolment trends in a comprehensive HIV programme in rural north-central Nigeria: improved care indices, but declining quality of clinical data over time. Pathog Glob Health. 2015 Mar;109(2):75-83. PubMed PMID: 25822098.

\section{PRESENTATIONS}

1). Odoh C, Sears L, Polvika B, Brock G, Zierold K. Elemental Exposure to Copper and Attention Deficit Hyperactivity Disorders among Children in Proximity to Coal Ash Storage Sites [Poster Presentation]. Society for Epidemiologic Research (SER), Baltimore, Maryland, June 2018.

2). Odoh C, Sears L, Polvika B, Brock G, Zierold K. Utility of the Behavioral Assessment and Research Systems (BARS) in Measuring Attention Among Children Residing Near Coal Ash Storage Sites [Poster Presentation]. Society for Epidemiologic Research (SER), Baltimore, Maryland, June 2018.

3). Odoh C, Sears L, Polvika B, Brock G, Zierold K. Autism-Like Behaviors and Exposure to Pollutants among Underserved Children in Kentucky [Poster Presentation]. Society for Pediatric and Perinatal Epidemiologic Research (SPER), Baltimore, Maryland, June 2018.

4). Odoh C, Sears L, Hanchette C, Polvika B, Brock G, Zierold K. Attention Deficit Hyperactivity Disorders and Aluminum Exposure among Underserved Children [Poster Presentation]. American Academy of Health Behavior (AAHB), Portland, Oregon, March 2018. 
5). Tompkins L, Odoh C, Zierold K. The Health and Exposure Histories of One Community Battling Environmental Discrimination [Poster Presentation]. American Academy of Health Behavior (AAHB), Portland, Oregon, March 2018.

6). Odoh Chisom. Burden of Tuberculosis in Sub-Saharan Africa [Radio Segment]. University of Louisville Radio Station [UofL Today with Mark Hebert radio show], Louisville, KY, September 2017.

7). Odoh C, Sears L, Hanchette C, Polvika B, Brock G, Zierold K. Association Between Fly Ash Exposure and Social Functioning in Children [Poster Presentation]. Society for Epidemiologic Research (SER), Seattle, Washington, June 2017.

8). Odoh C, Sanderson M, Williams EA, Hull, PC. Changes in Predictors of HPV Vaccination among Adolescents in the United States, 2008 to 2013 [Poster Presentation]. Meharry-Vanderbilt Ingram Cancer Center-Tennessee State University Cancer Partnership 14th Annual Retreat, Nashville, TN May 2015. (Poster won first place for graduate student presentation).

9). Odoh C, Casali BT, Keri R. Testing the Inhibitors Rapamycin and Dasatinib on the Viability of Breast Cancer Cells [Poster Presentation]. National Conference on Undergraduate Research, Ithaca, New York, May 2011.

\section{HONORS AND AWARDS}

- 2013 Beta Kappa Chi National Scientific Honor Society

- 2009-2012 Provost Scholar (Students with G.P.A of 3.5 and above)

- 2010 Ella Shepherd Moore Scholarship Recipient, Fisk University

- 2016 Conference Travel Grant, Society for Epidemiologic Research

- 2016 Conference Travel Grant, University of Louisville Graduate School

- 2016 Conference Travel Grant, University of Louisville School Department of Epidemiology and Population Science (June and November)

\section{SERVICE ACTIVITIES}

\section{Data Analyst-Volunteer}

Vanderbilt Institute for Global Health- Nashville, TN

- Assistance with creation of survey on mobile phone use among the infant care providers in Kano, Nigeria.

- Entry and analysis of survey using Research Electronic Data Capture (REDCAP)

\section{Statistician-Volunteer}

Friends for Global Health- Abuja, Nigeria

- Assistance with creation of survey on cardiac and pulmonary abnormalities in sickle cell disease study, among patients with asthma in Nigeria. 
- Entry and analysis of survey using Research Electronic Data Capture (REDCAP) and SAS.

- Carried out the statistical analysis for the manuscript yielded from this project.

\section{Community Health Assessment Volunteer}

Green River District Health Department (GRDHD)- Owensboro, KY

- Utilization of Community Assessment for Public Health Emergency Response (CASPER), an epidemiological tool used to conduct needs assessment.

- Calculation of number of households to be selected in each cluster.

- Interviewing household members from selected clusters using the CASPER methodology.

- Use of android tablets to administer surveys.

- Gained in-depth interviewing techniques and skills from working closely with a CDC health officer. 